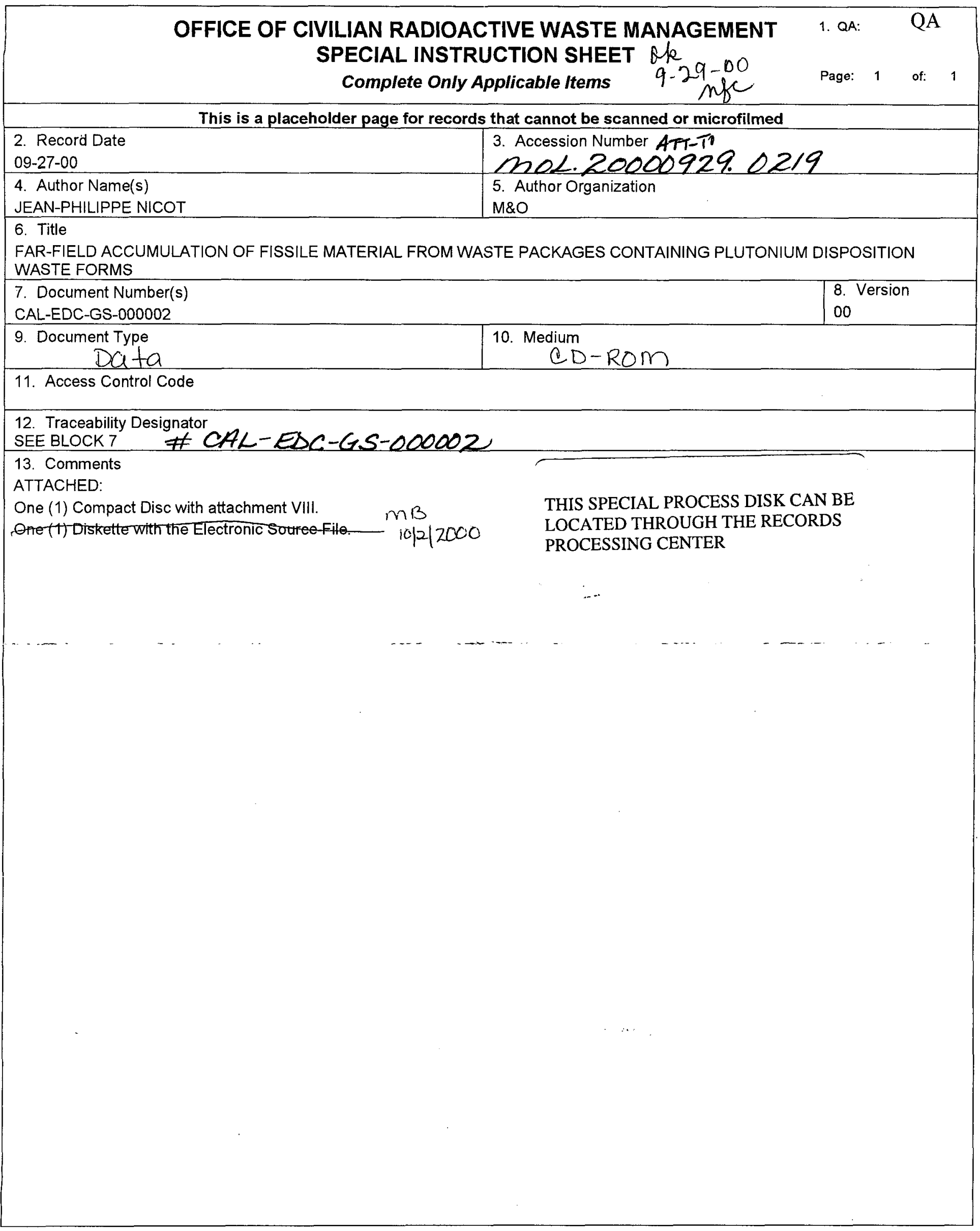




\section{OFFICE OF CIVILIAN RADIOACTIVE WASTE MANAGEMENT \\ CALCULATION COVER SHEET}

1. $\mathrm{QA}: \quad \mathrm{QA}$

Page: 1 Of: 80

2. Calculation Title

Far-Field Accumulation of Fissile Material from Waste Packages Containing Plutonium Disposition Waste Forms

3. Document Identifier (including Revision Number)

CAL-EDC-GS-000002 REV 00

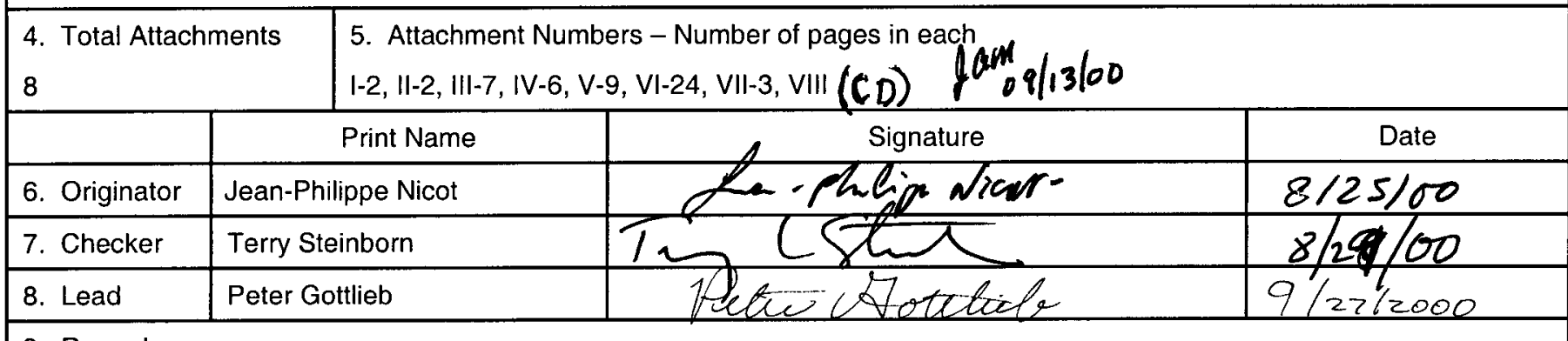

9. Remarks

Revision History

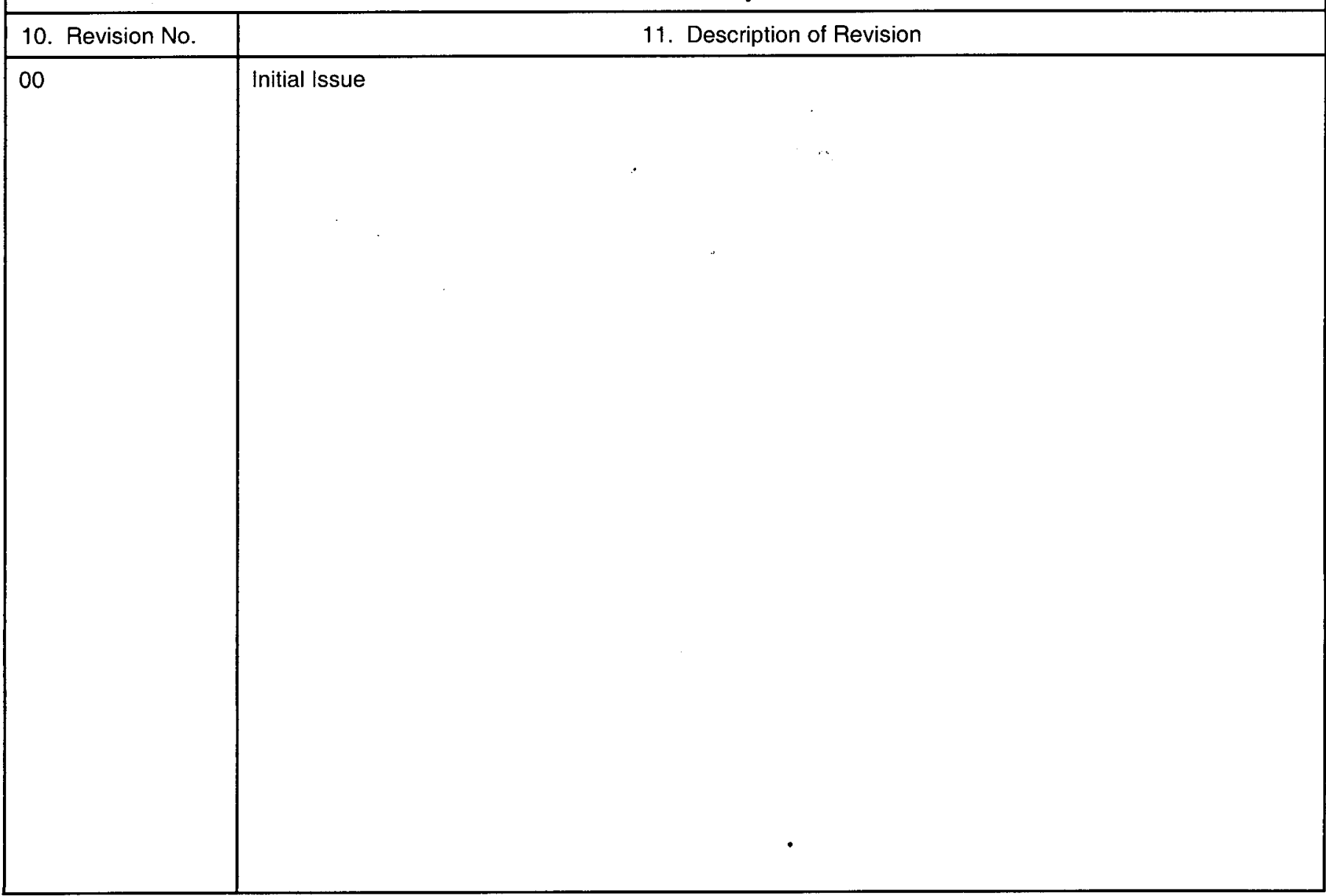


Waste Package Department Calculation

Title: Far-Field Accumulation of Fissile Material from Waste Packages Containing Plutonium Disposition Waste Forms

Document Identifier: CAL-EDC-GS-000002 REV 00

Page 2 of 80

\section{CONTENTS}

Page

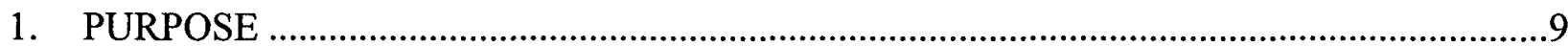

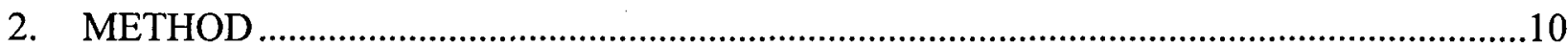

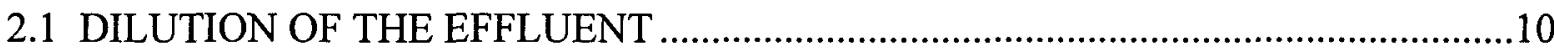

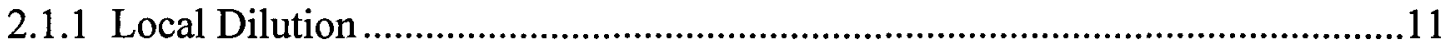

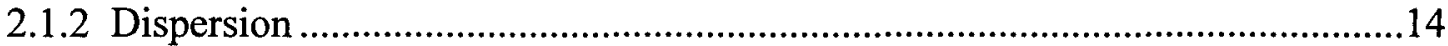

2.1.3 Implementation of Dilution: the MIX Keyword .............................................17

2.1.4 Why Dilution Initiates Actinide Precipitation ................................................18

2.2 SCALING BY THE VOLUME OF WATER ...............................................................20

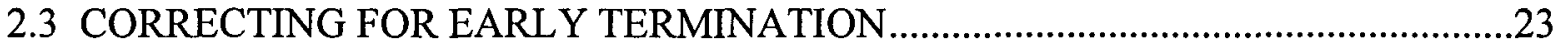

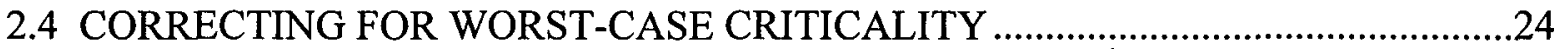

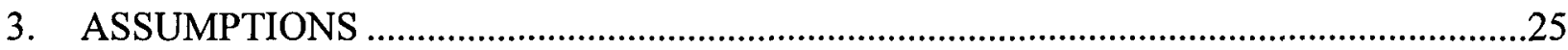

4. USE OF COMPUTER SOFTWARE AND MODELS ...........................................................30

4.1 SOFTWARE

4.1.1 PHREEQC Software Package............................................................................30

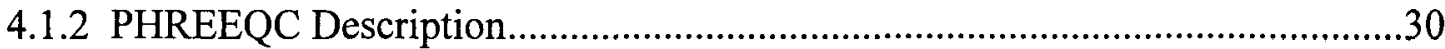

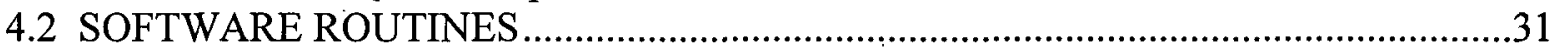

4.2.1 C Program "transl.c" Version1.0s........................................................................31

4.2.2 Microsoft Excel Spreadsheets.............................................................................31

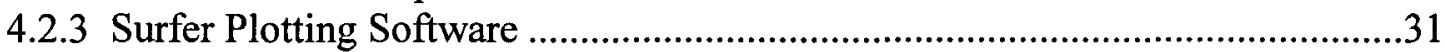

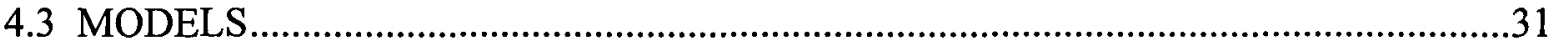

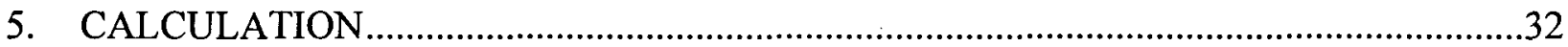

5.1 INPUTS

5.1.1 J-13 Well Water Composition ……………….................................................32

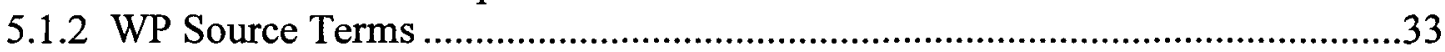

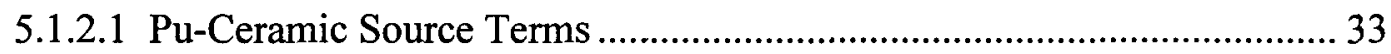

5.1.2.1a Early Breach Time (negligible decay of $\mathrm{Pu}$ )......................................... 38

5.1.2.1b Medium Breach Time (50\% decay of $\mathrm{Pu})$.............................................. 39

5.1.2.1c Late Breach Time (complete decay of $\mathrm{Pu}$ ).............................................. 39

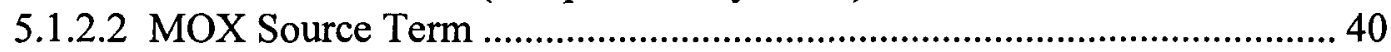

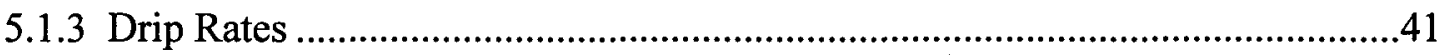

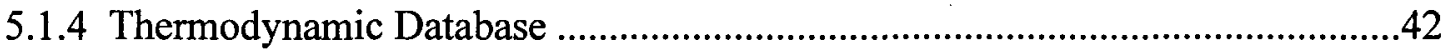

5.1.5 Fracture Wall Dissolution.............................................................................42

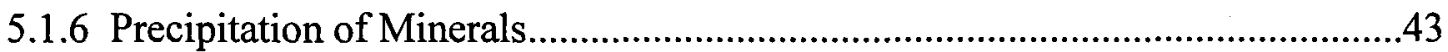

5.1.7 Fracture System Effects on Actinide Precipitation...........................................43

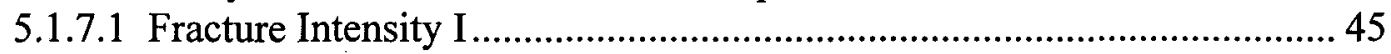

5.1.7.2 Fracture Aperture 2B ........................................................................ 46

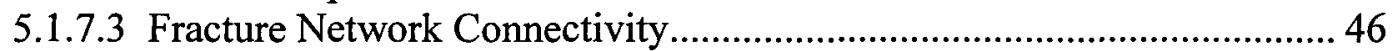

5.1.7.4 Fracture Orientation (dip and directions).................................................. 47 
Waste Package Department Calculation

Title: Far-Field Accumulation of Fissile Material from Waste Packages Containing Plutonium Disposition Waste Forms

Document Identifier: CAL-EDC-GS-000002 REV 00

Page 3 of 80

\section{CONTENTS (Continued)}

Page

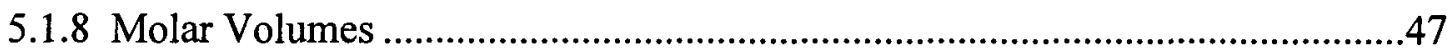

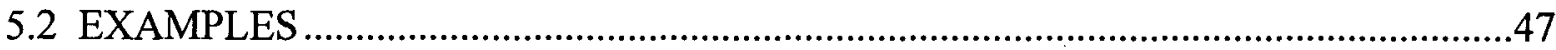

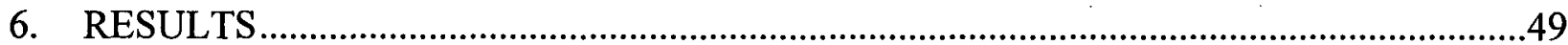

6.1 RESULTS FOR THE EARLY BREACH TIME SCENARIO (PE0A1231 CASE) ......49

6.1.1 Uranium and Plutonium Mineral Precipitation..............................................49

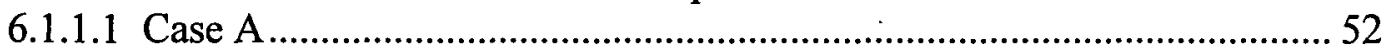

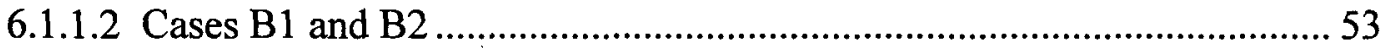

6.1.1.3 Summary of Cases ....................................................................... 54

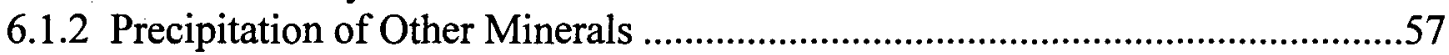

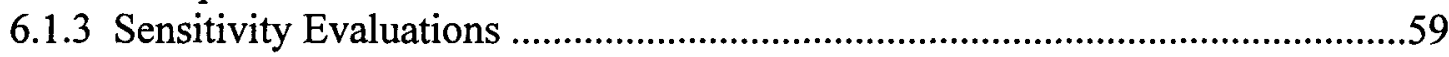

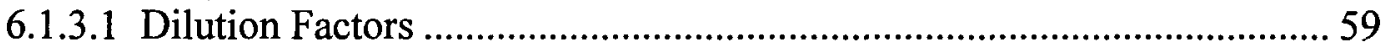

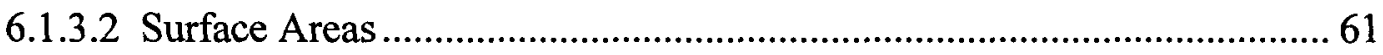

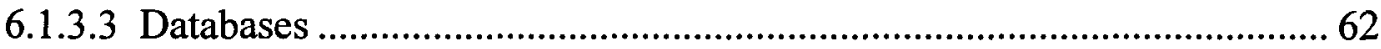

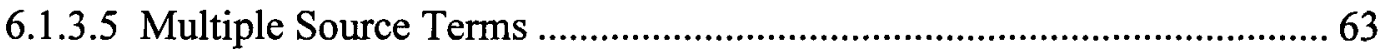

6.2 RESULTS FOR THE MEDIUM BREACH AND LATE BREACH TIME

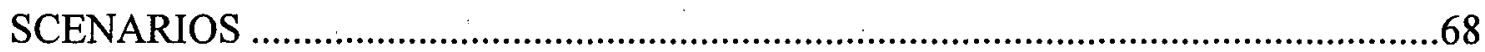

6.3 RESULTS FOR PW2A1231 SCENARIOS ....................................................... 71

6.4 RESULTS FOR THE MOX03AP2 SCENARIOS ...............................................74

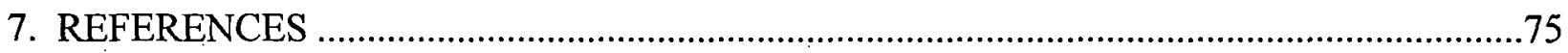

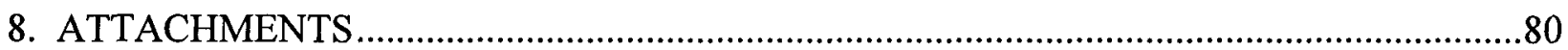


Title: Far-Field Accumulation of Fissile Material from Waste Packages Containing Plutonium Disposition Waste Forms

Document Identifier: CAL-EDC-GS-000002 REV 00

Page 4 of 80

\section{FIGURES}

Page

2-1. Percentage of the Initial Saturation Recovered as a Function of the Initial

Saturation and Recovery Criteria

2-2. Relative Concentration for Point and Line Source Solutions as a Function

of Distance (a) Longitudinal Direction (b) Transverse Direction. 16

2-3. Implementation of the MIX keyword: a) Classical Dispersion, Numbers

Show Reduction in Concentration in Successive Cells b) Local Dilution,

Numbers Show Increase in Volume in Successive Cells 18

2-4. Conceptual Model of the Fractured Rock

5-1. Uranium, $\mathrm{Pu}$, and $\mathrm{Np}$ Molar Concentrations and Ionic Strengths from

Time of WP Breach for Source Terms (a) pe0a1231 and (b) PW2a1231

5-2. Uranium, $\mathrm{Pu}$, and $\mathrm{Np}$ Molar Concentrations and Ionic Strengths from

Time of WP Breach for Source Term mox03ap2

5-3. Conceptual Model of Cases A and B

6-1. Spatial Variation in Chemical Parameters for the Base Case A at 100

Years after Breach Time 50

6-2. Spatial Variation in Aqueous Molar Concentrations for the Base Case A at 100 Years after Breach Time

6-3. Precipitation of Minerals in Cell 22 over Time $\left(\mathrm{SA}=100,000 \mathrm{~cm}^{2}\right)$ for

Base Case B2

6-4. Spatial Distribution of Actinide Minerals after 2,500 Years of

Precipitation (case A- SA $=1,000,000 \mathrm{~cm}^{2}$ ).

6-5. Spatial Variations in Mineral Deposits for Case A (SA=1,000,000 $\mathrm{cm}^{2}$

after 2,500 years)

6-6. Moles of Pu and U Minerals Precipitated as a Function of Cell Number (case B1 - SA=20,000 $\mathrm{cm}^{2}$ for 2,500 years)

6-7. Spatial Variation in Actinide Density for the Different Saturated Cases

(B1, B2, and B3)

6-8. Uranium Accumulation Molar Density 56 
Title: Far-Field Accumulation of Fissile Material from Waste Packages Containing Plutonium Disposition Waste Forms

Document Identifier: CAL-EDC-GS-000002 REV 00

Page 5 of 80

\section{FIGURES (Continued)}

6-9. Plutonium Accumulation Molar Density

6-10. Volumes of Minerals as a Function of Cell Number for Case A $\left(\mathrm{SA}=1,000,000 \mathrm{~cm}^{2}\right)$

6-11. Volumes of Minerals as a Function of Cell Number for Case B1 $\left(\mathrm{SA}=20,000 \mathrm{~cm}^{2}\right)$

6-12. Comparison of Volume of Minerals Produced as a Function of the Wall Surface Area / Liter of Water.

6-13. Sensitivity Analysis for Dilution Factors $\left(\mathrm{SA}=20,000 \mathrm{~cm}^{2}\right)$

6-14. Total Number of Moles of Actinide Precipitated as a Function of Dilution $\left(\mathrm{SA}=20,000 \mathrm{~cm}^{2}\right)$

6-15. Total Number of Moles of Actinide Precipitated as a Function of Surface Area (NO dilution) 60

6-16. Sensitivity Analysis for Surface Areas (dilution factor of 10\%)

6-17. Total Number of Moles of Actinide Precipitated as a Function of Surface Area (dilution factor of $10 \%$ ).

6-18. $\mathrm{Pu}$ - U Minerals Accumulation for the Old (data0.nuc.R8a) and New (data0.nuc.R8s) Databases $\left(\mathrm{SA}=20,000 \mathrm{~cm}^{2}\right)$.

6-19. Actinide Accumulation for the Old (data0.nuc.R8a) and New (data0.nuc.R8s) Databases $\left(\mathrm{SA}=20,000 \mathrm{~cm}^{2}\right)$.

6-20. Hypothetical EQ6 Source Terms and Corresponding PHREEQC Step

Function

6-21. Result Comparison of Time-Varying and Constant Source Term (at $~ 4,000$ years)

6-22. Maximum Actinide Accumulation with Variable Source Term (at time 5,840 years)

6-23. Accumulation of $\mathrm{Pu}(\mathrm{OH})_{4}$ Through Time (left axis) and Space (bottom axis) for the Variable Source Term. 
Waste Package Department

Calculation

Title: Far-Field Accumulation of Fissile Material from Waste Packages Containing Plutonium Disposition Waste Forms

Document Identifier: CAL-EDC-GS-000002 REV 00

Page 6 of 80

\section{FIGURES (Continued)}

Page

6-24. Accumulation of Soddyite Through Time (left axis) and Space (bottom axis) for the Variable Source Term

6-25. Accumulation of Haiweeite Through Time (left axis) and Space (bottom axis) for the Variable Source Term

6-26. Actinide Mineral Precipitation after 2,500 Years (SA=1,000,000 $\mathrm{cm}^{2}-$ half

$\mathrm{Pu}$ decayed).....

6-27. Actinide Mineral Precipitation after 2,500 Years (SA=1,000,000 $\mathrm{cm}^{2}$ - all

Pu decayed).

6-28. Actinide Precipitation as a Function of the Cell Number and Pu Decay (after 2,500 years of deposition - case pe0a1231): (a) $1,000,000 \mathrm{~cm}^{2}$

Saturated (b) $1,000,000 \mathrm{~cm}^{2}$ Unsaturated

6-29. Actinide Precipitation as a Function of the Cell Number and Pu Decay (after 2,500 years of deposition - case pe0a1231-20,000 $\mathrm{cm}^{2}$ ).

6-30. Actinide Precipitation as a Function of Cell Number and Decay (after

7,000 years of deposition - case pw2a1231): (a) 1,000,000 $\mathrm{cm}^{2}$ - Saturated

(b) $1,000,000 \mathrm{~cm}^{2}$ - Unsaturated

6-31. Actinide Precipitation as a Function of the Cell Number and Pu Decay (after 7,000 years of deposition - case pw2a1231 - 20,000 $\mathrm{cm}^{2}$ )

6-32. Accumulation of Actinides in the mox03ap2 Case $\left(\mathrm{SA}=20,000 \mathrm{~cm}^{2}\right)$ 
Waste Package Department

Calculation

Title: Far-Field Accumulation of Fissile Material from Waste Packages Containing Plutonium

Disposition Waste Forms

Document Identifier: CAL-EDC-GS-000002 REV 00

Page 7 of 80

\section{TABLES}

Page

2-1. Zone of Influence of Local Dilution as a Function of $\alpha_{V G}$ (see file expo-

VG.xls in CD-ROM electronic media - Attachment VIII)

2-2. Influence in Variations in $\mathrm{pH}$ and Ionic Strength for Actinide Precipitation

(varying parameter in italics)

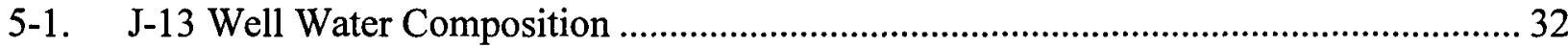

5-2. Elemental Molar Composition for J-13 Well Water.................................................. 33

5-3. Elemental Molar Composition for Non-Decayed Source Term at Time $=2,500$ Years (source term pe0a1231 from EQ6 output file pe0a1231.elem_aqu.txt)

5-4. Elemental Molar Composition for Non-Decayed Source Term at Time=7,940 Years (source term PW2a1231 from EQ6 output file PW2a1231.elem_aqu.txt)

5-5. Elemental Molar Composition for Non-Decayed Source Term at Time=4,050 Years (source term PW2a1231 from EQ6 output file PW2a1231.elem_aqu.txt)

5-6. Elemental $\mathrm{U}$ and $\mathrm{Pu}$ Concentrations for the Three Breach Time Scenarios (pe0a1231 case)

5-7. Elemental $U$ and Pu Concentrations for the Three Breach Time Scenarios (pw2a1231 case at 4,050 years after breach)

5-8. Elemental $\mathrm{U}$ and $\mathrm{Pu}$ Concentrations for the Three Breach Time Scenarios

(pw2a1231 case at 7,940 years after breach) 39

5-9. Elemental Molar Composition for Non-Decayed Source Term at Time $=13,880$ Years (source term mox03ap2 from EQ6 output file mox03ap2.elem_aqu.txt)

5-10. Normalized Molar Composition of Tuff.

5-11. List of Minerals Allowed to Precipitate in All PHREEQC Runs

5-12. Input Parameters for Cases $\mathrm{A}$ and $\mathrm{B}$ 45

5-13. Molar Volumes of Relevant Minerals 
Title: Far-Field Accumulation of Fissile Material from Waste Packages Containing Plutonium Disposition Waste Forms

Document Identifier: CAL-EDC-GS-000002 REV 00

Page 8 of 80

TABLES (Continued)

\section{Page}

6-1. Summary of Results (pe0a1231) (accumulation for 2,500 years) 54

6-2. Summary of Results for Different Databases (accumulation starts 2,500

years after breach time for 2,500 years)

6-3. Summary of Results for Case pe0a1231 for Different Pu Decay $\left(\mathrm{SA}=20,000 \mathrm{~cm}^{2}\right)$

6-4. Summary of Results for Case pe0a1231 for Different Pu Decay $\left(\mathrm{SA}=1,000,000 \mathrm{~cm}^{2}\right.$ - saturated).

6-5. Summary of Results for Case pe0a1231 for Different Pu Decay ( $\mathrm{SA}=1,000,000 \mathrm{~cm}^{2}$ - unsaturated).

6-6. Summary of Results for Case pw2a1231 for Different Pu Decay $\left(\mathrm{SA}=20,000 \mathrm{~cm}^{2}\right)$

6-7. Summary of Results for Case pw2a1231 for Different Pu Decay $\left(\mathrm{SA}=1,000,000 \mathrm{~cm}^{2}\right.$ - saturated).

6-8. Summary of Results for Case pw2a1231 for Different Pu Decay $\left(\mathrm{SA}=1,000,000 \mathrm{~cm}^{2}\right.$ - unsaturated). 
Title: Far-Field Accumulation of Fissile Material from Waste Packages Containing Plutonium Disposition Waste Forms

Document Identifier: CAL-EDC-GS-000002 REV 00

Page 9 of 80

\section{PURPOSE}

The objective of this calculation is to estimate the quantity of fissile material that could accumulate in fractures in the rock beneath plutonium-ceramic ( $\mathrm{Pu}$-ceramic) and Mixed-Oxide (MOX) waste packages (WPs) as they degrade in the potential monitored geologic repository at Yucca Mountain. This calculation is to feed another calculation (Ref. 31) computing the probability of criticality in the systems described in Section 6 and then ultimately to a more general report on the impact of plutonium on the performance of the proposed repository (Ref. 32 ), both developed concurrently to this work. This calculation is done in accordance with the development plan TDP-DDC-MD-000001 (Ref. 9), item 5. The original document described in item 5 has been split into two documents: this calculation and Ref. 4.

The scope of the calculation is limited to only very low flow rates because they lead to the most conservative cases for $\mathrm{Pu}$ accumulation and more generally are consistent with the way the effluent from the WP (called source term in this calculation) was calculated (Ref. 4). Ref. 4 ("InDrift Accumulation of Fissile Material from WPs Containing Plutonium Disposition Waste

Forms") details the evolution through time (breach time is initial time) of the chemical composition of the solution inside the WP as degradation of the fuel and other materials proceed. It is the chemical solution used as a source term in this calculation. Ref. 4 takes that same source term and reacts it with the invert; this calculation reacts it with the rock. In addition to reactions with the rock minerals (that release $\mathrm{Si}$ and $\mathrm{Ca}$ ), the basic mechanisms for actinide precipitation are dilution and mixing with resident water as explained in Section 2.1.4. No other potential mechanism such as flow through a reducing zone is investigated in this calculation. No attempt was made to use the effluent water from the bottom of the invert instead of using directly the effluent water from the WP.

This calculation supports disposal criticality analysis and has been prepared in accordance with AP-3.12Q, Calculations (Ref. 49). This calculation uses results from Ref. 4 on actinide accumulation in the invert and more generally does reference heavily the cited calculation. In addition to the information provided in this calculation, the reader is referred to the cited calculation for a more thorough treatment of items applying to both the invert and fracture system such as the choice of the thermodynamic database, the composition of J-13 well water, tuff composition, dissolution rate laws, $\mathrm{Pu}(\mathrm{OH})_{4}$ solubility and also for details on the source term composition. The flow conditions (seepage rate, water velocity in fractures) in the drift and the fracture system beneath initially referred to the TSPA-VA because this work was prepared before the release of the work feeding the TSPA-SR. Some new information feeding the TSPASR has since been included. Similarly, the soon-to-be-qualified thermodynamic database data0.ymp has not been released yet. 
Title: Far-Field Accumulation of Fissile Material from Waste Packages Containing Plutonium Disposition Waste Forms

Document Identifier: CAL-EDC-GS-000002 REV 00

Page 10 of 80

\section{METHOD}

The method outlined in this section is in accordance with the development plan TDP-DDC-MD000001 (Ref. 9). Since the development plan does not address the control of electronic management of data, the evaluation was done according to $A P-S V .1 Q$, Control of the Electronic Management of Information (Ref. 50). Source terms and thermodynamic databases were sent by email attachment from the computer where they were obtained as Technical Product Outputs to the computer where they were used.

The calculation proceeds first by setting up the different source terms including decay or no decay of the plutonium into uranium to bracket the breach times (early in the history of the proposed repository plutonium would not have had time to decay to uranium as it would at later times). The calculation then progresses by doing PHREEQC runs to compute actinide accumulation for different parameter values. The main parameter is surface area. Each of its values corresponds to several different pairs of saturation states of the fracture system and average fracture aperture. The calculation finishes with the application of the correction for worst-case criticality described in Section 2.4.

This Method section examines first the general mechanisms for actinide precipitation, then the details of the translation of the simulation results to the final results. Finally, two simplifying and timesaving corrections are described. It should be noted that PHREEQC is a onedimensional code and that runs are independent of the chosen mechanism. The results need to be scaled to the appropriate model. Sections 2.1.1 and 2.1.2 are intended to show that dilution and mixing are plausible mechanisms at the scale of interest but not to give accurate results about the spatial distribution of their effects. Both mechanisms are illustrated by analytical solutions developed for porous media. For this reason, they are not applicable in their details to fracture systems. Actinide accumulation occurs in volumes of size smaller than the size of the porous media equivalent to the fracture system should be. More accurate results could be provided by fully coupled geochemical and flow models. Section 6 will only give bounding results.

With regard to the development of this calculation, the control of electronic management of data was evaluated in accordance with AP-SV.1Q, Control of the Electronic Management of Information (Ref. 50). The evaluation (Ref. 45) determined that current work processes and procedures are adequate for the control of electronic management of data for this activity.

\subsection{DILUTION OF THE EFFLUENT}

The purpose of this section is to show that dilution is a credible mechanism for precipitation of actinide minerals. Dilution leads to a shift in equilibrium leading to possible precipitation of actinides. This dilution mechanism is combined with the fracture wall mineral dissolution (Section 5.1.5). Dilution of the effluent from the WP could occur through two mechanisms: (1) local dilution due to re-mixing with water flowing around the drift (this mechanism is applicable to unsaturated cases) and (2) classical dispersion resulting from the dispersion of effluent over a complex network of fractures underneath the drift applicable to both unsaturated and saturated cases. 
Title: Far-Field Accumulation of Fissile Material from Waste Packages Containing Plutonium Disposition Waste Forms

Document Identifier: CAL-EDC-GS-000002 REV 00

Page 11 of 80

\subsubsection{Local Dilution}

When the successive engineered barriers divert the percolation flux, a "dry shadow" builds up underneath the drift (Ref. 2). As the flow proceeds downwards, water progressively invades this volume. This section does not attempt to accurately model the "dry shadow" underneath the drift but to establish that local dilution is a plausible dilution mechanism within a limited distance underneath the drift. As a corollary of this model with local dilution alone, the area where precipitation occurs is limited to the vertical "shadow" of the drift and the envelope of U mineralization is box-like.

The Total System Performance Assessment-Viability Assessment (TSPA-VA) seepage model indicates that a very low seep flow rate of 1.5 liter/year (see Section 5.1.3) can be attained with a small percolation rate of about $3 \mathrm{~mm} /$ year (Ref. 1, Fig. 2-112). Percolation rate is defined as the water flow rate through the unsaturated pile of volcanic rocks overlying the potential repository while the seepage rate is defined as the actual flow rate of water entering the drift. The drip rate is the amount of water dripping into and out of the WP. Because all the seepage is assumed to flow through the WP, seepage rate and drip rate are numerically equal. For such a low percolation rate $(3 \mathrm{~mm} / \mathrm{year})$, the percentage of water actually seeping into the drift made available by percolation (seepage percentage) is about $1 \%$. The seepage percentage is calculated, as described in Ref. 1 (p. 2-111), by dividing the seep flow rate by the percolation rate, dividing by the area of $75 \mathrm{~m}^{2}$, and multiplying by 100 . The same conclusions can be drawn from the new data released for the TSPA-SR (see Assumption 3.17). Such a low seepage percentage suggests that dilution is large under such a mechanism.

The process of local dilution is roughly consistent with a simplified analytical solution by Philip et al. (Ref. 2) that describes the saturated perturbation introduced by a cylindrical cavity in a uniform unsaturated flow field. Philip et al. determined that the length $d$ of the down-gradient zone beyond which the flow field is back in some sense (Ref. 2, p. 26 and see below) to its undisturbed condition is given, with Ref. 2 notations, by (Ref. 2, Eq. 87c):

$$
r_{*}(\pi) \approx l(18+5.5 \alpha l)
$$

where $l$ is the radius of the cavity (top of their Section 4.1) and $\alpha$ is the coefficient of the exponential form of the relative permeability. With this calculation notation, their Eq. 87c becomes:

$$
d \approx \frac{D}{2}\left(17+5.5 \alpha \frac{D}{2}\right)=46.75+41.60 \alpha
$$

where the equation has been modified to shift the origin to the bottom of the cylindrical cavity (i.e., subtracting $l$ from their Eq. 87c), $D$ is the diameter of the cylindrical cavity, $\alpha$ (in length ${ }^{-1}$ units) is the coefficient of the exponential form of the relative permeability $k_{\mathrm{r}}$, and the drift 
Title: Far-Field Accumulation of Fissile Material from Waste Packages Containing Plutonium Disposition Waste Forms

diameter, $5.5 \mathrm{~m}$, has been substituted for $D$ in the second part of the equation. The relative permeability is given by:

$$
k_{r}=\exp (-\alpha \Psi)
$$

where $\Psi(\mathrm{m})$ is the absolute value of the capillary pressure (function of saturation). The parameter $\alpha$ typically varies from less than $1 \mathrm{~m}^{-1}$ for fine texture material to more than $5 \mathrm{~m}^{-1}$ for coarse material. A fracture system can be approximated by very coarse material, i.e., the parameter $\alpha$ is likely to be high.

Eq. 2.1 is applicable when some measure of the flow field is almost back to its original value. That measure turns out to be the relative permeability (function of saturation). The initial measure given in Ref. 2 is the ratio $\vartheta$ (their Eq. 14) of the final to the original Kirchhoff potential $\Theta$ defined by (their Eq. 4):

$$
\Theta=\int_{-\infty}^{\Psi} K d \Psi=K_{0} \int_{-\infty}^{\Psi} k_{r} d \Psi=K_{0} \int_{-\infty}^{\Psi} \exp (-\alpha \Psi) d \Psi=-\frac{K_{0}}{\alpha}[\exp (-\alpha \Psi)]_{-\infty}^{\Psi}
$$

Hence

$$
\vartheta=\frac{\Theta}{\Theta_{0}}=\frac{[\exp (-\alpha \Psi)]_{-\infty}^{\Psi}}{[\exp (-\alpha \Psi)]_{-\infty}^{\Psi_{0}}}=\frac{k_{r}}{k_{r 0}}
$$

Eq. 2.1 was derived by assuming that the limit of the region of influence is given by $|\theta-1|=\varepsilon$ (beginning of their Section 5.7) with $\varepsilon=0.01$ (beginning of their Section 7.6), i.e., when the relative permeabilities (initial and at some point down-gradient of the drift) differ by only $1 \%$. Eq. 2.1 can be scaled to other values of $\varepsilon$ by observing that in their Eq. 78 , their dimensionless distance $r$ is proportional to $\varepsilon^{-2 / 3}$ :

$$
d \approx\left(\frac{0.01}{\varepsilon}\right)^{2 / 3}(46.75+41.60 \alpha) \quad(\mathrm{m})
$$

The correction coefficient is equal to 0.215 for $\varepsilon=0.1$. 
Waste Package Department Calculation

Title: Far-Field Accumulation of Fissile Material from Waste Packages Containing Plutonium Disposition Waste Forms

Document Identifier: CAL-EDC-GS-000002 REV 00

Page 13 of 80

Table 2-1. Zone of Influence of Local Dilution as a Function of $\alpha_{\mathrm{VG}}$ (see file expo-VG.xls in electronic media - Attachment VIII)

\begin{tabular}{|c|c|c|c|c|}
\hline $\begin{array}{c}\text { Van } \\
\text { Genuchten } \\
\alpha_{\mathrm{VG}}\left(\mathrm{Pa}^{-1}\right) \\
\end{array}$ & $\begin{array}{c}\text { Exponential } \\
\alpha\left(\mathrm{m}^{-1}\right)\end{array}$ & $\begin{array}{c}\text { Zone of Influence } \\
\text { at } 99 \%(\varepsilon=0.01) \\
d(\mathrm{~m}) \\
\end{array}$ & $\begin{array}{c}\text { Zone of Influence } \\
\text { at } 90 \%(\varepsilon=0.1) \\
d(\mathrm{~m})\end{array}$ & $\begin{array}{c}\text { Zone of Influence } \\
\text { at } 50 \%(\varepsilon=0.5)^{\mathrm{a}} \\
d(\mathrm{~m})\end{array}$ \\
\hline $2 \times 10^{-4}$ & 4.84 & 248 & 53 & 18 \\
\hline $4 \times 10^{-4}$ & 9.61 & $>300$ & 96 & 33 \\
\hline $9 \times 10^{-4}$ & 21.78 & $>300$ & 205 & 70 \\
\hline $3 \times 10^{-3}$ & 72.76 & $>300$ & $>300$ & 226 \\
\hline
\end{tabular}

NOTE: ${ }^{2}$ Results for $\varepsilon=0.5$ are only indicative as the derivation assumed small $\varepsilon$.

To approximate the length of the zone of influence by Eq. 2.1, it is necessary to estimate $\alpha$ for the fracture system surrounding the drift. Least-square fitting $\alpha$ (see file expo-VG.xls) to the Van Genuchten expressions of relative fracture permeability and capillary pressure (see Eq. 2-12 and 2-13 of Ref. 1) with $m=0.492$ (Ref. 36) and $\alpha_{V G}$ approximated as a range between $2 \times 10^{-4}$ and $3 \times 10^{-3} \mathrm{~Pa}^{-1}$ (Tables T2-19 and T2-21 of Ref. 1 for formation Tsw34 to Tsw36), yields a value of $\alpha$ between approximately 5 and $70 \mathrm{~m}^{-1}$. Table $2-1$ gives the length of the zone of influence for a range of $\alpha$ and three values of $\varepsilon$. A similar table with $m=0.633$ would display slightly larger values (see file expo-VG.xls - worksheet Exponential alpha $\mathrm{m}=0.633$ ).

The ratio of the permeability varies faster than the ratio of the saturation because permeability varies by several orders of magnitude. This is especially true at the low saturations considered in this calculation. An example read from Figure 2-1 (left lowermost diamond) shows that, even if the permeability is only $50 \%$ of what it is above the drift, the saturation is already at $85 \%$ of its value of 0.05 above the drift. Another example with an initial saturation of 0.3 shows that the saturation is already back to about $97.5 \%$ of its value although the relative permeability is only at $90 \%$ of its original value. The conclusion from the inspection of Figure $2-1$ is that the saturation (i.e., ultimately the volume of water per unit surface area) is almost back to their original values with the measure $\vartheta$ at only 0.5 . Figure $2-1$ also shows that there is more than $85 \%$ recovery at 18 meters from the bottom of the drift (with exponential $\alpha=4.84$ ) or at 226 meters with exponential $\alpha=72.76$ (see file expo-VG.xls - worksheet Dilution factors). If we assume that $1 \%$ of the total flow actually goes through the drift and the WP, this means that the WP water is diluted by a factor of 85 in 18 or 226 meters.

Despite its rigorous derivation, Eq. 2.1 presents only an order of magnitude of the zone of influence. It was derived for homogeneous porous media. The Van Genuchten $\alpha$ values are also subject to caution. They were derived assuming average fracture intensity. In this calculation, only higher fracture intensity is of interest, as only it can generate substantial accumulation. The direction that the Van Genuchten $\alpha$ values take for higher intensities is unclear. Full dilution, i.e., saturations back to original conditions, is clearly more conservative over short distances as it maximizes the accumulation density of the fissile material. This section suggests that that short 
Title: Far-Field Accumulation of Fissile Material from Waste Packages Containing Plutonium Disposition Waste Forms

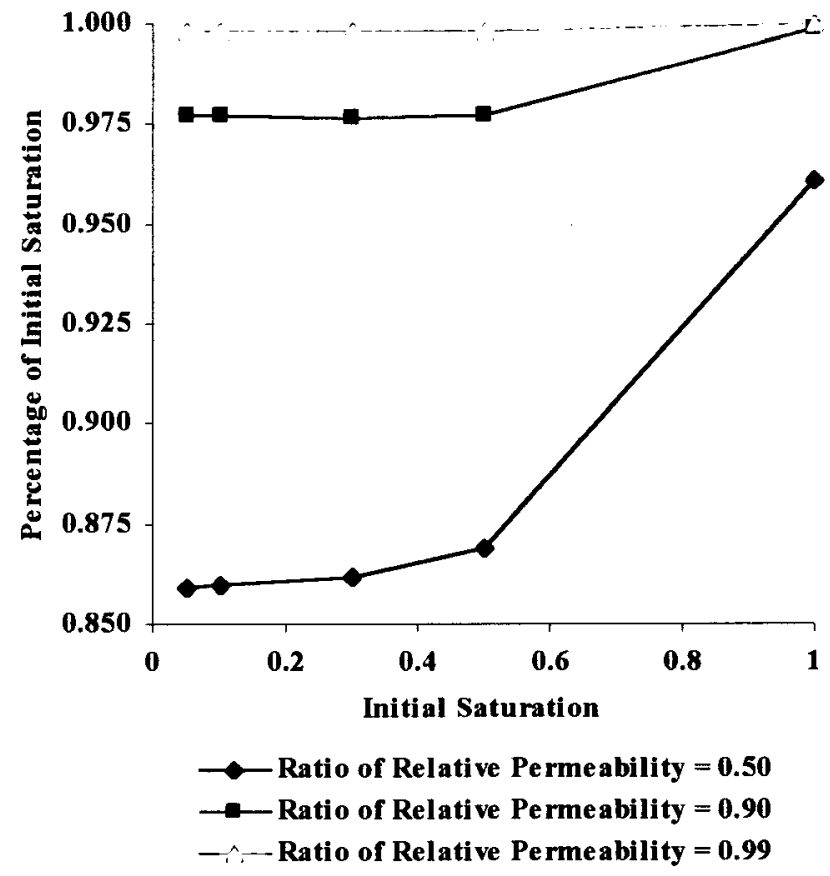

Figure 2-1. Percentage of the Initial Saturation Recovered as a Function of the Initial Saturation and Recovery Criteria

distance can be as small as 10 meters. Although no hard values from Section 2.1.1 are used, this section was intended to prove that dilution and mixing could occur on short distances.

\subsubsection{Dispersion}

With dispersion, dilution increases with distance from the source and, for example, a dilution factor of $10 \%$ for a cell corresponds to a "loss" through dispersion in the course of the cell length of $10 \%$ of the moles initially present. The mineralization region is relatively more spread out with dispersion than it is with local dilution. The shape of the $U$ mineralization envelope resembles a more or less hollow cone of increasing diameter for a point source and a pair of diverging planes for a line source. Because the solution near the source and toward the center of the envelope may be too concentrated in total dissolved species to allow precipitation of actinides (see Section 2.1.4), a region free of mineralization may remain in the center of the envelope at some distance from the source as time progresses. However, far from the source, the solution toward the center of the envelope becomes dilute enough to allow precipitation, so that a horizontal bridge of mineralization fills in the mineralization envelope, leaving a region free of mineralization near the source and toward the center of the envelope. The shape of the mineralization also changes through time. At time 0 after breach time, the sharp concentration gradient between the resident water and the WP water produces a thin mineralization zone at the front of the infiltration area. As time proceeds, the mineralized zone moves forward with the water flow in the same way as a redox roll front would do (but the main parameter in this case is dilution and decrease in $\mathrm{pH}$ - see Section 2.1.4). The mineralized zone also moves sideways due 
Title: Far-Field Accumulation of Fissile Material from Waste Packages Containing Plutonium

Disposition Waste Forms

Document Identifier: CAL-EDC-GS-000002 REV 00

Page 15 of 80

to transverse dispersion and will eventually deplete the front of material to precipitate. It should be noted that this is a bounding calculation, the ionic strength of the WP water will actually decrease progressively mitigating this process. The most favorable time for accumulation is at early time after breach time when the mineralization is as compact as possible.

Dispersion can be conceptualized by comparing the dilution factors to the following formula (Ref. 3, Eq. 10.6 .39 , p. 634 where his $D^{\prime}$ is $D_{L}$ and his $D^{\prime \prime}$ is $D_{T}$ and where the Darcian velocity $q$ has been replaced by the pore water velocity $q / n=v_{x}$ ) representing the steady-state concentration distribution of a point source in a uniform two-dimensional flow field (i.e., a line source in a three-dimensional representation) (see file dispersion_linesource.xls in electronic media Attachment VIII).

$$
\frac{C}{C_{0}}=\frac{Q}{2 \pi \sqrt{D_{L} D_{T}}} \exp \left(\frac{x v_{x}}{2 D_{L}}\right) K_{0}\left(\left(\frac{v_{x}^{2}}{4 D_{L}}\left(\frac{x^{2}}{D_{L}}+\frac{y^{2}}{D_{T}}\right)\right)^{0.5}\right)
$$

where $C_{0}$ is the injection concentration taken as $1, Q$ is the seepage rate per meter of line source, $D_{L}$ and $D_{T}$ are the longitudinal and transverse dispersion respectively, $v_{x}$ is the field velocity assumed uniform and $x$ and $y$ are the coordinates spanning the two-dimensional space beneath the proposed repository where the source term has for coordinates $(0,0) . K_{0}$ is the modified Bessel function of second kind and zero order. For a three-dimensional model with a point source (see file dispersion_pointsource.xls in electronic media - Attachment VIII), the following formula can be derived (see Attachment I):

$$
\frac{C}{C_{0}}=\frac{Q}{2 \pi \sqrt{D_{L} D_{T} D_{T}}}\left(\frac{x^{2}}{D_{L}}+\frac{y_{1}^{2}}{D_{T}}+\frac{y_{2}^{2}}{D_{T}}\right)^{-0.5} \exp \left(\frac{x v_{x}}{2 D_{L}}\right) \exp \left(-\left(\frac{v_{x}^{2}}{4 D_{L}}\left(\frac{x^{2}}{D_{L}}+\frac{y_{1}^{2}}{D_{T}}+\frac{y_{2}^{2}}{D_{T}}\right)\right)^{0.5}\right)
$$

where $y_{1}$ and $y_{2}$ are the coordinates of a horizontal plane perpendicular to the main direction of flow and where $Q$ is the seepage rate in $\mathrm{m}^{3} / \mathrm{s}$. Whether a point or a line source is appropriate depends on the geometry of the repository. If a single WP is considered, the point-source representation is more suitable. The base case of the present calculation (dilution of $10 \%$ ) shows mineral precipitation for dilution factors ranging from 1 to 40 . Thus, the three-dimensional space where precipitation can occur is such that $x, y_{1}$ and $y_{2}$ satisfy

$$
(0.9)^{40}=0.015<\frac{C}{C_{0}}<0.9=(0.9)^{1}
$$

NOTE: 40 and 1 are true exponents.

Choice of transverse and longitudinal dispersions has some effect on the results. They are usually expressed as a linear function of the velocity. The proportionality coefficient, or dispersivity, is usually taken as $10 \%$ of the characteristic length of the system in a saturated system for longitudinal dispersivity and 1\% for transverse dispersivity (Assumption 12). In unsaturated systems, the dispersivity is higher, up to the characteristic length of the system. 
Title: Far-Field Accumulation of Fissile Material from Waste Packages Containing Plutonium Disposition Waste Forms

Figure 2-2 suggests that dispersion is applicable to distances one order of magnitude smaller than mixing and that the mineralization front is on the order of one meter across. However, the source term $\mathrm{Q}$ moves downward with the front. The maximum potential for actinide accumulation occurs along the symmetry axis/plane. Classical dispersion does not have any scale restriction and is also applicable instead of local dilution in the immediate vicinity of the drift in the case of saturated fractures because the source term has to spread out to be diluted by the ambient water. The possible accumulation can grow outside of the initial footprint.

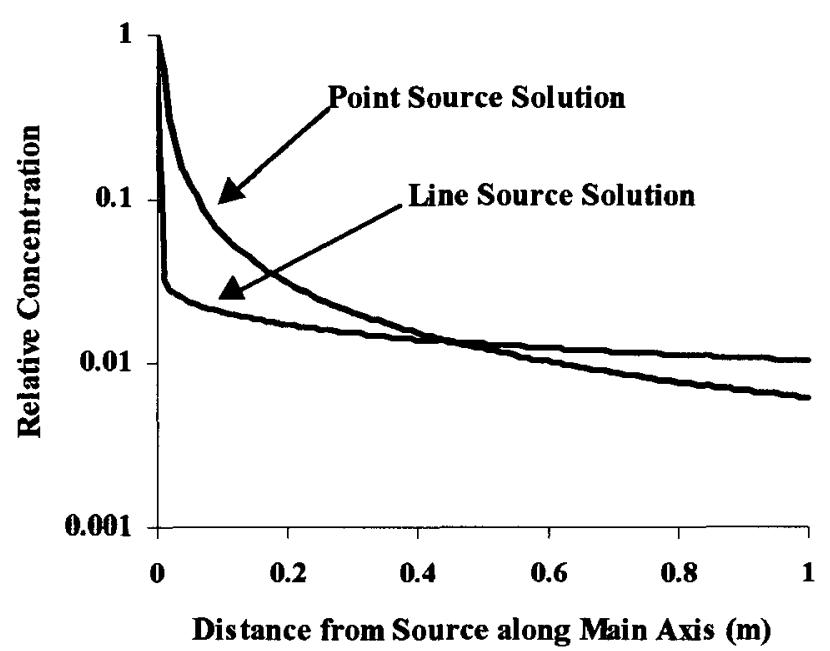

(a)

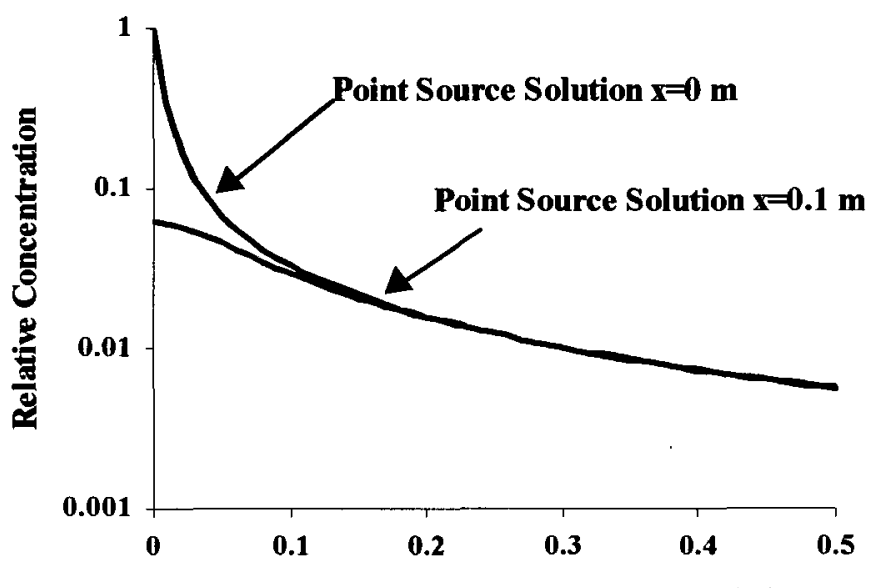

Distance from Source Tranverse to Main Axis (m)

(b)

NOTE: From file dispersion_pointsource_plot.xls.

Figure 2-2. Relative Concentration for Point and Line Source Solutions as a Function of Distance (a) Longitudinal Direction (b) Transverse Direction 
Title: Far-Field Accumulation of Fissile Material from Waste Packages Containing Plutonium Disposition Waste Forms

\subsubsection{Implementation of Dilution: the MIX Keyword}

Local dilution is clearly a mixing process but classical dispersion is as well. The geochemical code PHREEQC (Section 4) does have a built-in keyword to handle dispersion and diffusion. However, it was felt more appropriate for this work to directly use the MIX keyword (that is also used by the code to handle directly dispersion and diffusion). The relationship between mixing and dispersion is given by Eq. 110 of the PHREEQC manual (Ref. 22, p.85):

$$
\text { Mixing Factor }=\frac{D_{L} \Delta t}{n(\Delta x)^{2}}
$$

where $n$ is a numerical parameter used in PHREEQC and is different from 1 only in cases where the mixing factor is larger than $1 / 3$. This calculation uses dilution factors up to 0.2 , thus legitimating the use of $n=1$. Eq. 2.8 can be modified by using the definition of the hydrodynamic dispersion $D_{L}$ :

$$
\frac{D_{L} \Delta t}{(\Delta x)^{2}}=\frac{\alpha_{L}(\Delta x / \Delta t) \Delta t}{(\Delta x)^{2}}=\frac{\alpha_{L}}{\Delta x}
$$

where $\alpha_{L}$ is the longitudinal dispersivity and $\Delta x$ is the cell length. We are also interested in transverse dispersivity because of the trail left by the front as it moves downwards:

$$
\text { Mixing Factor }=\frac{\alpha_{T}}{\Delta x}
$$

where $\alpha_{T}$ is the transverse dispersivity equals to $1 \%$ of the characteristic length of the system (Assumption 12). This characteristic length, defined as the length with significant actinide deposition, must be iterated with the results (See Section 6.1.3.1 about sensitivity of the mixing factors). Uranium or plutonium have significant accumulation for approximately 10 to 20 cells, that is $\alpha_{T}=0.01^{*}(10 \text { or } 20)^{*} \Delta x$, consistent with the mixing factor of $10 \%$ used in the PHREEQC simulations.

Figure 2-3a represents classical dispersion and assumes that any mass leaving the central axis of the system is lost for the simulation. This assumption is acceptable as the relative concentration outside of that central axis is low (that is lower than the 0.015 mentioned in Eq. 2-7). The model represented by Figure 2-3a gives an upper bound of the density of mineralization because the actual source is not a point but of finite area. The point-source approximation is strictly valid only if the source area is small compared to the distance considered during the simulations. This is clearly not the case because the vertical extent of the actinide mineralization is at most of the same order of magnitude as the area of infiltration. The actual mineralization lies between the mixing cases described in the next sections and no mixing at all (this is likely to be the case in the central part of the infiltration area). The approach taken is thus conservative. Figure 2-3b displays a case with local dispersion and assumes that the $1 \%$ seepage fraction is progressively 
Title: Far-Field Accumulation of Fissile Material from Waste Packages Containing Plutonium Disposition Waste Forms

diluted in 100 cells to reach the $100 \%$ percolation rate existing above the drift. The PHREEQC simulation is still done in successive cells of one kilogram each but the run results have to be multiplied by the number of cells (equivalent in this case to the cell number) to obtain the final results.

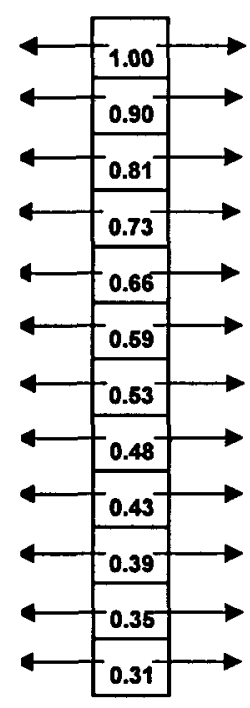

(a)

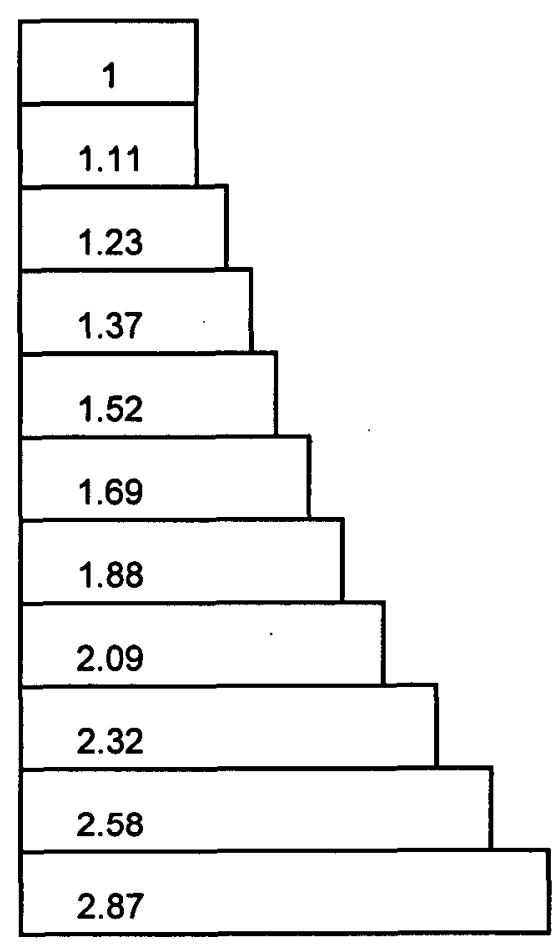

(b)

Figure 2-3. Implementation of the MIX keyword: a) Classical Dispersion, Numbers Show Reduction in Concentration in Successive Cells b) Local Dilution, Numbers Show Increase in Volume in Successive Cells

\subsubsection{Why Dilution Initiates Actinide Precipitation}

The purpose of this section is to describe the dilution-triggered precipitation mechanisms, and to illustrate these mechanisms by examples. Both mechanisms are driven by the dilution of the WP effluent by the J-13 well water (Assumption 3.2 and Section 5.1.1), which has two effects:

- It brings the pH down from about 8.8 in the WP effluent of the pe0a1231 case (see Section 5.1.2.1) or higher (about 10 in the PW2a1231 case - see Section 5.1.2.1) to 8.1 in the J-13 well water (Table 5-2). It should be noted that the $\mathrm{pH}$ of 8.1 is somewhat above the value nominally assumed in connection with $\mathrm{J}-13$ well water. This is because the unsaturated zone is expected to be in equilibrium with a higher carbon dioxide concentration, as is explained in connection with the water compositions given in Table 5-1 of Ref. 7

- It brings the ionic strength down from 2 and above (see Section 5.1.2.1) too much lower values. 
Waste Package Department

Calculation

Title: Far-Field Accumulation of Fissile Material from Waste Packages Containing Plutonium Disposition Waste Forms

Document Identifier: CAL-EDC-GS-000002 REV 00

Page 19 of 80

In systems open to the atmosphere and at high $\mathrm{pHs}, \mathrm{Pu}$ and $\mathrm{U}$ are complexed by carbonate ions yielding aqueous species such as the tri-plutonyl carbonate $\left[\left(\mathrm{PuO}_{2}\right)_{3}\left(\mathrm{CO}_{3}\right)_{6}{ }^{6}\right]$ or plutonyl carbonate $\left[\mathrm{PuO}_{2}\left(\mathrm{CO}_{3}\right)_{3}{ }^{4-}\right]$ and uranyl carbonates $\left[\mathrm{UO}_{2}\left(\mathrm{CO}_{3}\right)_{3}{ }^{4-}\right.$ and $\left.\mathrm{UO}_{2}\left(\mathrm{CO}_{3}\right)_{2}{ }^{2-}\right]$ (these are the most common $\mathrm{Pu}$ and $\mathrm{U}$ aqueous species in the different runs of this work). When the $\mathrm{pH}$ goes down, availability of the carbonate ion is less, forcing the actinides out of solution (see also Ref. 5 - Figures $\mathrm{C}-2$ and $\mathrm{C}-3$ ), down to a $\mathrm{pH}$ of 7 (which is well above the minimum of 8.1 used here). Another important aspect of the $\mathrm{Pu}$ and $\mathrm{U}$ complexes is their large size and charge. Charge is an important parameter when it comes to estimating equilibrium concentrations because equilibrium concentrations are written in terms of activity, product of the molal concentration and of the activity coefficient. Activity coefficients are functions of both the charge of the species and the ionic strength of the solution (see Attachment 5 - Eq. V-1b). At high ionic strength, activity coefficients of highly charged species are small, making their apparent concentration or activity small and thus "hiding", in effect, the actinide complexes within the solution. When the ionic strength decreases (e.g., by dilution), the activity coefficient increases by orders of magnitude. The activity coefficient increases faster than the concentration decreases, thus the activity as a whole increases leading to precipitation of minerals.

To illustrate these two mechanisms, a simplified pe0a1231 case was set (see Attachment III Section III-1) and a few sensitivity analysis runs were done. The Saturation Index (SI), log of the ratio of the ion activity product to the reaction constant, gives a measure of how much actinide could precipitate. If SI is negative, the mineral cannot precipitate. On the other hand, the more positive $\mathrm{SI}$ is, the more abundant the precipitation of that mineral species is (ignoring kinetics considerations). To keep the $\mathrm{pH}$ at the same level while varying the ionic strength, the fictitious species $\mathrm{pH}_{-}$fixH and $\mathrm{pH}_{-}$fixOH were introduced. They maintain the $\mathrm{pH}$ at a given level by adding $\mathrm{HCl}$ or $\mathrm{KOH}$ respectively to the solution. To keep the ionic strength at the same level while varying the $\mathrm{pH}$, the compound $\mathrm{KCl}$ was added in an amount sufficient to reach the target ionic strength. This was done to keep the actinide concentration identical (at 1\%) in the same set of runs. The runs were done at two levels of actinide concentrations by mixing $99 \%$ of WP effluent with $1 \%$ of J-13 well water and by mixing $1 \%$ of WP effluent to $99 \%$ of J-13 well water. Table 2-2 illustrates that decreasing either $\mathrm{pH}$ or ionic strength increases the SI of actinide minerals typically expected to precipitate in the fracture system. Rows 1 and 2 of Table 2-2 show that when $\mathrm{pH}$ decreases by less than one $\mathrm{pH}$ unit, the SIs increase by several orders of magnitude. Rows 3 to 5 indicate that at constant pH (around 8.0 to 8.1), the SIs decrease with increasing ionic strength. Rows 10 and 11 at low ionic strength and constant $\mathrm{pH}$ indicate that the ionic strength effect is not an artifact of reaching the validity limit of the B-dot formulation at high ionic strength but is a true effect. 
Waste Package Department Calculation

Title: Far-Field Accumulation of Fissile Material from Waste Packages Containing Plutonium Disposition Waste Forms

Document Identifier: CAL-EDC-GS-000002 REV 00

Page 20 of 80

Table 2-2. Influence in Variations in pH and lonic Strength for Actinide Precipitation (varying parameter in italics)

\begin{tabular}{|c|c|c|c|c|c|c|c|}
\hline & \multicolumn{3}{|c|}{ Saturation Index (SI) of: } & \multirow[b]{2}{*}{ pH } & \multirow[b]{2}{*}{$\mathbf{P e}$} & \multirow[b]{2}{*}{ I.S. ${ }^{b}$} & \multirow[b]{2}{*}{ Comments } \\
\hline $\begin{array}{c}\text { Row } \\
\#\end{array}$ & Soddyite & Haiweeite & $\mathrm{Pu}(\mathrm{OH})_{4}$ & & & & \\
\hline \multicolumn{8}{|c|}{ Variable pH at High lonic Strength with High Actinide Concentration } \\
\hline 1 & 5.30 & 4.01 & 1.72 & 8.0 & 12.606 & 1.898 & $\begin{array}{l}\text { File: ST1_pH=8.0. } \\
\text { Correction for } \mathrm{pH}\end{array}$ \\
\hline 2 & -1.26 & -2.89 & 0.01 & 8.84 & 11.765 & 1.963 & $\begin{array}{l}\text { File: ST1. } \\
\text { No pH or I.S. Corrections }\end{array}$ \\
\hline \multicolumn{8}{|c|}{ Constant pH and Variable lonic Strength with Low Actinide Concentrations } \\
\hline 3 & 5.75 & 10.41 & 2.34 & 8.115 & 12.48 & 0.996 & $\begin{array}{l}\text { File: ST99_0.1K. } \\
\text { Correction for I.S. by adding } 0.1 \\
\text { moles of KCl. }\end{array}$ \\
\hline 4 & 3.11 & 7.70 & 1.12 & 8.023 & 12.589 & 1.487 & $\begin{array}{l}\text { File: ST99 1.5K. } \\
\text { Correction for I.S. by adding } 1.5 \\
\text { moles of } \mathrm{KCl}\end{array}$ \\
\hline 5 & 2.71 & 7.48 & 0.94 & 8.036 & 12.58 & 1.969 & $\begin{array}{l}\text { File: ST99_2K. } \\
\text { Correction for I.S. by adding } 2 \\
\text { moles of } \mathrm{KCl}\end{array}$ \\
\hline \multicolumn{8}{|c|}{ Variable pH at High lonic Strength with Low Actinide Concentration } \\
\hline $64^{\mathrm{c}}$ & 3.11 & 7.70 & 1.12 & 8.023 & 12.589 & 1.487 & $\begin{array}{l}\text { File: ST99_1.5K. } \\
\text { Correction for I.S. by adding } 1.5 \\
\text { moles of } \mathrm{KCl}\end{array}$ \\
\hline 7 & -3.31 & 2.56 & -0.59 & 8.818 & 11.795 & 1.505 & $\begin{array}{l}\text { File: ST99_1.5K } \mathrm{pH}=8.8 .^{\mathrm{a}} \\
\text { Correction for } \mathrm{pH} \text { and for I.S. by } \\
\text { adding } 1.5 \text { moles of } \mathrm{KCl}\end{array}$ \\
\hline \multicolumn{8}{|c|}{ Variable pH at low lonic Strength } \\
\hline 8 & 6.27 & 11.40 & 2.75 & 8.263 & 12.338 & 0.0213 & $\begin{array}{l}\text { File: ST99. } \\
\text { No pH or I.S. Corrections }\end{array}$ \\
\hline 9 & 1.80 & 7.67 & 1.51 & 8.795 & 11.806 & 0.0342 & $\begin{array}{l}\text { File: } \mathbf{S T 9 9} \mathrm{pH}=8.8 .^{\mathrm{a}} \\
\text { Correction for } \mathrm{pH}\end{array}$ \\
\hline \multicolumn{8}{|c|}{ Constant pH and Variable lonic Strength at Low lonic Strength } \\
\hline 10 & 3.66 & 8.33 & 0.92 & 8.52 & 12.081 & 0.3795 & $\begin{array}{l}\text { File: } \mathbf{S T 7 5} \text { NoNa_pH=8.52. } \\
\text { Correction for } \mathrm{pH} \text { and for I.S. by } \\
\text { deleting } \mathrm{Na}\end{array}$ \\
\hline 11 & 3.13 & 7.30 & 1.21 & 8.524 & 12.079 & 0.4995 & $\begin{array}{l}\text { File: ST75. } \\
\text { No pH or I.S. Corrections }\end{array}$ \\
\hline
\end{tabular}

NOTE: $\quad$.dat for input file and .out for output file.

I.S. = lonic Strength.

${ }^{\mathrm{C}}$ Both cases describe the same run.

\subsection{SCALING BY THE VOLUME OF WATER}

The fracture system is modeled by a series of 100 cells ("solution 1 to $100 "$ "), each of vertical length $1_{c}$. The first cell receives the constant composition solution dripping from the WP ("solution 0"). At each time step TS, the water is moved from one cell to the next and a fresh solution is moved into the first cell. The incoming water augmented of the products of the wall 
Title: Far-Field Accumulation of Fissile Material from Waste Packages Containing Plutonium Disposition Waste Forms

dissolution reacts with the solids already present in the cell and produces a solution of possibly different composition ready to move to the next cell. Dilution is handled by mixing, in given proportions, resident water ("solution 999" - see Section 5.1.1) and the current cell water.

The two main interacting parameters are the rock surface area accessible for mineral dissolution and the amount of water contacting that surface area. The surface area is a simple function of the geometry of the system. Because the PHREEQC runs are normalized to one kilogram of water ( one liter of water), the surface area needs to be scaled by the volume of water in a cell. If the fracture intensity is $I \mathrm{~m} / \mathrm{m}^{2}$ over a cross-sectional area of infiltration (or footprint) $A \mathrm{~m}^{2}$, the total surface area is: $\mathrm{SA}=2^{*} I^{*} A^{*} l_{c}$ where $l_{c}$ is the vertical cell length and the factor 2 accounts for the 2 walls of a fracture (Figure 2-4). The volume of water contained in the fractured rock is: $V=I^{*} A^{*} l_{c}^{*}(2 B)^{*} S$, where $S$ is the average water saturation in the fracture and $2 B$ is the fracture width.

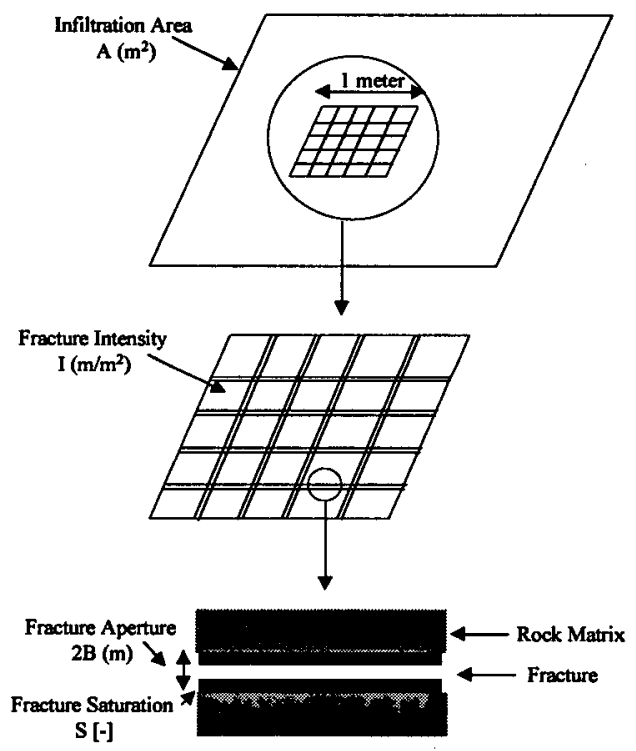

Figure 2-4. Conceptual Model of the Fractured Rock

Hence, the surface area per liter of water $S A_{S C l}$ is expressed by:

$$
S A_{S C 1}=\frac{2 * I^{*} A^{*} l c}{I^{*} A^{*} l c^{*}(2 B) * S}\left(\mathrm{~m}^{2} / \mathrm{m}^{3}\right)=\frac{20}{(2 B)^{*} S}\left(\mathrm{~cm}^{2} / \mathrm{L}\right)
$$

Thus, for a fully saturated fracture system $1 \mathrm{~mm}$ in width, $S A_{S C l}$ is equal to $20,000 \mathrm{~cm}^{2} / \mathrm{L}$. For a $10 \%$ saturated fracture system $1 \mathrm{~mm}$ in width, $S A_{S C l}$ is equal to $200,000 \mathrm{~cm}^{2} / \mathrm{L}$. This formulation does not take into account neither plugging of the matrix pores nor other means of limiting the exchange between the rock minerals and the fracture water. It is possible to increase the surface area to account for micro-porosity within grains (called the B.E.T. formulation in this calculation). It is also assumed that the surface areas stay constant as the tuff dissolves (Assumption 3.14). Note that the factor $(2 B)^{*} S$ is less variable than $2 B$ because large fractures 
Title: Far-Field Accumulation of Fissile Material from Waste Packages Containing Plutonium Disposition Waste Forms

will have smaller degrees of saturation for the same flow rate than narrower ones. If the simulation time step TS is larger than the residence time RT ( $=1 / \mathrm{DR}$ where DR is the drip rate) the surface area is scaled further to $S A_{S C 2}$.

$$
S A_{S C 2}=\frac{20}{(2 B)^{*} S} \frac{R T}{T S}\left(\mathrm{~cm}^{2} / \mathrm{L}\right)
$$

Despite the final scaling (Eq. 2.21), this formulation is only approximate and as the time step varies further from the residence time, the quality of the approximation deteriorates.

The saturation fraction $S$ is a function of four parameters: the flow rate DR out of the WP (which is assumed identical to the seepage rate into the WP), the footprint $A$, the fracture aperture $2 B$, and the fracture intensity $I$. The saturation fraction will adjust to achieve a steady state between the cross-sectional area open to flow and the flow rate (Assumption 3.16). The mathematical expression of the saturation fraction $S$ is given by the Van Genuchten formulation (Ref. 1 - Eq. 2-12 and 2-13) and by the assumption that water saturation is the saturation sustaining the infiltration rate FU scaled to a unit area. Numerically, the infiltration rate and the conductivity are identical (vertical flow with a unit gradient - Assumption 3.3):

$$
\mathrm{FU}=\mathrm{DR} / A=K^{*} k_{r}
$$

$K$ is the saturated hydraulic conductivity and $k_{r}$ is the relative permeability. The conductivity $k$ is given by the cubic law (Ref. 13, Eq. 3.38, pp. 86-87 where $N$ is used for fracture intensity instead of $I$ in this calculation) and lowered by a roughness coefficient computed from the field data scaling:

$$
\frac{K}{I}=r \frac{\rho g(2 B)^{3}}{12 \mu}
$$

where $\rho, g$ and $\mu$ are the water density, the gravitational constant and the water viscosity respectively. The roughness coefficient $r$, which is assumed identical for all fractures (Assumptions 3.8 and 3.9), is obtained through field results:

$$
\frac{K_{\text {field }}}{I_{\text {field }}}=r \frac{\rho g\left(2 B_{\text {field }}\right)^{3}}{12 \mu}
$$

where $K_{\text {field }}, I_{\text {field }}$ and $2 B_{\text {field }}$ are obtained from field data.

Following Assumption 3.4 that all the fractures are conductive to water and Assumptions 3.5 and 3.6 that the fractures are all identical and of constant aperture, the local saturated hydraulic conductivity is given by: 
Title: Far-Field Accumulation of Fissile Material from Waste Packages Containing Plutonium Disposition Waste Forms

$$
K=K_{\text {field }} \frac{I}{I_{\text {field }}} \frac{(2 B)^{3}}{\left(2 B_{\text {field }}\right)^{3}}
$$

The relative permeability coefficient $k_{r}$ is given by the Van Genuchten (Assumption 3.11) expression (Eq. 2-13 of Ref. 1):

$$
k_{r}=S_{e}^{1 / 2}\left[1-\left(1-S_{e}^{1 / m}\right)^{m}\right]^{2}
$$

where $m$ is the Van Genuchten coefficient and $S_{e}$ is the reduced saturation with a residual water saturation of 0.01 . Hence,

$$
F U=K_{\text {field }} \frac{I}{I_{\text {field }}} \frac{(2 B)^{3}}{\left(2 B_{\text {field }}\right)^{3}} S_{e}^{1 / 2}\left[1-\left(1-S_{e}^{1 / m}\right)^{m}\right]^{2}
$$

Eq. 2.18 is solved iteratively for $S_{e}$ for given FU, $I$, and $2 B$ (see file sat_calc.xls in electronic media - Attachment VIII) according to the following formula:

$$
\left[\frac{F U / K}{\left[1-\left(1-S_{e}^{1 / m}\right)^{m}\right]^{2}}\right]^{2}=S_{e}
$$

Among the seven parameters cited (DR, 2B, $I, A, l_{c}, S$ and TS), five need to be provided by the user: generally DR, $2 B, I, A$, and, in addition, the saturation $S$ that is computed from the four previous parameters. The volume of water in the fractured rock within the vertical distance $l_{c}$ of a cell length is $V=I^{*} A^{*} l_{c}^{*}(2 B)^{*} S$. At steady state, mass balance considerations require that $V=\mathrm{DR} * \mathrm{TS}$. Hence $l_{c}$ and TS can be chosen so that:

$$
\mathrm{V}=\mathrm{DR} * \mathrm{TS}=I^{*} A^{*} l_{c}^{*}(2 B)^{*} S
$$

Because, in PHREEQC, one kilogram of water is moved to the next cell every time step, the true mass of solid precipitated in a time step can be scaled to the true amount of water in the system considered:

$$
\text { TRUE results }=P H C \text { results } * V=P H C \text { results } * D R * T S
$$

where TRUEresults represent the final results and PHCresults are the direct results from a PHREEQC run.

\subsection{CORRECTING FOR EARLY TERMINATION}

To avoid unproductive use of computer resources and time, most of the runs were not allowed to run to completion, but were stopped after a few hundred simulated years. Early termination is 
Title: Far-Field Accumulation of Fissile Material from Waste Packages Containing Plutonium Disposition Waste Forms

justified because the system quickly reaches steady-state conditions as all the inputs are constant (concentrations, flow rates, surface area). As illustrated in Section 6.1.1 and Figure 6-3, the masses of most species within a given cell are approximately linear functions of simulated time and, therefore, simple multiplicative factors can be applied. However, some species in some cells do not show a constant rate of increase, but show a nearly constant value. In such cases, no correction for early termination is necessary. Similarly, when a variable concentration source term was used, no early termination correction was applied because in this case the rate of increase in the mineral accumulation is not constant.

\subsection{CORRECTING FOR WORST-CASE CRITICALITY}

The footprint of a WP (parameter $A$ from Section 2.2) is about $8 \mathrm{~m}^{2}$ (WP Length $\mathrm{x}$ WP Diameter $=5.165 \mathrm{~m} \times 1.564 \mathrm{~m}=8.1 \mathrm{~m}^{2}$ - Ref. 33, Table 5). However, the area considered for accumulation may exceed this value by more than one order of magnitude and then be scaled back to a smaller area according to the correction for worst-case criticality. The reasoning behind this correction is twofold. It is conceivable that the water will keep flowing along the drift grade past many fractures depending on the geometric details of the fracture intersection with the drift floor and thus the infiltration area may occupy an area larger than a typical WP footprint. Secondly and more importantly, a cubic shape is more conservative for criticality than a rectangle for the same mass of fissile material because closest to a spherical shape, the most reactive shape everything else being equal. Consequently, all accumulations elongated in the vertical direction can be made more conservative and can integrate at the same time uncertainties about the water velocity by recalculating their dimensions to obtain a cube according to the following equation:

$$
\mathrm{DR} * \mathrm{TS}=I^{*}\left(n^{*} l_{c} * n^{*} l_{c}\right) l_{c} *(2 B) * S
$$

Eq. 2.22 is derived from Eq. 2.20 by posing that $\mathrm{A}=\left(n^{*} l_{c}\right)^{2}$ where $n$ is the number of cells with significant actinide accumulation. Eq. 2.22 is then solved for $l_{c}$. This scaling does not affect the density of the mineralization (i.e., total mass and volume stay the same), which is the true driver of criticality. 
Title: Far-Field Accumulation of Fissile Material from Waste Packages Containing Plutonium Disposition Waste Forms

\section{ASSUMPTIONS}

The following assumptions are used in the course of this calculation.

3.1 It is assumed that the effluent from the WP is not chemically affected by its contact with the invert. The rationale of this assumption is that it is conservative for fracture precipitation because no fissile material is lost in the invert and all of the fissile material is available to be precipitated in the fractures underneath the drift. In this case, there is no accumulation in the invert. No processes in the invert could change the chemistry of the solution in such a way to reduce the potential for fissile deposition in the rock below the invert. This includes $\mathrm{Eh}$ and $\mathrm{pH}$ as well as loss of fissile materials in the invert. This assumption was made to maximize the mass of actinides available for deposition and to take into account a possible invert shortcut. This assumption is used in Section 5.1.

3.2 It is assumed that the ambient water in the fracture system has the same composition as the J-13 well water. The rationale for this assumption is that the groundwater composition is controlled largely by transport through the host rock, over pathways of hundreds of meters. The actual water composition is given in Table 5-4 of Ref. 7, and the explanation for the modification in $\mathrm{pH}$ is given in connection with that table, and in Section 2.1.4 of this document. J-13 well water is most appropriate for the groundwater composition because it was collected from the same stratigraphic unit that the repository will occupy, although the repository location is above the water table. The host rock composition is similar in both the unsaturated and the saturated areas of this unit and is not expected to change substantially over time. The travel time along the fracture system is very large in most instances (Fig. 2-116 of Ref. 1) so that the water has time to equilibrate with the host-rock before it reaches the water table. Hence the water present in the fracture system in the vicinity of the drift and the saturated zone water as represented by the $\mathrm{J}-13$ well water have likely a similar composition. This assumption is used in Section 5.1 .

3.3 It is assumed that advective transport occurs in the vertical direction. The rationale of this assumption is that most of the fractures are vertical (Ref. 6, Appendix 2 and 3 Tables). This assumption is used in Section 2.2. A corollary of this assumption is that vertical permeabilities are used.

3.4 It is assumed that all the fractures within the footprint area beneath the WP are conductive to water. The rationale of this assumption is that connectivity of fractures is high (Ref. 10 p. 7-26; Ref. 11, p. 64; and Section 5.1.7.3) and that it is conservative for mineralization. This assumption is used throughout Section 2.2.

3.5 It is assumed that all of the fractures have the same average aperture. The rationale of this assumption is the following: if it were not the case, the largest fracture(s) would take most of the flow according to the cubic law (Ref. 13, pp. 86-87). This assumption is then conservative because it leads to a more compact mineralization shape. Aperture 
Waste Package Department

Calculation

Title: Far-Field Accumulation of Fissile Material from Waste Packages Containing Plutonium Disposition Waste Forms

Document Identifier: CAL-EDC-GS-000002 REV 00

Page 26 of 80

variability would favor the widest fractures and would lead to a more elongated mineralization less conservative for criticality. This assumption is used in Section 2.2.

3.6 It is assumed that the fracture aperture is constant within a single fracture. The rationale of this assumption is that it is conservative. In reality, apertures vary within the same fracture. However, this assumption is conservative because it leads to a more compact mineralization shape. Aperture variability would favor the widest section of the fractures and lead to a more elongated mineralization less conservative for criticality. This assumption is used in Section 2.2.

3.7 It is assumed that there is no channeling in the fracture planes. No part of the fracture is restricted from flow and from the accompanying precipitation and dissolution. The rationale for this assumption is that it is conservative because it increases the surface area available for tuff dissolution and because it leads to a more compact mineralization shape. This assumption is used in Section 6.1.

3.8 It is assumed that the fracture surface area is independent of fracture aperture. The fracture surface area is calculated as the surface area of parallel plates; the distance between them has no effect on the surface area. The rationale of this assumption is that the increase in surface area resulting from a different model would be difficult to ascertain and can be addressed by sensitivity studies. This assumption is used in Section 2.2 .

3.9 It is assumed that the fracture roughness as defined by Eq. 2.15 is the same for all apertures. The rationale of this assumption is that it is consistent with the fracture plate model used in this calculation. This assumption is used in Section 2.2.

3.10 Three mutually exclusive alternative assumptions are made about the time the WP is breached. The assumptions yield three alternative scenarios in which (a) a negligible amount of the Pu has decayed to U by the time the WP is breached, (b) half of the Pu has decayed to $U$ by the time the WP is breached, and (c) virtually all of the Pu has decayed to $U$ by the time the WP is breached. ${ }^{239} \mathrm{Pu}$ decays to ${ }^{235} \mathrm{U}$ with a half-life of about 24,000 years, so the three scenarios represent breach times of approximately (a) a thousand years or less, (b) 24,000 years, and (c) 120,000 years or more. The rationale of the assumptions is that the resulting set of decay scenarios bounds the possible WP breach times (cases a and c) and provides a reasonable intermediate case (case b). These assumptions are used in Section 5.

3.11 It is assumed that the relationship between fracture saturation and relative permeability follows the Van Genuchten formulation with $m=0.492$ (Ref. 38). The rationale of this assumption is that it is reliable except at very low water saturation; and at very low water saturation, whether or not the assumption holds is unimportant because low water saturation systems are less prone to critical mineral deposition. This assumption is used in Section 2.2. 
Title: Far-Field Accumulation of Fissile Material from Waste Packages Containing Plutonium Disposition Waste Forms

3.12 It is assumed that longitudinal dispersivity is about $10 \%$ of the characteristic length of the system for a fractured saturated medium with good connectivity and the same as the system characteristic length for fractured, unsaturated medium. The rationale of the first part of this assumption is engineering practice and is illustrated in Fig. 2.17, p. 72 and Fig. 2.18, p. 73 of Ref. 14. The second part of the assumption states that the dispersivity in an unsaturated medium can be one order of magnitude higher than in a saturated medium. Attachment II details the rationale of this assumption. This assumption is used in Section 2.2. It is further assumed that transverse dispersivity is approximately $10 \%$ of the longitudinal dispersivity. The rationale of this assumption is engineering practice and is further justified in Attachment II. This-assumption is used in Section 2.2.

3.13 It is assumed that solutes do not diffuse into the rock matrix. The rationale for this assumption is that deposits are likely to plug small pores responsible for matrix diffusion practical. This will happen at early times preventing a significant amount of radionuclides to diffusing in the matrix. This assumption is used in Section 6.1.

3.14 It is assumed that the surface area and volume of fractures do not change as the tuff dissolves. The rationale of the first part of this assumption is that it is conservative because it maximizes the amount of chemical elements, such as $\mathrm{Si}$, needed for actinide precipitation. The only direction that the tuff surface area can go is towards a decrease because of the precipitation of alteration or new minerals. The second part of the assumption is conservative as well because it allows a larger surface area per liter of water, which is favorable to precipitation (Figure 6-17). This assumption is used in Sections 2.2 and 6.1 .

3.15 It is assumed that the partial pressures of $\mathrm{CO}_{2}$ and $\mathrm{O}_{2}$ are the same in the fractures and in the drift. The rationale of this assumption is that the fractures are unsaturated and atmospheric pumping will equilibrate fracture and drift pressures. The case of saturated fractures with reducing conditions is not treated in this calculation. This assumption is used in Section 5.1.

3.16 It is assumed that the average fracture water saturation is the saturation that would sustain the infiltration rate $F U$ (numerically, the infiltration rate and the conductivity are identical, because of Assumption 3.3). The rationale of this assumption is conservation of mass at steady state. This assumption is used in Section 2.2.

3.17 It is assumed that the average velocity in the fracture system is $0.03 \mathrm{~m} /$ year. The rationale for this assumption is the following. A seepage rate of 1.5 liter/year translates into a percolation flux of $3 \mathrm{~mm} / \mathrm{year}$, which gives a seepage fraction of about $1 \%$ (Ref. 1, Fig. 2-112). This percolation flux needs now to be translated into a flow velocity into the system. Fig. 2-116 of Ref. 1 shows that the $50^{\text {th }}$ percentile transport time between the repository and the water table located 250 meters below is 2,000 years for the present-day climate (percolation rate of $8 \mathrm{~mm} /$ year). This translates into an average velocity of 0.125 
Title: Far-Field Accumulation of Fissile Material from Waste Packages Containing Plutonium Disposition Waste Forms

meter/year. Interpolating linearly Fig. 2-116 between present day infiltration rate at 8 $\mathrm{mm} / \mathrm{year}$ and one fifth of present day infiltration to obtain average velocity at $3 \mathrm{~mm} /$ year yields a $50^{\text {th }}$ percentile transport time of 8,000 years. This number is assumed to be representative of the average velocity that can be computed at $250 \mathrm{~m} / 8000$ years $=0.03$ meter/year to be consistent with the seepage rate of 1.5 liter/year. This assumption is used in Section 6.1. Note: since these calculations were performed, new data are available for the seepage rate (Ref. 37). A seepage rate of $1.5 \mathrm{liter} / \mathrm{year}$ translates into an average infiltration rate of $4.15 \mathrm{~mm} /$ year $[(1.5 \mathrm{~L} /$ year - $0 \mathrm{~L} /$ year $) /(3.21 \mathrm{~L} /$ year -0 $\mathrm{L} /$ year $) \times(5 \mathrm{~mm} /$ year $-3.4 \mathrm{~mm} /$ year $)+3.4 \mathrm{~mm} /$ year]. This value is very similar to the 8 $\mathrm{mm} / \mathrm{year}$ used previously, especially if the standard deviation of the seepage rate (about $1.5 \mathrm{~L} /$ year) is taken into account.

3.18 It is assumed that the velocity of 0.03 meter/year is also applicable in the few meters underneath the repository in saturated conditions. The rationale of this assumption is that the velocity of 0.03 meter/year is a rough approximation that can be changed to produce more conservative results (in the criticality sense) but still realistic and consistent with the original input. In unsaturated conditions, the velocity of 0.03 meter/year is a lower bound of the velocity in the few meters underneath the disposal drifts. ). The rationale of this part of the assumption is the following. The dry shadow area footprint $A$ stays constant but the area open to flow increases with the saturation $S$. At the same time the flow $Q$ becomes progressively larger as mixing progresses. Conservation of mass, that should always be verified, tells that $Q=v A n S$ where $n$ is the porosity and $v$ the pore velocity. The saturation is in general smaller underneath the disposal drifts than away from them because of the "dry-shadow" effect (Section 2). If the saturation $S$ increases slower than the steady-state flow rate $Q$ increases, $v$ has to increase to satisfy the conservation of mass equation. This is indeed the case as shown in worksheet "convex" of the spreadsheet sat_calc.xls (Attachment VIII). This assumption is used in Section 6.1 .

3.19 The composition of the effluent solution is assumed constant for the duration of the simulation. The rationale of this assumption is that it is conservative because it maximizes the mass of uranium released. The duration of the simulation is chosen so that this assumption is realistic. This assumption is used in Section 5.1. This assumption will be relaxed in sensitivity analyses.

3.20 It is assumed that adsorption on clays and Fe hydroxides is lumped with precipitation. The rationale of this assumption is that even high partition coefficients $(\mathrm{Kd})$ generates smaller accumulations than true precipitation. This assumption is used in Section 6.1.1.

3.21 It is assumed that all solids that are deposited remain in place; no solids are entrained or otherwise re-mobilized, except possibly by dissolving later. The rationale for this assumption is that it is conservative because it precludes the loss of fissile material from the mineralization region as suspended solids. This assumption is used in Section 6.1. 
Title: Far-Field Accumulation of Fissile Material from Waste Packages Containing Plutonium Disposition Waste Forms

Document Identifier: CAL-EDC-GS-000002 REV 00

Page 29 of 80

3.22 It is assumed that $\mathrm{PuO}_{2}$ does not precipitate and that the log10 of the solubility product for $\mathrm{Pu}(\mathrm{OH})_{4}$ can be reduced by 4 orders of magnitude: The reaction $\mathrm{Pu}(\mathrm{OH})_{4}+4 . \mathrm{H}^{+1}=$ $\mathrm{Pu}^{+4}+4 . \mathrm{H}_{2} \mathrm{O}$ was given a $\log _{10}$ of the solubility product of -3.75 instead of the value of 0.75 as in the data0.nuc.R8a EQ6 database. The rationale for this assumption is that there are indications (see Ref. 26, Ref. 34, and Ref. 4 - Section 5.1.3) that the solubility of $\mathrm{Pu}(\mathrm{OH})_{4}$ is lower than that indicated by the EQ3/6 thermodynamic data library and that it is consistent with the source term. The assumption is conservative for external criticality considerations since it favors precipitation of Pu. This assumption is used in Section 5.1.

3.23 It is assumed that $25^{\circ} \mathrm{C}$ thermodynamic data can be used for the calculations. The rationale of this assumption is two-fold. First, the initial breach and filling of a WP is unlikely to occur before $10^{4}$ years (Ref. 24, Figure C-12), when the WP contents have cooled to $<50^{\circ} \mathrm{C}$ (Ref. 25 , Figure 3-22). Second, the assumption is conservative, with respect to loss of many actinides; most studies (Ref. 26, Table 3; Ref. 27, Table 2) show that actinide solubility decreases slightly as temperature increases, apparently due to the increase in crystallinity and precipitation rates at higher temperatures. This assumption is used in Section 5.1.

3.24 It is assumed that the concentrations of the minor constituents of J-13 well water can be adequately represented by values for $\mathrm{Li}, \mathrm{B}$, and $\mathrm{PO}_{4}$ taken from Reference 35, Table 4.2; values for $\mathrm{Al}, \mathrm{Fe}$, and $\mathrm{Mn}$ in equilibrium with diaspore, pyrolusite, and goethite, respectively; and the values for the trace elements, $\mathrm{Cr}$ and $\mathrm{Mo}$, set to a molality of $10^{-16}$. The rationale for this assumption is that even if the chemistry of the infiltrating water varies substantially, the effects of such variations will likely be insignificant for WPs that undergo significant degradation. An evaluation of the effects of varying the chemistry of the water dripping into a WP is given in Section 5.3.2 of Ref. 7. This assumption is used in Section 5.1. 
Waste Package Department

Calculation

Title: Far-Field Accumulation of Fissile Material from Waste Packages Containing Plutonium

Disposition Waste Forms

Document Identifier: CAL-EDC-GS-000002 REV 00

Page 30 of 80

\section{USE OF COMPUTER SOFTWARE AND MODELS}

This calculation uses the baselined software package PHREEQC and one software routine: transl.c.

\subsection{SOFTWARE}

\subsubsection{PHREEQC Software Package}

The PHREEQC Version 2.0.38(beta) [shortened to Version 2.0(beta)] software has been qualified under the $A P-S I .1 Q$ procedure under the Software Tracking Number 10068-2.0-00 and the Software Activity Number LV-1999-002. Ref. 30 gives the Validation Test Report information. PHREEQC runs were performed on a Duke Engineering \& Services Dell Pentium II computer (CPU\#DES52134, Room 204, DE\&S, 9111 Research Boulevard, Austin, TX). The software was obtained through Configuration Management. Input and output files are listed in Attachment IV and are accessible from the electronic media (Attachment VIII). All input parameters used in the input files are described in Section 5 of this calculation and output files are processed in Section 6. The software is appropriate for use in this calculation and has been used within the range of parameters for which the software has been verified.

\subsubsection{PHREEQC Description}

The PHREEQC family of software products originated in the late 1970's and was developed by the U.S. Geological Survey. However, PHREEQC is a totally new, integrated version rewritten in the C language (Ref. 22). PHREEQC Version 2.0(beta) contains capabilities such as speciation-solubility and kinetically controlled reaction pathway features, which are found in many geochemical software packages, but also includes surface complexation, ion exchange, absorption and solid solutions, and a very versatile treatment of rate laws. In addition, PHREEQC has transport features with handling of dispersion and diffusion in a double-porosity medium. It also has inverse modeling capabilities. However, unlike EQ6, which is a similar geochemical modeling program, PHREEQC supports only the use of the Davies or B-dot equations for the activity coefficients. The thermodynamic database used by PHREEQC in this work is a direct transcription of the EQ6 database (data0.nuc.R8a), translated into a PHREEQCreadable format using the software routine transl.c as described in Attachments V and VI.

PHREEQC models the consequences of reacting an aqueous solution with a set of reactants according to thermodynamic laws. It can also include very complex kinetics laws through a BASIC interpreter coupled to the program. PHREEQC handles advective transport by moving aqueous solutions from one cell to the next, allowing the contents of each cell to reach equilibrium (or not) with the solids and surface features present in the cell (Ref. 22). Diffusion and dispersion are handled by mixing the contents of cells in proportion to the diffusion (or dispersion) parameters. PHREEQC uses a finite-difference scheme and is therefore subject to numerical dispersion. Inclusion of dispersion-diffusion increases several-fold the run time of a particular set of parameters. PHREEQC uses a hybrid Newton-Raphson technique to solve the 
Title: Far-Field Accumulation of Fissile Material from Waste Packages Containing Plutonium Disposition Waste Forms

set of equations at each time step. It is restricted to a constant time step, unlike the dynamic time stepping of EQ6.

\subsection{SOFTWARE ROUTINES}

\subsubsection{Program “transl.c" Version1.0s}

PHREEQC is distributed with a limited thermodynamic library, making the use of the more extensive EQ6 thermodynamic data library desirable. Using the EQ6 library also adds consistency and accuracy to the PHREEQC outputs and comparability and compatibility with calculations made using EQ6 as well. Because the two programs require different input formats, a C programming language routine named "transl.c" Version 1.0 s was written to handle the translation ("s" stands for "short" as opposed to the long version where temperature variations are included - temperature variations are not required in this calculation). The code "transl.c" is included as Attachment VI and its user's manual is included as Attachment V). The resulting thermodynamic database, called phreeqc.nuc_xx-xx or phreeqc.nuc_xx, is valid for a range of temperatures or at a constant temperature, as specified by the user of "transl.c". This calculation uses the thermodynamic database phreeqc.nuc_25, which was translated from the EQ6 thermodynamic database "data0.nucR8a". Files related to the database translation are in the directory Database_files on electronic media (Attachment VIII).

\subsubsection{Microsoft Excel Spreadsheets}

Spreadsheet analyses were performed with Microsoft Excel 97 SR-2, installed on a PC. The specific spreadsheets used for results reported in this document are in the included electronic media (Attachment VIII). The spreadsheets are sufficiently labeled to allow an independent reviewer to redo the calculations. The spreadsheet functions have been summarized in Attachment VII. The spreadsheets have been verified and documented according to the procedure AP-SI.1Q, Software Management (Ref. 51). Formulas used are listed in the spreadsheets and have been checked where used and found to be identical. The macro "goalseek_saturation" V.1.0 developed in the spreadsheet sat_calc.xls is also listed in Attachment VII along with the method and results of verification.

\subsubsection{Surfer Plotting Software}

When a 2-D (two-dimensional) representation as given by plots on spreadsheets is not adequate, the 3-D (three-dimensional) surfer32 plotting software was used. All the information needed to build the Surfer input files was developed on excel spreadsheets.

\subsection{MODELS}

None used. 
Title: Far-Field Accumulation of Fissile Material from Waste Packages Containing Plutonium Disposition Waste Forms

Document Identifier: CAL-EDC-GS-000002 REV 00

Page 32 of 80

\section{CALCUlation}

\subsection{INPUTS}

\subsubsection{J-13 Well Water Composition}

The J-13 well water has been widely used as a surrogate for the fracture water of the unsaturated zone (Assumption 3.2). Original analyses of the J-13 well water (Table 5-1) were provided by Harrar et al. (Ref. 35, Table 4.1 [DTN: MO0006J13WTRCM.000, Ref. 44] and Table 4.2).

Table 5-1. J-13 Well Water Composition

\begin{tabular}{|c|c|}
\hline PH & $7.41^{\mathrm{a}}$ \\
\hline Element/lon & Concentration (mg/l) \\
\hline $\mathrm{Nat}$ & 45.8 \\
\hline Si & 28.5 \\
\hline $\mathrm{Ca}$ & 13 \\
\hline$\overline{\mathrm{K}}$ & 5.04 \\
\hline$\overline{\mathrm{Mg}}$ & 2.01 \\
\hline Alkalinity & $143^{\mathrm{a}}$ \\
\hline F- & 2.18 \\
\hline Cl- & 7.14 \\
\hline NO3- & 8.78 \\
\hline SO4-- & 18.4 \\
\hline $\mathrm{Li}^{\mathrm{b}}$ & $4.80 \mathrm{E}-02$ \\
\hline $\mathrm{B}^{\mathrm{b}}$ & 1.34E-01 \\
\hline PO4-'- & $1.20 \mathrm{E}-01$ \\
\hline
\end{tabular}

DTN: MO0006J13WTRCM.000

NOTES: a Initial values. Recalculated assuming equilibrium $\mathrm{CO}_{2}$ and $\mathrm{O}_{2}$

b Minor constituents not covered by DTN (Assumption 3.24).

In addition, $\mathrm{Al}, \mathrm{Fe}$, and $\mathrm{Mn}$ are assumed to be in equilibrium with diaspore, pyrolusite, and goethite, respectively, and trace elements $\left(\mathrm{Cr}, \mathrm{Mo}\right.$ ) are set to a molality of $10^{-16}$ (Assumption 3.24). With these assumptions, the J-13 well water composition, as given in Table 5-1, changes to the composition given in Table 5-2 (see files J13ww.dat and J13ww.out for PHREEQC run and file J13ww.xls for comparison in directory j13ww in electronic media - Attachment VIII).

$\mathrm{J}-13$ well water is used as resident water in the cells before the breakthrough of the WP water ("solution 1 to 100" of PHREEQC input file of Attachment III - Section III-2) and as mixing water ("solution 999" of PHREEQC input file of Attachment III - Section III-2) (Assumption 3.2). For consistency, the retained J-13 well water is the one used in Ref. 4 and copied from the EQ6 pickup files. Table 5-2 gives its composition. $\mathrm{CO}_{2}$ and $\mathrm{O}_{2}$ are also assumed to be in equilibrium with their atmospheric concentrations (Assumption 3.15). 
Title: Far-Field Accumulation of Fissile Material from Waste Packages Containing Plutonium Disposition Waste Forms

Table 5-2. Elemental Molar Composition for J-13 Well Water

\begin{tabular}{|c|c|c|c|}
\hline $\mathrm{PH}$ & $\mathbf{8 . 1}$ & Element & Mole/kg \\
\hline $\mathrm{Pe}$ & 12.5 & $\mathbf{P}$ & $1.26 \mathrm{E}-06$ \\
\hline Element & Mole/kg & $\mathrm{K}$ & $1.29 \mathrm{E}-04$ \\
\hline $\mathrm{Al}$ & $2.55 \mathrm{E}-08$ & $\mathrm{Li}^{\mathrm{a}}$ & $6.92 \mathrm{E}-06$ \\
\hline $\mathrm{B}$ & $1.24 \mathrm{E}-05$ & $\mathrm{Mg}$ & $8.27 \mathrm{E}-05$ \\
\hline $\mathrm{Ca}$ & $3.24 \mathrm{E}-04$ & $\mathrm{Mn}^{\mathrm{a}}$ & $3.05 \mathrm{E}-16$ \\
\hline $\mathrm{Cl}$ & $2.01 \mathrm{E}-04$ & $\mathrm{Mo}^{\mathrm{a}}$ & $1.00 \mathrm{E}-16$ \\
\hline $\mathrm{Cr}^{\mathrm{a}}$ & $1.00 \mathrm{E}-16$ & $\mathrm{~N}$ & $1.42 \mathrm{E}-04$ \\
\hline $\mathrm{F}$ & $1.15 \mathrm{E}-04$ & $\mathrm{Na}$ & $1.99 \mathrm{E}-03$ \\
\hline $\mathrm{Fe}$ & $3.60 \mathrm{E}-12$ & $\mathrm{~S}$ & $1.90 \mathrm{E}-04$ \\
\hline $\mathrm{C}$ & $2.09 \mathrm{E}-03$ & $\mathrm{Si}$ & $1.01 \mathrm{E}-03$ \\
\hline LogPO2 & -0.7 & $\log \mathrm{PCO} 2$ & -3.0 \\
\hline
\end{tabular}

SOURCE: files J13ww.out and J13ww.xls (Attachment VIII) NOTE: ${ }^{a}$ Concentration set to zero for the simulations.

\subsubsection{WP Source Terms}

The source terms have WP effluent water composition, i.e., either the invert is shortcut or its chemical effects are ignored (Assumption 3.1). It is a conservative position as the mechanisms described in this calculation (dilution, mixing with $\mathrm{J}-13$ well water and reaction with the tuff) also occur in the invert. The chemistry of the solution is then no more altered than it will be by reacting in the fracture system. Precipitation of fissionable elements may also occur if solutions encounter reducing conditions (related to the presence of steel in the invert) before they enter the fracture system. Ignoring this effect is conservative, as it permits the maximum amount of fissionable elements to enter the fracture system.

\subsubsection{Pu-Ceramic Source Terms}

The Pu-ceramic source terms for all of the breach-time scenarios are taken "as is" or in modified form (to account for the decay of Pu), from Ref. 4 (Section 5.2), EQ6 run pe0a1231 at time 2,500 years (Figure 5-1a, Table 5-3a, and files pe0a1231.elem_aqu.txt and pe0a1231.elem_aqu.xls in electronic media - Attachment VIII) and from EQ6 run pw2a1231 at times 4,050 and 7,940 years (Figure 5-1b, Table 5-4 and Table 5-5, and files pw2a1231.elem_aqu.txt and pw2a1231.elem_aqu.xls in electronic media - Attachment VIII). Ref. 4 (Section 5.3) gives details about the differences between the two source terms. In short, pw2a1231 has smaller degradation rates, thought to be more realistic, leading to smaller $\mathrm{Pu}$ and $\mathrm{U}$ concentrations. It is otherwise assumed that the source terms are not affected by the invert (Assumption 3.1). Because the Pu concentration in the WP effluent is approximately constant (within one order of magnitude) between 2,000 and 4,000 years after breach time for pe0a1231 and because the $U$ concentration is at its peak, it is assumed that the source term stays constant during 2,500 years (Assumption 3.19). For case pw2a1231, although the Pu concentration is reasonably constant for about 7,000 years, the $U$ concentration varies by one order of magnitude. Consequently, two 
Title: Far-Field Accumulation of Fissile Material from Waste Packages Containing Plutonium Disposition Waste Forms

time intervals of constant source terms have been retained: one at the lowest $U$ concentration (time $=4,050$ years) and one at the $U$ peak (time $=7,940$ years). The first constant source term (at 4,050 years) is applicable for 3,000 years, from 3,000 years after breach time to 6,000 years after breach time while the second constant source term (at 7,940 years) is applicable for 4,000 years, from 6,000 years after breach time to 10,000 years after breach time. The total accumulation is the sum of the accumulations during both time intervals. It should be noted that the high ionic strength makes the calculation approximate in the first cells before concentration reaches lower levels by dilution in the further downstream cells. 
Title: Far-Field Accumulation of Fissile Material from Waste Packages Containing Plutonium

Disposition Waste Forms

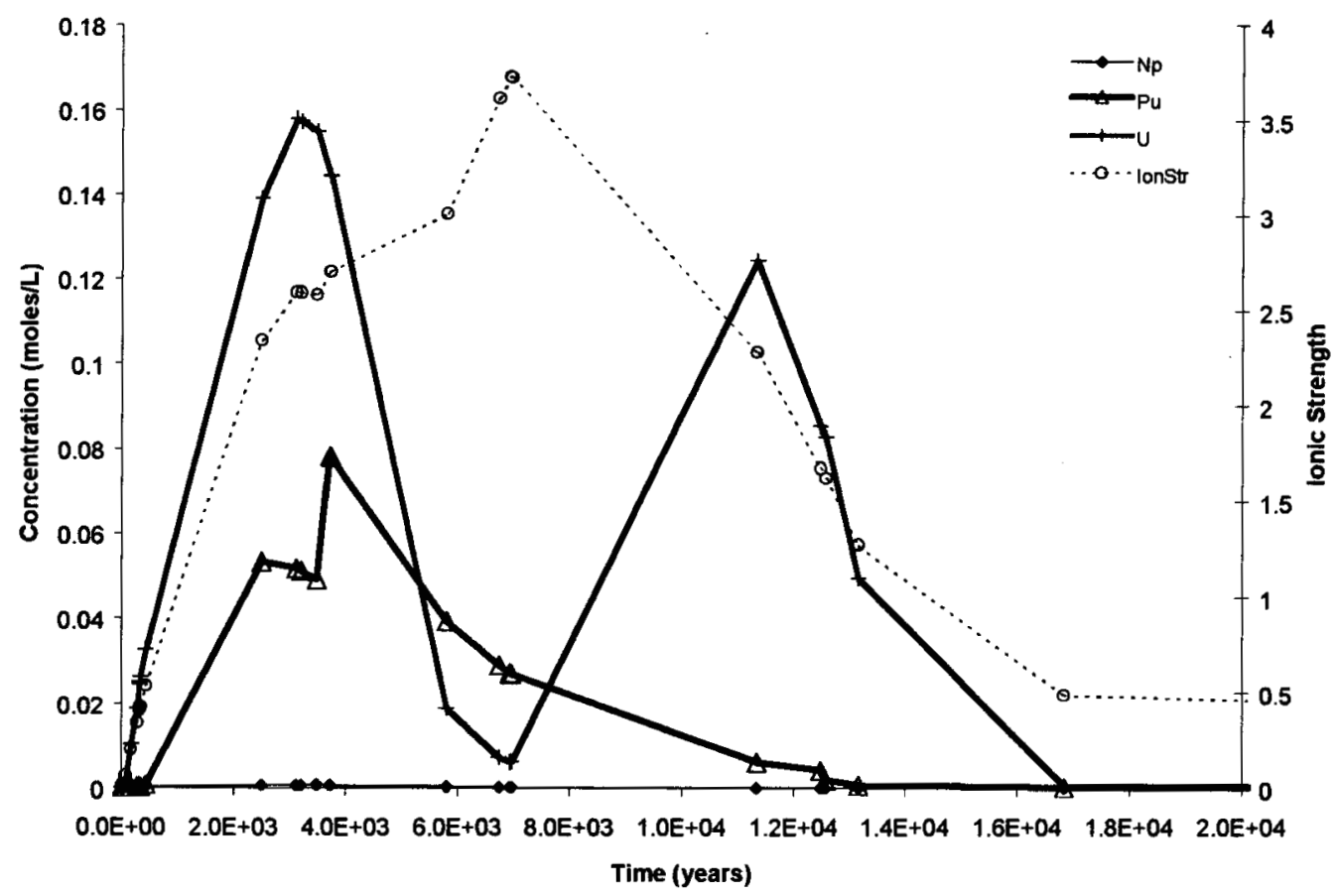

(a)

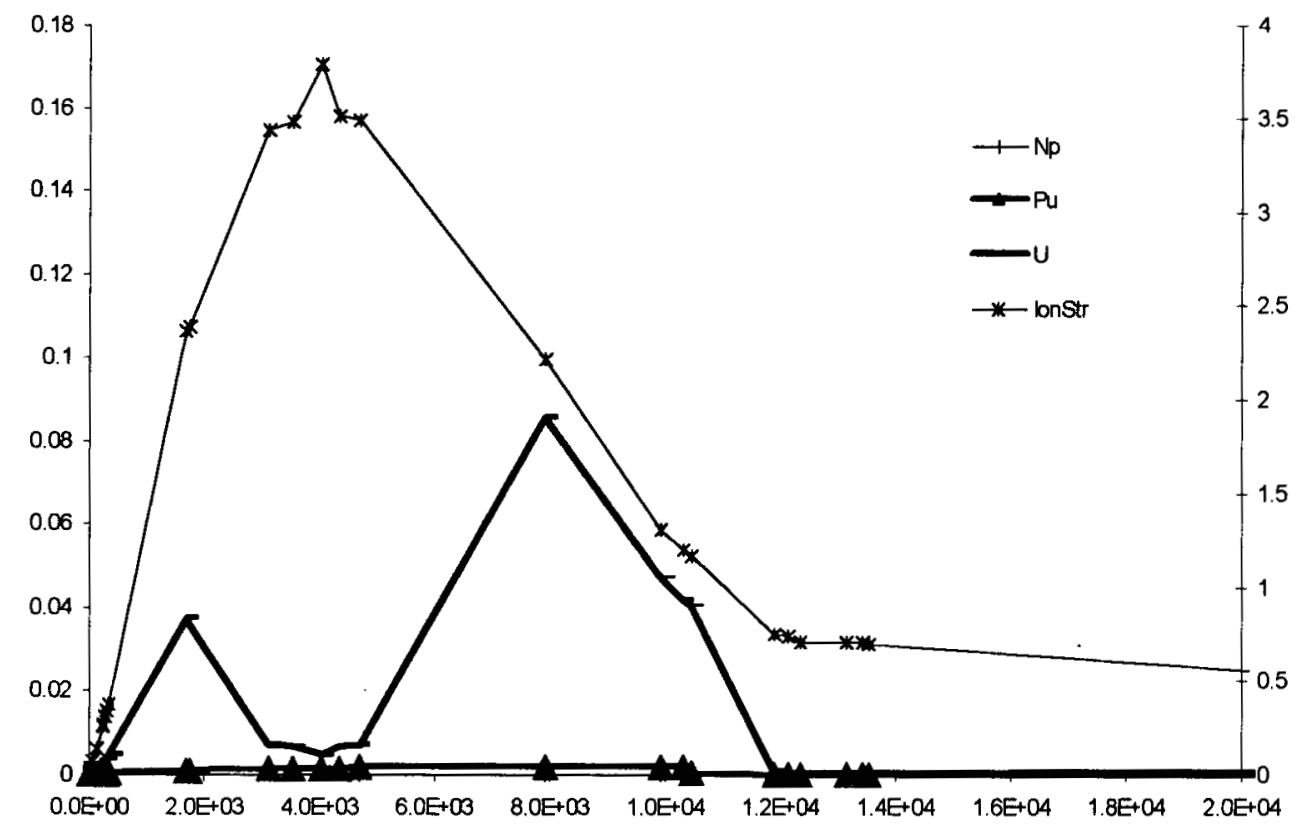

(b)

SOURCE: Data from Ref. 4.

NOTE: Both source terms are plotted on the same scale.

Figure 5-1. Uranium, $\mathrm{Pu}$, and $\mathrm{Np}$ Molar Concentrations and lonic Strengths from Time of WP Breach for Source Terms (a) pe0a1231 and (b) PW2a1231 
Waste Package Department

Calculation

Title: Far-Field Accumulation of Fissile Material from Waste Packages Containing Plutonium

Disposition Waste Forms

Document Identifier: CAL-EDC-GS-000002 REV 00

Page 36 of 80

Table 5-3. Elemental Molar Composition for Non-Decayed Source Term at Time=2,500 Years (source term pe0a1231 from EQ6 output file pe0a1231.elem_aqu.txt)

\begin{tabular}{|c|c|}
\hline Characteristic & Value \\
\hline $\mathrm{PH}$ & $8.78 E+00$ \\
\hline Eh & $7.00 \mathrm{E}-01$ \\
\hline $\mathrm{Pe}$ & $1.18 \mathrm{E}+01$ \\
\hline Element & Concentration (mole/L) \\
\hline $\mathrm{Na}$ & $9.76 \mathrm{E}-01$ \\
\hline $\mathrm{C}$ & $5.52 \mathrm{E}-01$ \\
\hline$U$ & $1.39 \mathrm{E}-01$ \\
\hline $\mathrm{Cr}$ & 1.32E-01 \\
\hline $\mathrm{B}$ & $9.79 \mathrm{E}-02$ \\
\hline $\mathrm{K}$ & $6.64 \mathrm{E}-02$ \\
\hline $\mathrm{Pu}$ & $5.32 \mathrm{E}-02$ \\
\hline $\mathrm{s}$ & $1.41 \mathrm{E}-02$ \\
\hline$F$ & 4.03E-03 \\
\hline $\mathbf{N}$ & 2.71E-03 \\
\hline $\mathrm{Np}$ & 5.37E-04 \\
\hline $\mathrm{Cl}$ & 2.01E-04 \\
\hline $\mathrm{Si}$ & $1.00 \mathrm{E}-04$ \\
\hline $\mathrm{Ca}$ & 6.63E-05 \\
\hline $\mathrm{Mg}$ & 4.26E-05 \\
\hline $\mathrm{Li}$ & 6.92E-06 \\
\hline Gd & $2.64 \mathrm{E}-07$ \\
\hline$P$ & $1.62 E-07$ \\
\hline $\mathrm{Ni}$ & $3.15 \mathrm{E}-08$ \\
\hline $\mathrm{Al}$ & $6.94 \mathrm{E}-09$ \\
\hline $\mathrm{Ba}$ & 1.03E-09 \\
\hline $\mathrm{Zr}$ & $6.18 \mathrm{E}-10$ \\
\hline $\mathrm{Ti}$ & $2.06 \mathrm{E}-10$ \\
\hline $\mathrm{Fe}$ & $1.29 \mathrm{E}-12$ \\
\hline $\mathrm{Mn}^{\mathrm{a}}$ & $4.32 \mathrm{E}-16$ \\
\hline $\mathrm{Cu}^{\mathrm{a}}$ & $1.00 \mathrm{E}-16$ \\
\hline $\mathrm{Mo}^{\mathrm{a}}$ & $1.00 \mathrm{E}-16$ \\
\hline $\mathrm{Pb}^{\mathrm{a}}$ & $1.00 \mathrm{E}-16$ \\
\hline$T c^{a}$ & $1.00 \mathrm{E}-16$ \\
\hline
\end{tabular}

SOURCE: Ref. 4.

NOTE: ${ }^{a}$ Concentration set to zero for the simulations. 
Waste Package Department Calculation

Title: Far-Field Accumulation of Fissile Material from Waste Packages Containing Plutonium Disposition Waste Forms

Document Identifier: CAL-EDC-GS-000002 REV 00

Page 37 of 80

Table 5-4. Elemental Molar Composition for Non-Decayed Source Term at Time $=7,940$ Years (source term PW2a1231 from EQ6 output file PW2a1231.elem_aqu.txt)

\begin{tabular}{|c|c|}
\hline Characteristic & Value \\
\hline $\mathrm{PH}$ & $9.66 \mathrm{E}+00$ \\
\hline En & 6.48E-01 \\
\hline $\mathrm{Pe}$ & $1.09 E+01$ \\
\hline Element & $\begin{array}{c}\text { Concentration } \\
\text { (mole/L) }\end{array}$ \\
\hline $\mathrm{Na}$ & $1.39 E+00$ \\
\hline C & $6.16 \mathrm{E}-01$ \\
\hline $\mathrm{Cr}$ & 2.18E-01 \\
\hline B & 1.51E-01 \\
\hline $\bar{K}$ & $8.92 \mathrm{E}-02$ \\
\hline $\mathrm{U}$ & $8.56 \mathrm{E}-02$ \\
\hline $\bar{S}$ & $1.21 \mathrm{E}-02$ \\
\hline $\mathbf{N}$ & 4.41E-03 \\
\hline$F$ & 4.33E-03 \\
\hline $\mathrm{Pu}$ & 1.81E-03 \\
\hline Si & 6.74E-04 \\
\hline $\mathrm{Cl}$ & 2.01E-04 \\
\hline $\mathbf{P}$ & 3.79E-05 \\
\hline $\mathrm{Np}$ & 2.05E-05 \\
\hline $\mathrm{Ca}$ & $5.68 \mathrm{E}-06$ \\
\hline $\mathrm{Mg}$ & 4.99E-06 \\
\hline Gd & $5.49 \mathrm{E}-07$ \\
\hline AI & 5.11E-09 \\
\hline $\mathrm{Zr}$ & $6.02 E-10$ \\
\hline $\mathrm{Ni}$ & 5.70E-10 \\
\hline $\mathrm{Ti}$ & $2.01 \mathrm{E}-10$ \\
\hline $\mathrm{Ba}$ & $3.78 \mathrm{E}-11$ \\
\hline $\mathrm{Fe}$ & 2.78E-12 \\
\hline$M n^{a}$ & $3.06 \mathrm{E}-15$ \\
\hline
\end{tabular}

SOURCE: Ref. 4.

NOTE: ${ }^{a}$ Concentration set to zero for the simulations. 
Title: Far-Field Accumulation of Fissile Material from Waste Packages Containing Plutonium Disposition Waste Forms

Table 5-5. Elemental Molar Composition for Non-Decayed Source Term at Time $=4,050$ Years (source term PW2a1231 from EQ6 output file PW2a1231.elem_aqu.txt)

\begin{tabular}{|c|c|}
\hline Characteristic & Value \\
\hline $\mathrm{pH}$ & $10.00 \mathrm{E}+00$ \\
\hline Eh & $6.29 \mathrm{E}-01$ \\
\hline pe & $1.06 \mathrm{E}+01$ \\
\hline Element & $\begin{array}{c}\text { Concentration } \\
\text { (mole/L) }\end{array}$ \\
\hline $\mathrm{Na}$ & $3.27 \mathrm{E}+00$ \\
\hline $\bar{C}$ & $1.69 E+00$ \\
\hline$\overline{\mathrm{K}}$ & $2.11 \mathrm{E}-01$ \\
\hline$B$ & $2.06 E-01$ \\
\hline $\mathrm{Cr}$ & $1.73 \mathrm{E}-01$ \\
\hline $\mathrm{S}$ & 4.23E-02 \\
\hline$F$ & 1.44E-02 \\
\hline $\bar{U}$ & $4.69 \mathrm{E}-03$ \\
\hline $\mathbf{N}$ & 3.52E-03 \\
\hline Si & 2.97E-03 \\
\hline $\mathrm{Pu}$ & $1.61 \mathrm{E}-03$ \\
\hline$P$ & $3.65 \mathrm{E}-04$ \\
\hline $\mathrm{Cl}$ & 2.01E-04 \\
\hline $\mathrm{Np}$ & 1.62E-05 \\
\hline $\mathrm{Ca}$ & 3.06E-06 \\
\hline $\mathrm{Mg}$ & $2.92 E-06$ \\
\hline Gd & 8.36E-07 \\
\hline $\mathrm{Al}$ & 1.34E-09 \\
\hline $\mathrm{Zr}$ & $4.46 \mathrm{E}-10$ \\
\hline $\mathrm{Ti}$ & $1.49 \mathrm{E}-10$ \\
\hline $\mathrm{Ni}$ & 1.05E-10 \\
\hline $\mathrm{Ba}$ & $1.99 \mathrm{E}-11$ \\
\hline $\mathrm{Fe}$ & $3.53 E-12$ \\
\hline $\mathrm{Mn}^{\mathrm{a}}$ & $6.79 \mathrm{E}-15$ \\
\hline
\end{tabular}

SOURCE: Ref. 4.

NOTE: ${ }^{a}$ Concentration set to zero for the simulations.

\subsubsection{1a Early Breach Time (negligible decay of Pu)}

The source term for the scenario in which the WP is breached before a substantial fraction of the $\mathrm{Pu}$ has decayed to $\mathrm{U}$ is taken directly from Ref. 4 (Section 5.2). That is EQ6 run pe0a1231 at time 2,500 years after breach or EQ6 run pw2a1231 at times 4,050 and 7,940 years after breach. 
Waste Package Department

Calculation

Title: Far-Field Accumulation of Fissile Material from Waste Packages Containing Plutonium

Disposition Waste Forms

Document Identifier: CAL-EDC-GS-000002 REV 00

Page 39 of 80

\subsubsection{1b Medium Breach Time (50\% decay of $\mathrm{Pu})$}

The source term for the scenario in which the WP is breached after one half-life of ${ }^{239} \mathrm{Pu}$ is adapted from Ref. 4 (Section 5.2). That is EQ6 run pe0a1231 at time 2,500 years after breach (Table 5-3) and EQ6 run pw2a1231 at times 4,050 and 7,940 years after breach (Table 5-4 and Table 5-5) with the $\mathrm{U}$ and $\mathrm{Pu}$ concentrations adjusted as shown in Table 5-6, Table 5-7, and Table 5-8. However, because changing the composition of a solution alters its equilibrium, uranium and plutonium minerals were allowed to equilibrate before entering the first cell (practically, this is equivalent to precipitation of $\mathrm{Pu}(\mathrm{OH}) 4$ and Soddyite and Haiweeite within the WP). Those runs have a "_mod" ending - see Attachment VI). Alternatively, in some early runs, this correction of the source term was not done but the Pu and $\mathrm{U}$ minerals in the first cell were disregarded as precipitation that should have happened in the WP.

Table 5-6. Elemental $\mathrm{U}$ and Pu Concentrations for the Three Breach Time Scenarios (pe0a1231 case)

\begin{tabular}{|l|c|c|c|}
\hline & \multicolumn{3}{|c|}{ Elemental Concentration (mole/L) } \\
\hline Breach Time Scenario & $\mathrm{U}$ & $\mathrm{Pu}$ & Sum \\
\hline Early (no Pu decay) & $1.39 \mathrm{E}-01$ & $5.32 \mathrm{E}-02$ & $1.92 \mathrm{E}-01$ \\
\hline Medium (50\% Pu decay) & $1.66 \mathrm{E}-01$ & $2.66 \mathrm{E}-02$ & $1.92 \mathrm{E}-01$ \\
\hline Late (100\% Pu decay) & $1.92 \mathrm{E}-01$ & $0.00 \mathrm{E}+00$ & $1.92 \mathrm{E}-01$ \\
\hline
\end{tabular}

Table 5-7. Elemental $\mathrm{U}$ and $\mathrm{Pu}$ Concentrations for the Three Breach Time Scenarios (pw2a1231 case at 4,050 years after breach)

\begin{tabular}{|l|c|c|c|}
\hline & \multicolumn{3}{|c|}{ Elemental Concentration (mole/L) } \\
\hline Breach Time Scenario & $\mathrm{U}$ & $\mathrm{Pu}$ & Sum \\
\hline Early (no Pu decay) & $4.69 \mathrm{E}-03$ & $1.61 \mathrm{E}-03$ & $6.30 \mathrm{E}-03$ \\
\hline Medium (50\% Pu decay) & $5.50 \mathrm{E}-03$ & $0.80 \mathrm{E}-03$ & $6.30 \mathrm{E}-03$ \\
\hline Late (100\% Pu decay) & $6.30 \mathrm{E}-03$ & $0.00 \mathrm{E}+00$ & $6.30 \mathrm{E}-03$ \\
\hline
\end{tabular}

Table 5-8. Elemental $\mathrm{U}$ and Pu Concentrations for the Three Breach Time Scenarios (pw2a1231 case at 7,940 years after breach)

\begin{tabular}{|l|c|c|c|}
\hline & \multicolumn{3}{|c|}{ Elemental Concentration (mole/L) } \\
\hline Breach Time Scenario & $\mathrm{U}$ & $\mathrm{Pu}$ & Sum \\
\hline Early (no Pu decay) & $8.56 \mathrm{E}-02$ & $0.181 \mathrm{E}-02$ & $8.74 \mathrm{E}-02$ \\
\hline Medium (50\% Pu decay) & $8.65 \mathrm{E}-02$ & $0.090 \mathrm{E}-02$ & $8.74 \mathrm{E}-02$ \\
\hline Late (100\% Pu decay) & $8.74 \mathrm{E}-02$ & $0.00 \mathrm{E}+00$ & $8.74 \mathrm{E}-02$ \\
\hline
\end{tabular}

\subsubsection{1c Late Breach Time (complete decay of $\mathrm{Pu}$ )}

The source term for the scenario in which the WP is breached after five or more half-lives of ${ }^{239} \mathrm{Pu}$ is adapted from Ref. 4 (Section 5.2). That is EQ6 run pe0a1231 at time 2,500 years after breach (Table 5-3) and EQ6 run pw2a1231 at times 4,050 and 7,940 years after breach (Table 5-4 and Table 5-5) with the $U$ and Pu concentrations adjusted as shown in Table 5-7 and Table 5-8. 
Waste Package Department

Calculation

Title: Far-Field Accumulation of Fissile Material from Waste Packages Containing Plutonium Disposition Waste Forms

Document Identifier: CAL-EDC-GS-000002 REV 00

Page 40 of 80

\subsubsection{MOX Source Term}

The MOX source terms for all of the breach-time scenarios are taken, "as is" or in modified form (to account for the decay of Pu), from Ref. 8, EQ6 nun mox03ap2 at time 13,880 years (Figure 5-2, Table 5-9 and files mox3ap2_elem_aqu.txt and mox3ap2_elem_aqu.xls in electronic media - Attachment VIII). The source term modification for decay of $\mathrm{Pu}$ was handled as described in Section 5.1.2.1.

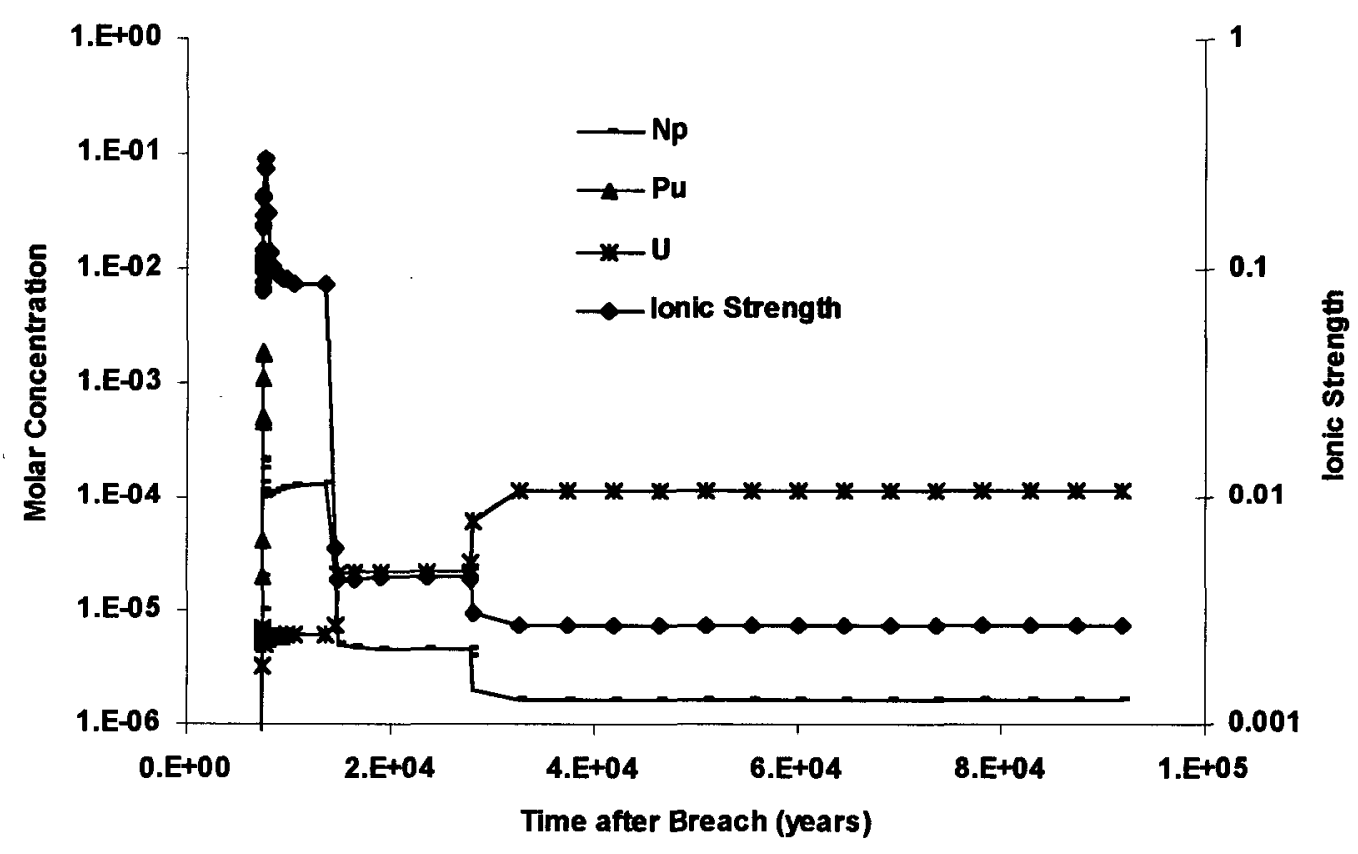

Figure 5-2. Uranium, $\mathrm{Pu}$, and $\mathrm{Np}$ Molar Concentrations and lonic Strengths from Time of WP Breach for Source Term mox03ap2 
Waste Package Department

Calculation

Title: Far-Field Accumulation of Fissile Material from Waste Packages Containing Plutonium

Disposition Waste Forms

Document Identifier: CAL-EDC-GS-000002 REV 00

Page 41 of 80

Table 5-9. Elemental Molar Composition for Non-Decayed Source Term at Time=13,880 Years (source term mox03ap2 from EQ6 output file mox03ap2.elem_aqu.txt)

\begin{tabular}{|c|c|}
\hline Characteristic & Value \\
\hline $\mathrm{PH}$ & 5.99 \\
\hline Eh & 0.86 \\
\hline $\mathrm{Pe}$ & 14.61 \\
\hline Element & $\begin{array}{c}\text { Concentration } \\
\text { (mole/L) }\end{array}$ \\
\hline Mo & 0.0504 \\
\hline Cs & 0.0206 \\
\hline $\mathrm{Ni}$ & 0.0144 \\
\hline Tc & 0.0111 \\
\hline B & 0.00825 \\
\hline$P d$ & 0.00598 \\
\hline $\mathrm{Ca}$ & 0.00411 \\
\hline $\bar{Y}$ & 0.00390 \\
\hline$R \mathbf{b}$ & 0.00345 \\
\hline $\mathrm{Sr}$ & 0.00310 \\
\hline $\mathrm{Na}$ & 0.00286 \\
\hline $\mathrm{Mg}$ & 0.00277 \\
\hline $\mathrm{Sm}$ & 0.00253 \\
\hline $\mathrm{Ag}$ & 0.00252 \\
\hline $\mathrm{Pr}$ & 0.00178 \\
\hline La & 0.00100 \\
\hline Gd & 0.000866 \\
\hline $\mathrm{K}$ & 0.000653 \\
\hline$N$ & 0.000639 \\
\hline $\mathrm{Eu}$ & 0.000588 \\
\hline $\mathrm{Nd}$ & 0.000389 \\
\hline
\end{tabular}

\begin{tabular}{|c|c|}
\hline Element & $\begin{array}{c}\text { Concentration } \\
\text { (mole/L) }\end{array}$ \\
\hline $\mathrm{Ba}$ & 0.000221 \\
\hline $\mathrm{Am}$ & 0.000147 \\
\hline C & 0.000126 \\
\hline$F$ & 0.000118 \\
\hline $\mathrm{Np}$ & 9.35E-05 \\
\hline$S$ & $1.28 \mathrm{E}-05$ \\
\hline $\mathrm{Cr}$ & 1.10E-05 \\
\hline $\mathrm{Li}$ & 6.92E-06 \\
\hline$U$ & 4.91E-06 \\
\hline $\mathrm{Cl}$ & 3.87E-07 \\
\hline $\mathrm{Pu}$ & $8.80 \mathrm{E}-08$ \\
\hline Sn & 2.15E-08 \\
\hline $\mathrm{Al}$ & 3.44E-09 \\
\hline $\mathrm{Zr}$ & $5.39 \mathrm{E}-10$ \\
\hline $\mathrm{Si}$ & $4.23 \mathrm{E}-10$ \\
\hline $\mathrm{Ti}$ & $1.80 \mathrm{E}-10$ \\
\hline$M n^{a}$ & $6.94 \mathrm{E}-12$ \\
\hline $\mathrm{Fe}$ & 3.83E-12 \\
\hline$P^{a}$ & $1.40 \mathrm{E}-12$ \\
\hline $\mathrm{Ru}^{\mathrm{a}}$ & $2.31 \mathrm{E}-13$ \\
\hline $\mathrm{Cu}^{\mathrm{a}}$ & $1.05 \mathrm{E}-16$ \\
\hline $\mathrm{Zn}^{a}$ & $1.00 \mathrm{E}-16$ \\
\hline $\mathrm{Pb}^{\mathrm{a}}$ & $1.00 \mathrm{E}-16$ \\
\hline $\mathrm{Ce}^{\mathrm{a}}$ & $4.12 \mathrm{E}-17$ \\
\hline $\mathrm{Rh}^{\mathrm{a}}$ & $2.81 \mathrm{E}-19$ \\
\hline
\end{tabular}

SOURCE: Ref. 8.

NOTE: ${ }^{a}$ Concentration set to zero for the simulations.

\subsubsection{Drip Rates}

The drip rate is taken from a correlation between percolation rate and drip rate (Ref. 1, Fig. 2112). Specifically, percolation rates of $40 \mathrm{~mm} /$ year and $8 \mathrm{~mm} /$ year correlate with drip rates onto the WP of $0.15 \mathrm{~m}^{3} /$ year and $0.015 \mathrm{~m}^{3} /$ year, respectively. The choice of these particular percolation and drip rates is discussed in detail in Ref. 7. For the present study, the drip rate was restricted to a value of $1.5 \mathrm{~L} /$ year consistent with the input conditions of the source term. It should be noted that the MOX case has a flow rate of $15 \mathrm{~L} /$ year but eventually it is not relevant because very little actinide is precipitated (Section 6.4). 
Title: Far-Field Accumulation of Fissile Material from Waste Packages Containing Plutonium Disposition Waste Forms

\subsubsection{Thermodynamic Database}

The EQ6 thermodynamic database data0.nuc.R8a (consistent with Ref. 4) is used. The EQ6 thermodynamic database data0.nuc.R8a is a composite thermodynamic database derived from the data $0 . s k b$ and other databases provided by Lawrence Livermore National Laboratory tailored for WP degradation studies. The detailed history of the database is provided in the heading of the file data0.nuc.R8a in directory database_files (Attachment VIII - electronic media). The most significant modification is that the precipitation of $\mathrm{Pu}$ is enhanced by 4 orders of magnitude (Assumption 3.22). The more recent database data0.nuc.R8s (Ref. 4 - Section 5.1), modified from data0.nuc.R8a in the course of Ref. 4 calculation by using information from Ref. 42, is also used as part of the sensitivity analysis. All calculations are done at $25^{\circ} \mathrm{C}$ (Assumption 3.23).

\subsubsection{Fracture Wall Dissolution}

The walls are made of tuff whose normalized composition is computed in spreadsheet Tuff_compostion.xls (Attachment VIII) and reproduced in Table 5-10. The initial rock makeup comes from Ref. 36. Because the different species making up the tuff have approximately the same density, molar and relative surface compositions are numerically identical.

Table 5-10. Normalized Molar Composition of Tuff

\begin{tabular}{|c|c|}
\hline Component & $\begin{array}{c}\text { Relative } \\
\text { Surface Area }\end{array}$ \\
\hline Annite & 0.020 \\
\hline Phlogopite & 0.009 \\
\hline Anorthite & 0.028 \\
\hline Albite & 0.306 \\
\hline Microcline & 0.276 \\
\hline Cristobalite & 0.361 \\
\hline Sum & 1.000 \\
\hline
\end{tabular}

The rate laws follow the transition-state theory (TST) formalism (Ref. 4, Section 5.3.2):

$$
\frac{\Delta \text { Moles }}{\Delta t}=S A^{*} S A_{\text {rel }} *\left(a+b\left[O H^{-}\right] 0.3\right) *(1-S R)
$$

for cristobalite, microcline, albite, and anorthite and of the form:

$$
\frac{\Delta \text { Moles }}{\Delta t}=S A^{*} S A_{\text {rel }} *\left(a\left[H^{+}\right] 0.37+b+c\left[H^{+}\right]-0.22\right) *(1-S R)
$$

for annite and phlogopite where SA is the surface area and SR is the saturation ratio. The coefficients $a, b$, and $c$ are fitted to experimental results. Details about the choice of the numerical values of these coefficients are given in Ref. 4 (Section 5.3.2). The original sources for that information are Ref. 39, 40 and 41 for quartz, feldspars and micas respectively. It should 
Waste Package Department Calculation

Title: Far-Field Accumulation of Fissile Material from Waste Packages Containing Plutonium Disposition Waste Forms

Document Identifier: CAL-EDC-GS-000002 REV 00

Page 43 of 80

be noted that if the same minerals become supersaturated, they do not precipitate back in the rock, but stay in a supersaturated solution because re-precipitation under the same mineralogical form is very slow.

\subsubsection{Precipitation of Minerals}

Unlike the EQ6 code that senses the phases that should be precipitated, PHREEQC requires the user to specify them. This can be a challenging task in an unknown complex system. This is the reason why the potential minerals for precipitation are chosen with the help of EQ6 runs in similar systems (that is in the invert). They are given in the "EQUILIBRIUM_PHASES" field of the PHREEQC input file (Attachment III - Section III-2). Table 5-11 displays the list of minerals that appeared in EQ6 invert runs (Ref. 4) and that were used in the PHREEQC runs. In addition quartz was not used because it is less soluble than cristobalite, which is the most common silica phase in the rock. Instead, chalcedony was chosen as the $\mathrm{SiO}_{2}$ species (Ref. 4 Section 6.2). Dolomite was also suppressed because of slow kinetics deposition at $25^{\circ} \mathrm{C}$. A sensitivity run was done with dolomite with no effect on the actinide accumulation (see electronic media *_withDol.xls - Attachment VIII). In the couple goethite/hematite, only one of these two species is allowed to precipitate in the same run. All runs were done with goethite. One sensitivity run was done with hematite with no effect on the actinide accumulation (see electronic media *_withHem.xls - Attachment VIII). The different species of nontronite and saponite represent an approximation of the smectite solid solution.

Table 5-11. List of Minerals Allowed to Precipitate in All PHREEQC Runs

\begin{tabular}{|c|c|}
\hline GdOHCO3 & Saponite-Na \\
\hline GdPO4:H2O & Nontronite-Ca \\
\hline Haiweeite & Nontronite-K \\
\hline Calcite & Nontronite-Mg \\
\hline Magnesite & Nontronite-Na \\
\hline Chalcedony & Boehmite \\
\hline Diaspore & Pu(OH)4 \\
\hline Goethite / Hematite & Ni2SiO4 \\
\hline Clinoptiolite-Ca & Soddyite \\
\hline Clinoptilolite-K & Schoepite \\
\hline Clinoptiolite-Na & UO2CO3 \\
\hline Saponite-Ca & UO2(OH)2(beta) \\
\hline Saponite-H & Na2U2O7 \\
\hline Saponite-K & CaUO4 \\
\hline Saponite-Mg & \\
\hline &
\end{tabular}

\subsubsection{Fracture System Effects on Actinide Precipitation}

The fracture system is described in the following sections and subsections. The initial geometry of the system as described below is not a function of the source term although after correction for worst-criticality (Section 2.4), the footprint $A$ and cell length $l_{c}$ are indeed functions of the source term. 
Title: Far-Field Accumulation of Fissile Material from Waste Packages Containing Plutonium Disposition Waste Forms

Two ideal systems, bounding cases of the general system, will be considered. In one system, Case A, the fracture system underneath the repository is unsaturated. In Case A, local dilution will be the main mechanism and the vertical column where minerals can precipitate is the region directly underneath the footprint of the WP (Figure 5-3). The other system, Case B, results from assuming saturated flow (i.e., $S=l$ ). Local saturation could occur because of local plugging or constrictions or because there are only very few active fractures. In Case B, dilution can happen only by transverse dispersion laterally and longitudinal dispersion at the front; the cross section of the cone-like region affected by the mineral deposition can be much larger than the footprint of the WP. It is, nevertheless, conservatively assumed that the mineralization is contiguous and convex (Section 2.1).

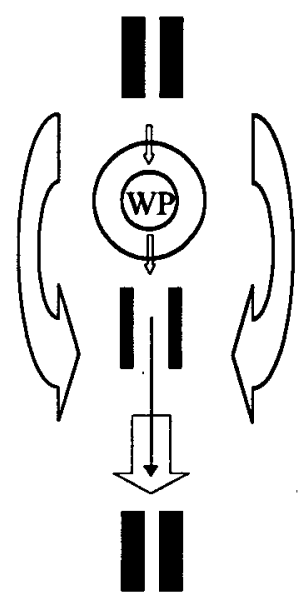

A

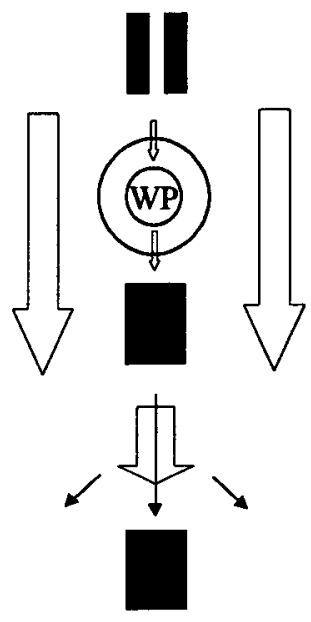

B

NOTE: Large arrows represent water flow, simple arrows represent transport. Size of black rectangles represent the water saturation in the fracture system.

Figure 5-3. Conceptual Model of Cases A and B

Table 5-12 displays the parameters for Cases A and B. For Case A, the surface area per unit fluid volume should decrease with mixing, because the saturation increases, reflecting an increased water volume. However, it is conservative to assume a constant surface area, because an increase in surface area produces either an increase in the mineral deposition (Figure 6-15) or at least no decrease (Figure 6-16). The only difference between cases B1 and B2 is the fracture aperture, $1 \mathrm{~mm}$ and $0.2 \mathrm{~mm}$, respectively. The only difference between cases B2 and B3 is the change in surface area due to the B.E.T. formulation.

The initial cell length can be very roughly approximated by considering field data (base case of Chapter 2 of TSPA-VA - Ref. 1) (Assumption 3.17) and can be modified according to the method described in Section 2.4. At the given drip rate of 1.5 liter/year and assuming a constant source term with no Pu decay, the system releases a total of 521 moles $(\sim 124 \mathrm{~kg})$ of uranium and 200 moles $(\sim 48 \mathrm{~kg})$ of $\mathrm{Pu}$ in 2,500 years (pe0a1231 source term). Similarly, in the pw2a231 
Waste Package Department

Calculation

Title: Far-Field Accumulation of Fissile Material from Waste Packages Containing Plutonium Disposition Waste Forms

Document Identifier: CAL-EDC-GS-000002 REV 00

Page 45 of 80

case, the system releases a total of $21+513=534$ moles $(\sim 5+122=127 \mathrm{~kg})$ of uranium and $7.2+10.9=18.1$ moles $(\sim 1.8+2.6=4.4 \mathrm{~kg})$ of $\mathrm{Pu}$ in 7,000 years.

Table 5-12. Input Parameters for Cases A and B

\begin{tabular}{|c|c|c|}
\hline Parameter & Case A & Cases B1, B2, and B3 \\
\hline Fracture Aperture 2B (mm) & 0.75 & $1,0.2,02$ \\
\hline Fracture Intensity $\mid\left(\mathrm{m} / \mathrm{m}^{2}\right)$ & 10 & 10 \\
\hline Initial Cross-Sectional A $\left(\mathrm{m}^{2}\right)^{\mathrm{a}}$ & 150 & $3.3,16.67,16,67$ \\
\hline Drip Rate DR (Lyear) & 1.5 & 1.5 \\
\hline Time-step TS (year) & 0.67 & 0.67 \\
\hline Water Velocity (m/year) & 0.03 & 0.03 \\
\hline Saturation Fraction & 0.03 & 1 \\
\hline Surface Area SA (cm $\left.{ }^{2} / \mathrm{L}\right)$ & $1,000,000$ & $20,000-100,000-1,000,000$ \\
\hline Initial Cell Length $\mathrm{I}_{c}(\mathrm{~m})$ & 0.03 & 0.03 \\
\hline
\end{tabular}

NOTE: "These two parameters are called "initial" because they will be scaled towards conservatism according to Section 2.4

Details about the geometry of the fractured system (parameters $I$ and $2 B$ ) near the repository are given in the following subsections.

\subsubsection{Fracture Intensity I}

Fracture intensity can be studied on surface outcrops, along survey lines in the ESF and in boreholes. The drawback of borehole studies is the inability to tell long fracture trace lengths from short fractures. The fracture intensity I can be expressed in several ways: in \#/m (=I1 or fracture frequency), in $\mathrm{m} / \mathrm{m}^{2}(=\mathrm{I} 2)$ or in $\mathrm{m}^{2} / \mathrm{m}^{3}(=\mathrm{I} 3)$. Because most of the fractures are vertical (Ref. 6 Appendix 2 and 3 Tables), I2 and I3 are equivalent. The fracture frequency or I1 is reported from ESF studies as $1.880,1.810$ and 2.10 fracture/meter in TSw34, TSw35, and TSw36 respectively for fractures having a trace length larger than $1 \mathrm{~m}$ (Ref. 36). About $50 \%$ of the fractures are less than $1 \mathrm{~m}$ long (Ref. 10, Table 7.17) in TSw34. The fracture frequency is corroborated by Fig 7.5, p7-24 of Ref. 10, which shows 4 fractures/m along survey line in TSw34 (for fractures $>0.3$ in length). Some areas of the ESF are more densely fractured because fracture frequency as high as $1 / 0.23=4.35$ fracture $/ \mathrm{m}$ for fracture $>1 \mathrm{~m}$ are sustained for several meters of drift in TSw34 (Ref. 6, Table 13) and can even reach 8 fracture/m (Ref. 6, Fig.4b) in the IFZ (Intensely Fractured Zone) along at least 10 meters of drift.

Fracture frequency (or I1) is only part of the picture as the average trace length needs to be incorporated into the characterization process. Both fracture frequency and average trace length and to a lesser degree fracture orientations come together to compose fracture intensity (or 12). Fracture intensity is more relevant to flow in the system because it describes the fracture porosity in the formation and then gives the permeability from the cubic law. Although fracture intensity can be derived from the parameters mentioned above either analytically or through numerical simulation, direct outcrop or ESF measurements are more accurate. Outcrop measurements are representative of the subsurface as shown by the fracture intensity measurements in the TSw34 formation (Ref. 6, Appendix 2 Tables) and give a fracture intensity of $1.7 \mathrm{~m} / \mathrm{m}^{2}$ for fractures 
Title: Far-Field Accumulation of Fissile Material from Waste Packages Containing Plutonium Disposition Waste Forms

$>1.5 \mathrm{~m}$ (Ref. 6, p102). Ref. 12 (Table 3 for FSU3 unit equivalent to the TWs34 and Tws35 horizons) mentions $\mathrm{I} 1=1.82$ fracture $/ \mathrm{m}$ and $\mathrm{I} 2=1.22 \mathrm{~m} / \mathrm{m}^{2}$ from ESF studies for fractures greater than 1.5 meters in length. This work uses a conservative fracture intensity of $10 \mathrm{~m} / \mathrm{m}^{2}$ consistent with the highest fracture frequency for fracture $>1 \mathrm{~m}$ found within the current underground works. The highest fracture density is the most conservative because it increases the porosity available for accumulation of materials per given volume of rock.

\subsubsection{Fracture Aperture 2B}

In the ideal world of parallel plate fractures, the aperture is constant (Assumption 3.6) but real fractures always show aperture variations. For this reason fracture aperture is difficult to measure directly and one measurement may not be representative of the entire fracture. As for all spatially variable properties, they can be characterized by three parameters: an average value, a measure of the range generally through the standard deviation, and a measure of how fast these variations take place, optionally including anisotropy. Chemical transport properties are more sensitive to the last two parameters (see section on dispersivity) than flow. Because of this difficulty, one has to introduce both concepts of hydraulic and solute or tracer aperture. The later is always larger than the former (Ref. 43). Flow tends to be impeded by constrictions (that are measured as hydraulic aperture) while transport is more function of the largest openings where the solute has to diffuse (or disperse).

In the project, borehole pneumatic tests executed on small volumes isolated with packers yield the fracture permeabilities that can be directly translated to hydraulic aperture by application of the cubic law. Ref. 10, Chap.7 provides details and references. Ref. 10 (Table7.12) presents an average hydraulic aperture of $140 \mu \mathrm{m}$ in Tsw34, $182 \mu \mathrm{m}$ in Tsw35 and $190 \mu \mathrm{m}$ in TSw36 whereas Ref. 1 (Chap. 2, p2-40) and Ref. 10 (Chap. 7 p7-18) mention an average hydraulic aperture of $81 \mu \mathrm{m}$ for TSw34. In this work, the average aperture is assumed to vary in the range $100-1000 \mu \mathrm{m}$ to take into account the solute transport effect. The highest fracture aperture is the most conservative because it allows the maximum accumulation of materials per given volume of rock for a given fracture intensity.

\subsubsection{Fracture Network Connectivity}

Several arguments suggest that the connectivity of the fracture network is good even at the meter scale (Ref. 10, p7-26). Numerical simulations by Anna and data from two boreholes (Ref. 12, Table 4) suggest that only $30 \%$ to $35 \%$ of the fractures $>1.5 \mathrm{~m}$ are not connected to the network. Using geometric arguments, Sonnenthal et al. (Ref. 10, p7-25) claim that the network is well above its percolation threshold and likely to form a well-connected network geometrically. More generally, Sweetkind and Williams-Stroud (Ref. 11, p64) establish that the connectivity is high in welded units such as TSw34 to TSw36. On the other hand, computer simulations suggest that only, $18 \%$ to $27 \%$ (Ref. 23 ) of these connected fractures are active under ambient conditions. As such, it is legitimate to assume that at the beginning of the flow domain (bottom of the drift) all the fractures contacted by dripping water are active. This is the physical basis for Assumption 3.4, that all the modeled fractures in a WP footprint are conductive to water. 
Title: Far-Field Accumulation of Fissile Material from Waste Packages Containing Plutonium Disposition Waste Forms

Document Identifier: CAL-EDC-GS-000002 REV 00

Page 47 of 80

\subsubsection{Fracture Orientation (dip and directions)}

Visual inspection of Fig. 11 in Ref. 12 indicates two main nearly vertical sets of fractures oriented $\mathrm{N} 30 \mathrm{E}$ and $\mathrm{N} 115 \mathrm{E}$ (that are crossing at an angle of approximately $90^{\circ}$ ). The fracture cutoff was $1.5 \mathrm{~m}$ and only fractures with a length above $1.5 \mathrm{~m}$ were studied. The fractures can be modeled as 2 perpendicular sets of vertical fractures. The N30E set is more abundant that the other set.

\subsubsection{Molar Volumes}

Molar volumes are directly extracted from the EQ6 database data0.nuc.R8a and approximated as explained in the notes to Table 5-13 when data are missing.

Table 5-13. Molar Volumes of Relevant Minerals

\begin{tabular}{|c|c|}
\hline Mineral & Molar Volume $\left(\mathrm{cm}^{3} / \mathrm{mole}\right)$ \\
\hline Calcite & 36.934 \\
\hline Chalcedony & 22.688 \\
\hline Clinoptilolite & $700^{a}$ \\
\hline Diaspore & 17.76 \\
\hline Haiweeite & 322.00 \\
\hline Nontronite & $135.00^{\circ}$ \\
\hline $\mathrm{Pu}(\mathrm{OH}) 4$ & $36^{c}$ \\
\hline Saponite & $140^{\circ}$ \\
\hline Soddyite & 131.27 \\
\hline \multicolumn{2}{|c|}{$\begin{array}{l}{ }^{a} \text { Calculated from dehydrated mineral }=544.7 \\
\mathrm{~cm}^{3} / \text { mole and information from data0. } \\
\text { Maximum value for all species. } \\
{ }^{\circ} \text { Calculated from } \mathrm{Pu}=12 \mathrm{~cm}^{3} / \text { mole and } \mathrm{PuO} 2=23.83 \\
\sim 24 \mathrm{~cm}^{3} / \text { mole. }\end{array}$} \\
\hline
\end{tabular}

\subsection{EXAMPLES} $\sim 24 \mathrm{~cm}^{3} /$ mole.

The constant source terms are taken to be the effluent from the WP (Ref. 4, Section 5.2, EQ6 runs pe0a1231 at 2,500 years and pw2a1231 at 4.050 and 7,940 years after WP breach, respectively, and Ref. 8 EQ6 run mox03ap2). The source solution flows first through the invert, which is assumed inert for this calculation (Assumption 3.1), and then through the fractured rock, where it reacts with the fracture walls. As it moves along, the effluent water is diluted by the surrounding water, represented in the calculation by the J-13 well water composition (Assumption 3.2). Results of the simulations are presented in a normalized fashion (moles of minerals precipitated per liter of water); they are then scaled according to the geometry of the system as described in Section 2.2 (Eq. 2.21).

Because the PHREEQC results need to be scaled to provide useful information, the same run can be used along with different scalings to produce different realistic cases. The three source terms: pe0a1231, pw2a1231, and mox03ap2 are treated in a similar way. The "run matrix" is determined by 2 main factors: the amount of $\mathrm{Pu}$ decayed (none, half or all) and the surface area of fracture wall per liter of water (from 0 to $1,000,000 \mathrm{~cm}^{2}$ but mainly 20,000 and $1,000,000$ $\mathrm{cm}^{2}$ ). The latter is a surrogate for the mass of $\mathrm{Si}$ and $\mathrm{Ca}$ injected in the solution and needed to 
Title: Far-Field Accumulation of Fissile Material from Waste Packages Containing Plutonium Disposition Waste Forms

form the $\mathrm{U}$ minerals typical of this type of environment. Most runs admit a mixing factor of $10 \%$ but some use $5 \%, 20 \%$, or no dilution. A given value of the surface area, i.e., of the product (2B)*S [aperture * saturation], can be interpreted as the surface area of a fully saturated fracture system with a small aperture or as the surface area of a larger unsaturated fracture aperture. When the PHREEQC results are translated to a 3-D system, the cross-sectional area and volume on which to apply the results can vary (Section 2.2 ). A fully saturated fracture can transport much more water than the very small flux assumed in this study and thus can provide a more compact mineralization than unsaturated fractures. The relative probability of each case still needs to be determined. 
Title: Far-Field Accumulation of Fissile Material from Waste Packages Containing Plutonium Disposition Waste Forms

Document Identifier: CAL-EDC-GS-000002 REV 00

Page 49 of 80

\section{RESULTS}

Three cases are presented for the pe0a1231 source term (Section 6.1): unsaturated fractures with a surface area of $1,000,000 \mathrm{~cm}^{2} /$ liter of water (Case A of Table 5-12) used as a base case and, saturated fractures with surface areas of $20,000,100,000$, and $1,000,000 \mathrm{~cm}^{2} /$ liter of water (Cases B1, B2 and B3 of Table 5-12). The base case is also treated for variable amounts of Pu decay according to Section 5.1.2 (Section 6.2). The pw2a1231 and mox03ap2 source terms are presented as part of the sensitivity analysis in Sections 6.3 and 6.4. All the results presented in this section are extracted from files stored on electronic media (Attachment VIII).

Three major components of the calculation are planned to be updated in the near future: the thermodynamic database, the fracture system geometry, and the percolation/seepage results.

This document may be affected by technical product input information that requires confirmation. Any changes to the document that may occur as a result of completing the confirmation activities will be reflected in subsequent revisions. The status of the input information quality may be confirmed by review of the Document Input Reference System (DIRS) database.

\subsection{RESULTS FOR THE EARLY BREACH TIME SCENARIO (PE0A1231 CASE)}

\subsubsection{Uranium and Plutonium Mineral Precipitation}

The results show that dilution is an efficient means to precipitate minerals. A comprehensive analysis is also presented for the base case, Case $\mathrm{A}$, with dilution $=10 \%$ and surface area $=$ $1,000,000 \mathrm{~cm}^{2} /$ liter of water. Figure 6-1 and Figure 6-2 display solution parameters and elemental concentrations. The chemical parameters $\mathrm{pH}$ and pe show little change, varying from 9 to 8.5 and 11.5 to 12 , respectively. The ionic strength ranges from more than 2 orders of magnitude greater than 1 down to approximately 0.01 . Figure 6-3 illustrates the linear increase through time of the mass precipitated in a given cell (case B2). This observation justifies the method for correcting for early termination that is described in Section 2.3. 
Title: Far-Field Accumulation of Fissile Material from Waste Packages Containing Plutonium Disposition Waste Forms

$$
\text { Time }=100 \text { years }- \text { Mixing }=10 \%-\text { Surface Area }=1,000,000 \mathrm{~cm}^{2}
$$

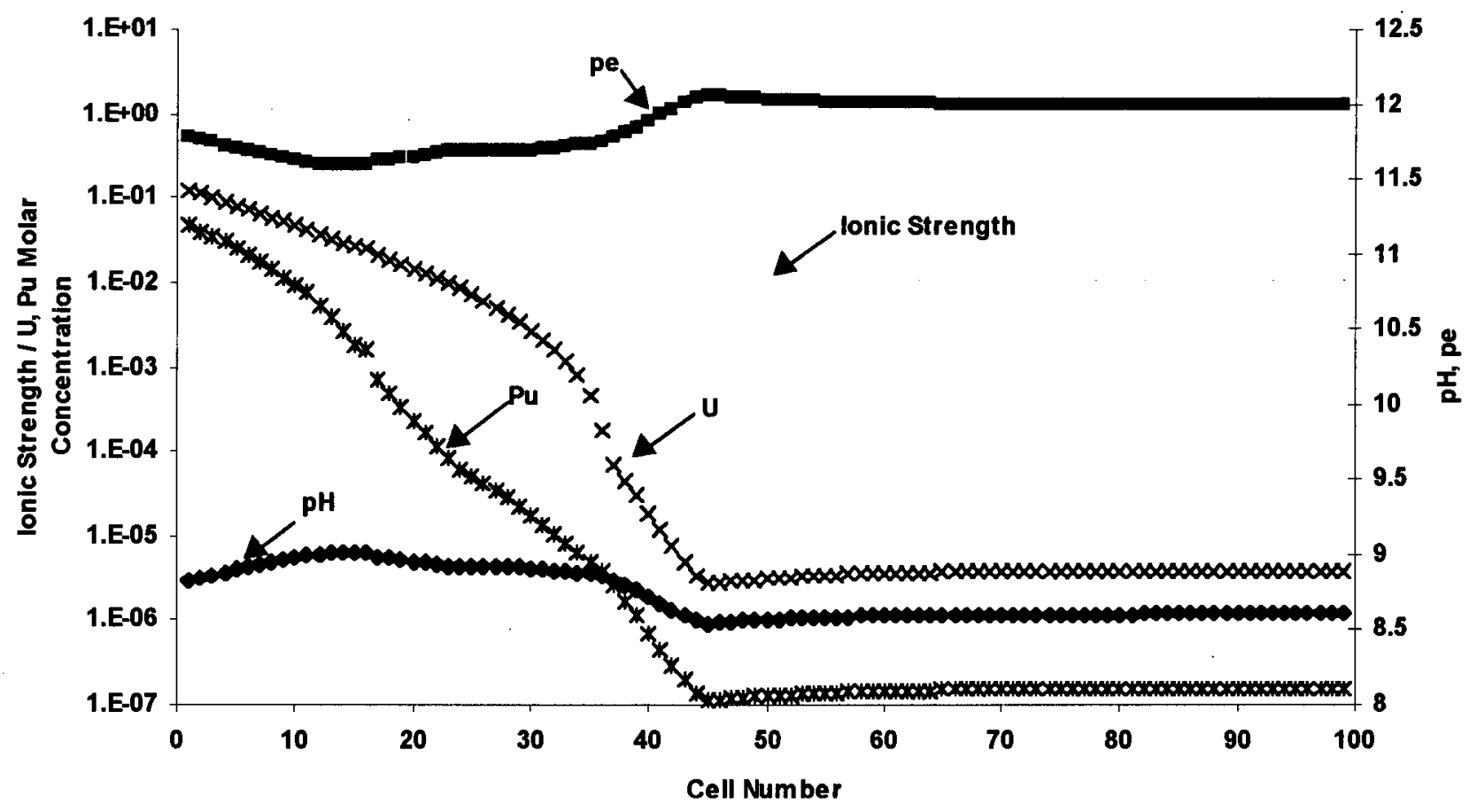

NOTE: The base case is defined by mixing $=10 \%$ and surface area $=1,000,000 \mathrm{~cm}^{2}$. The plateaus of $U$ and $\mathrm{Pu}$ concentrations correspond to redissolution of soddyite and $\mathrm{Pu}(\mathrm{OH}) 4$ after an initial precipitation.

Figure 6-1. Spatial Variation in Chemical Parameters for the Base Case A at 100 Years after Breach Time 
Waste Package Department Calculation

Title: Far-Field Accumulation of Fissile Material from Waste Packages Containing Plutonium Disposition Waste Forms

Time $=100$ years - Mixing $=10 \%-$ Surface Area $=1,000,000 \mathrm{~cm}^{2}$

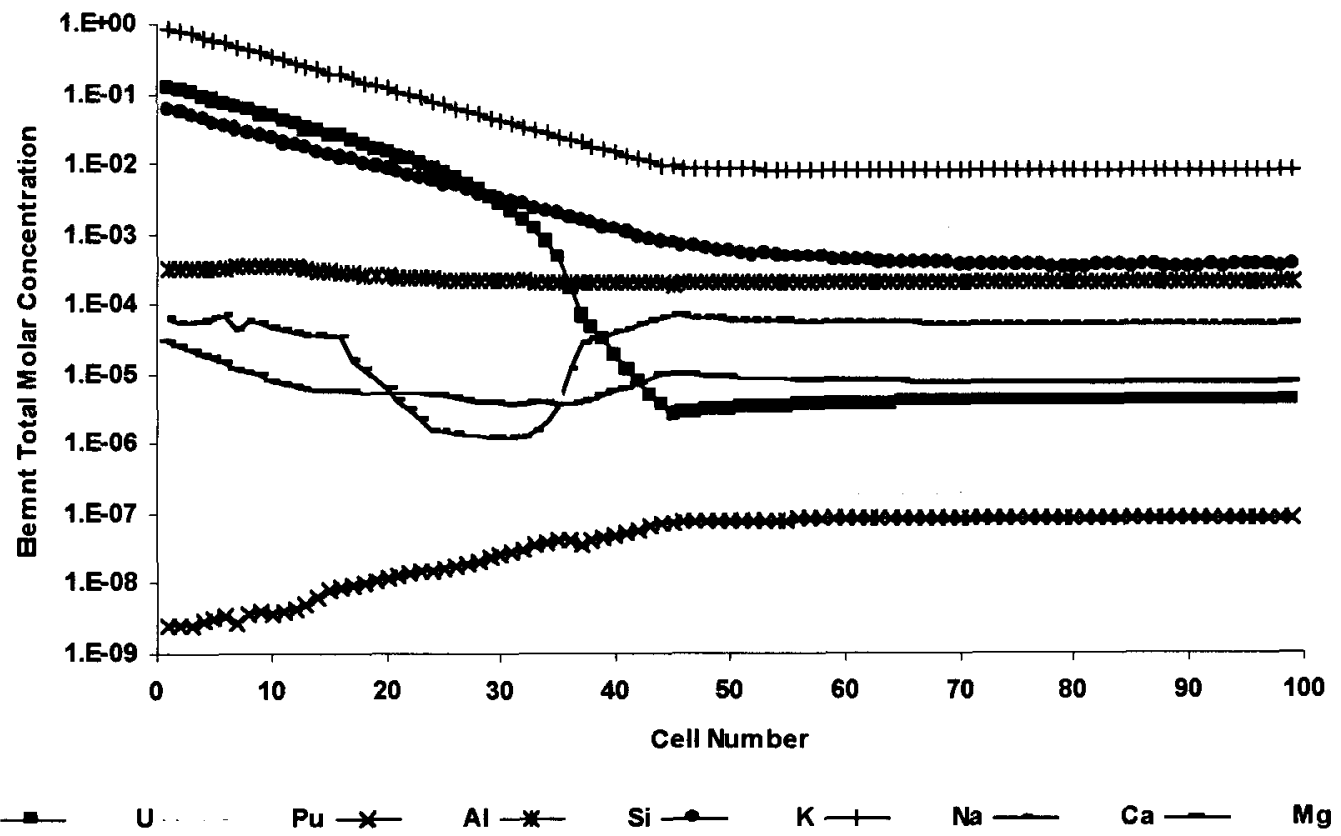

Figure 6-2. Spatial Variation in Aqueous Molar Concentrations for the Base Case A at 100 Years after Breach Time

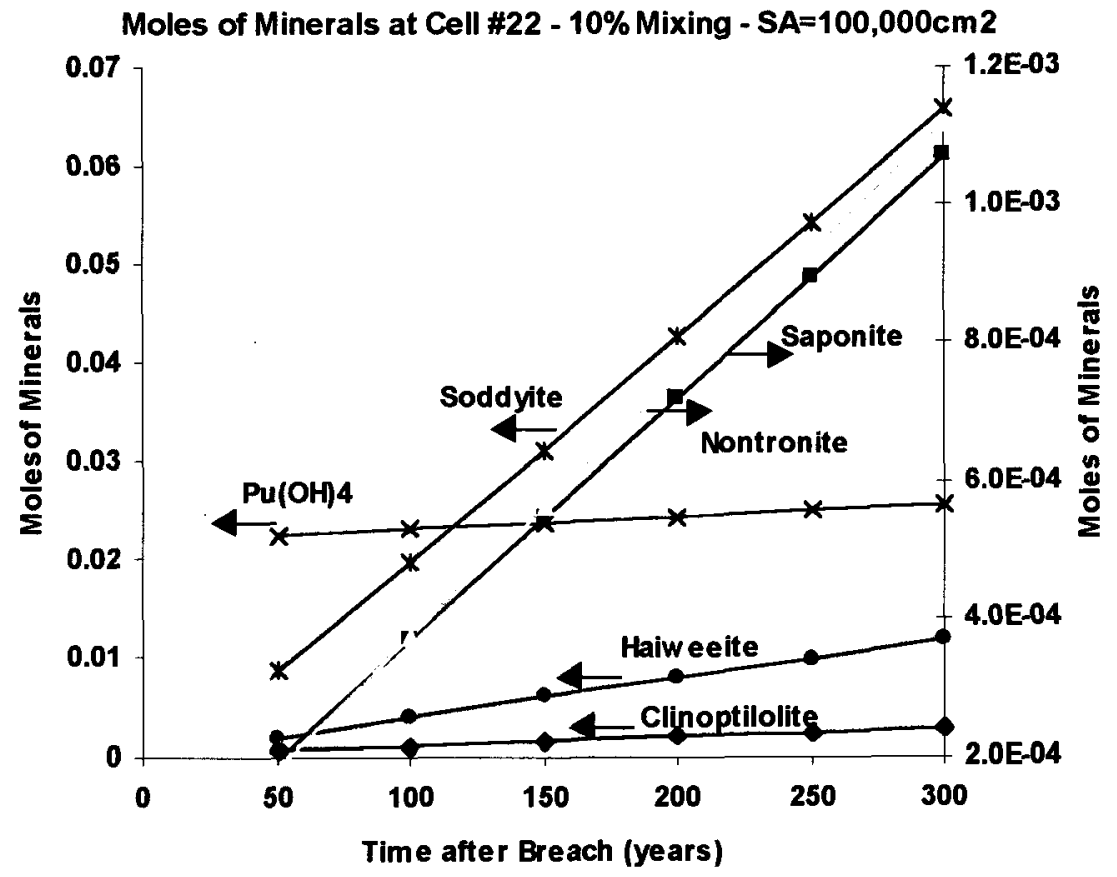

Figure 6-3. Precipitation of Minerals in Cell 22 over Time $\left(S A=100,000 \mathrm{~cm}^{2}\right)$ for Base Case B2 
Title: Far-Field Accumulation of Fissile Material from Waste Packages Containing Plutonium Disposition Waste Forms

All the cases use 100 cells. If the assumption (Assumption 3.18) is made that the velocity of 0.03 meter/year is also applicable in the few meters underneath the disposal drifts, then the 100 cells used in the simulation represent 3 meters (they will be scaled later according to Section 2.4). The different cases assume that mineralization is uniformly distributed over all the fractures (Assumption 3.7), that none precipitates in the matrix (Assumption 3.13), that adsorption is lumped into precipitation (Assumption 3.20) and, that there is no remobilization of precipitated minerals (Assumption 3.21).

\subsubsection{Case A}

This case corresponds to unsaturated fractures. The total number of moles precipitated in 2,500 years is extrapolated from the incremental precipitation in 50 years because the precipitation rates are fairly constant through time and thus can be scaled to any duration. The spatial distribution of the actinide mineralization is plotted on Figure 6-4.

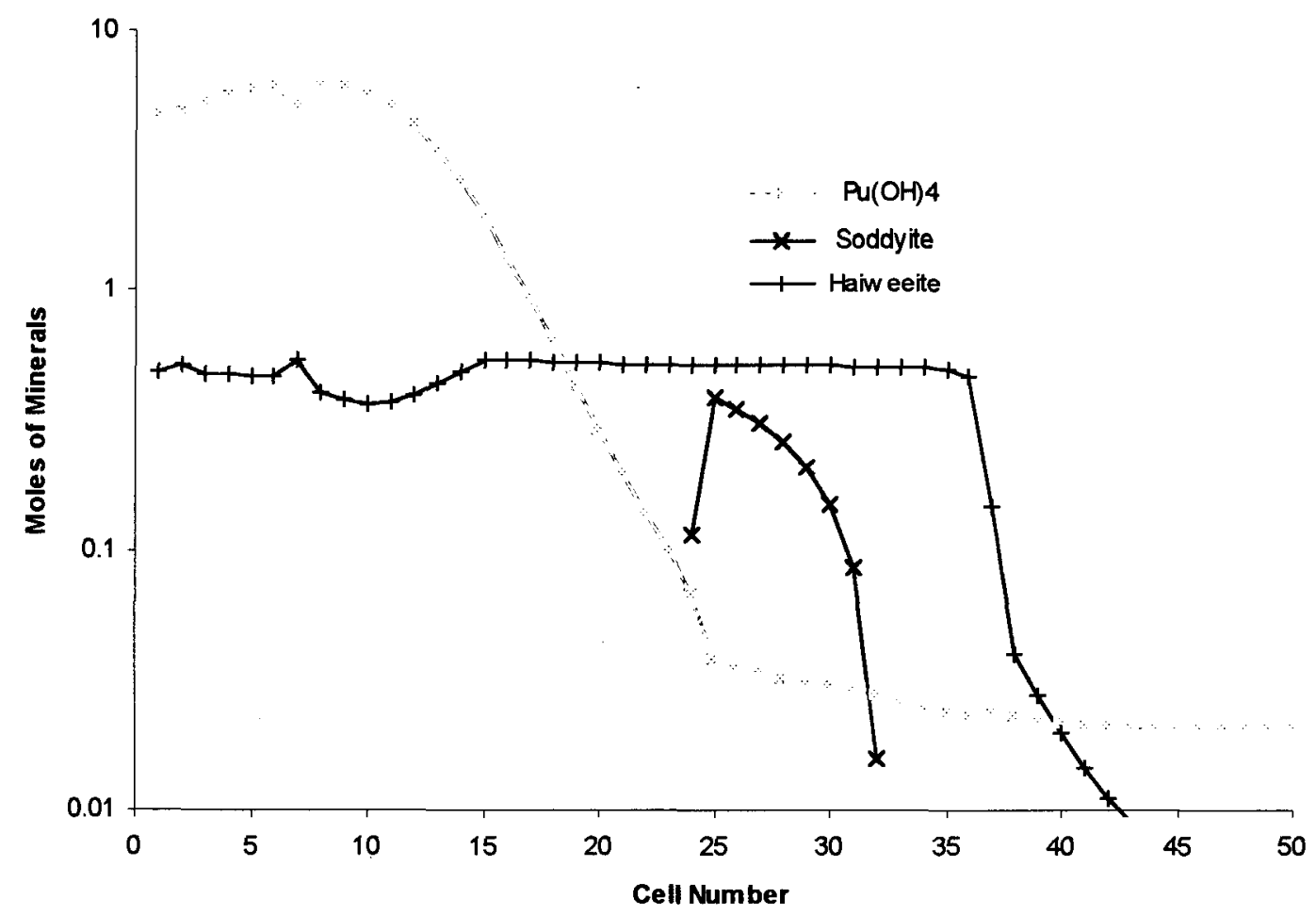

Figure 6-4. Spatial Distribution of Actinide Minerals after 2,500 Years of Precipitation (case $A-S A=1,000,000 \mathrm{~cm}^{2}$ )

As mentioned in Section 2.4 , if a water velocity of $0.03 \mathrm{~m} /$ year is assumed, the cross-sectional area over which infiltration takes place is fairly large $\left(150 \mathrm{~m}^{2}\right)$, on the other hand, if the true WP footprint $\left(\sim 8 \mathrm{~m}^{2}\right)$ is used, the mineralization is elongated in the vertical direction. The criticality worst-case corresponds to a cube of dimensions given by Eq. 2.22 with $n=40$. This is 
Title: Far-Field Accumulation of Fissile Material from Waste Packages Containing Plutonium Disposition Waste Forms

Document Identifier: CAL-EDC-GS-000002 REV 00

Page 53 of 80

approximate because the saturation fraction $S$ changes slightly and non-linearly with the footprint $A$. However, the saturation increases with decreasing footprint, therefore decreasing the surface area per liter of water and the scaling is consequently conservative.

Figure 6-5 displays all the other significant minerals accompanying the actinide deposits. They mainly consist of clays and zeolites. Under conditions where $U$ silicates do not precipitate, chalcedony takes over, similarly calcite and soddyite are exclusive.

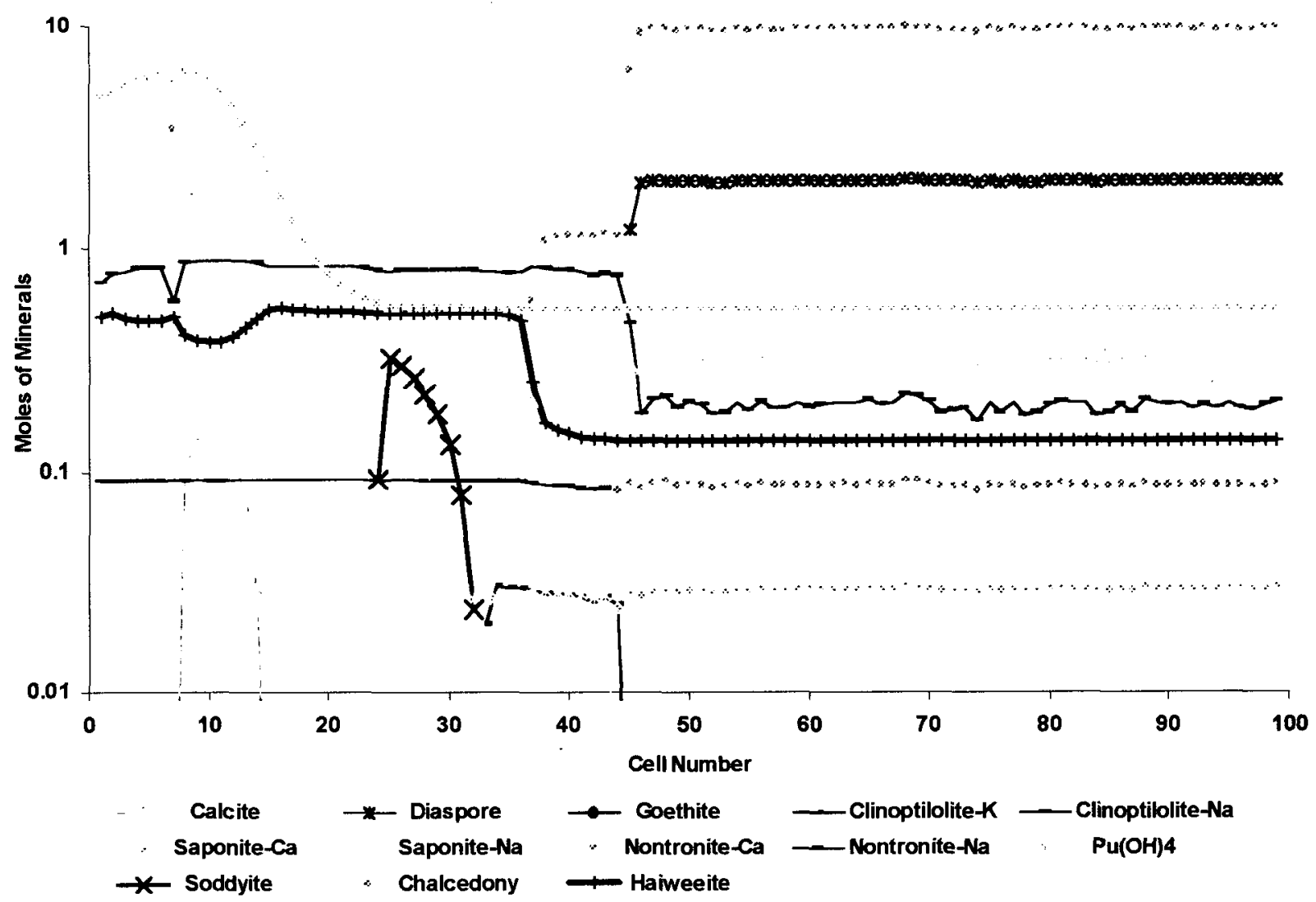

Figure 6-5. Spatial Variations in Mineral Deposits for Case A $\left(S A=1,000,000 \mathrm{~cm}^{2}\right.$ after 2,500 years)

\subsubsection{Cases B1 and B2}

Case B1 assumes classical dispersion in accordance with the ranges of applicability of the dilution mechanisms provided in Table 2-1. In this case, the treatment can only be qualitative because PHREEQC is fundamentally a one-dimensional model. Figure 6-6 displays the amounts of uranium minerals present in a cell at a given time step for the base case. Haiweeite precipitates initially in cells 60 and beyond but then very slowly dissolves away. Haiweeite mass is smaller than that of soddyite in Case B1 because the surface area available to dissolution is 
Waste Package Department

Calculation

Title: Far-Field Accumulation of Fissile Material from Waste Packages Containing Plutonium Disposition Waste Forms

Document Identifier: CAL-EDC-GS-000002 REV 00

Page 54 of 80

much less, therefore reducing the availability of $\mathrm{Ca}$ (from anorthite). Case B2 has plots of similar shapes.

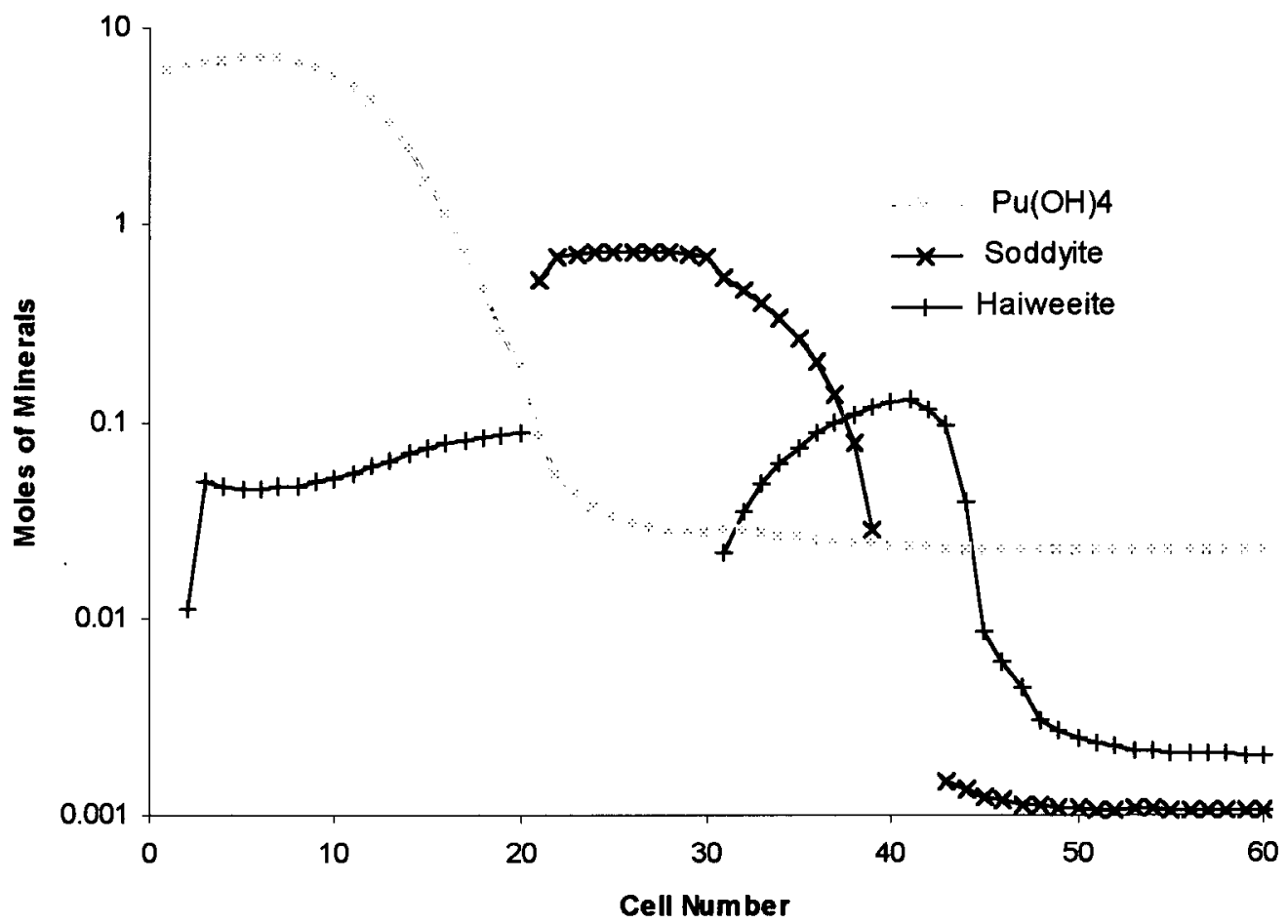

Figure 6-6. Moles of Pu and U Minerals Precipitated as a Function of Cell Number (case $B 1-S A=20,000 \mathrm{~cm}^{2}$ for 2,500 years)

\subsubsection{Summary of Cases}

Table 6-1 summarizes the results.

Table 6-1. Summary of Results (pe0a1231) (accumulation for 2,500 years)

\begin{tabular}{|c|c|c|c|}
\hline $\begin{array}{c}\text { Case } A \\
\text { (Unsaturated) } \\
S A=1,000,000 \mathrm{~cm}^{2} / \mathrm{L}\end{array}$ & $\begin{array}{c}\text { Case B1 } \\
\text { (Saturated) } \\
S A=20,000 \mathrm{~cm}^{2} / \mathrm{L}\end{array}$ & $\begin{array}{c}\text { Case B2 } \\
\text { (Saturated) } \\
\mathrm{SA}=100,000 \mathrm{~cm}^{2} / \mathrm{L}\end{array}$ & $\begin{array}{c}\text { Case B3 } \\
\text { (Saturated + B.E.T.) } \\
\text { SA=1,000,000 cm } / L\end{array}$ \\
\hline $\begin{array}{c}177.9 \text { moles } P u \\
474.4 \text { moles } U \\
\# \text { of cells }=40\end{array}$ & $\begin{array}{l}85.3 \text { moles Pu } \\
23.2 \text { moles } U \\
\# \text { of cells }=40\end{array}$ & $\begin{array}{l}84.6 \text { moles } \mathrm{Pu} \\
25.3 \text { moles } \mathrm{U} \\
\# \text { of cells }=40\end{array}$ & $\begin{array}{l}78.5 \text { moles } \mathrm{Pu} \\
39.7 \text { moles } \mathrm{U} \\
\# \text { of cells }=40\end{array}$ \\
\hline $\begin{array}{c}A=5.85 \times 5.85 \mathrm{~m}^{2} \\
I_{c}=0.146 \mathrm{~m}\end{array}$ & $\begin{array}{c}A=1.6 \times 1.6 \mathrm{~m}^{2} \\
I_{c}=0.04 \mathrm{~m}\end{array}$ & $\begin{array}{c}A=2.72 \times 2.72 \mathrm{~m}^{2} \\
I_{c}=0.068 \mathrm{~m}\end{array}$ & $\begin{array}{c}A=2.72 \times 2.72 \mathrm{~m}^{2} \\
I_{c}=0.068 \mathrm{~m}\end{array}$ \\
\hline $\begin{array}{l}\text { Average Density: } \\
0.9 \mathrm{moles} / \mathrm{m}^{3} \mathrm{Pu} \\
2.3 \mathrm{moles} / \mathrm{m}^{3} \mathrm{U}\end{array}$ & $\begin{array}{c}\text { Average Density: } \\
20.8 \text { moles } / \mathrm{m}^{3} \mathrm{Pu} \\
5.7 \mathrm{moles} / \mathrm{m}^{3} \mathrm{U}\end{array}$ & $\begin{array}{l}\text { Average Density: } \\
4.2 \mathrm{moles} / \mathrm{m}^{3} \mathrm{Pu} \\
1.3 \mathrm{moles} / \mathrm{m}^{3} \mathrm{U}\end{array}$ & $\begin{array}{l}\text { Average Density: } \\
3.9 \mathrm{moles} / \mathrm{m}^{3} \mathrm{Pu} \\
2.0 \mathrm{moles} / \mathrm{m}^{3} \mathrm{U}\end{array}$ \\
\hline
\end{tabular}


Title: Far-Field Accumulation of Fissile Material from Waste Packages Containing Plutonium Disposition Waste Forms

Document Identifier: CAL-EDC-GS-000002 REV 00

Page 55 of 80

The higher total number of moles in the unsaturated case (case A) is the consequence of the choice of considering the mineralization front being in contact with the drift. As the front moves downwards, the trail it leaves on the sides will increase the mass of mineralization. Both mechanisms will end up precipitating most of the actinides present in the WP water.

If the results for the saturated results are plotted on the same graph and the uranium density in moles $/ \mathrm{m}^{3}$ is used (Figure 6-7), it appears that the actinide density is smaller for higher surface areas.

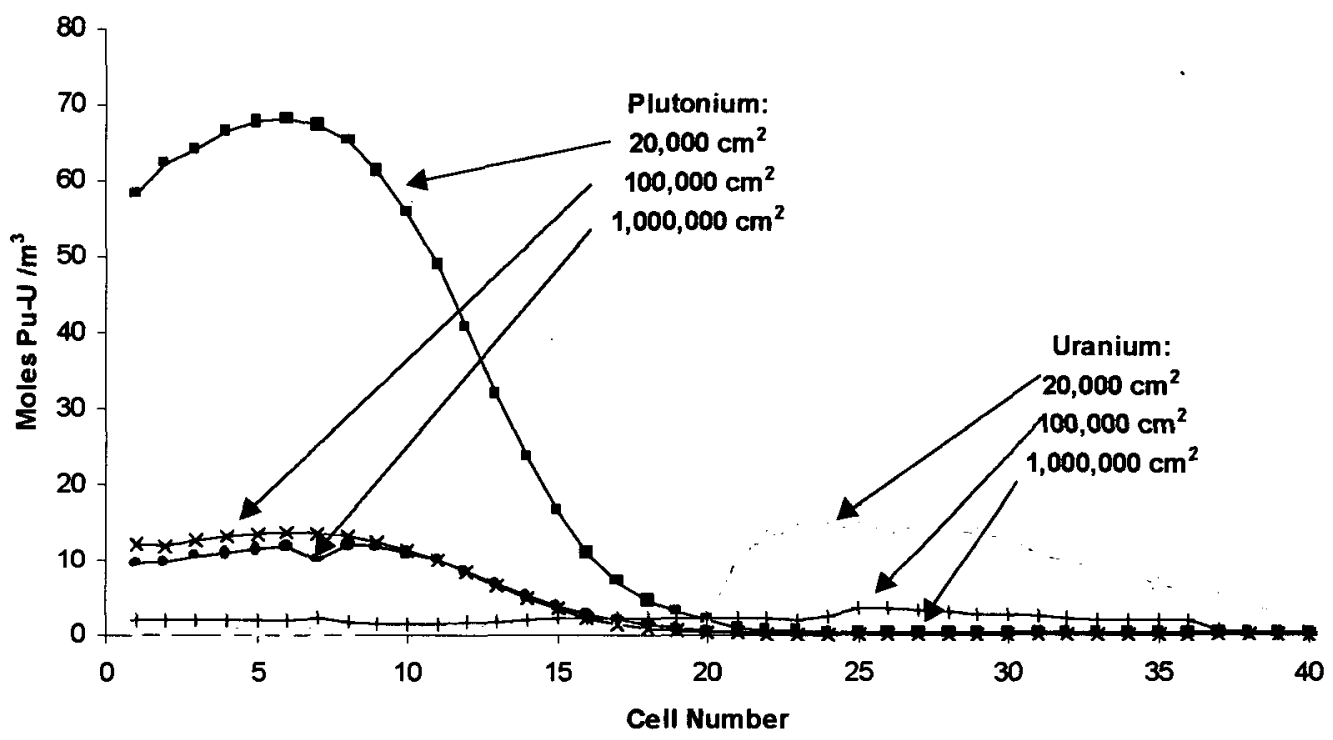

Figure 6-7. Spatial Variation in Actinide Density for the Different Saturated Cases (B1, B2, and B3)

If the actinide accumulation is further scaled according to Sections 2.1.3 and 2.4 to yield their true spatial accumulation (Figure 6-8 and Figure 6-9) so that unsaturated and saturated cases can be compared, case A comes out with a much higher density. It should be noted again that saturated cases represent early stages of the front when the mineralization is still largely in contact with the bottom of the drift. 
Title: Far-Field Accumulation of Fissile Material from Waste Packages Containing Plutonium Disposition Waste Forms

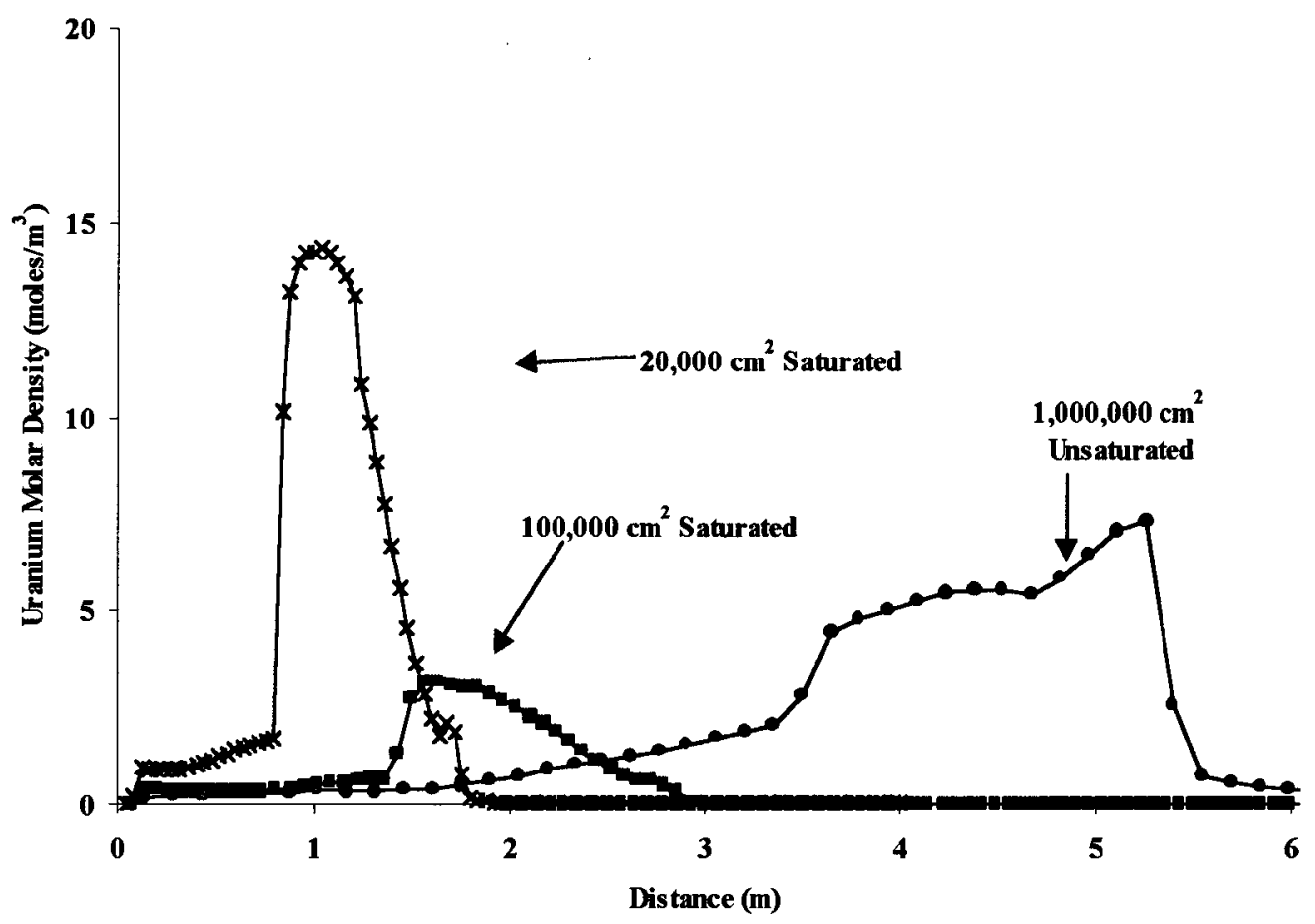

Figure 6-8. Uranium Accumulation Molar Density

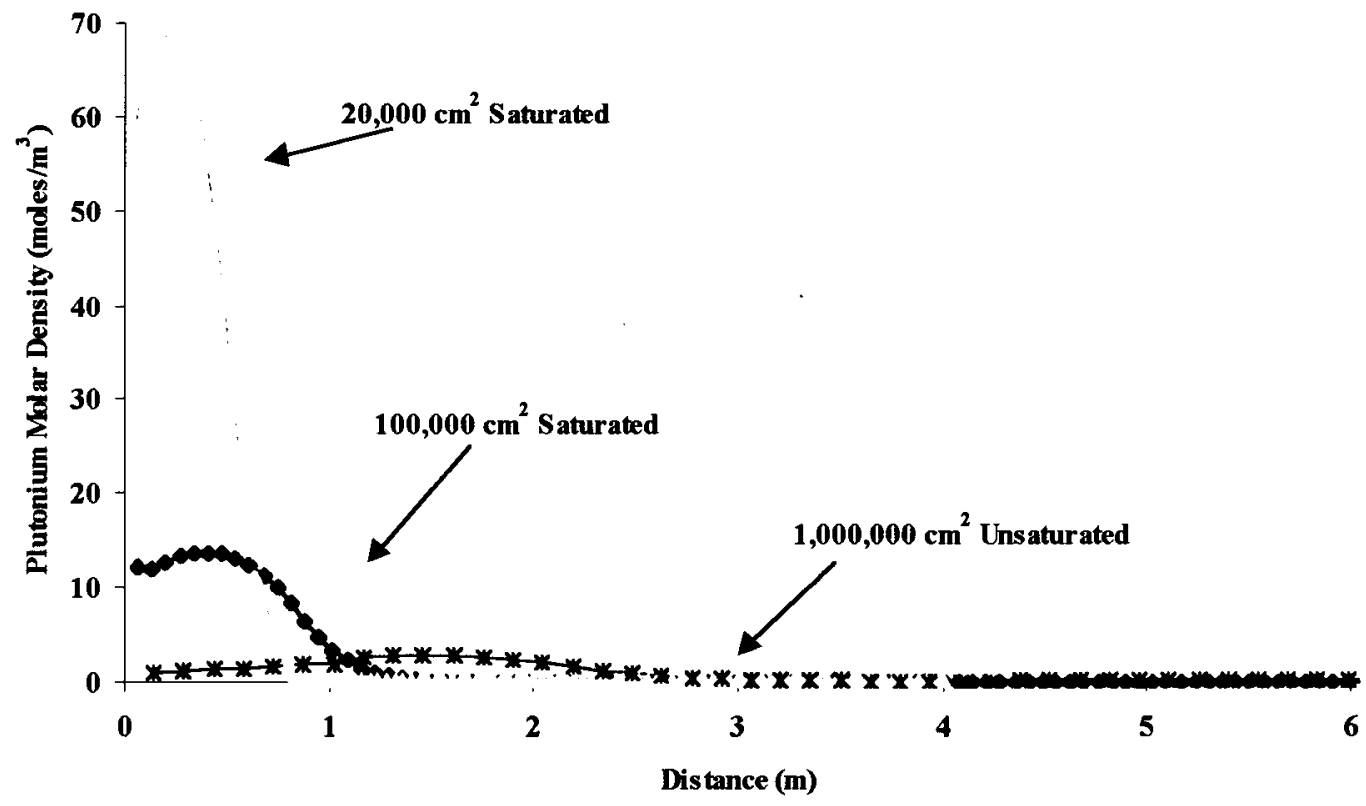

Figure 6-9. Plutonium Accumulation Molar Density 
Title: Far-Field Accumulation of Fissile Material from Waste Packages Containing Plutonium Disposition Waste Forms

Document Identifier: CAL-EDC-GS-000002 REV 00

Page 57 of 80

\subsubsection{Precipitation of Other Minerals}

Figure 6-10 and Figure 6-11 show that the history of mineral deposition is complex. Deposition only occurs over limited ranges of dilution. Because other minerals also take space in the fracture opening, it is important to check that all minerals occupy a volume smaller than the available fracture space. Figure 6-10 can be misleading because although mineral deposits occupy almost $100 \%$ of the water space, the water itself occupies only a very small fraction of the fracture space (low saturations) leaving plenty of space for additional precipitation.

Using molar volumes from Table 5-13, the maximum volume occupied by the precipitated minerals is less than $200 \mathrm{~cm}^{3}$ /liter of water (Figure 6-12), i.e., less than $20 \%$ of the fracture space is occupied by the new minerals in the saturated case. The two other curves represent unsaturated cases whose saturation is $10 \%$ at most (see file sat_calc.xls - Attachment VIII), i.e., a maximum of $\sim 1000 \mathrm{~cm}^{3} /$ liter of water $\mathrm{x} 0.1$ liter of water $/$ liter of fracture volume $=\sim 100 \mathrm{~cm} 3$ / liter of fracture volume $=\sim 10 \%$ of fracture volume at most. Similarly in the $500,000 \mathrm{~cm}^{2}$ case, only about $6 \%$ of the fracture volume is occupied by minerals. In addition, the increase in fracture volume by mineral dissolution is not taken into account.

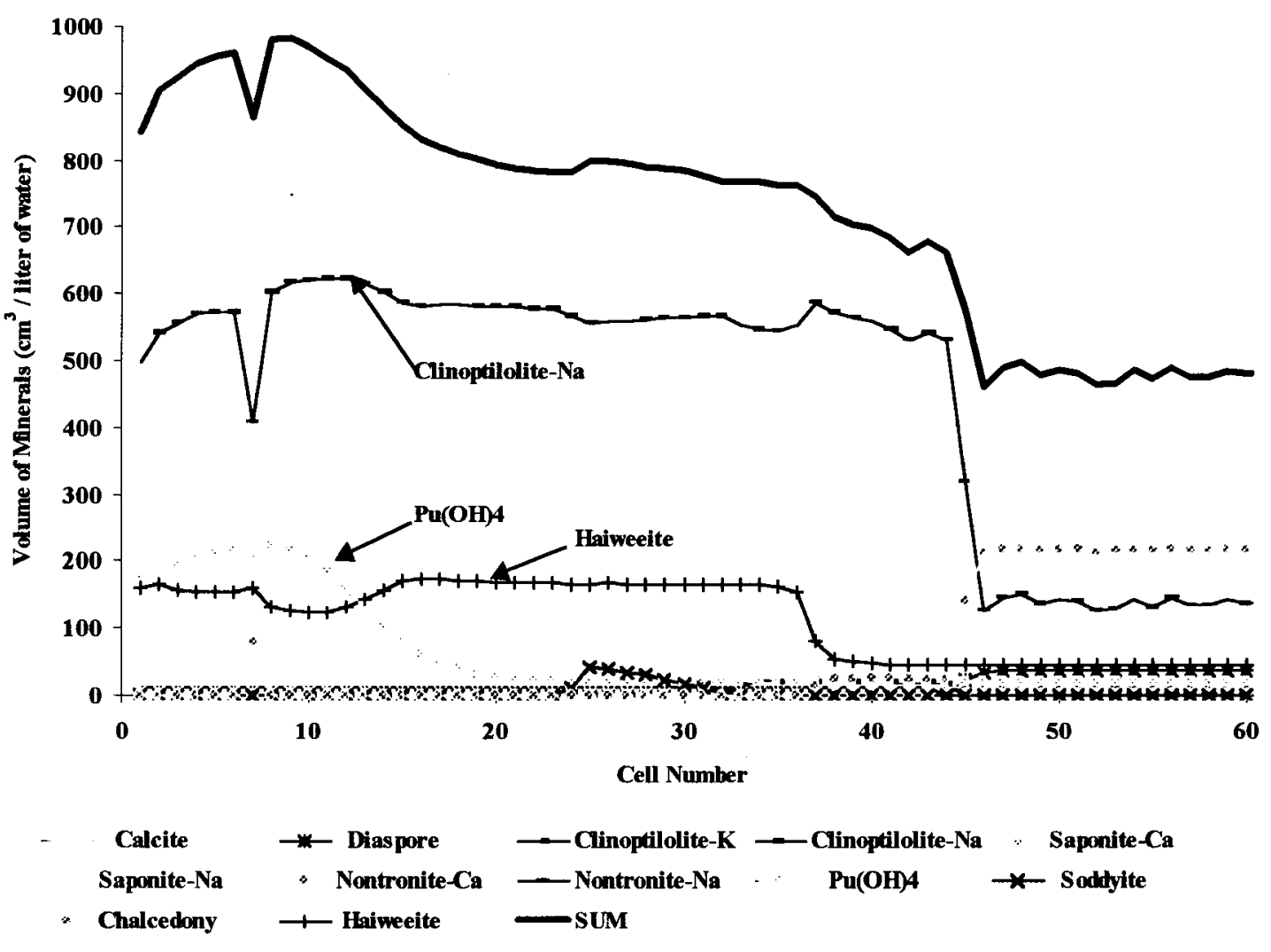

Figure 6-10. Volumes of Minerals as a Function of Cell Number for Case $A(S A=1,000,000$ $\mathrm{cm}^{2}$ ) 
Title: Far-Field Accumulation of Fissile Material from Waste Packages Containing Plutonium Disposition Waste Forms

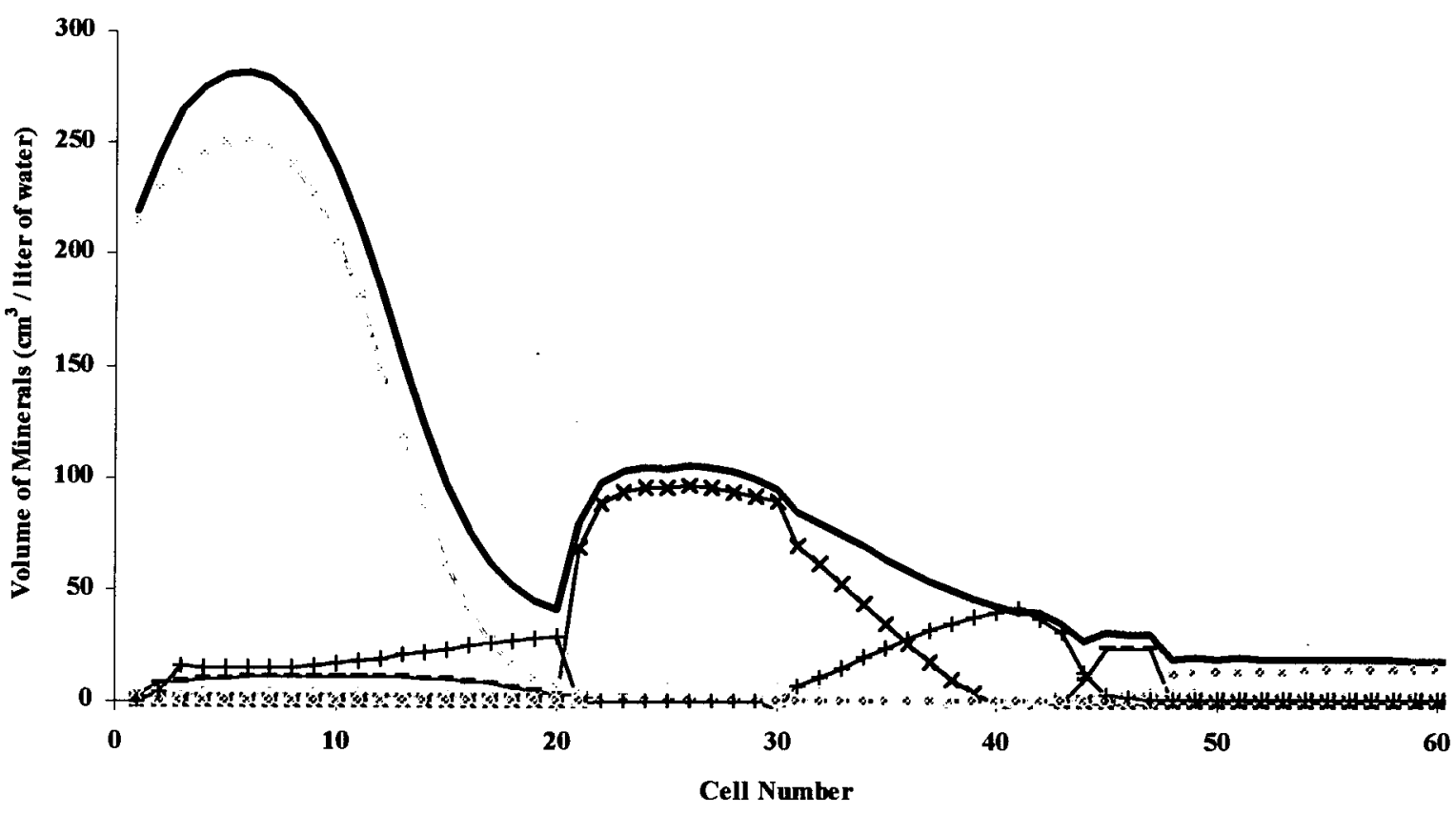

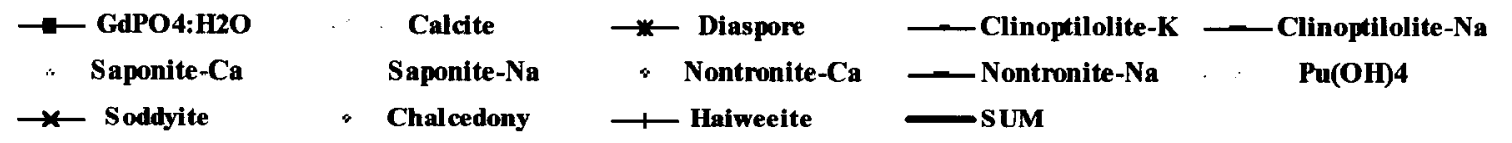

Figure 6-11. Volumes of Minerals as a Function of Cell Number for Case $B 1\left(S A=20,000 \mathrm{~cm}^{2}\right)$

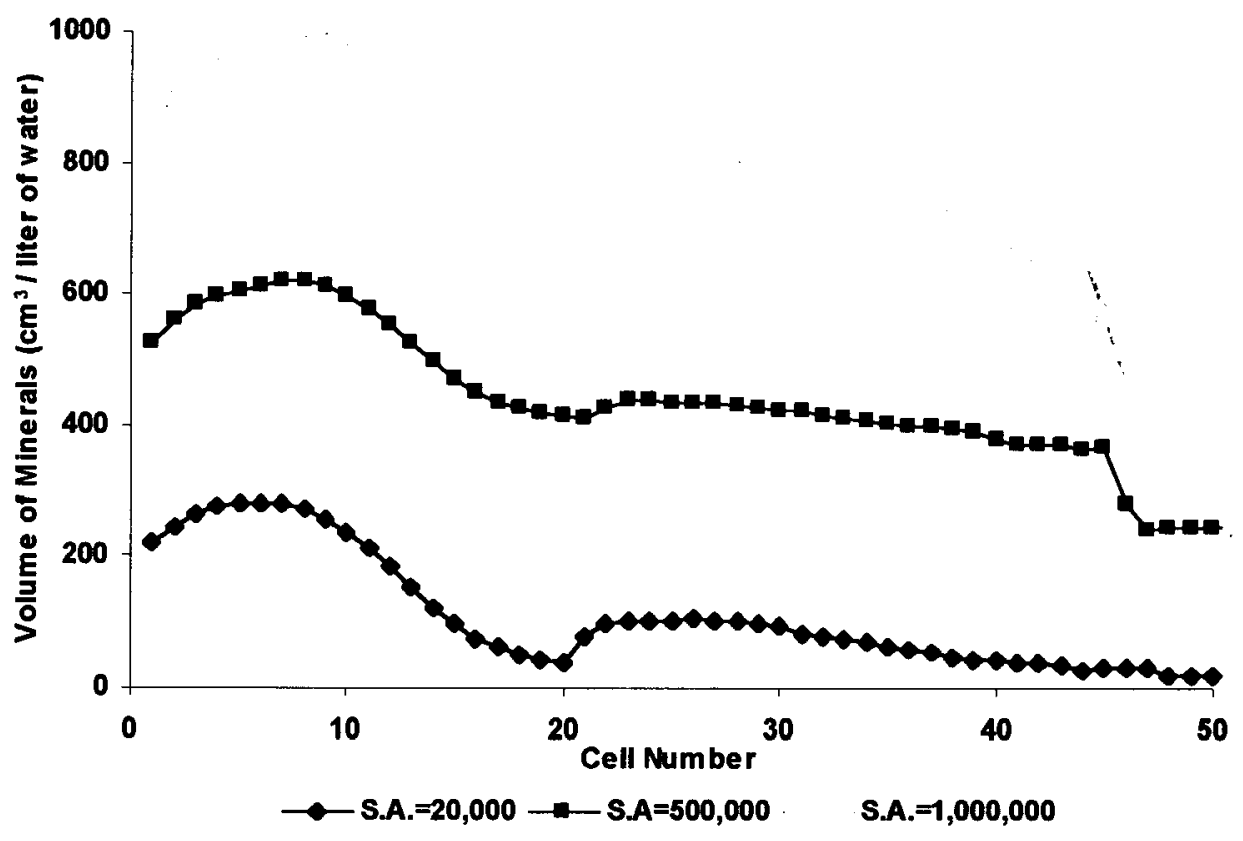

Figure 6-12. Comparison of Volume of Minerals Produced as a Function of the Wall Surface Area / Liter of Water 
Title: Far-Field Accumulation of Fissile Material from Waste Packages Containing Plutonium Disposition Waste Forms

\subsubsection{Sensitivity Evaluations}

Sensitivity analyses were done on the base case $B 1(S A=20,000 \mathrm{~cm} 2$, source term $=p 0 \mathrm{a} 1231)$ by varying the dilution factors $\left(5,10\right.$ and $20 \%$ ), the rock surface areas (from 0 to $1,000,000 \mathrm{~cm}^{2}$ /liter of water), the thermodynamic database, and by using variable mixing and multiple source terms. It is concluded that the total actinide accumulation is not very sensitive to any of the aforementioned factors except sharp decrease with low or no dilution.

\subsubsection{Dilution Factors}

Figure 6-13 and Figure 6-14 show that even if the total amount of precipitation is similar for different levels of dilution, the actinide density increases with dilution.

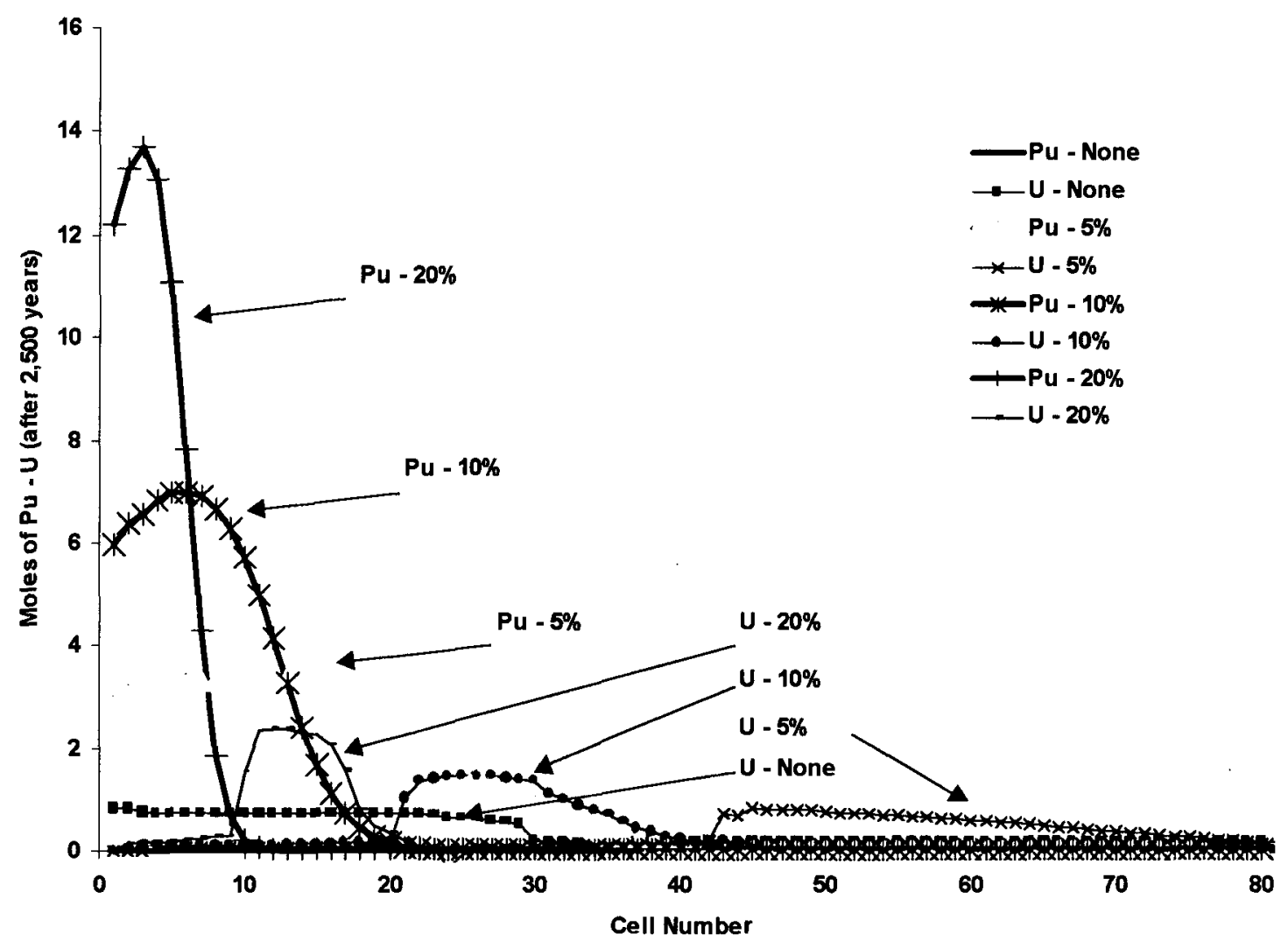

Figure 6-13. Sensitivity Analysis for Dilution Factors $\left(S A=20,000 \mathrm{~cm}^{2}\right)$

Figure 6-14 also illustrates that with no dilution, little plutonium and uranium is precipitated. A dilution factor between 5 and $10 \%$ is the most conservative. For practical reasons (number of runs done), the value of $10 \%$ was picked as representative and conservative. 
Title: Far-Field Accumulation of Fissile Material from Waste Packages Containing Plutonium Disposition Waste Forms

Figure 6-15 shows that uranium accumulation increases with surface area mainly because of the increased availability of $\mathrm{Si}$ and $\mathrm{Ca}$ present in the $\mathrm{U}$ minerals. Such high surface area without dilution is only possible with very high B.E.T. surface area. These high B.E.T. surface areas, even if present at the early stages of precipitation, are unlikely to stay high because of the accumulation itself that would plug the small pores initially responsible for them.

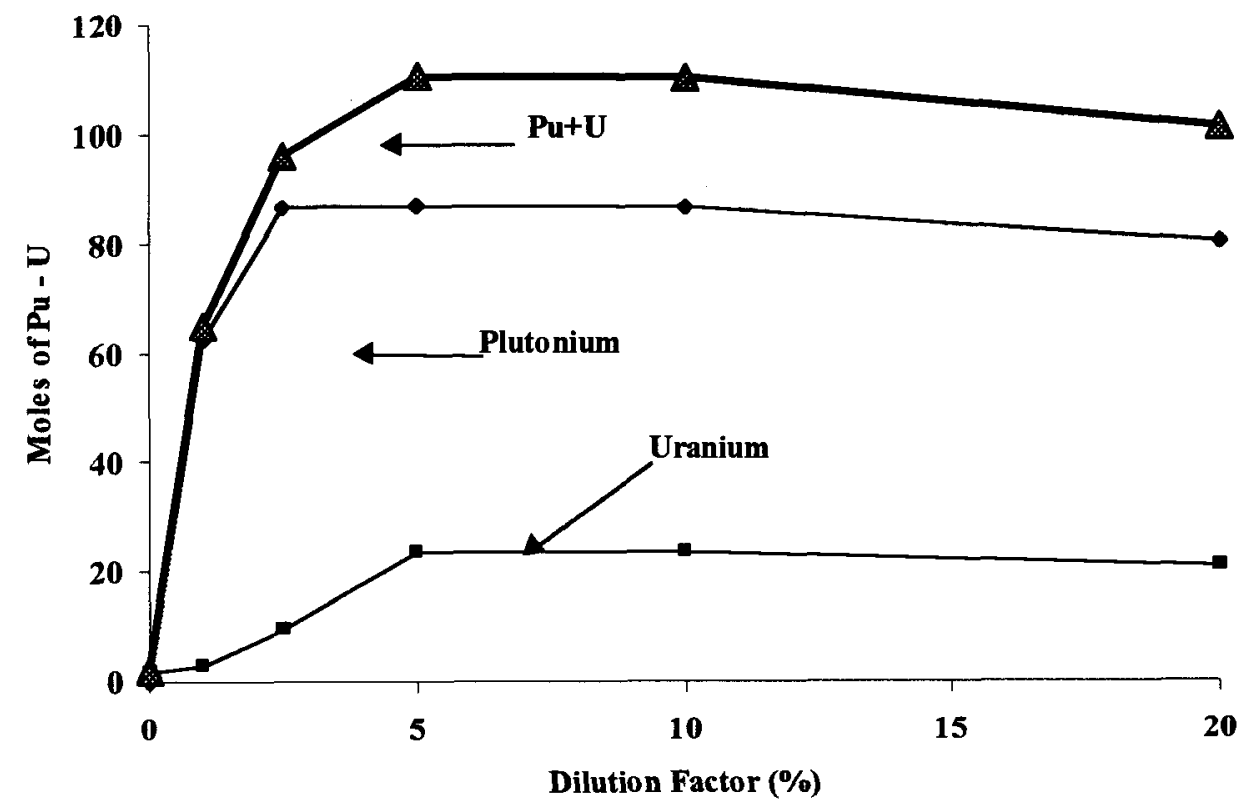

Figure 6-14. Total Number of Moles of Actinide Precipitated as a Function of Dilution $\left(\mathrm{SA}=20,000 \mathrm{~cm}^{2}\right)$

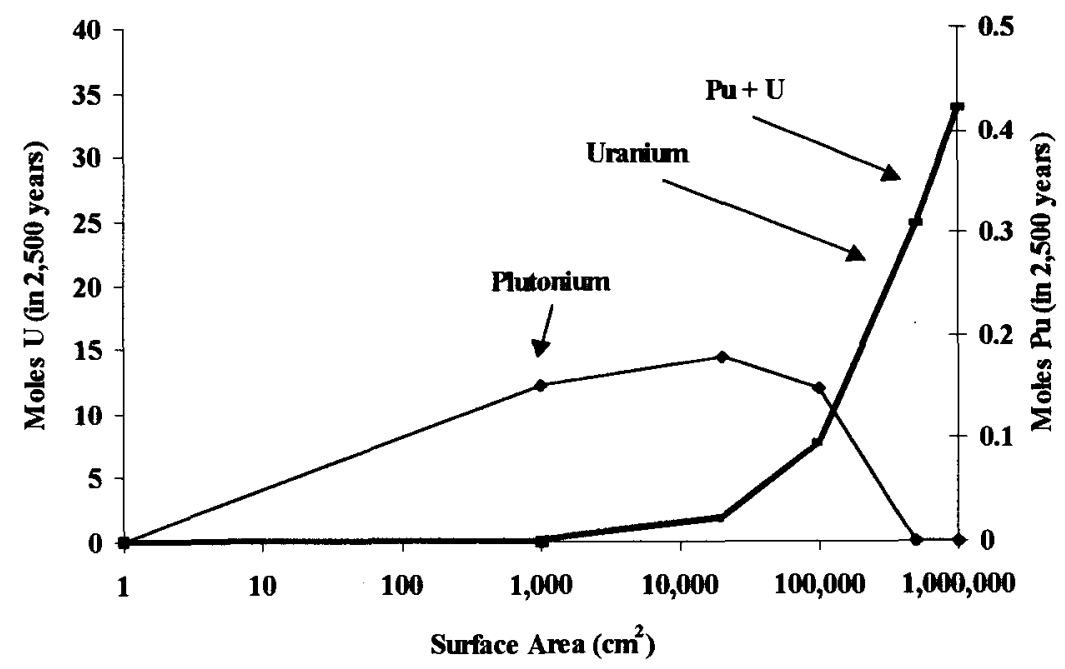

Figure 6-15. Total Number of Moles of Actinide Precipitated as a Function of Surface Area (NO dilution) 
Waste Package Department Calculation

Title: Far-Field Accumulation of Fissile Material from Waste Packages Containing Plutonium Disposition Waste Forms

\subsubsection{Surface Areas}

Surface areas have little influence on the total amount deposited except for high values where the $\mathrm{U}$ accumulation increases (Figure 6-16 and Figure 6-17). However, the latter case has the lowest density (Figure 6-7).

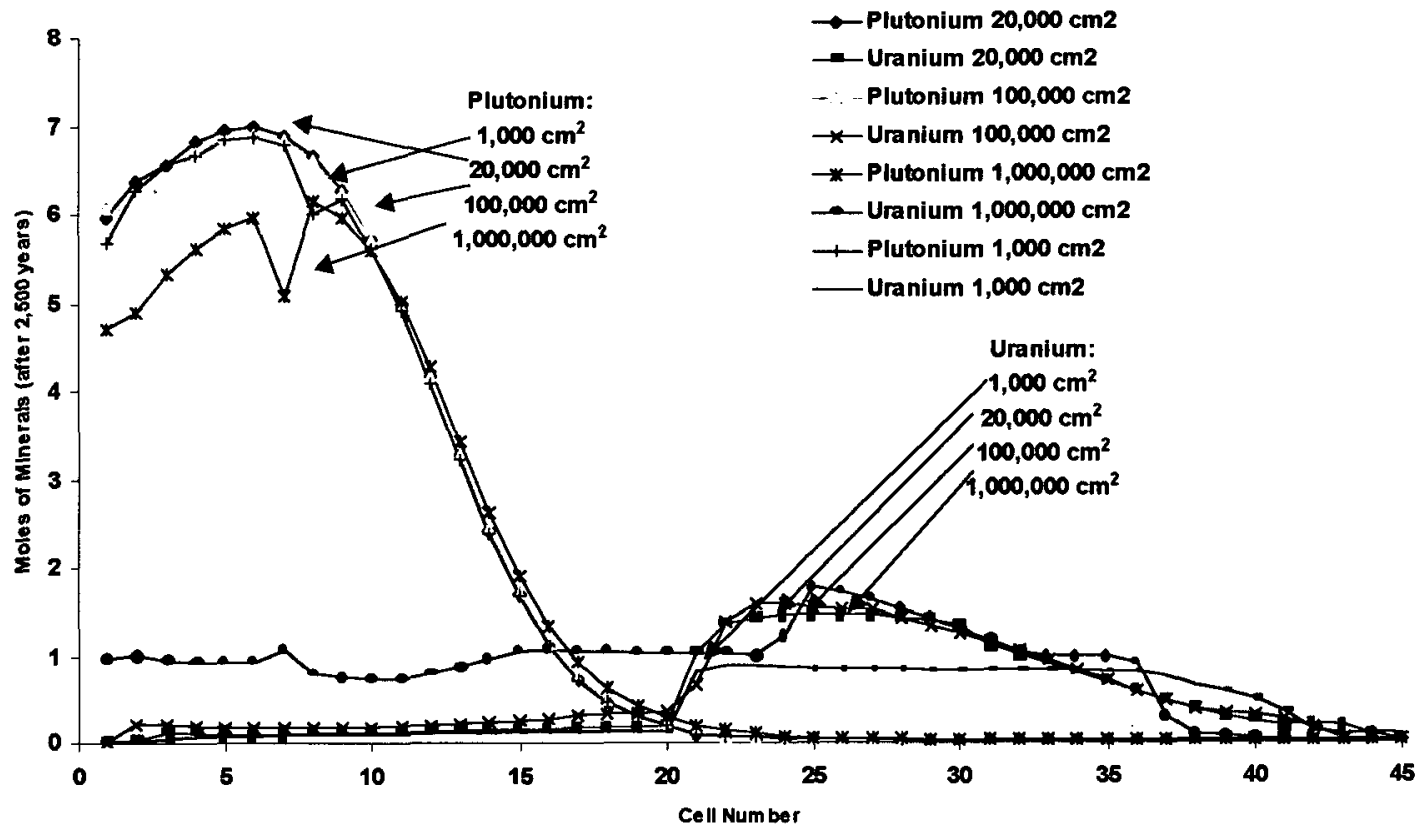

Figure 6-16. Sensitivity Analysis for Surface Areas (dilution factor of 10\%)

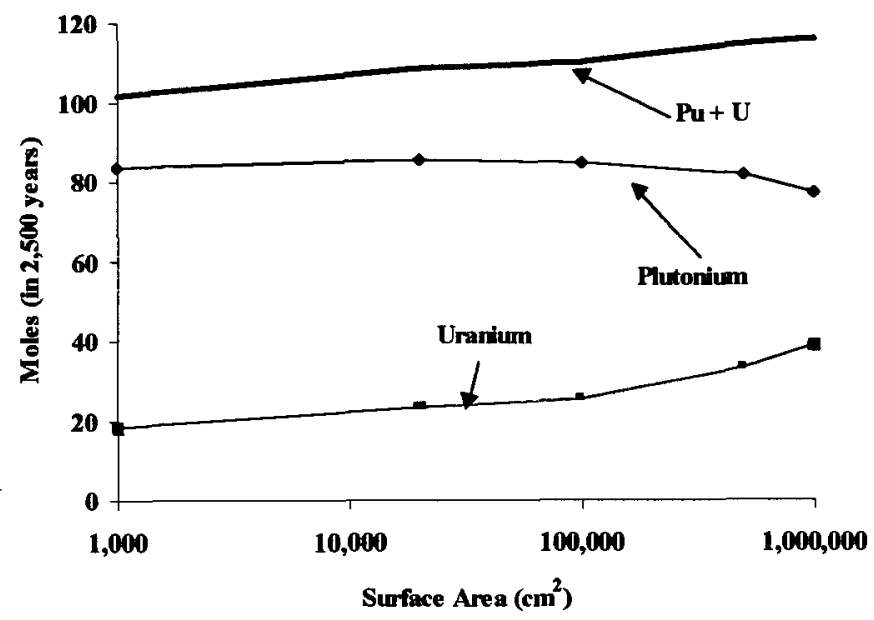

Figure 6-17. Total Number of Moles of Actinide Precipitated as a Function of Surface Area (dilution factor of $10 \%$ ) 
Title: Far-Field Accumulation of Fissile Material from Waste Packages Containing Plutonium Disposition Waste Forms

\subsubsection{Databases}

Changes to the thermodynamic database (see Section 5.1.4 for details) may have a big impact on the final results. To test the sensitivity of the results presented in this report (that use the data0.nuc.R8a database), a few cases were executed with a preliminary version (data0.nuc.R8s) of the database that will ultimately be used (data0.ymp).

The results differ in the details (Figure 6-18 and Figure 6-19); in particular, uranium minerals are more consistently high, but they agree with each other (Table 6-2). Soddyite $\left[\left(\mathrm{UO}_{2}\right)_{2} \mathrm{SiO}_{4}: 2 \mathrm{H}_{2} \mathrm{O}\right]$ and haiweeite $\left[\mathrm{Ca}\left(\mathrm{UO}_{2}\right)_{2}\left(\mathrm{Si}_{2} \mathrm{O}_{3}\right)_{3}: 5 \mathrm{H}_{2} \mathrm{O}\right]$ are substituted by uranophane $\left[\mathrm{Ca}\left(\mathrm{UO}_{2}\right)\left(\mathrm{SiO}_{3}\right)(\mathrm{OH})_{2}: 5 \mathrm{H}_{2} \mathrm{O}\right]$ and $\mathrm{Na}$-boltwoodite $\left[\mathrm{NaUO}_{2} \mathrm{SiO}_{4} \mathrm{H}_{3} 0: \mathrm{H} 20\right]$. The "new" database predicts a slightly higher accumulation for $\mathrm{Pu}$ and about twice as much $\mathrm{U}$. It should be noted that the source term used in these runs was also obtained by running EQ6 with that same "new" database.

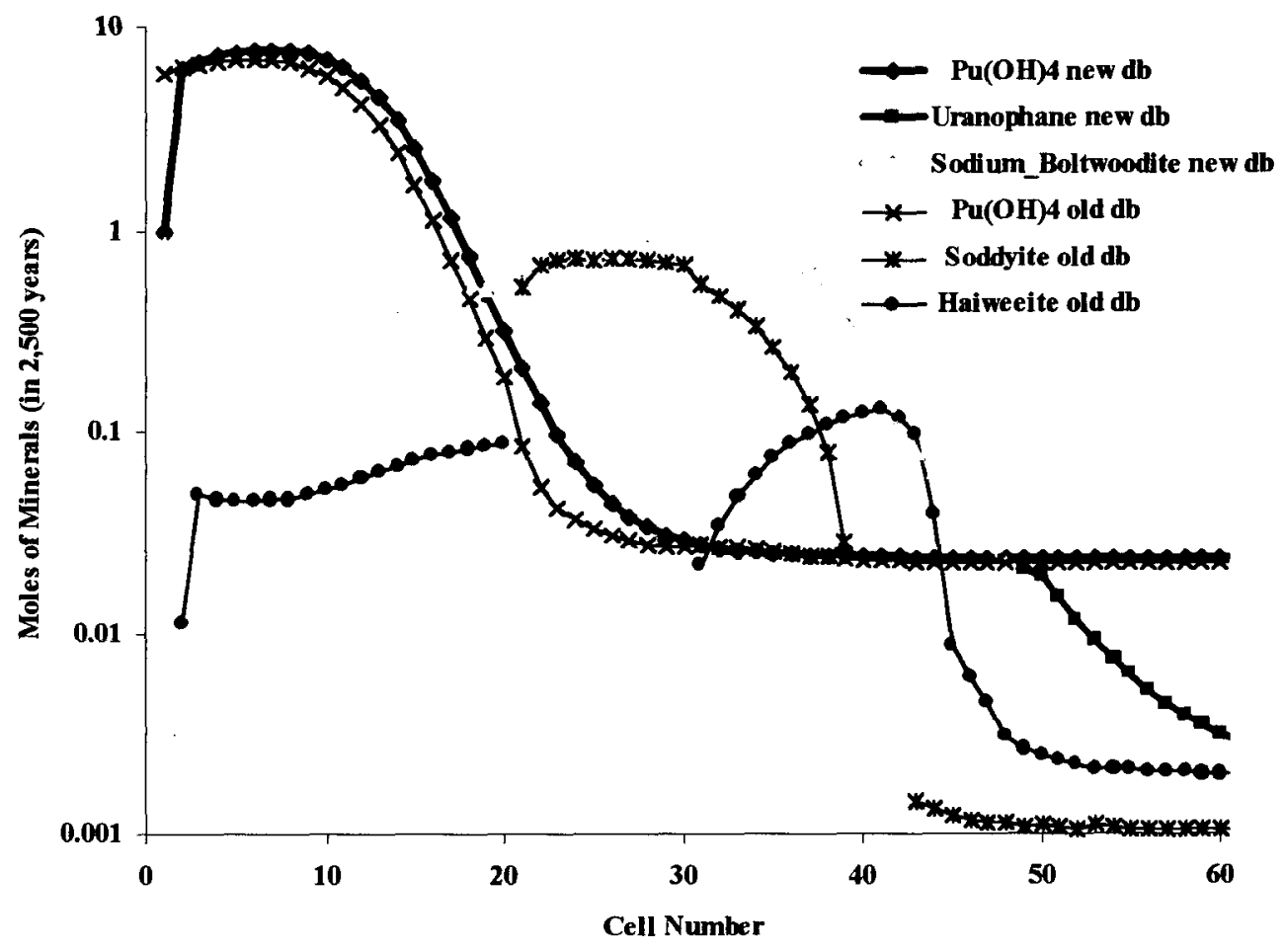

NOTE: db stands for database.

Figure 6-18. $\mathrm{Pu}-\mathrm{U}$ Minerals Accumulation for the Old (data0.nuc.R8a) and New (data0.nuc.R8s) Databases $\left(S A=20,000 \mathrm{~cm}^{2}\right)$ 
Title: Far-Field Accumulation of Fissile Material from Waste Packages Containing Plutonium Disposition Waste Forms

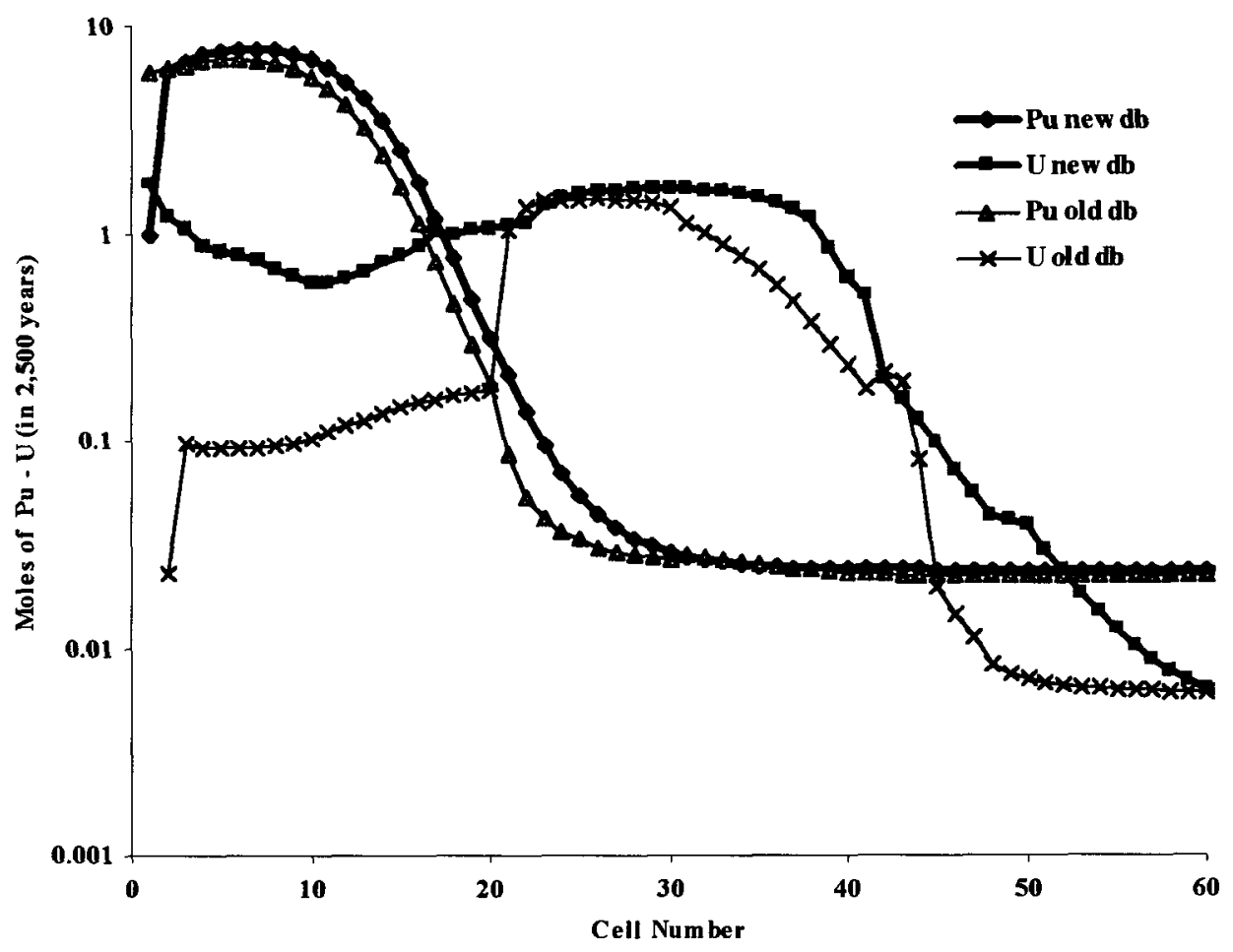

Figure 6-19. Actinide Accumulation for the Old (data0.nuc.R8a) and New (data0.nuc.R8s) Databases ( $S A=20,000 \mathrm{~cm}^{2}$ )

Table 6-2. Summary of Results for Different Databases (accumulation starts 2,500 years after breach time for 2,500 years)

\begin{tabular}{|c|c|}
\hline $\begin{array}{l}S A=20,000 \mathrm{~cm}^{2} \Omega \\
\text { Data0.nuc.R8s } \\
\text { ("New" database) }\end{array}$ & $\begin{array}{c}S A=20,000 \mathrm{~cm}^{2} / L \\
\text { DataO.nuc. R8a } \\
\text { ("Old" database) }\end{array}$ \\
\hline $\begin{array}{l}94.6 \text { moles } \mathrm{Pu} \\
46.8 \text { moles U } \\
\# \text { of cells }=40\end{array}$ & $\begin{array}{l}85.3 \text { moles } \mathrm{Pu} \\
23.2 \text { moles } U \\
\# \text { of cells }=40\end{array}$ \\
\hline $\begin{array}{c}A=1.6 \times 1.6 \mathrm{~m}^{2} \\
I_{c}=0.04 \mathrm{~m}\end{array}$ & $\begin{array}{c}A=1.6 \times 1.6 \mathrm{~m}^{2} \\
I_{c}=0.04 \mathrm{~m}\end{array}$ \\
\hline $\begin{array}{l}\text { Average Density: } \\
23.1 \mathrm{moles} / \mathrm{m}^{3} \mathrm{Pu} \\
11.4 \mathrm{moles} / \mathrm{m}^{3} \mathrm{U}\end{array}$ & $\begin{array}{l}\text { Average Density: } \\
20.8 \mathrm{moles} / \mathrm{m}^{3} \mathrm{Pu} \\
5.7 \mathrm{moles} / \mathrm{m}^{3} \mathrm{U}\end{array}$ \\
\hline
\end{tabular}

\subsubsection{Multiple Source Terms}

One run was done using a variable source term mimicking the time-varying EQ6 source terms. The variable source terms were approximated by a step function. Each step starts midway 
Title: Far-Field Accumulation of Fissile Material from Waste Packages Containing Plutonium

Disposition Waste Forms

Document Identifier: CAL-EDC-GS-000002 REV 00

Page 64 of 80

between the current and previous EQ6 times and ends similarly midway between the current and next EQ6 times as displayed on the hypothetical case of Figure 6-20.

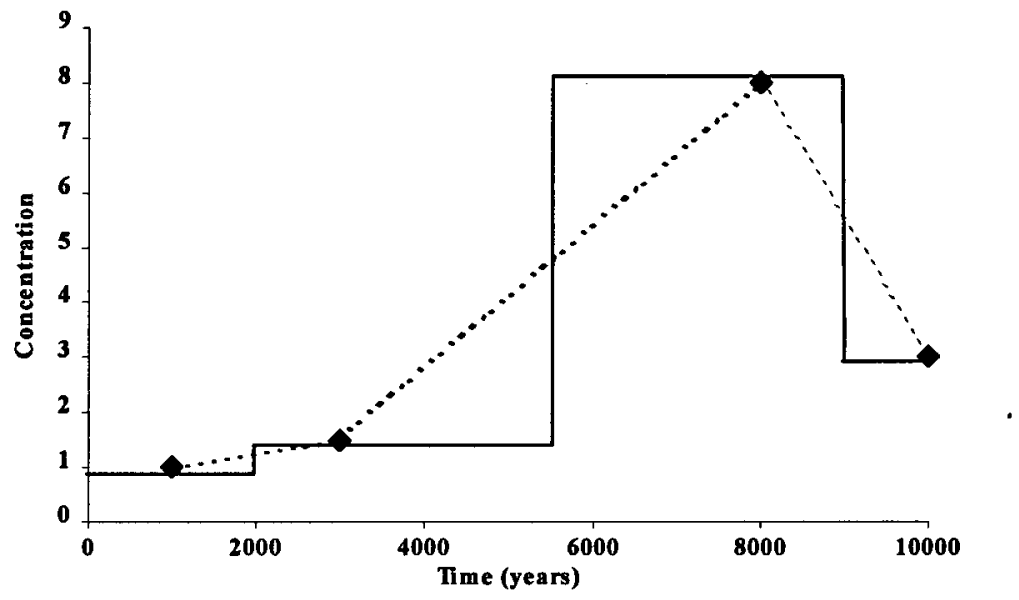

Figure 6-20. Hypothetical EQ6 Source Terms and Corresponding PHREEQC Step Function

Because the time step used ( 20 years) is different from the residence time ( 0.67 years), the extra scaling described in Section 2.2 was used. Distortions are introduced because of this scaling and results should only be considered informative. The surface area used in this case is $900,000 \mathrm{~cm}^{2}$ comparable to the $1,000,000-\mathrm{cm}^{2}$ case. Figure $6-21$ shows that accumulations at $\sim 4,000$ years after breach time follow the same pattern. The plateaus of the $\mathrm{Pu}(\mathrm{OH}) 4$ _Multi curve beyond cell 25 and of the Haiweeite_Multi curve beyond cell 40 are likely due to PHREEQC artifacts and should be disregarded. 
Title: Far-Field Accumulation of Fissile Material from Waste Packages Containing Plutonium Disposition Waste Forms

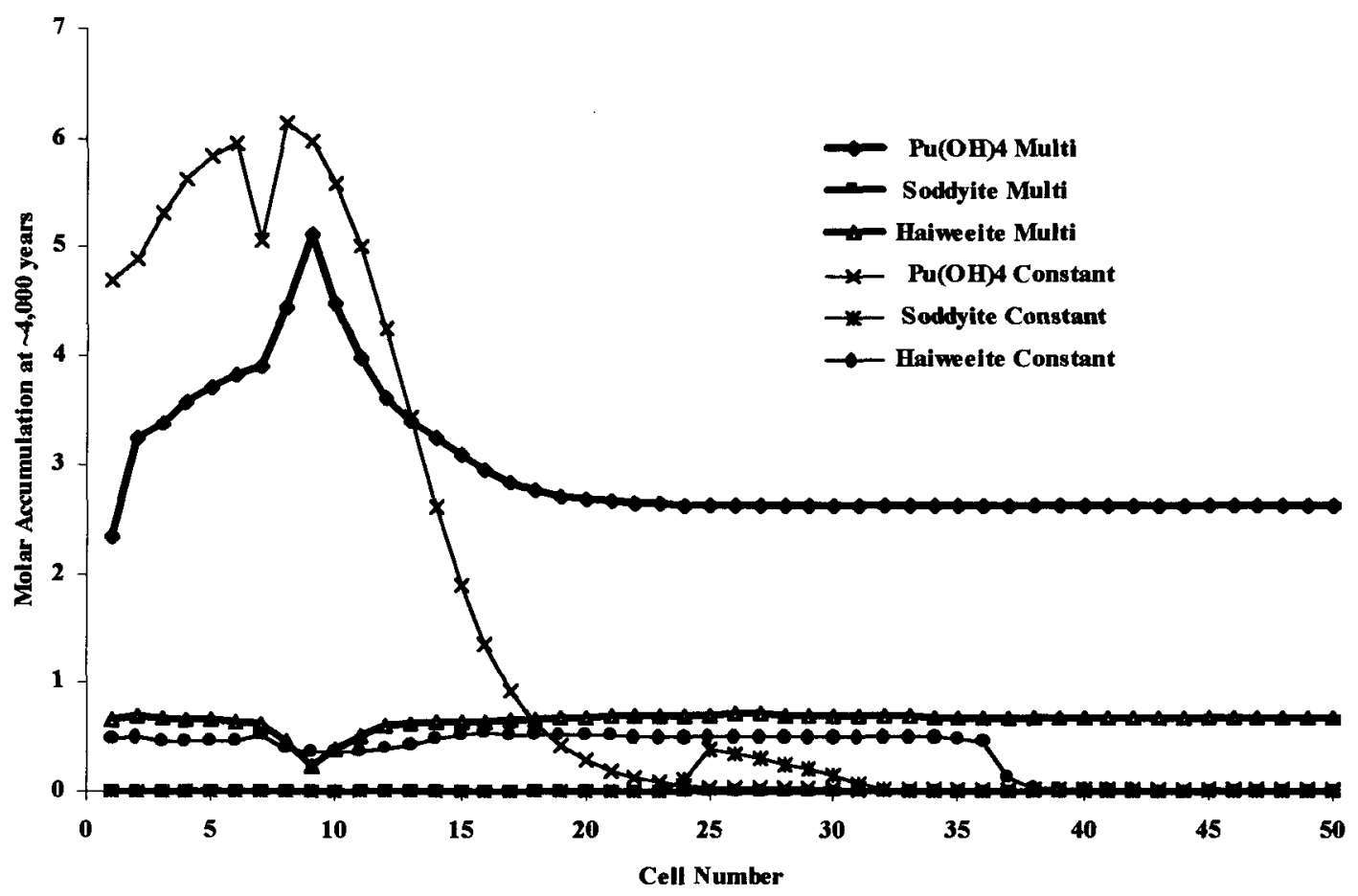

Figure 6-21. Result Comparison of Time-Varying and Constant Source Term (at $\sim 4,000$ years)

However, as displayed in Figure 6-22, accumulation keeps increasing to about 6,000 years. However, the sum of the first 31 cells yields a total $\mathrm{Pu}$ accumulation of 48.5 moles and the sum of the first 51 cells yields a total $U$ accumulation of 11.5 moles compared to the 78.5 and 39.7 moles of $\mathrm{Pu}$ and $\mathrm{U}$, respectively, for the constant source term case (Table 6-1). Figure 6-23 and Figure 6-24 display actinide mineral accumulation through space and time (Note the difference in the vertical scale). The sharp peak of $\mathrm{Pu}(\mathrm{OH})_{4}$ of Figure 6-23 corresponds to the peak on Figure 6-22. However, the plateaus in higher cell numbers in all the three figures should be disregarded. 
Title: Far-Field Accumulation of Fissile Material from Waste Packages Containing Plutonium Disposition Waste Forms

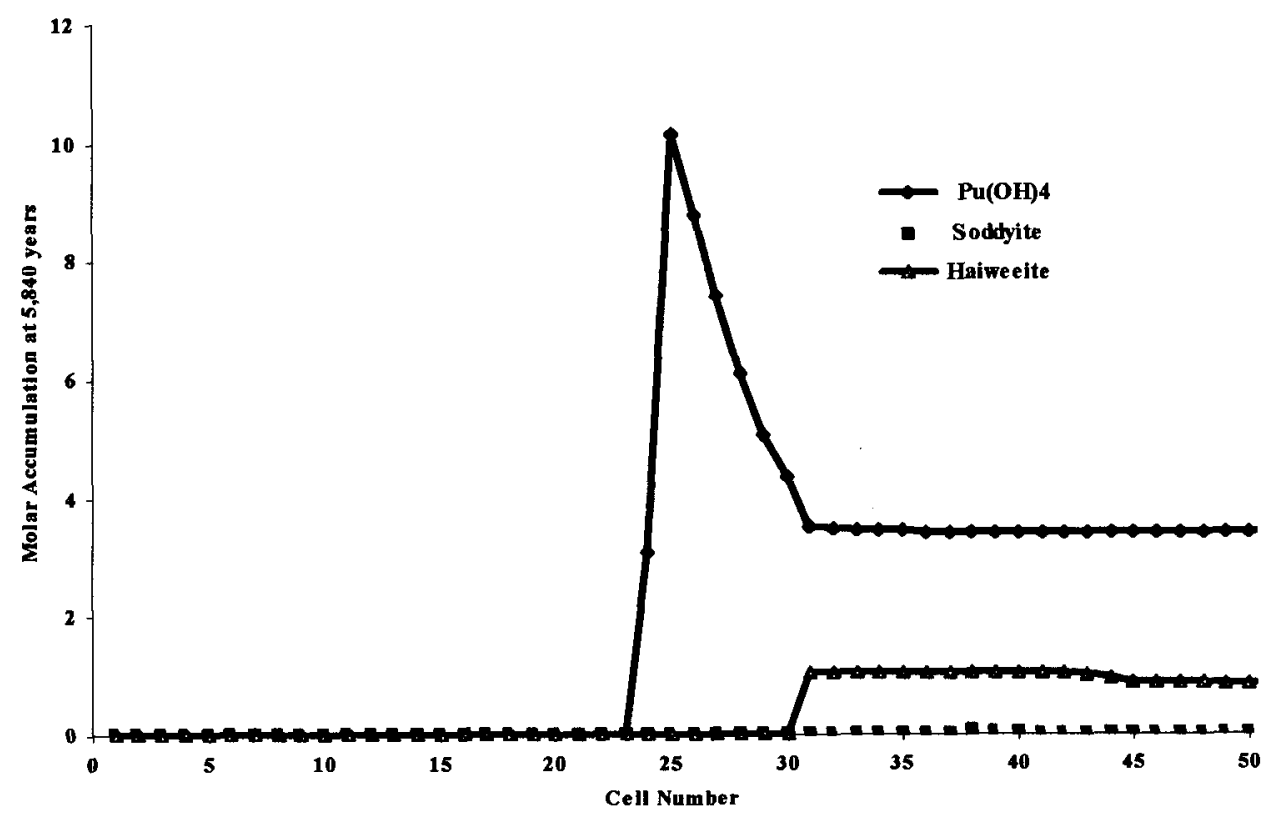

Figure 6-22. Maximum Actinide Accumulation with Variable Source Term (at time 5,840 years)

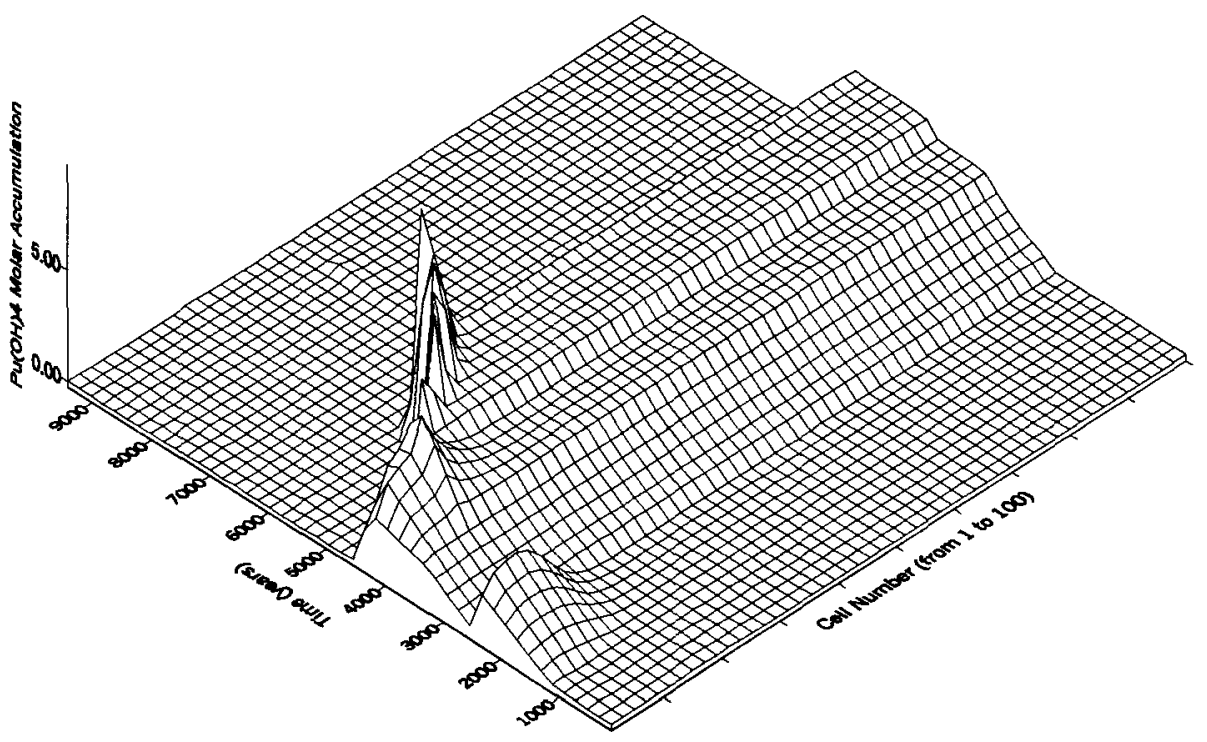

Figure 6-23. Accumulation of $\mathrm{Pu}(\mathrm{OH})_{4}$ Through Time (left axis) and Space (bottom axis) for the Variable Source Term 
Title: Far-Field Accumulation of Fissile Material from Waste Packages Containing Plutonium Disposition Waste Forms

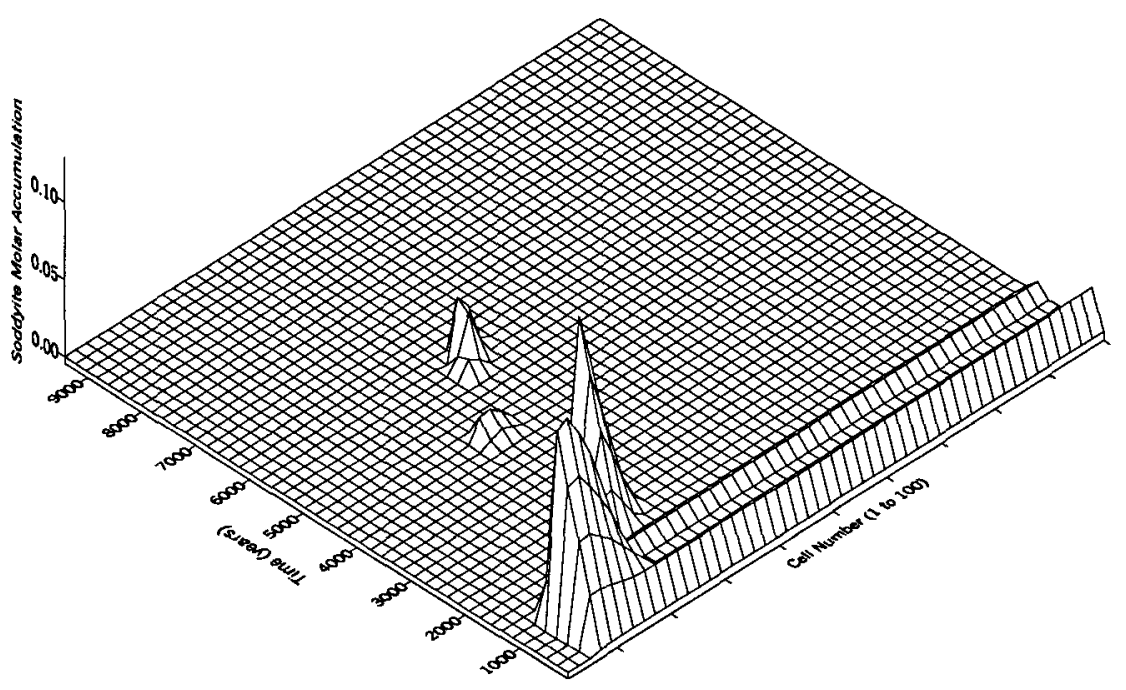

Figure 6-24. Accumulation of Soddyite Through Time (left axis) and Space (bottom axis) for the Variable Source Term

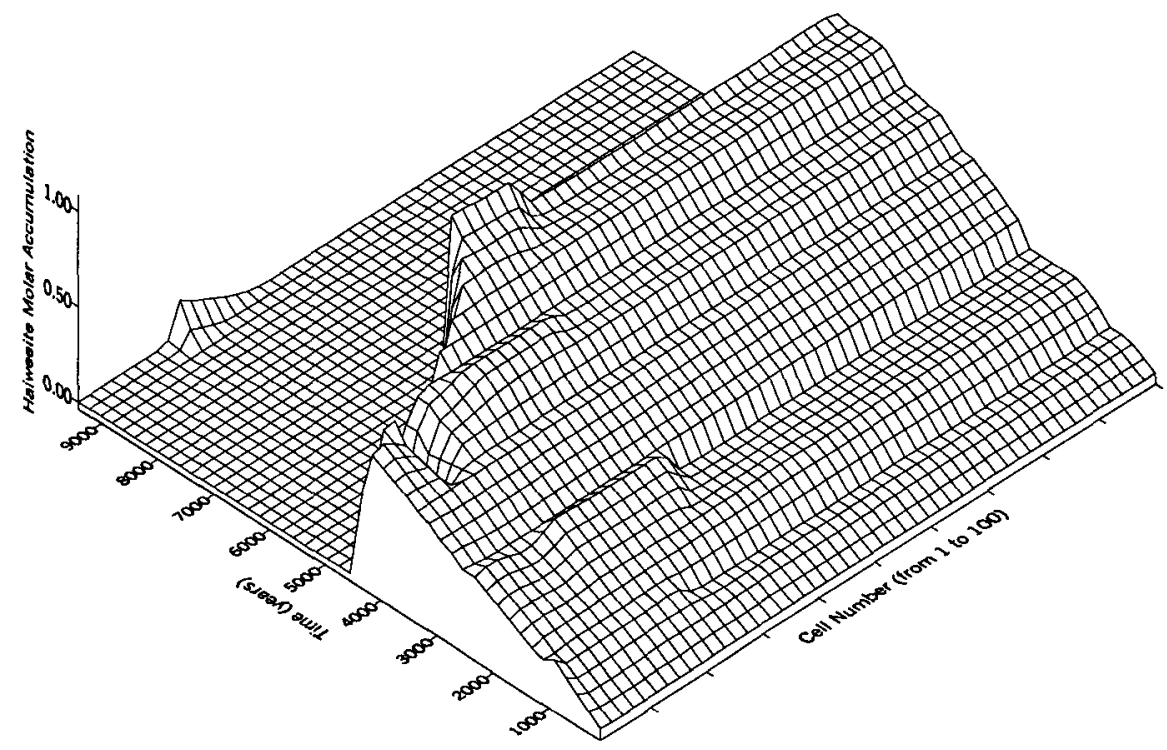

Figure 6-25. Accumulation of Haiweeite Through Time (left axis) and Space (bottom axis) for the Variable Source Term 
Title: Far-Field Accumulation of Fissile Material from Waste Packages Containing Plutonium

Disposition Waste Forms

Document Identifier: CAL-EDC-GS-000002 REV 00

Page 68 of 80

\subsection{RESULTS FOR THE MEDIUM BREACH AND LATE BREACH TIME SCENARIOS}

Results for medium and late breach times are summarized in Table 6-3 and Table 6-4 for 20,000 and $1,000,000 \mathrm{~cm}^{2}$ respectively. Figure $6-26$ and Figure $6-27$ plot the results as a function of the cell numbers for the case 1,000.000 $\mathrm{cm}^{2}$. Figure 6-28 and Figure 6-29 compare the results for different $\mathrm{Pu}$ decays. The surface area has little effect on the Pu precipitation (42.8\% for 20,000 $\mathrm{cm}^{2}$ vs $30.3 \%$ for $1,000,000 \mathrm{~cm}^{2}$ ) but has a larger effect on the U precipitation $(4.5 \% \mathrm{vs} 7.5 \%)$ because of the extra Si released into the system, needed to precipitate uranyl silicates, the main form of $\mathrm{U}$ precipitation.

Table 6-3. Summary of Results for Case pe0a1231 for Different Pu Decay (SA=20,000 $\mathrm{cm}^{2}$ )

\begin{tabular}{|c|c|c|c|c|c|}
\hline & $\begin{array}{c}\mathrm{Pu} \\
\text { all Pu }\end{array}$ & $\begin{array}{c}\mathbf{U} \\
\text { all Pu }\end{array}$ & $\begin{array}{c}\mathrm{Pu} \\
\text { half } \mathrm{Pu}\end{array}$ & $\begin{array}{c}\mathbf{U} \\
\text { half Pu}\end{array}$ & $\begin{array}{c}\mathbf{U} \\
\text { no Pu }\end{array}$ \\
\hline $\begin{array}{c}\text { Total Accumulation in the first 50 } \\
\text { cells (moles) }\end{array}$ & 85.3 & 23.2 & 30.2 & 36.4 & 57.4 \\
\hline $\begin{array}{c}\text { Percentage of Total Actinide } \\
\text { mass going through the system }\end{array}$ & 42.8 & 4.5 & 30.3 & 5.9 & 8.0 \\
\hline $\begin{array}{c}\text { Total Actinide in the first 50 cells } \\
\text { (moles) }\end{array}$ & \multicolumn{2}{|c|}{108.6} & 66.6 & 57.4 \\
\hline
\end{tabular}

Table 6-4. Summary of Results for Case pe0a1231 for Different Pu Decay $\left(S A=1,000,000 \mathrm{~cm}^{2}\right.$ - saturated)

\begin{tabular}{|c|c|c|c|c|c|}
\hline & $\begin{array}{c}\text { Pu } \\
\text { all Pu }\end{array}$ & $\begin{array}{c}\mathbf{U} \\
\text { all Pu }\end{array}$ & $\begin{array}{c}\text { Pu } \\
\text { half Pu }\end{array}$ & $\begin{array}{c}\text { U } \\
\text { half Pu }\end{array}$ & $\begin{array}{c}\mathbf{U} \\
\text { no Pu }\end{array}$ \\
\hline $\begin{array}{c}\text { Total Accumulation in the first 50 } \\
\text { cells (moles) }\end{array}$ & 77.0 & 39.0 & 26.8 & 51.2 & 124.5 \\
\hline $\begin{array}{c}\text { Percentage of Total Actinide } \\
\text { mass going through the system }\end{array}$ & 38.6 & 7.5 & 26.9 & 8.4 & 17.3 \\
\hline $\begin{array}{c}\text { Total Actinide in the first 50 cells } \\
\text { (moles) }\end{array}$ & \multicolumn{2}{|c|}{116.1} & & 79.0 & 124.5 \\
\hline
\end{tabular}

Table 6-5. Summary of Results for Case pe0a1231 for Different Pu Decay $\left(S A=1,000,000 \mathrm{~cm}^{2}\right.$ - unsaturated)

\begin{tabular}{|c|c|c|c|c|c|}
\hline & $\begin{array}{c}\text { Pu } \\
\text { all Pu }\end{array}$ & $\begin{array}{c}\text { U } \\
\text { all Pu }\end{array}$ & $\begin{array}{c}\text { Pu } \\
\text { half Pu }\end{array}$ & $\begin{array}{c}\text { U } \\
\text { half Pu }\end{array}$ & $\begin{array}{c}\text { U } \\
\text { no Pu }\end{array}$ \\
\hline $\begin{array}{c}\text { Total Accumulation in the first 50 } \\
\text { cells (moles) }\end{array}$ & 177.9 & 474.4 & 56.4 & 575.9 & 630.4 \\
\hline $\begin{array}{c}\text { Percentage of Total Actinide } \\
\text { mass going through the system }\end{array}$ & 89.3 & 91.6 & 56.6 & 92.7 & 87.5 \\
\hline $\begin{array}{c}\text { Total Actinide in the first 50 cells } \\
\text { (moles) }\end{array}$ & \multicolumn{2}{|c|}{652.3} & 632.2 & 630.4 \\
\hline
\end{tabular}


Title: Far-Field Accumulation of Fissile Material from Waste Packages Containing Plutonium Disposition Waste Forms

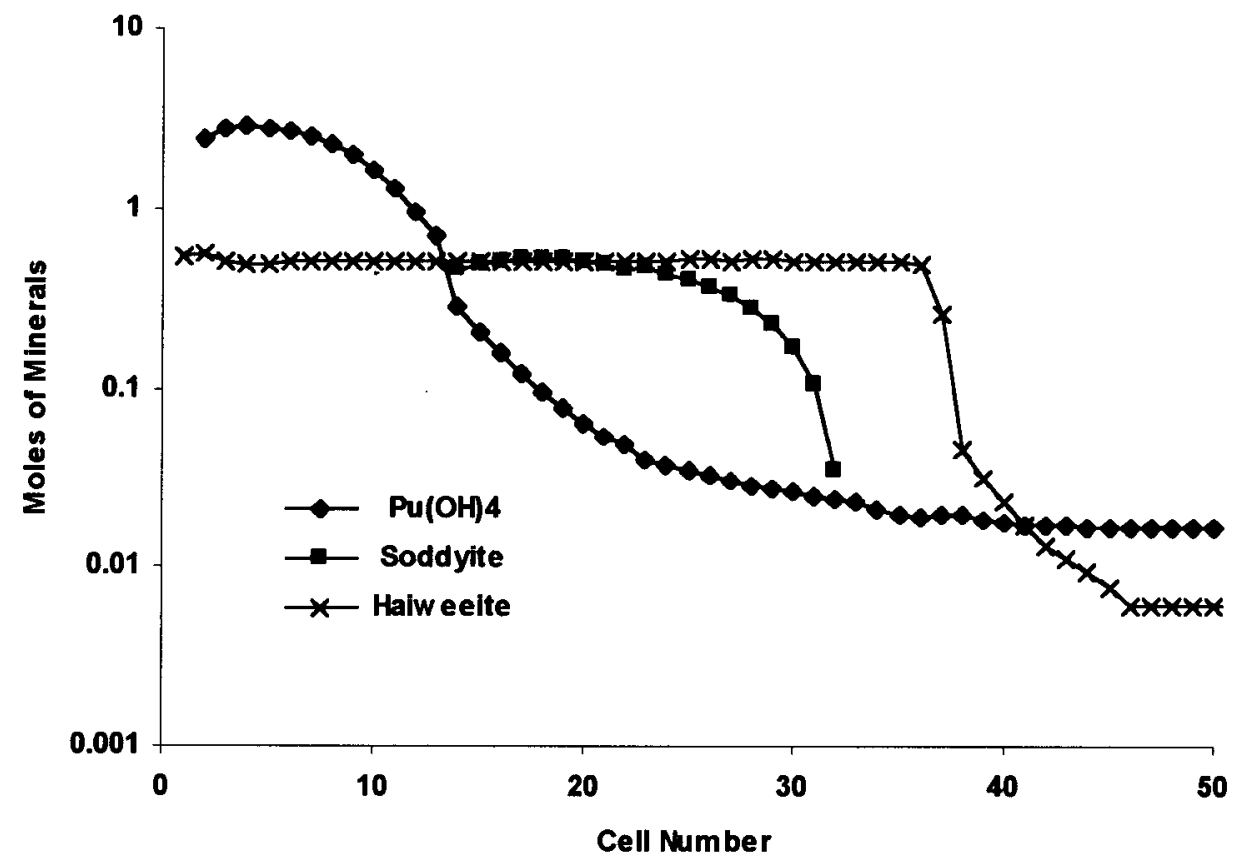

Figure 6-26. Actinide Mineral Precipitation after 2,500 Years $\left(S A=1,000,000 \mathrm{~cm}^{2}-\right.$ half Pu decayed)

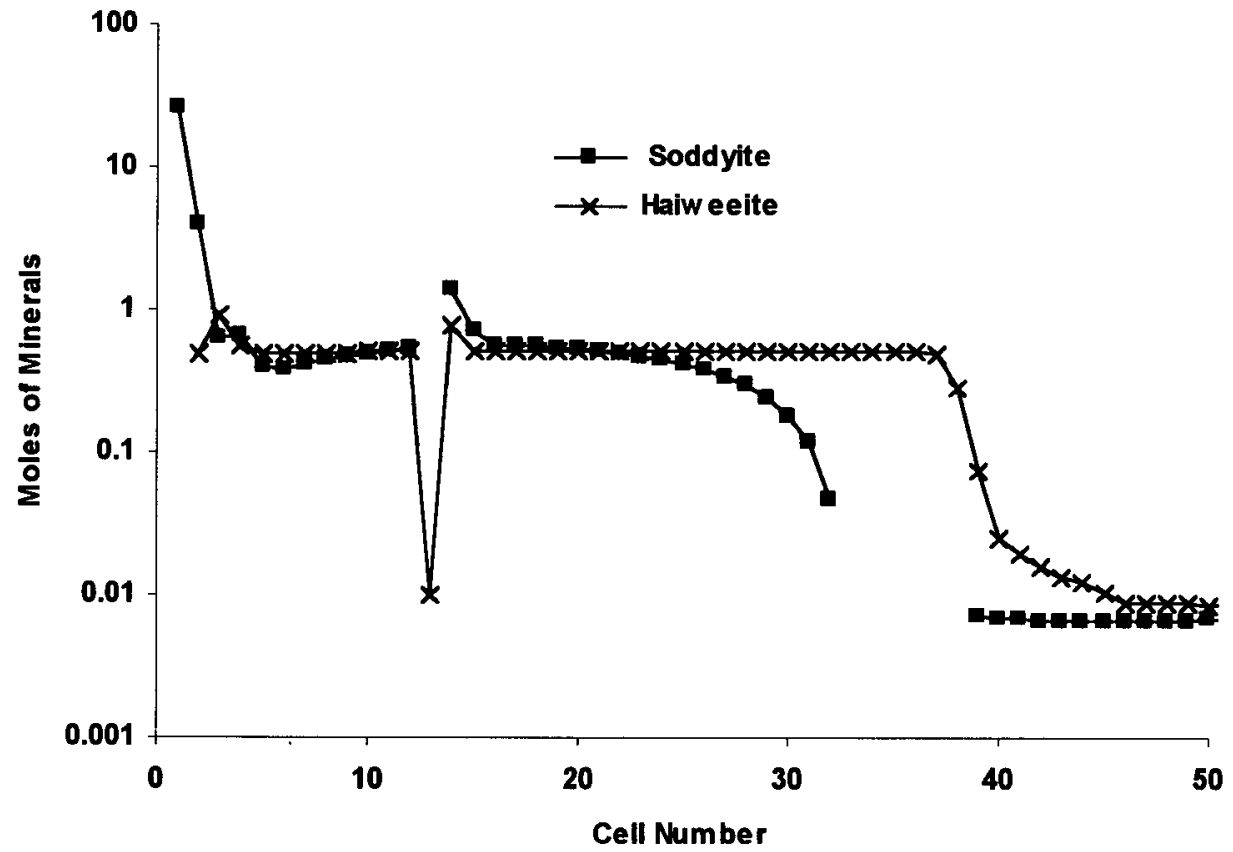

Figure 6-27. Actinide Mineral Precipitation after 2,500 Years $\left(S A=1,000,000 \mathrm{~cm}^{2}\right.$ - all Pu decayed) 
Title: Far-Field Accumulation of Fissile Material from Waste Packages Containing Plutonium Disposition Waste Forms

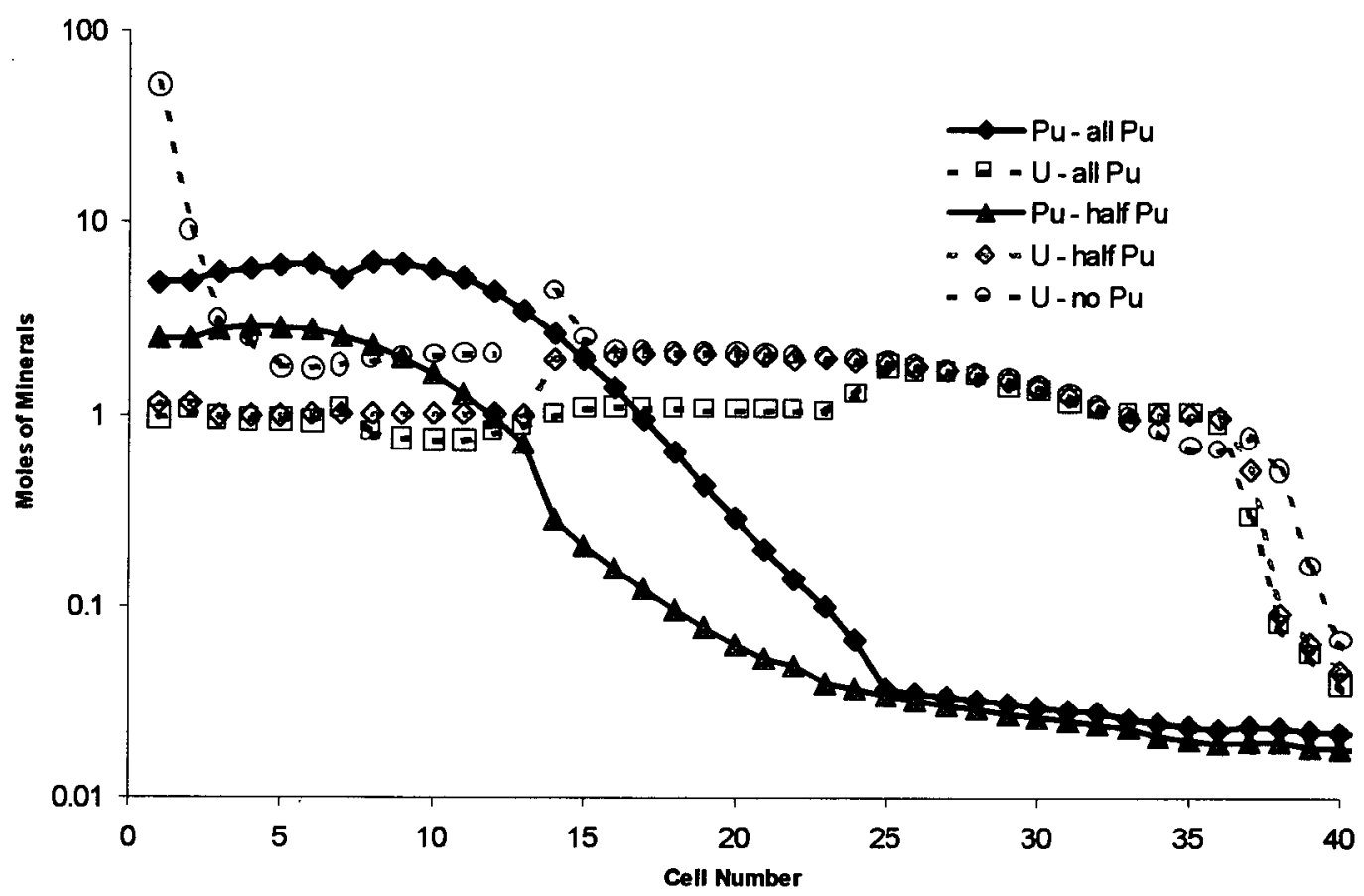

(a)

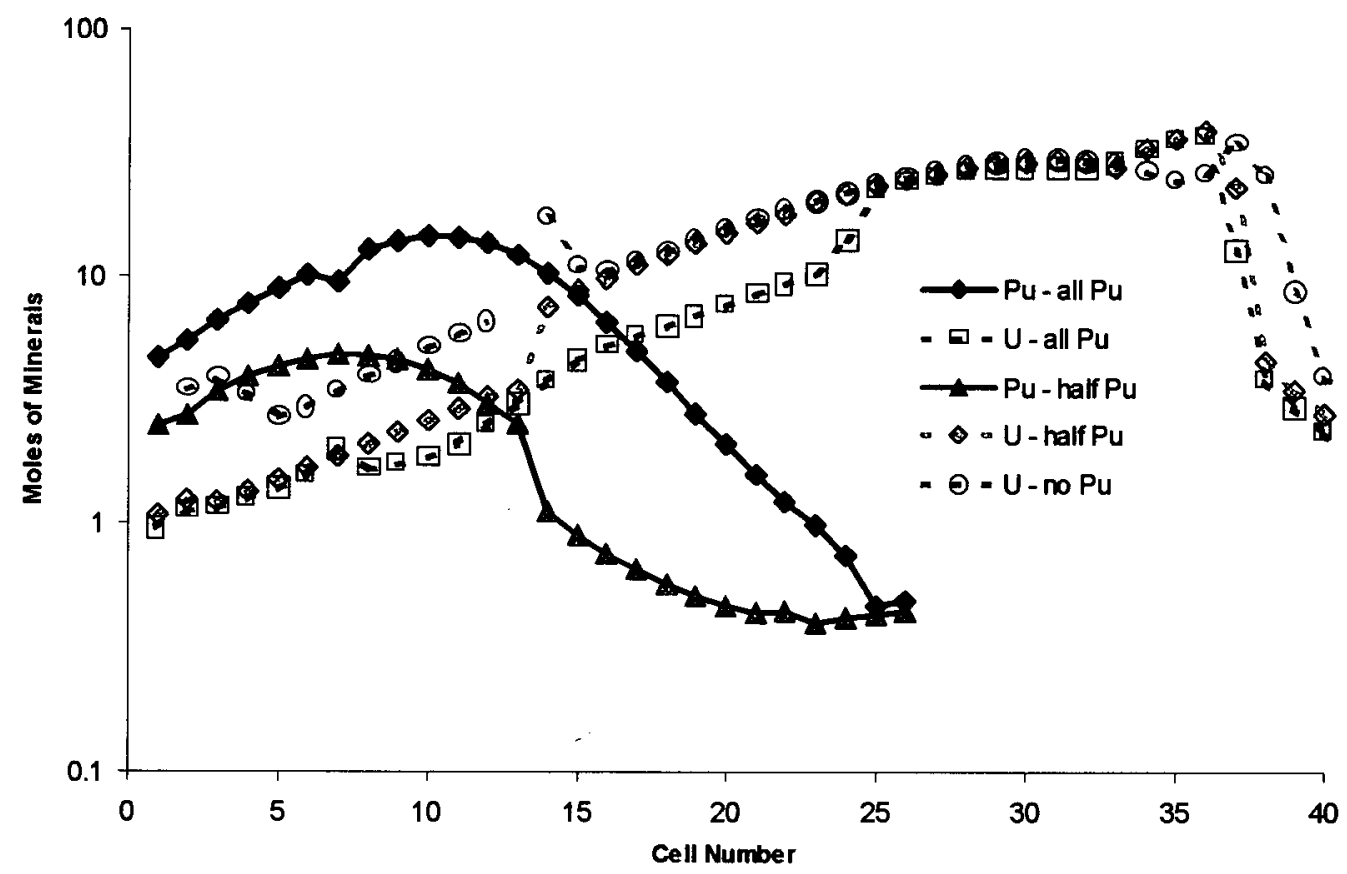

(b)

Figure 6-28. Actinide Precipitation as a Function of the Cell Number and Pu Decay (after 2,500 years of deposition - case pe0a1231): (a) $1,000,000 \mathrm{~cm}^{2}$ Saturated (b) $1,000,000 \mathrm{~cm}^{2}$ Unsaturated 
Title: Far-Field Accumulation of Fissile Material from Waste Packages Containing Plutonium Disposition Waste Forms

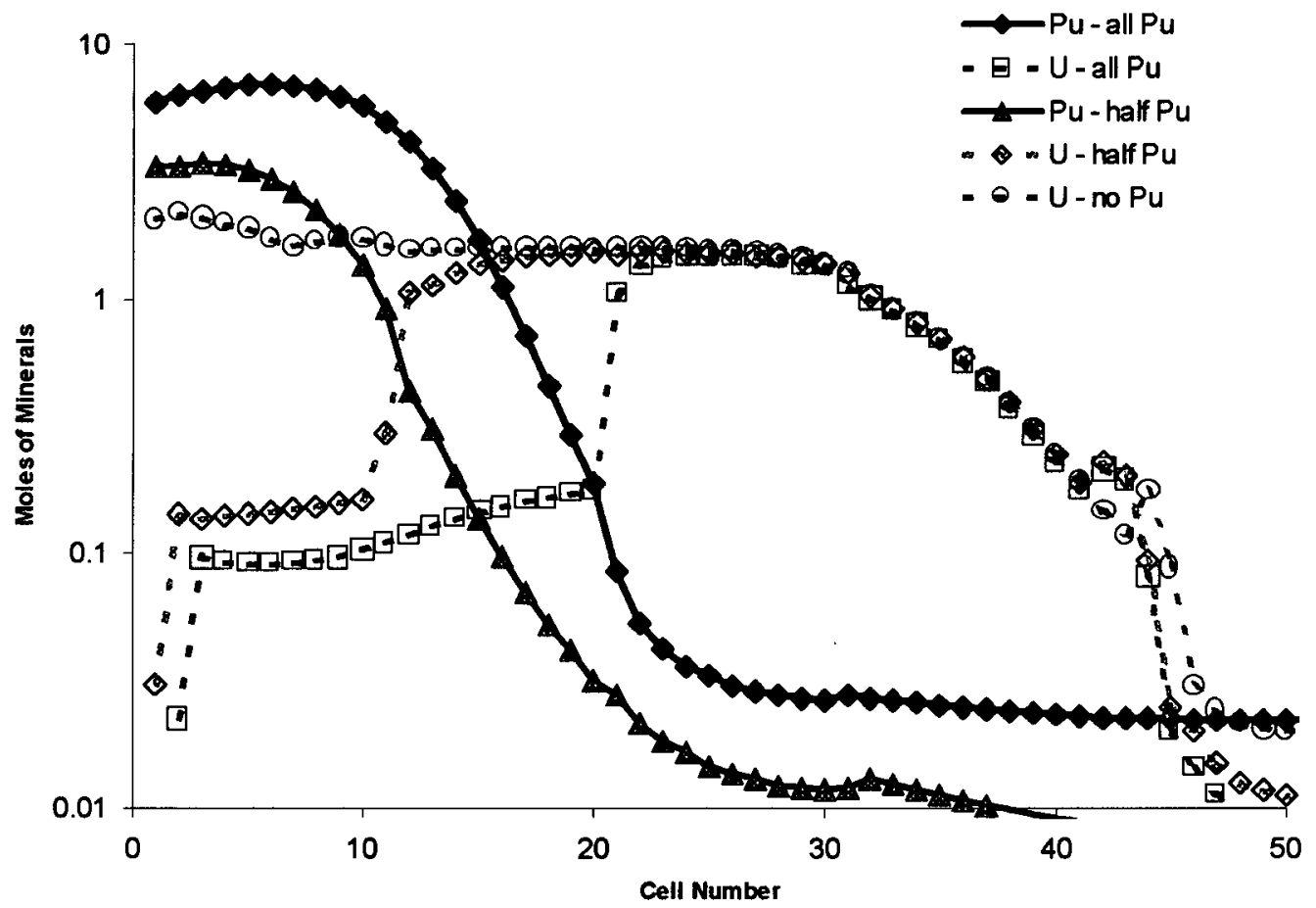

Figure 6-29. Actinide Precipitation as a Function of the Cell Number and Pu Decay (after 2,500 years of deposition - case pe0a1231-20,000 $\mathrm{cm}^{2}$ )

General results mimic results from Section 6.1.

\subsection{RESULTS FOR PW2A1231 SCENARIOS}

An analysis similar to the ones in Sections 6.1 and 6.2 was also performed with the source term pw2a1231. The saturated cases with surface area of $20,000 \mathrm{~cm}^{2}$ are likely to be closer to criticality than the unsaturated case with surface area of $1,000,000 \mathrm{~cm}^{2}$ because they are less spread out. The different cases are briefly presented in Table 6-6 and Table 6-7.

Table 6-6. Summary of Results for Case pw2a1231 for Different Pu Decay $\left(S A=20,000 \mathrm{~cm}^{2}\right)$

\begin{tabular}{|c|c|c|c|c|c|}
\hline & $\begin{array}{c}\text { Pu } \\
\text { all Pu }\end{array}$ & $\begin{array}{c}\mathbf{U} \\
\text { all Pu }\end{array}$ & $\begin{array}{c}\text { Pu } \\
\text { half Pu }\end{array}$ & $\begin{array}{c}\text { U } \\
\text { half Pu }\end{array}$ & $\begin{array}{c}\text { U } \\
\text { no Pu }\end{array}$ \\
\hline $\begin{array}{c}\text { Total Accumulation in the first 50 } \\
\text { cells (moles) }\end{array}$ & 0.32 & 8.07 & 0.12 & 8.20 & 8.32 \\
\hline $\begin{array}{c}\text { Percentage of Total Actinide } \\
\text { mass going through the system }\end{array}$ & 1.8 & 1.6 & 1.3 & 1.6 & 1.6 \\
\hline $\begin{array}{c}\text { Total Actinide in the first 50 cells } \\
\text { (moles) }\end{array}$ & \multicolumn{2}{|c|}{8.39} & & 8.32 & 8.32 \\
\hline
\end{tabular}


Title: Far-Field Accumulation of Fissile Material from Waste Packages Containing Plutonium Disposition Waste Forms

Table 6-7. Summary of Results for Case pw2a1231 for Different Pu Decay $\left(S A=1,000,000 \mathrm{~cm}^{2}\right.$ saturated)

\begin{tabular}{|c|c|c|c|c|c|}
\hline & $\begin{array}{c}\mathrm{Pu} \\
\text { all Pu }\end{array}$ & $\begin{array}{c}\mathrm{U} \\
\text { all Pu }\end{array}$ & $\begin{array}{c}\mathrm{Pu} \\
\text { half } \mathrm{Pu}\end{array}$ & $\begin{array}{c}\mathrm{U} \\
\text { half Pu }\end{array}$ & $\begin{array}{c}\mathrm{U} \\
\text { no } \mathrm{Pu}\end{array}$ \\
\hline $\begin{array}{c}\text { Total Accumulation in the first 50 } \\
\text { cells (moles) }\end{array}$ & 0.3 & 15.0 & 0.1 & 15.2 & 15.4 \\
\hline $\begin{array}{c}\text { Percentage of Total Actinide } \\
\text { mass going through the system }\end{array}$ & 1.7 & 2.9 & 1.3 & 2.5 & 2.9 \\
\hline $\begin{array}{c}\text { Total Actinide in the first 60 cells } \\
\text { (moles) }\end{array}$ & \multicolumn{2}{|c|}{15.3} & \multicolumn{2}{|c|}{15.3} & 15.4 \\
\hline
\end{tabular}

Table 6-8. Summary of Results for Case pw2a1231 for Different Pu Decay $\left(S A=1,000,000 \mathrm{~cm}^{2}\right.$ unsaturated)

\begin{tabular}{|c|c|c|c|c|c|}
\hline & $\begin{array}{c}\mathrm{Pu} \\
\text { all } \mathbf{P u}\end{array}$ & $\underset{\text { all } \mathrm{Pu}}{\mathbf{P u}}$ & $\begin{array}{c}\mathrm{Pu} \\
\text { half } \mathrm{Pu}\end{array}$ & $\begin{array}{c}\mathrm{U} \\
\text { half } \mathrm{Pu}\end{array}$ & $\underset{\text { no } P u}{U}$ \\
\hline $\begin{array}{c}\text { Total Accumulation in the first } 50 \\
\text { cells (moles) }\end{array}$ & 15.8 & 474.4 & 7.5 & 482.5 & 490.6 \\
\hline $\begin{array}{l}\text { Percentage of Total Actinide } \\
\text { mass going through the system }\end{array}$ & 87.2 & 92.0 & 83.5 & 92.0 & 91.9 \\
\hline $\begin{array}{l}\text { Total Actinide in the first } 60 \text { cells } \\
\text { (moles) }\end{array}$ & \multicolumn{2}{|c|}{490.2} & \multicolumn{2}{|c|}{490.1} & 490.6 \\
\hline
\end{tabular}

The results are to be compared to Table 6-3 and Table 6-4 and are one order of magnitude lower for the saturated cases. In the unsaturated case, the actinide density is similar in both source terms. The pw2a1231 case has less mass but also less cells with significant accumulation, i.e., 490.2 moles of actinide over 30 cells $(16.3 \mathrm{moles} / \mathrm{cell})$ compared to $652.3 / 50=13.0 \mathrm{moles} / \mathrm{cell}$ for the pe0a1231 case (Table 6-5). However, the $\mathrm{Pu}$ accumulation is significantly higher in the pe0a1231 case (89.3 moles against 15.8) because of the higher Pu source term concentration (see Section 5.1.7). 
Title: Far-Field Accumulation of Fissile Material from Waste Packages Containing Plutonium Disposition Waste Forms

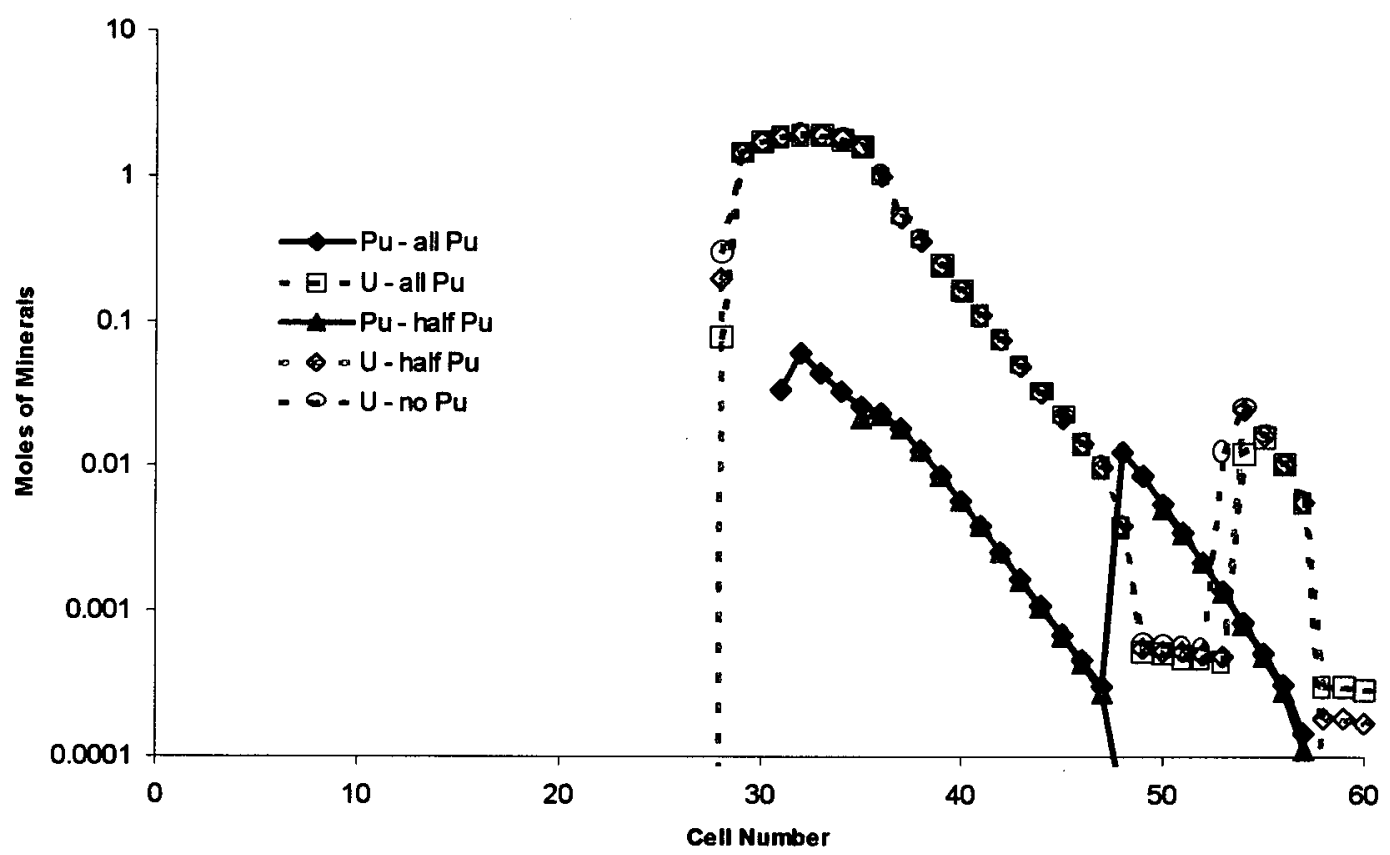

(a)

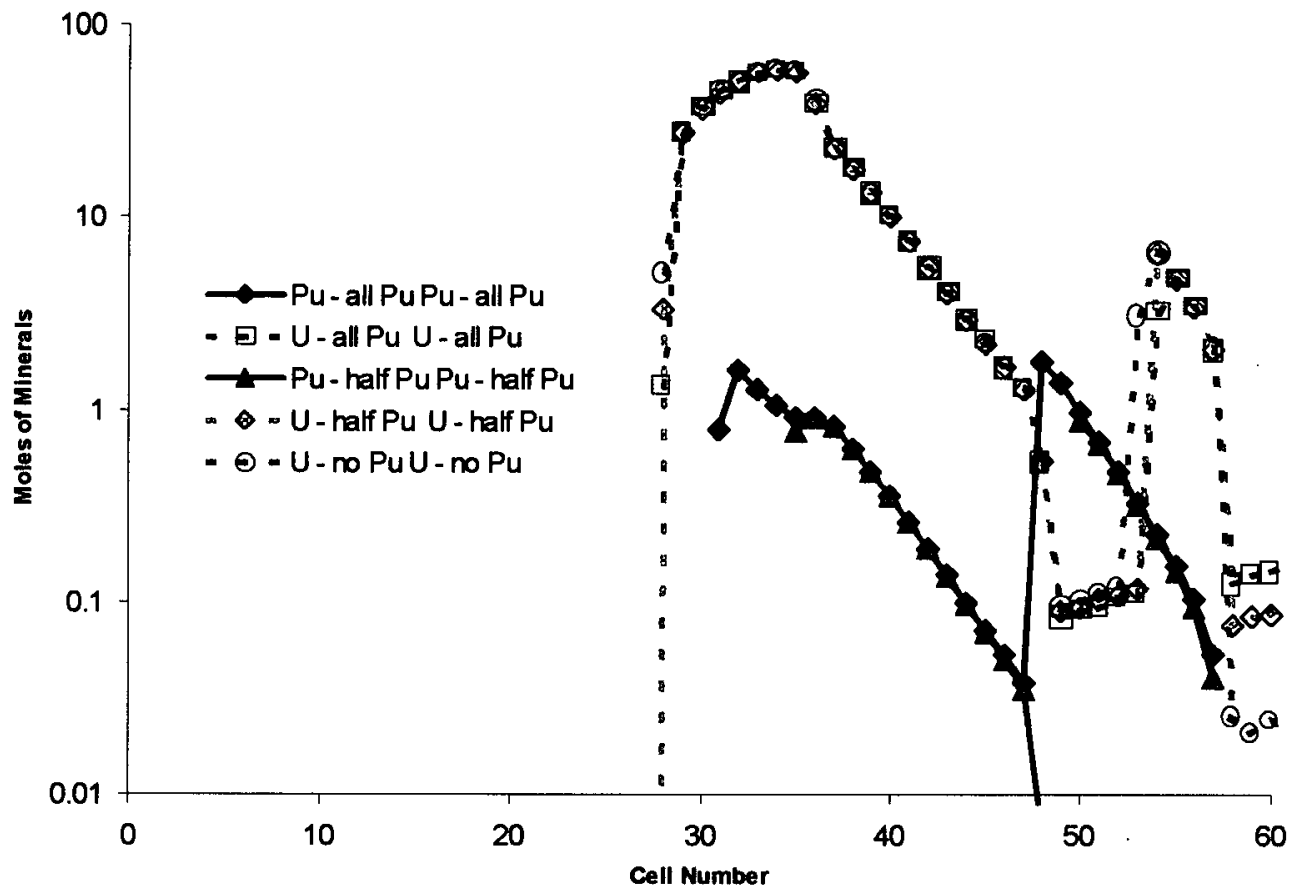

(b)

NOTE: The double peaks correspond to the combination of the two source terms at 4,050 and 7,940 years.

Figure 6-30. Actinide Precipitation as a Function of Cell Number and Decay (after 7,000 years of deposition - case pw2a1231): (a) $1,000,000 \mathrm{~cm}^{2}$ - Saturated (b) $1,000,000 \mathrm{~cm}^{2}$ Unsaturated 
Title: Far-Field Accumulation of Fissile Material from Waste Packages Containing Plutonium Disposition Waste Forms

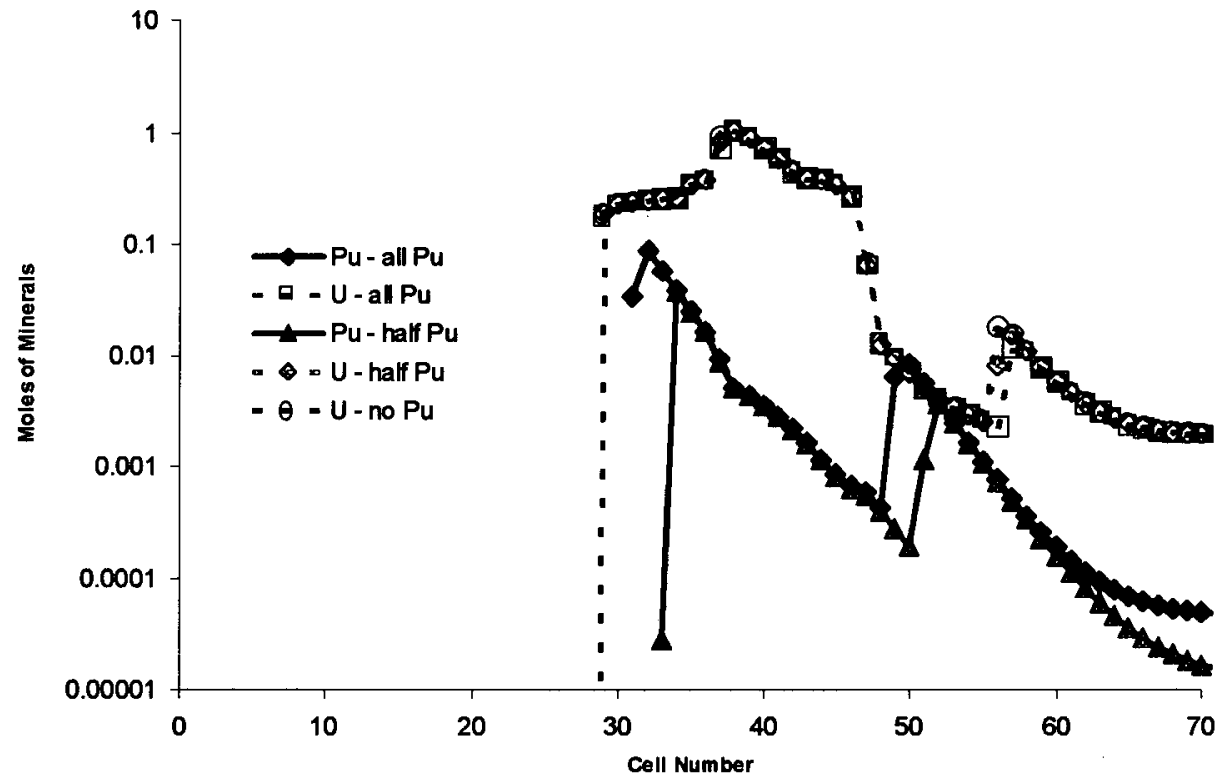

Figure 6-31. Actinide Precipitation as a Function of the Cell Number and Pu Decay (after 7,000 years of deposition - case pw2a1231 $-20,000 \mathrm{~cm}^{2}$ )

\subsection{RESULTS FOR THE MOX03AP2 SCENARIOS}

Results show that actinide accumulation is not possible under a MOX WP. The source term shows only a very short-lived $\mathrm{Pu}$ spike, not likely to generate $\mathrm{Pu}$ accumulation, and $\mathrm{U}$ mineralization is only possible, if any, in the first two cells in moderate quantities (Figure 6-32).

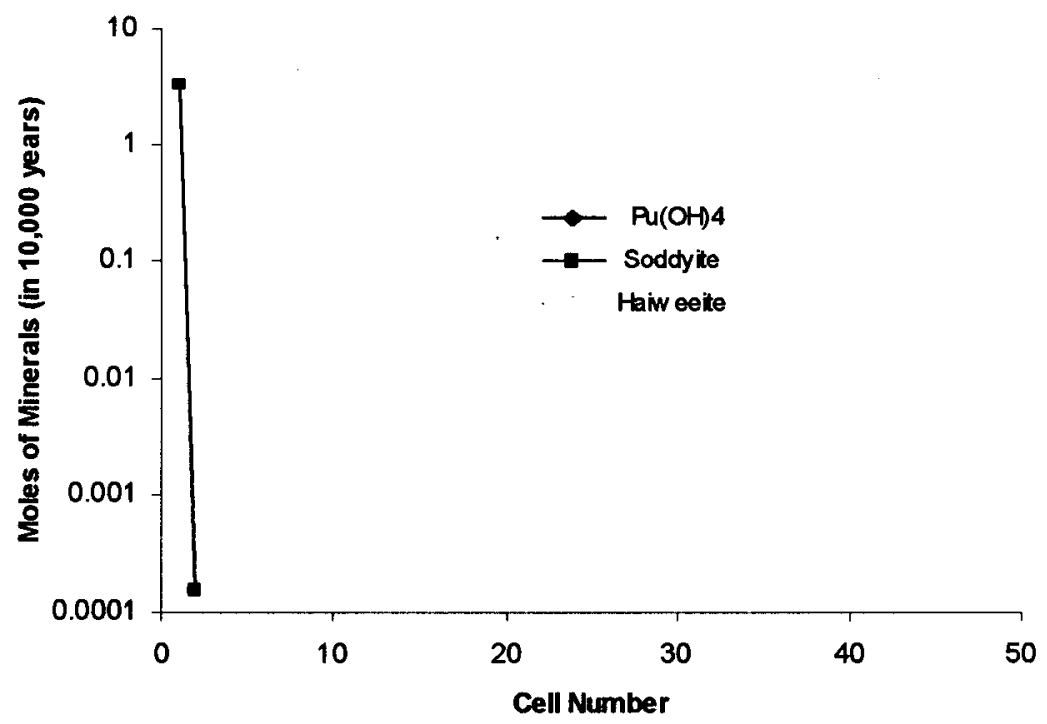

Figure 6-32. Accumulation of Actinides in the mox03ap2 Case $\left(S A=20,000 \mathrm{~cm}^{2}\right)$ 
Title: Far-Field Accumulation of Fissile Material from Waste Packages Containing Plutonium Disposition Waste Forms

\section{REFERENCES}

1. CRWMS M\&O 1998. "Unsaturated Zone Hydrology Model." Chapter 2 of Total System Performance Assessment-Viability Assessment (TSPA-VA) Analyses Technical Basis Document. B00000000-01717-4301-00002 REV 01. Las Vegas, Nevada: CRWMS M\&O. ACC: MOL.19981008.0002.

2. Philip, J.R.; Knight, J.H.; and Waechter, R.T. 1989. "Unsaturated Seepage and Subterranean Holes: Conspectus, and Exclusion Problem for Circular Cylindrical Cavities." Water Resources Research, 25, (1), 16-28. Washington, D.C.: American Geophysical Union. TIC: 239117.

3. Bear, J. 1988. Dynamics of Fluids in Porous Media. New York, New York: Dover Publications. TIC: 217568.

4. CRWMS M\&O 2000. In-Drift Accumulation of Fissile Material from Waste Packages Containing Plutonium Disposition Waste Forms. CAL-EDC-GS-000001 REV 00. Las Vegas, Nevada: CRWMS M\&O. Submit to RPC URN-0531.

5. CRWMS M\&O 1997. Degraded Mode Criticality Analysis of Immobilized Plutonium Waste Forms in a Geologic Repository. Predecisional Document. A00000000-017175705-00014 REV 01. Las Vegas, Nevada: CRWMS M\&O. ACC: MOL.19980422.0911.

6. Sweetkind, D.S.; Barr, D.L.; Polacsek, D.K.; and Anna, L.O. 1997. Administrative Report: Integrated Fracture Data in Support of Process Models, Yucca Mountain, Nevada. Milestone SPG32M3. Denver, Colorado: U.S. Geological Survey. ACC: MOL.19971017.0726.

7. CRWMS M\&O 1999. EQ6 Calculation for Chemical Degradation of Pu-Ceramic Waste Packages: Effects of Updated Materials Composition and Rates. CAL-EDCMD-000003 REV 00. Las Vegas, Nevada: CRWMS M\&O. ACC: MOL.19990928.0235.

8. CRWMS M\&O 1998. EQ6 Calculations for Chemical Degradation of PWR LEU and PWR MOX Spent Fuel Waste Packages. BBA000000-01717-0210-00009 REV 00. Las Vegas, Nevada: CRWMS M\&O. ACC: MOL.19980701.0483.

9. CRWMS M\&O 1999. FY 1999 Plutonium Disposition Waste Package Criticality Tasks. TDP-DDC-MD-000001 REV 00. Las Vegas, Nevada: CRWMS M\&O. ACC: MOL.19990729.0059. 
Title: Far-Field Accumulation of Fissile Material from Waste Packages Containing Plutonium

Disposition Waste Forms

Document Identifier: CAL-EDC-GS-000002 REV 00

Page 76 of 80

10. Bodvarsson, G.S.; Bandurraga, T.M.; and Wu, Y.S., eds. 1997. The Site-Scale Unsaturated Zone Model of Yucca Mountain, Nevada, for the Viability Assessment. LBNL-40376. Berkeley, California: Lawrence Berkeley National Laboratory. ACC: MOL.19971014.0232.

11. Sweetkind, D.S. and Williams-Stroud, S.C. 1996. Characteristics of Fractures at Yucca Mountain, Nevada: Synthesis Report. Administrative Report. Denver, Colorado: U.S. Geological Survey. ACC: MOL.19961213.0181.

12. Anna, L.O. 1998. Preliminary Three-Dimensional Discrete Fracture Model of the Topopah Spring Tuff in the Exploratory Studies Facility, Yucca Mountain Area, Nye County, Nevada. Open-File Report 97-834. Denver, Colorado: U.S. Geological Survey. TIC: 236829.

13. Domenico, P.A. and Schwartz, F.W. 1990. Physical and Chemical Hydrogeology. New York, New York: John Wiley \& Sons. TIC: 234782.

14. Fetter, C.W. 1993. Contaminant Hydrogeology. New York, New York: Macmillan Publishing. TIC: 240691.

15. Jury, W.A.; Gardner, W.R.; and Gardner, W.H. 1991. Soil Physics. 5th Edition. New York, New York: John Wiley \& Sons. TIC: 241000.

16. Padilla, I.Y.; Yeh, T.-C. J.; and Conklin, M.H. 1999. "The Effect of Water Content on Solute Transport in Unsaturated Porous Media." Water Resources Research, 35, (11), 3303-3313. Washington, D.C.: American Geophysical Union. TIC: 246456.

17. Haga, D.; Niibori, Y.; and Chida, T. 1999. "Hydrodynamic Dispersion and Mass Transfer in Unsaturated Flow." Water Resources Research, 35, (4), 1065-1077. Washington, D.C.: American Geophysical Union. TIC: 246455.

18. Forrer, I.; Kasteel, R.; Flury, M.; and Fluhler, H. 1999. "Longitudinal and Lateral Dispersion in an Unsaturated Field Soil." Water Resources Research, 35, (10), 30493060. Washington, D.C.: American Geophysical Union. TIC: 246454.

19. Gelhar, L.W. 1993. Stochastic Subsurface Hydrology. Englewood Cliffs, New Jersey: Prentice-Hall. TIC: 240652.

20. Haldeman, W.R.; Chuang, Y.; Rasmussen, T.C.; and Evans, D.D. 1991. "Laboratory Analysis of Fluid Flow and Solute Transport through a Fracture Embedded in Porous Tuff." Water Resources Research, 27, (1), 53-65. Washington, D.C.: American Geophysical Union. TIC: 246453.

21. Keum, D-K.; Park, C-K.; Hahn, P-S.; and Vandergraaf, T.T. 1997. "A Stratified Channel Model with Local Longitudinal Dispersion." Nuclear Technology, 120, 211 223. Hinsdale, Illinois: American Nuclear Society. TIC: 246457. 
Title: Far-Field Accumulation of Fissile Material from Waste Packages Containing Plutonium Disposition Waste Forms

22. CRWMS M\&O 2000. Software User's Manual (UM) for PHREEQC Version 2.0 (beta). SDN: 10068-UM-2.0-00. Las Vegas, Nevada: CRWMS M\&O. ACC: MOL.20000114.0118.

23. Liu, H.H.; Doughty, C.; and Bodvarsson, G.S. 1998. "An Active Fracture Model for Unsaturated Flow and Transport in Fractured Rocks." Water Resources Research, 34, (10), 2633-2646. Washington, D.C.: American Geophysical Union. TIC: 243012.

24. YMP (Yucca Mountain Site Characterization Project) 1998. Disposal Criticality Analysis Methodology Topical Report. YMP/TR-004Q, Rev. 0. Las Vegas, Nevada: Yucca Mountain Site Characterization Office. ACC: MOL.19990210.0236.

25. DOE (U.S. Department of Energy) 1998. Total System Performance Assessment. Volume 3 of Viability Assessment of a Repository at Yucca Mountain. DOE/RW0508. Washington, D.C.: U.S. Department of Energy, Office of Civilian Radioactive Waste Management. ACC: MOL.19981007.0030.

26. Wilson, C.N. and Bruton, C.J. 1989. Studies on Spent Fuel Dissolution Behavior Under Yucca Mountain Repository Conditions. PNL-SA-16832. Richland, Washington: Pacific Northwest Laboratory. ACC: HQX.19890918.0047.

27. Efurd, D.W.; Runde, W.; Banar, J.C.; Janecky, D.R.; Kaszuba, J.P.; Palmer, P.D.; Roensch, F.R.; and Tait, D. 1998. "Neptunium and Plutonium Solubilities in a Yucca Mountain Groundwater." Environmental Science \& Technology, 32, (24), 3893-3900. Easton, Pennsylvania: Environmental Science \& Technology. TIC: 243857.

28. Gradshyeyn, I.S. and Ryzhik, I.M. 1979. Table of Integrals, Series, and Products: Corrected and Enlarged Edition. San Diego, California: Academic Press, Inc. TIC: 244648.

29. Abramowitz, M. and Stegun, I.A., eds. 1972. Handbook of Mathematical Functions with Formulas, Graphs, and Mathematical Tables. National Bureau of Standards, Applied Mathematics Series. 55, 1046. Washington, D.C.: U.S. Department of Commerce. TIC: 229060.

30. CRWMS M\&O 1999. Software Validation Test Report (VTR) for PHREEQC Version 2.0 (beta). SDN: 10068-VTR-2.0-00. Las Vegas, Nevada: CRWMS M\&O. ACC: MOL.20000113.0408.

31. CRWMS M\&O 2000. Probability of External Criticality of Plutonium Disposition Waste Forms. CAL-EBS-NU-000011 REV 00. Las Vegas, Nevada: CRWMS M\&O. ACC: MOL.20000920.0164. 
Title: Far-Field Accumulation of Fissile Material from Waste Packages Containing Plutonium Disposition Waste Forms

32. CRWMS M\&O 2000. Waste Package Related Impacts of Plutonium Disposition Waste Forms in a Geologic Repository. TDR-EBS-MD-000003 REV 01 ICN 01. Las Vegas, Nevada: CRWMS M\&O. ACC: MOL.20000510.0163.

33. CRWMS M\&O 2000. Uncanistered Spent Nuclear Fuel Disposal Container System Description Document. SDD-UDC-SE-000001 REV 01. Las Vegas, Nevada: CRWMS M\&O. ACC: MOL.20000822.0004.

34. Rai, D. and Ryan, J.L. 1982. "Crystallinity and Solubility of Pu(IV) Oxide and Hydrous Oxide in Aged Aqueous Suspensions." Radiochimica Acta, 30, 213-216. München, Germany: R. Oldenbourg Verlag. TIC: 219107.

35. Harrar, J.E.; Carley, J.F.; Isherwood, W.F.; and Raber, E. 1990. Report of the Committee to Review the Use of J-13 Well Water in Nevada Nuclear Waste Storage Investigations. UCID-21867. Livermore, California: Lawrence Livermore National Laboratory. ACC: NNA.19910131.0274.

36. Lipman, P.W.; Christiansen, R.L.; and O'Connor, J.T. 1966. A Compositionally Zoned Ash-Flow Sheet in Southern Nevada. Professional Paper 524-F. Washington, D.C.: U.S. Geological Survey. TIC: 219972.

37. SN9912T0511599.002. Revised Seepage Abstraction Results for TSPA-SR (Total System Performance Assessment-Site Recommendation). Submittal date: 12/15/1999.

38. MO9901RIB00044.000. Reference Information Base Data Item - Hydrologic Characteristics: Unsaturated Zone Flow Characteristics. Submittal date: 01/06/1999.

39. Brady, P.V. and Walther, J.V. 1990. "Kinetics of Quartz Dissolution at Low Temperatures." Chemical Geology, 82, 253-264. Amsterdam, The Netherlands: Elsevier Science Publishers B.V. TIC: 235349.

40. Brady, P.V. and Walther, J.V. 1989. "Controls on Silicate Dissolution Rates in Neutral and Basic $\mathrm{pH}$ Solutions at $25^{\circ} \mathrm{C}$ Modeling." Geochimica et Cosmochimica Acta, 53, 2823-2830. New York, New York: Pergamon Press. TIC: 235216.

41. Knauss, K.G. and Wolery, T.J. 1989. "Muscovite Dissolution Kinetics as a Function of pH and Time at $70^{\circ} \mathrm{C} . "$ Geochimica et Cosmochimica Acta, 53, 1493-1501. Elmsford, New York: Pergamon Press. TIC: 236215.

42. LA9912WR831372.004. EQ Database for $\mathrm{Np}, \mathrm{Pu}$, and Tc Solubility Calculations. Submittal date: $12 / 09 / 1999$.

43. Tsang, Y.W. 1992. "Usage of "Equivalent Apertures" for Rock Fractures as Derived from Hydraulic and Tracer Tests." Water Resources Research, 28, (5), 1451-1455. Washington, D.C.: American Geophysical Union. TIC: 245891. 
Title: Far-Field Accumulation of Fissile Material from Waste Packages Containing Plutonium Disposition Waste Forms

44. MO0006J13WTRCM.000. Recommended Mean Values of Major Constituents in J13 Well Water. Submittal date: 06/07/2000. Submit to RPC URN-0532.

45. CRWMS 2000. Process Control Evaluation for Supplement V: "Far-Field Accumulation of Fissile Material from Waste Packages Containing Plutonium Disposition Waste Forms (21019074M1)". Las Vegas, Nevada: CRWMS M\&O. ACC: MOL.20000830.0283.

\section{Reference Used in Attachment $V$}

46. Daveler, S.A. and Wolery, T.J. 1992. EQPT, A Data File Preprocessor for the EQ3/6 Software Package. User's Guide, and Related Documentation (Version 7.0). UCRLMA-110662 PT II. Livermore, California: Lawrence Livermore National Laboratory. TIC: 205240.

\section{References Used in Attachemnt VII}

47. MO9708RIB00040.000. RIB Item \#40/Rev. 0: Hydrologic Characteristics: Hydrogeologic Unit Characteristics. Submittal date: 08/29/1997. Submit to RPC URN-0534.

48. Parrington, J.R.; Knox, H.D.; Breneman, S.L.; Baum, E.M.; and Feiner, F. 1996. Nuclides and Isotopes, Chart of the Nuclides. 15th Edition. San Jose, California: General Electric Company and KAPL, Inc. TIC: 233705.

\section{Procedures}

49. AP-3.12Q, Rev. 0, ICN 2. Calculations. Washington, D.C.: U.S. Department of Energy, Office of Civilian Radioactive Waste Management. ACC: MOL.20000620.0068.

50. AP-SV.1Q, Rev. 0, ICN 2. Control of the Electronic Management of Information. Washington, D.C.: U.S. Department of Energy, Office of Civilian Radioactive Waste Management. ACC: MOL.20000831.0065.

51. AP-SI.1Q, Rev. 2, ICN 4. Software Management. Washington, D.C.: U.S. Department of Energy, Office of Civilian Radioactive Waste Management. ACC: MOL.20000223.0508. 
Title: Far-Field Accumulation of Fissile Material from Waste Packages Containing Plutonium Disposition Waste Forms

Document Identifier: CAL-EDC-GS-000002 REV 00

Page 80 of 80

\section{ATTACHMENTS}

A list of attachments to this calculation is provided below.

Attachment Title

I Derivation of the 3-D Point Source Concentration Distribution (2 pages)

II Dispersivity in Unsaturated Fractured Porous Media (2 pages)

III Example Input File (7 pages)

IV Files on Electronic Media Compact Disk-Read Only Memory (CD-ROM) (6 pages)

V User's Manual for transl.c (9 pages)

VI C Language Code for transl.c (24 pages)

VII Software Routines (3 pages)

VIII Electronic Media (CD-ROM) 
Title: Far-Field Accumulation of Fissile Material from Waste Packages Containing Plutonium Disposition Waste Forms

Document Identifier: CAL-EDC-GS-000002 REV 00

ATTACHMENT I, Page I-1 of I-2

\section{ATTACHMENT I}

\section{Derivation of the 3-D Point Source Concentration Distribution}

Bear (Ref. 3, p. 634, Eq. 10.6.37) states that the effect of an instantaneous slug of mass $d M=C_{o} Q d t$ is:

$$
d C(x, y, t)=\frac{d M}{2 \pi \sqrt{2 D_{x} t} \sqrt{2 D_{y} t}} \exp \left\{-\frac{(x-v t)^{2}}{4 D_{x} t}-\frac{y^{2}}{4 D_{y} t}\right\}
$$

where $q / n$ has been changed to $\mathrm{v}$ and $D^{\prime}$ and $D^{\prime \prime}$ have been changed to $\mathrm{D}_{\mathrm{x}}$ and $\mathrm{D}_{\mathrm{y}}$ following notations of Section 2.1. Eq. 2.6b of Section 2.1 is obtained by integrating Eq. I-1 through time to obtain a continuous source term. The purpose of this attachment is to integrate the corresponding 3-D equation written as follows:

$$
d C\left(x, y_{1}, y_{2}, t\right)=\frac{d M}{\sqrt{4 \pi D_{x} t} \sqrt{4 \pi D_{y} t} \sqrt{4 \pi D_{y} t}} \exp \left\{-\frac{(x-v t)^{2}}{4 D_{x} t}-\frac{y_{1}^{2}}{4 D_{y} t}-\frac{y_{2}^{2}}{4 D_{y} t}\right\}
$$

Eq. I-2 can be integrated following the same scheme that is displayed in Eq. 10.6 .38 of Ref. 3 to yield:

$$
C\left(x, y_{1}, y_{2}, t\right)=\int_{b=0}^{=t} \frac{C_{0} Q}{\sqrt{4 \pi D_{x}(t-\theta)} \sqrt{4 \pi D_{y}(t-\theta)} \sqrt{4 \pi D_{y}(t-\theta)}} \exp \left\{-\frac{(x-v(t-\theta))^{2}}{4 D_{x}(t-\theta)}-\frac{y_{1}^{2}}{4 D_{y}(t-\theta)}-\frac{y_{2}^{2}}{4 D_{y}(t-\theta)}\right\} d \theta
$$

and after rearranging:

$$
C\left(x, y_{1}, y_{2}, t\right)=\frac{C_{0} Q}{(4 \pi)^{3 / 2} \sqrt{2 D_{x} D_{y} D_{y}}} \exp \left(\frac{x v}{2 D_{x}}\right) \int_{\oint=0}^{\theta=t} \frac{1}{(t-\theta)^{3 / 2}} \exp \left\{-\left(\frac{y_{1}^{2}}{4 D_{y}}+\frac{y_{1}^{2}}{4 D_{y}}+\frac{y_{2}^{2}}{4 D_{y}}\right) \frac{1}{(t-\theta)}-\frac{v^{2}(t-\theta)}{4 D_{x}}\right\} d \theta
$$

A table of integrals (Ref. 28, p. 342, Eq. 3.478 - item 4) yields for $t=\infty$ (that is for steady concentrations):

$$
\int_{0}^{\infty} x^{\mathrm{v}-1} \exp \left(-\beta x^{p}-\gamma x^{-p}\right) d x=\frac{2}{p}\left(\frac{\gamma}{\beta}\right)^{\frac{\nu}{2 p}} K_{\frac{v}{p}}(2 \sqrt{\beta \gamma})
$$

where $\mathrm{K}_{v / \mathrm{p}}$ is the modified Bessel function of the second kind and $v / \mathrm{p}$ order. Comparing Eq. I-4 and I-5, we have:

$$
v-1=-3 / 2 \text { that is } v=-1 / 2, \mathrm{p}=1 \text { that is } v / \mathrm{p}=-1 / 2, \beta=\left(\frac{y_{1}^{2}}{4 D_{y}}+\frac{y_{1}^{2}}{4 D_{y}}+\frac{y_{2}^{2}}{4 D_{y}}\right) \text { and } \gamma=\frac{v^{2}}{4 D_{x}}
$$

By noting that (Ref. 29, Eq. 10.2.17): 
Waste Package Department

Calculation

Title: Far-Field Accumulation of Fissile Material from Waste Packages Containing Plutonium Disposition Waste Forms

Document Identifier: CAL-EDC-GS-000002 REV 00

ATTACHMENT I, Page I-2 of I-2

$$
K_{0.5}(x)=K_{-0.5}(x)=\sqrt{\frac{\pi}{2 x}} \exp (-x)
$$

Eq. $2.6 \mathrm{~b}$ is obtained. 
Title: Far-Field Accumulation of Fissile Material from Waste Packages Containing Plutonium Disposition Waste Forms

Document Identifier: CAL-EDC-GS-000002 REV 00 ATTACHMENT II, Page II-1 of II-2

\section{ATTACHMENT II}

\section{Dispersivity in Unsaturated Fractured Porous Media}

Dispersivity is a measure of the heterogeneity of a porous medium (Ref. 19, Chapter 5). Dispersivity is linearly proportional to the variance of the permeability and to the correlation length of the permeability field. Dispersivity in saturated porous media has been described in numerous books and papers (e.g., Refs. 3, 14, 15). The introduction of fractures and unsaturated conditions presents complications that affect the dispersivity in ways that are not as well understood. Heterogeneity increases with decreasing water saturation, because, for example, details of the arrangement of grains do not matter when the medium is saturated, but do matter when the saturation is low. Therefore, dispersivity increases with decreasing water saturation (Ref. 15, ). The introduction of fractures also causes an increase in dispersivity because the representative volume is increased relative to that of an unfractured porous medium.

A few recent publications (Refs. 16, 17, and 18) illustrate the increase in dispersivity due to decreasing water content in porous media. Haga et al. (Ref. 17, Fig. 8) show a factor of ten decrease in the Peclet Number, which is inversely related to dispersivity (Ref. 17, Eq. 4), from a fully saturated medium to a medium at minimal saturation. Data extracted from Padilla et al. (Ref. 16, Tables 1 and 2) displays the same behavior: about a factor of ten change in dispersivity between fully saturated and minimal saturation (Fig. II-1).

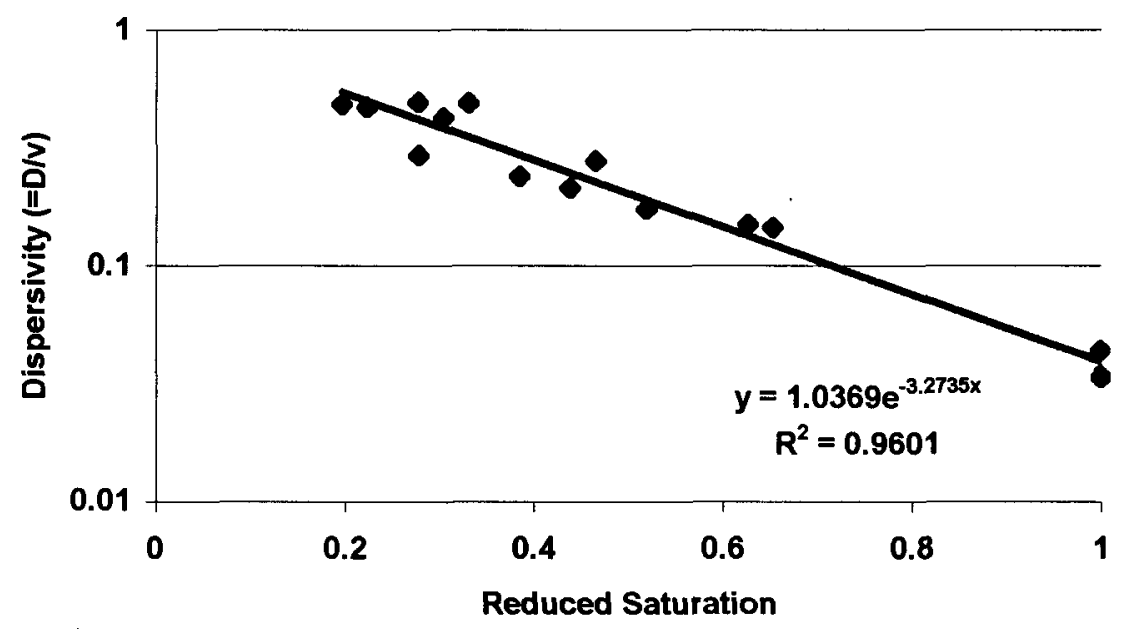

NOTE: Data from Ref. 16.

Figure II-1. Dispersivity vs Saturation

Ref. 18 deals with a field experiment and does not provide a clear relationship between saturation and dispersivity; however, the trend is the same (Ref. 18, Section 5). Other publications (Refs. 20 and 21) present results for saturated, fractured rock. Haldeman et al., 
Title: Far-Field Accumulation of Fissile Material from Waste Packages Containing Plutonium Disposition Waste Forms

Document Identifier: CAL-EDC-GS-000002 REV 00 ATTACHMENT II, Page II-2 of II-2

discussing results from a laboratory experiment, suggest that the longitudinal dispersivity is equal to the characteristic length of the system for saturated, fractured rock (Ref. 20, p. 63).

Very little information exists relative to the transverse dispersivity in a unsaturated/fractured medium. The general rule of thumb for uniform saturated medium is $10 \%$ of the longitudinal dispersivity (Ref. 14, Top of p. 66 cites a range of $1 / 6$ to $1 / 20$ that is $\sim 17 \%$ to $5 \%$ ). Ref. 18 (Section 5) cites from a field experiment in unsaturated medium a transverse dispersivity as high as 25 to $50 \%$ of the longitudinal dispersivity. 
Waste Package Department

Calculation

Title: Far-Field Accumulation of Fissile Material from Waste Packages Containing Plutonium Disposition Waste Forms

Document Identifier: CAL-EDC-GS-000002 REV $00 \quad$ ATTACHMENT III, Page III-1 of III-7

ATTACHMENT III

Example Input Files

\section{III -1 Base Case PHREEQC Input File}

Simplified Input file to illustrate precipitation mechanisms (file ST99_1.K_pH=8.8.dat)

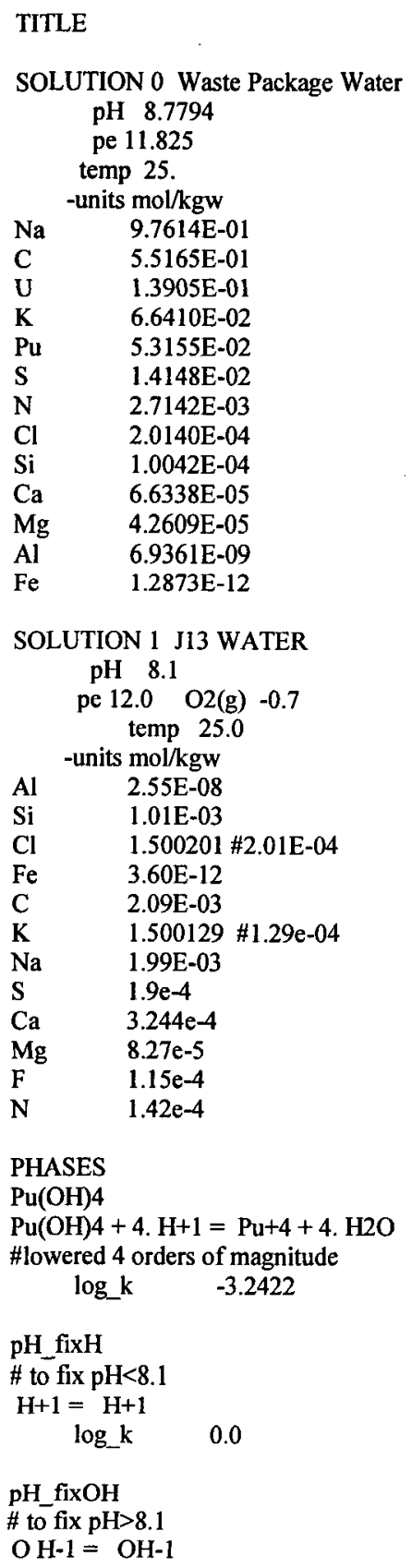


Waste Package Department

Calculation

Title: Far-Field Accumulation of Fissile Material from Waste Packages Containing Plutonium

Disposition Waste Forms

Document Identifier: CAL-EDC-GS-000002 REV $00 \quad$ ATTACHMENT III, Page III-2 of III-7

$\log k \quad 0.0$

EQUILIBRIUM_PHASES 0-1

$\begin{array}{lcc}\mathrm{CO} 2(\mathrm{~g}) & -3.0 & 9.9 \\ \mathrm{O} 2(\mathrm{~g}) & -0.7 & 9.9 \\ \text { \#pH_fixH } & -8.0 \mathrm{HCl} \\ \mathrm{pH} \_ \text {fixOH } & -5.2 \mathrm{KOH} \quad \#(5.2+8.8=14)\end{array}$

MIX 1

00.01

10.99

INCREMENTAL REACTIONS false

EQUILIBRIUM_PHASES 1

Haiweeite $\quad 0.0 \quad 0.0$

$\begin{array}{lll}\text { Calcite } & 0.0 & 0.0\end{array}$

$\begin{array}{lll}\text { Magnesite } 0.0 & 0.0 & \\ \text { Chalcedony } & 0.0 & 0.0\end{array}$

Diaspore $\quad 0.0 \quad 0.0$

$\begin{array}{lll}\text { Goethite } & 0.0 & 0.0\end{array}$

Boehmite $\quad 0.0 \quad 0.0$

$\begin{array}{lll}\mathrm{Pu}(\mathrm{OH}) 4 & 0.0 & 0.0\end{array}$

$\begin{array}{lll}\text { Soddyite } & 0.0 & 0.0\end{array}$

$\begin{array}{lll}\text { Schoepite } & 0.0 & 0.0\end{array}$

END

\section{III -2 Base Case PHREEQC Input File}

Input file for Base Case (Case A)

TITLE concentrations at time 2,500 years pe0a1231 - old database

SOLUTION 0 Waste Package Water

pH 8.7794

pe 11.825

temp 25.

-units $\mathrm{mol} / \mathrm{kgw}$

$\mathrm{Na} \quad 9.7614 \mathrm{E}-01$

C $\quad 5.5165 \mathrm{E}-01$

$\mathrm{U} \quad 1.3905 \mathrm{E}-01$

Cr $\quad 1.3167 \mathrm{E}-01$

B $\quad 9.7868 \mathrm{E}-02$

$\mathrm{K} \quad 6.6410 \mathrm{E}-02$

$\mathrm{Pu}$ 5.3155E-02

$\mathrm{S} \quad 1.4148 \mathrm{E}-02$

F $\quad 4.0338 \mathrm{E}-03$

$\mathrm{N} \quad 2.7142 \mathrm{E}-03$

$\mathrm{Np} \quad 5.3664 \mathrm{E}-04$

Cl $2.0140 \mathrm{E}-04$

$\mathrm{Si} \quad$ 1.0042E-04

$\mathrm{Ca} \quad 6.6338 \mathrm{E}-05$

$\mathrm{Mg} \quad 4.2609 \mathrm{E}-05$

$\mathrm{Li} \quad 6.9154 \mathrm{E}-06$

Gd 2.6408E-07

$\mathrm{P} \quad$ 1.6192E-07

$\mathrm{Ni} \quad 3.1497 \mathrm{E}-08$

Al 6.9361E-09

$\mathrm{Ba} \quad 1.0341 \mathrm{E}-09$

$\mathrm{Zr} \quad 6.1769 \mathrm{E}-10$

$\mathrm{Ti} \quad 2.0614 \mathrm{E}-10$

$\mathrm{Fe} \quad 1.2873 \mathrm{E}-12$

\#Mn 4.3219E-16

$\# \mathrm{Cu} \quad 1.0000 \mathrm{E}-16$ 
Waste Package Department

Calculation

Title: Far-Field Accumulation of Fissile Material from Waste Packages Containing Plutonium Disposition Waste Forms

Document Identifier: CAL-EDC-GS-000002 REV $00 \quad$ ATTACHMENT III, Page III-3 of III-7

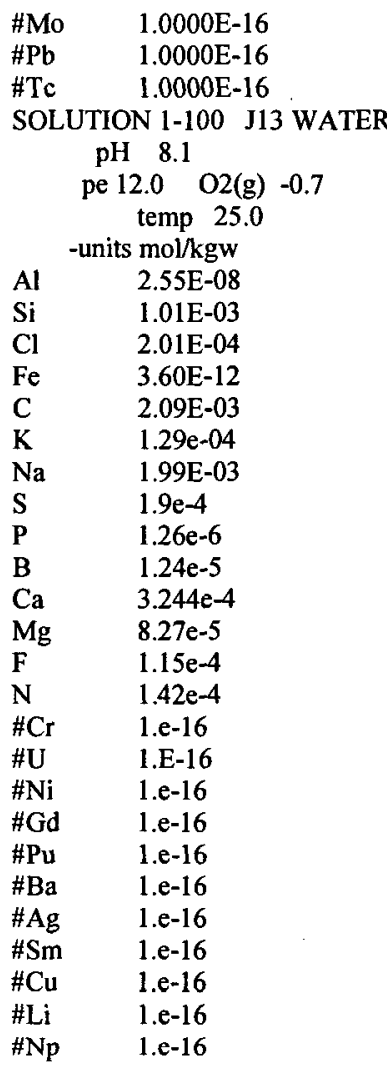

SOLUTION_SPECIES

$\mathrm{H} 2 \mathrm{O}+0.01 \mathrm{e}-=\mathrm{H} 2 \mathrm{O}-0.01$ $\log _{-} k \quad-9.0$

PHASES

$\mathrm{Pu}(\mathrm{OH}) 4$

$\mathrm{Pu}(\mathrm{OH}) 4+4 . \mathrm{H}+\mathrm{l}=\mathrm{Pu}+4+4 . \mathrm{H} 2 \mathrm{O}$

\#lowered 4 orders of magnitude

$\log _{-} k \quad-3.2422$

EQUILIBRIUM_PHASES 0-100

$\begin{array}{lrr}\mathrm{CO} 2(\mathrm{~g}) & -3.0 & 9.9\end{array}$

$\mathrm{O} 2(\mathrm{~g})$

$-0.7 \quad 9.9$

PRINT

-saturation_indices false -species false

SAVE SOLUTION 0-100

END

SOLUTION 999 J13 WATER

$$
\mathrm{pH} 8.1
$$$$
\text { pe } 12.0 \quad \mathrm{O} 2(\mathrm{~g})-0.7
$$$$
\text { temp } 25.0
$$

Al $\quad \begin{aligned} \text {-units mol } / \mathrm{kgw} \\ 2.55 \mathrm{E}-08\end{aligned}$

Si $\quad 1.01 \mathrm{E}-03$

Cl $\quad 2.01 \mathrm{E}-04$

$\mathrm{Fe} \quad 3.60 \mathrm{E}-12$

C $\quad 2.09 \mathrm{E}-03$

$\mathrm{K} \quad 129 \mathrm{e}-04$

$\mathrm{Na} \quad 1.99 \mathrm{E}-03$

$\mathrm{S} \quad 1.9 \mathrm{e}-4$ 
Waste Package Department

Calculation

Title: Far-Field Accumulation of Fissile Material from Waste Packages Containing Plutonium Disposition Waste Forms

Document Identifier: CAL-EDC-GS-000002 REV $00 \quad$ ATTACHMENT III, Page III-4 of III-7

\begin{tabular}{lll}
$\mathrm{P}$ & $1.26 \mathrm{e}-6$ \\
$\mathrm{~B}$ & $1.24 \mathrm{e}-5$ & \\
$\mathrm{Ca}$ & $3.244 \mathrm{e}-4$ & \\
$\mathrm{Mg}$ & $8.27 \mathrm{e}-5$ & \\
$\mathrm{~F}$ & $1.15 \mathrm{e}-4$ & \\
$\mathrm{~N}$ & $1.42 \mathrm{e}-4$ & \\
\#Cr & $1 . \mathrm{e}-16$ \\
\#U & $1 . \mathrm{E}-16$ & \\
\#Ni & $1 . \mathrm{e}-16$ & \\
\#Gd & $1 . \mathrm{e}-16$ & \\
\#Pu & $1 . \mathrm{e}-16$ & \\
\#Ba & $1 . \mathrm{e}-16$ & \\
\#Ag & $1 . \mathrm{e}-16$ & \\
\#Sm & $1 . \mathrm{e}-16$ & \\
\#Cu & $1 . \mathrm{e}-16$ & \\
\#Li & $1 . \mathrm{e}-16$ & \\
\#Np & $1 . \mathrm{e}-16$ & \\
EQUILIBRIUM_PHASES 999 & \\
CO2(g) & \multicolumn{2}{c}{-3.0} \\
O2(g) & 9.9 \\
SAVE SOLUTION 999 & \\
SA & \\
END &
\end{tabular}

USE SOLUTION 0-100

USE SOLUTION 999

EQUILIBRIUM_PHASES 1-100

$0.0 \quad 0.0$

$\begin{array}{lll}\mathrm{GdOHCO} 3 & 0.0 & 0.0\end{array}$

GdPO4: $\mathrm{H} 2 \mathrm{O} \quad 0.0 \quad 0.0$

Haiweeite $\quad 0.0 \quad 0.0$

$\begin{array}{lll}\text { Calcite } & 0.0 & 0.0\end{array}$

$\begin{array}{lll}\text { Magnesite } 0.0 & 0.0 & \\ \text { Chalcedony } & 0.0 & 0.0\end{array}$

\#Dolomite $\quad 0.0 \quad 0.0$

$\begin{array}{lll}\text { Diaspore } & 0.0 & 0.0\end{array}$

$\begin{array}{lll}\text { Goethite } & 0.0 & 0.0\end{array}$

$\begin{array}{lll}\text { Clinoptilolite-Ca } \quad 0.0 & 0.0\end{array}$

$\begin{array}{lll}\text { Clinoptilolite-K } & 0.0 & 0.0\end{array}$

Clinoptilolite-Na $\quad 0.0 \quad 0.0$

$\begin{array}{lll}\text { Saponite-Ca } & 0.0 & 0.0\end{array}$

$\begin{array}{lll}\text { Saponite-H } & 0.0 & 0.0\end{array}$

$\begin{array}{lll}\text { Saponite-K } & 0.0 & 0.0\end{array}$

Saponite-Mg $\quad 0.0 \quad 0.0$

$\begin{array}{lll}\text { Saponite-Na } & 0.0 & 0.0\end{array}$

$\begin{array}{lll}\text { Nontronite-Ca } & 0.0 & 0.0\end{array}$

$\begin{array}{lll}\text { Nontronite-K } & 0.0 & 0.0\end{array}$

Nontronite-Mg $\quad 0.0 \quad 0.0$

$\begin{array}{lll}\text { Nontronite-Na } & 0.0 & 0.0\end{array}$

$\begin{array}{lll}\text { Boehmite } & 0.0 & 0.0\end{array}$

$\mathrm{Pu}(\mathrm{OH}) 4 \quad 0.0 \quad 0.0$

$\begin{array}{lll}\mathrm{Ni} 2 \mathrm{SiO} 4 & 0.0 & 0.0\end{array}$

$\begin{array}{lll}\text { Soddyite } & 0.0 & 0.0\end{array}$

$\begin{array}{lll}\text { Schoepite } & 0.0 & 0.0\end{array}$

\#Na4UO2(CO3)3 $0.0 \quad 0.0$

$\begin{array}{lll}\mathrm{UO} 2 \mathrm{CO} 3 & 0.0 & 0.0\end{array}$

$\mathrm{UO2}(\mathrm{OH}) 2$ (beta) $\quad 0.0 \quad 0.0$

$\begin{array}{lll}\mathrm{Na} 2 \mathrm{U} 2 \mathrm{O} 7 & 0.0 & 0.0\end{array}$

$\begin{array}{lll}\mathrm{CaUO} & 0.0 & 0.0\end{array}$

$\begin{array}{lll}\text { \#Kasolite } & 0.0 & 0.0\end{array}$

$\begin{array}{lll}\mathrm{CO} 2(\mathrm{~g}) & -3.0 & 9.9\end{array}$

$\begin{array}{lll}\mathrm{O} 2(\mathrm{~g}) & -0.7 & 9.9\end{array}$

RATES

Cristobalite(alpha)

-start

300 SR_crst $=$ SR $("$ Cristobalite(alpha)" $)$ 
Title: Far-Field Accumulation of Fissile Material from Waste Packages Containing Plutonium Disposition Waste Forms Document Identifier: CAL-EDC-GS-000002 REV $00 \quad$ ATTACHMENT III, Page III-5 of III-7

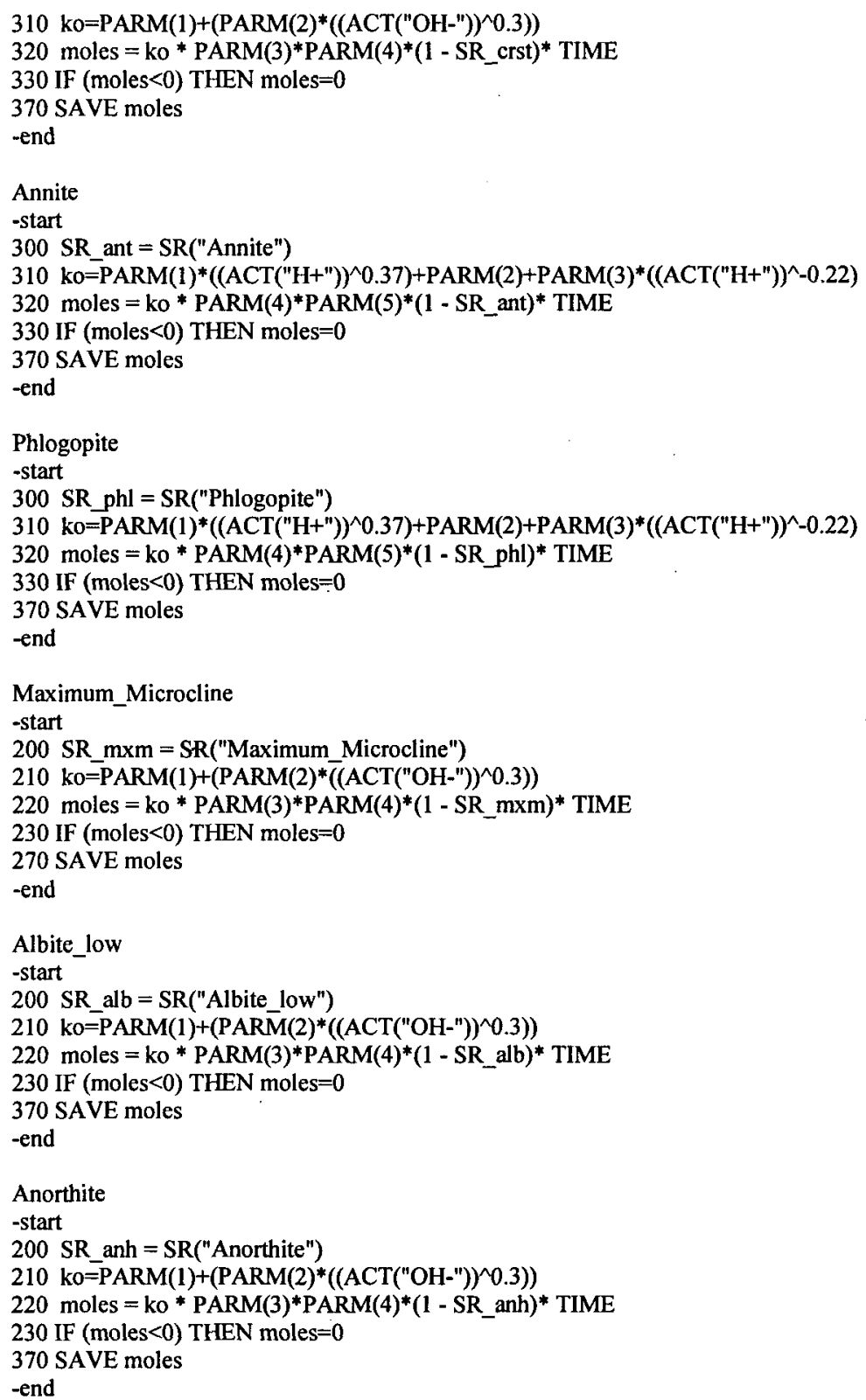


Title: Far-Field Accumulation of Fissile Material from Waste Packages Containing Plutonium Disposition Waste Forms

\begin{tabular}{|c|c|c|c|c|c|}
\hline & -parms & 1.e-16 & $2.5 \mathrm{e}-15$ & 0.276489793 & 1000000 \\
\hline $10 \mathrm{v}$ & & & & & \\
\hline & $-\mathrm{m}$ & 100.0 & & & \\
\hline & -parms & 1.e-16 & $2.5 \mathrm{e}-15$ & 0.305706489 & 1000000 \\
\hline & $-m$ & 100.0 & & & \\
\hline & -parms & 1.e-16 & $2.5 e-15$ & 0.027959037 & 100000 \\
\hline
\end{tabular}

\#TRANSPORT

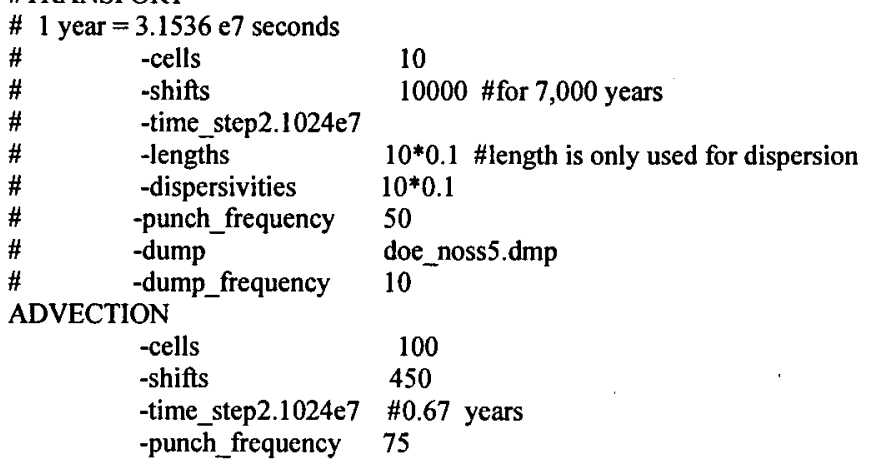

\section{SELECTED OUTPUT}

$$
\text { -file pe0a1231.xls }
$$

-totals Al Si Cr U Cl Fe C K Na S P B Ca Mg F N Ni Gd Pu Ba Ag Sm Li Ti Mn Cu Np -equilibrium phases GdOHCO3 GdPO4:H2O Calcite Dolomite Diaspore Goethite Clinoptilolite-Ca Clinoptilolite-K

Clinoptilolite-Na Saponite-Ca Saponite-H Saponite-K Saponite-Mg Saponite-Na Nontronite-Ca Nontronite-K Nontronite-Mg Nontronite-Na Boehmite $\mathrm{Pu}(\mathrm{OH}) 4 \mathrm{Ni2SiO} 4$ Soddyite Schoepite Chalcedony Haiweeite O2(g) CO2(g) Na4UO2(CO3)3 UO2CO3 UO2(OH)2(beta) Na2U2O7 CaUO4 Kasolite

-kinetic_reactants Cristobalite(alpha) Annite Phlogopite Maximum_Microcline Albite_low Anorthite -saturation indices $\mathrm{Pu}(\mathrm{OH}) 4$ Soddyite Schoepite Uraninite Haiweeite $\mathrm{Na} 4 \mathrm{UO} 2(\mathrm{CO} 3) 3 \mathrm{UO} 2 \mathrm{CO} 3 \mathrm{UO} 2(\mathrm{OH}) 2$ (beta) Na2U2O7

CaUO4 Kasolite Cristobalite(alpha) Chalcedony Annite Phlogopite Maximum_Microcline Albite low Anorthite Calcite Magnesite Rhodochrosite Siderite Smithsonite Strontianite Dolomite Goethite O2(g) CO2(g) Clinoptilolite-Ca Clinoptilolite-Cs Clinoptilolite-K Clinoptilolite-NH4 Clinoptilolite-Na Clinoptilolite-Sr Saponite-Ca Saponite-H Saponite-K Saponite-Mg Saponite-Na Beidellite-Ca Beidellite-K Beidellite-Mg Beidellite-Na Montmor-Ca Montmor-K Montmor-Mg Montmor-Na Nontronite-Ca Nontronite-K Nontronite-Mg Nontronite-Na LaPO4:H2O CePO4:H2O NdPO4:H2O GdPO4:H2O SmPO4:H2O

\# $\quad$-solid solutions Calcite Magnetite Rhodochrosite Siderite Smithsonite Strontianite Clinoptilolite-Ca Clinoptilolite-Cs

Clinoptilolite-K Clinoptilolite-NH4 Clinoptilolite-Na Clinoptilolite-Sr Saponite-Ca Saponite-H Saponite-K Saponite-Mg Saponite-Na Beidellite-Ca Beidellite-K Beidellite-Mg Beidellite-Na Montmor-Ca Montmor-K Montmor-Mg Montmor-Na Nontronite-Ca Nontronite-K Nontronite-Mg Nontronite-Na LaPO4:H2O CePO4:H2O NdPO4:H2O GdPO4:H2O SmPO4:H2O -molalities CO3-2 HCO3-1 (PuO2)3(CO3)6-6 PuO2(CO3)2-2 PuO2(CO3)2-3 PuO2(CO3)3-5 PuO2(CO3)3-4 PuO2CO3

(UO2)3(CO3)6-6 UO2(CO3)2-2 UO2(CO3)3-5 UO2(CO3)3-4 UO2CO3

-time true
-step true
-ionic_strength true

PRINT

$$
\text { -reset false }
$$

KNOBS

$$
\text { -selected_output true }
$$

MIX 1

10.9

$\begin{array}{lll}999 & 0.1\end{array}$

MIX 2

20.9

$\begin{array}{lll}999 & 0.1\end{array}$

MIX 99

990.9

$\begin{array}{lll}999 & 0.1\end{array}$

MIX 100

1000.9 
Waste Package Department

Calculation

Title: Far-Field Accumulation of Fissile Material from Waste Packages Containing Plutonium Disposition Waste Forms

Document Identifier: CAL-EDC-GS-000002 REV 00 ATTACHMENT III, Page III-7 of III-7

9990.1

INCREMENTAL_REACTIONS false

END

\# This command will write a dummy file into the Phreeqc directory at the end of the run

\# thus fixing the ending time of run

SELECTED_OUTPUT

END 
Title: Far-Field Accumulation of Fissile Material from Waste Packages Containing Plutonium Disposition Waste Forms

\section{ATTACHMENT IV-FILES ON ELECTRONIC MEDIA (CD-ROM)}

All the input, output, and pre- and post-processing files related to this calculation have been copied to a CD-ROM (Attachment VIII). Details about the organization of the CD-ROM and a list of files follow.

The files are organized into five sections. The general files and the files related to the database translation are presented below. The three remaining sections comprise run files whose nomenclature is detailed in the new paragraph. The files "dispersion..." describe particular cases of the equations presented in Section 2.1.2. The file expo-VG.xls computes the $\alpha$ of the exponential form of the permeability (Section 2.1.1). The files PuAccProfile_pe0a1231.xls and PuAccProfile_pw2a1231.xls present summary of the results and contain plots and tables described in the report. The file sat_calc.xls computes the fracture saturation for a given flow rate and fracture geometry.

The directory Database_files contains the routine transl text (transl.c), parameter (watersys.dat) and executable (transl.exe) files, the EQ6 source thermodynamic databases (data0.nuc.R8s and data0.nuc.R8a) and the output PHREEQC thermodynamic databases used in this calculation (phreeqc.nucR8s_25 and phreeqc.nuc_25).

The directory J13ww contains PHREEQC input, output and post-processing files related to the setup of the J-13 well water.

The directory Why_ppt contains PHREEQC input (*.dat) and output $\left({ }^{*}\right.$.out) files used to justify the use of dilution in this calculation. Details about the files are given in Section 2.1.4.

\section{File Name}

dispersion_linesource.xls

dispersion_pointsource.xls

dispersion_pointsource_plot.xls

expo-VG.xls

PuAccProfile_pe0a1231.xls

PuAccProfile_pw2a1231.xls

sat_calc.xls

Tuff_composition.xls

\section{Size (bytes) Date Time}

$7,251,456 \quad 09-08-00 \quad 1: 26 \mathrm{pm}$

$3,810,816 \quad 09-08-00 \quad 1: 26 \mathrm{pm}$

247,808 09-08-00 $\quad 1: 29 \mathrm{pm}$

$55,808 \quad 09-08-00 \quad 1: 35 \mathrm{pm}$

$501,248 \quad 09-08-00 \quad 1: 38 \mathrm{pm}$

$183,296 \quad 09-08-00 \quad 1: 39 \mathrm{pm}$

$130,048 \quad 09-08-00 \quad 1: 45 \mathrm{pm}$

$39,936 \quad 09-08-00 \quad 6: 51 \mathrm{pm}$

$\begin{array}{rll}2,299,784 & 11-25-98 & 9: 15 \mathrm{pm} \\ 2,299,935 & 11-09-99 & 7: 47 \mathrm{pm} \\ 228,515 & 09-11-99 & 4: 47 \mathrm{pm} \\ 228,522 & 11-15-99 & 6: 47 \mathrm{pm} \\ 45,460 & 09-11-99 & 4: 37 \mathrm{pm} \\ 245,809 & 09-11-99 & 4: 47 \mathrm{pm} \\ 349 & 09-11-99 & 4: 21 \mathrm{pm}\end{array}$

349 09-11-99

$4: 21 \mathrm{pm}$

\section{Directory: Database_files}

data0.nuc.R8a

data0.nuc.R8s

phreeqc.nuc_25

phreeqc.nucR8s_25

transl.c

transl.exe

watersys.dat 
Title: Far-Field Accumulation of Fissile Material from Waste Packages Containing Plutonium Disposition Waste Forms

Document Identifier: CAL-EDC-GS-000002 REV 00 ATTACHMENT IV, Page IV-2 of IV-6

Directory: J13ww

J13ww.dat

J13ww.out

J13ww.xls

Directory: Why_ppt

ST1.dat

ST1.out

$\mathrm{ST} 1 \_\mathrm{pH}=8.0$.dat

ST1_pH=8.0.out

ST75.dat

ST75.out

ST75_NoNa_pH=8.52.dat

ST75_NoNa_pH $=8.52$.out

ST99.dat

ST99.out

ST99 2K.dat

ST99_2K.out

ST99_0.1K.dat

ST99 0.1K.out

ST99 1.5 K.dat

ST99 1.5K.out

ST99 $1.5 \mathrm{~K}$ pH=8.8.dat

ST99_1.5K_pH=8.8.out

ST99 $\mathrm{pH}=8.8$.dat

ST99 $\mathrm{pH}=8.8$.out
$552 \quad 06-30-00$

82,153 $06-30-00$

$19,456 \quad 09-22-00$

1,161 05-17-00

$139,462 \quad 05-17-00$

$1,436 \quad 05-17-00$

140,045 05-17-00

$1,161 \quad 05-18-00$

139,466 05-18-00

$1,421 \quad 05-18-00$

126,746 05-18-00

$1,161 \quad 05-17-00$

$139,466 \quad 05-17-00$

$1,182 \quad 05-17-00$

139,493 05-17-00

$1,182 \quad 05-17-00$

$139,501 \quad 05-17-00$

1,182 05-17-00

$139,494 \quad 05-17-00$

$1,436 \quad 05-17-00$

$140,064 \quad 05-17-00$

$1,415 \quad 05-17-00$

$141,269 \quad 05-17-00$
$12: 54 \mathrm{pm}$

$12: 55 \mathrm{pm}$

10:05 am

$4: 52 \mathrm{pm}$

$4: 52 \mathrm{pm}$

$7: 47 \mathrm{pm}$

$7: 47 \mathrm{pm}$

$7: 47 \mathrm{pm}$

$7: 47 \mathrm{pm}$

$8: 37 \mathrm{pm}$

$8: 40 \mathrm{pm}$

$5: 09 \mathrm{pm}$

5:09 pm

$5: 59 \mathrm{pm}$

6:00 pm

$5: 15 \mathrm{pm}$

$5: 16 \mathrm{pm}$

$5: 26 \mathrm{pm}$

$5: 27 \mathrm{pm}$

$7: 33 \mathrm{pm}$

$7: 34 \mathrm{pm}$

$10: 53 \mathrm{pm}$

$10: 54 \mathrm{pm}$

Run files have the following format:

xxxxx_: first field represents the EQ6 generated source term;

(calcul, )_: second field is optional and applies only to the processed outputs;

$\mathrm{SA}=\mathrm{x} \_$: third field gives the surface area in $10^{3} \mathrm{~cm}^{2}$;

(all,half,all)_: fourth field refers to the presence and decay of the Pu:

- all: all the Pu is present

- half: half of the Pu is decayed into U

- no: all the Pu is decayed into $\mathrm{U}$

(NoDil, dil $=20 \%$, dil=5\%, varmix, mod, multi, withDol, withHem).: fifth field represents selfexplanatory variations from the base case:

- NoDil: no mixing with J13 water' 
Title: Far-Field Accumulation of Fissile Material from Waste Packages Containing Plutonium Disposition Waste Forms

Document Identifier: CAL-EDC-GS-000002 REV 00

ATTACHMENT IV, Page IV-3 of IV-6

- dil $=20 \%$ : dilution is $20 \%$

- dil $=5 \%$ : dilution is $5 \%$

- varmix: the mixing is variable according to Figure 2-3

- mod: the source term has been modified to the new equilibrium when half or all of the Pu has decayed to $U$.

- multi: run with multiple source terms

- withDol: dolomite not suppressed

- withHem: hematite used instead of goethite.

(dat,txt,xls): sixth field represents either input $\left({ }^{*}\right.$. dat $)$, output $\left({ }^{*}\right.$. out $)$ or processed $\left({ }^{*} \cdot\right.$.xls $)$ file.

File Name

Directory: Pu_MOX

mox03ap2_calcul_SA=20_all.xls

mox03ap2 calcul SA $=20$ all_NoDil.xls

mox03ap2_Elem_aqu_all.txt

mox03ap2_Elem_aqu_all.xls

mox03ap2_SA $=1,000$ all.dat

mox03ap2_SA=1,000_all.xls

mox03ap2 $\mathrm{SA}=1$ all. $\overline{d a t}$

mox03ap2 $\mathrm{SA}=1$ all.xls

mox03ap2_SA $=20$ _all.dat

mox03ap2_SA $=20$ all.xls

mox03ap2 $\mathrm{SA}=20$ all NoDil.dat

mox03ap2_SA $=20 \_$all_NoDil.xls

Directory: Pu_pe0a1231

pe0a1231.elem_aqu.txt

pe0a1231.elem aqu.xls

pe0a1231_calcul_multi.xls

pe0a1231_calcul_SA $=0.001$ all_NOdil.xls

pe0a1231_calcul_SA $=0$ all.xls

pe0a1231_calcul_SA $=1,000$ all.xls

pe0a1231_calcul_SA $=1,000$ all_NOdil.xls

pe0a1231 calcul_SA $=1,000$ all varmix.xls

pe0a1231_calcul $S A=1,000$ half.xls

pe0a1231_calcul_SA $=1,000$ no.xls

pe0a1231_calcul_SA $=1,000$ NOdil_half.xls

pe0a1231_calcul_SA $=100$ all.xls

pe0a1231 calcul SA $=100$ all NOdil.xls

pe0a1231_calcul_SA=1_all.xls
Size (bytes) Date Time

$\begin{array}{rcc}449,536 & 01-24-00 & 5: 48 \mathrm{am} \\ 404,480 & 01-21-00 & 9: 44 \mathrm{pm} \\ 46,828 & 01-20-00 & 5: 13 \mathrm{pm} \\ 442,880 & 01-21-00 & 10: 00 \mathrm{pm} \\ 10,446 & 01-21-00 & 5: 48 \mathrm{pm} \\ 471,240 & 01-23-00 & 4: 06 \mathrm{pm} \\ 10,427 & 12-24-99 & 3: 21 \mathrm{am} \\ 1,413,992 & 12-26-99 & 11: 08 \mathrm{am} \\ 10,434 & 12-24-99 & 3: 21 \mathrm{am} \\ 1,413,992 & 12-28-99 & 2: 40 \mathrm{pm} \\ 7,100 & 12-24-99 & 3: 21 \mathrm{am} \\ 1,413,992 & 12-26-99 & 3: 44 \mathrm{am}\end{array}$

34,416 12-01-99

264,704 01-13-00

2,384,384 02-02-00

581,632 05-17-00

$412,672 \quad 01-27-00$

1,250,304 06-29-00

$1,256,448 \quad 01-14-00$

$538,112 \quad 01-24-00$

496,128 01-20-00

244,224 01-20-00

634,368 $01-17-00$

901,120 01-18-00

584,192 05-18-00

$1,807,872$ 01-14-00

$7: 58 \mathrm{pm}$

$11: 13 \mathrm{pm}$

$9: 58 \mathrm{pm}$

$7: 12 \mathrm{pm}$

$8: 15 \mathrm{pm}$

$12: 05 \mathrm{pm}$

$3: 13 \mathrm{pm}$

5:00 am

$4: 44 \mathrm{am}$

4:48 am

$3: 09 \mathrm{pm}$

$12: 11 \mathrm{am}$

$1: 31 \mathrm{pm}$

$4: 07 \mathrm{pm}$ 
Title: Far-Field Accumulation of Fissile Material from Waste Packages Containing Plutonium Disposition Waste Forms

Document Identifier: CAL-EDC-GS-000002 REV 00

ATTACHMENT IV, Page IV-4 of IV-6

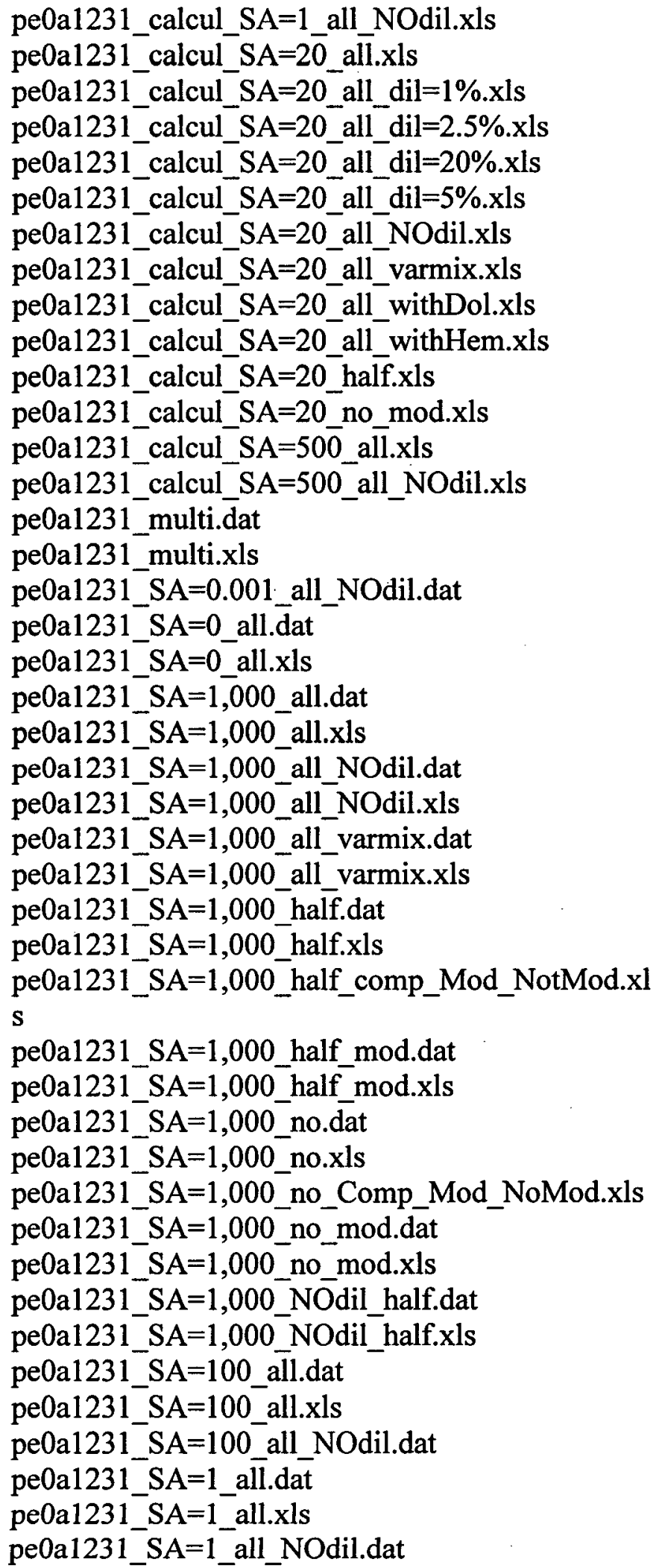

\begin{tabular}{|c|c|c|}
\hline & & \\
\hline 400 & $9-00$ & \\
\hline 588,28 & $7-00$ & \\
\hline 588,800 & $7-00$ & \\
\hline 81 & 00 & \\
\hline 582,6 & $8-00$ & \\
\hline 217 & $4-00$ & \\
\hline 202,7 & $4-00$ & \\
\hline 49 & 0 & \\
\hline & & \\
\hline 64 & 0 & \\
\hline & & \\
\hline 620 & $-24-00$ & \\
\hline & & \\
\hline 228 & $-15-00$ & \\
\hline 20 & & \\
\hline 7,0 & & \\
\hline & $-27-00$ & $1: 1$ \\
\hline 474,4 & $-27-00$ & \\
\hline 10,3 & $-22-99$ & \\
\hline 471,2 & $-23-99$ & \\
\hline & 0 & \\
\hline 413,5 & .00 & \\
\hline 11,9 & -20 & $7: 1$ \\
\hline 471,2 & 0 & \\
\hline & 0 & \\
\hline 708,9 & 0 & \\
\hline 150,5 & & \\
\hline & & \\
\hline 471,2 & & \\
\hline & & \\
\hline 708,9 & 0 & \\
\hline 130,0 & $24-00$ & \\
\hline 10 , & 0 & \\
\hline 471,240 & $-20-00$ & $5: 4$ \\
\hline $7,0^{\prime}$ & $-14-00$ & \\
\hline 471,240 & $-17-00$ & \\
\hline & & \\
\hline 413,992 & $2-27-99$ & $5: 3$ \\
\hline & & \\
\hline 10,372 & $2-22-99$ & $7: 2$ \\
\hline$, 413,9$ & $25-99$ & \\
\hline 70 & 7 & \\
\hline
\end{tabular}


Title: Far-Field Accumulation of Fissile Material from Waste Packages Containing Plutonium Disposition Waste Forms

Document Identifier: CAL-EDC-GS-000002 REV 00

ATTACHMENT IV, Page IV-5 of IV-6

pe0a1231 $\mathrm{SA}=20$ all.dat

pe0a1231_SA=20_all.xls

pe0a1231_SA $=20 \_$all_dil $=1 \%$.dat

pe0a1231_SA $=20 \_$all_dil $=2.5 \%$.dat

pe0a1231_SA $=20$ all_dil $=20 \%$.dat

pe0a1231_SA $=20$ all_dil $=20 \% . x \mathrm{xls}$

pe0a1231_SA $=20$ all_dil $=5 \%$.dat

pe0a1231_SA $=20 \_$all_dil $=5 \% . x \mathrm{~s}$

pe0a1231_SA $=20$ all_NOdil.dat

pe0a1231 $\mathrm{SA}=20$ all NOdil.xls

pe0a1231_SA $=20$ all_varmix.dat

pe0a1231_SA $=20$ all_varmix.xls

pe0a1231_SA=20_all_withDol.dat

pe0a1231_SA $=20 \_$all_withDol.xls

pe0a1231 $\mathrm{SA}=20$ all withHem.dat

pe0a1231_SA $=20$ all_withHem.xls

pe0a1231_SA $=20$ half.dat

pe0a1231_SA=20_no_mod.dat

pe0a1231_SA=20_no_mod.xls

pe0a1231_SA $=500$ all.dat

pe0a1231_SA=500_all.xls

pe0a1231_SA=500_all_NOdil.dat

pe0s1231.elem_aqu.txt

pe0s1231.elem_aqu.xls

pe0s1231_calcul_SA=20_all_newdb.xls

pe0s1231_SA $=20$ all_newdb.dat

pe0s1231_SA=20_all_newdb.xls

\section{Directory: Pu_PW2a1231}

PW2a1231.elem_aqu.txt

PW2a1231.elem_aqu.xls

PW2a1231_calcul_SA=1,000_all_4,050.xls

PW2a1231_calcul_SA $=1,000$ all 7,940.xls

PW2a1231_calcul_SA $=1,000$ _half_4050.xls

pw2a1231_calcul_SA=1,000_half_7,940_mod.xls

PW2a1231_calcul_SA=1,000_no_4050.xls

PW2a1231_calcul SA=1,000 no 7940 mod.xls

PW2a1231 calcul $S A=20$ all $4050 . x 1 s$

PW2a1231_calcul_SA=20_all_7,940.xls

PW2a1231_calcul_SA=20_half_4050.xls

pw2a1231_calcul_SA $=20$ half 7940 mod.xls

PW2a1231_calcul_SA=20_no_4050.xils

pw2a1231_calcul_SA=20 no 7940 mod.xls

PW2a1231_SA $=\overline{1}, 000$ all_4,050.dat
$10,379 \quad 12-21-99$

$708,909 \quad 12-22-99$

$10,578 \quad 05-15-00$

$10,774 \quad 05-15-00$

$10,378 \quad 12-22-99$

$1,413,992 \quad 12-25-99$

$10,578 \quad 12-22-99$

$1,413,992 \quad 12-24-99$

7,043 01-14-00

$1,413,992 \quad 01-15-00$

$11,888 \quad 01-23-00$

474,492 01-24-00

$10,377 \quad 12-22-99$

$1,413,992 \quad 12-26-99$

$10,415 \quad 02-02-00$

$482,370 \quad 02-02-00$

$10,508 \quad 01-21-00$

$10,515 \quad 01-21-00$

$1,413,99201-22-00$

$10,384 \quad 01-23-00$

471,240 01-24-00

7,049 05-17-00

$34,416 \quad 12-01-99$

$119,808 \quad 12-22-99$

705,024 05-21-00

$10,535 \quad 12-22-99$

$1,245,184 \quad 12-23-99$

31,736 01-13-00

406,016 01-31-00

201,216 01-20-00

546,304 01-20-00

$192,512 \quad 01-24-00$

248,832 01-20-00

188,928 01-24-00

$219,136 \quad 02-02-00$

195,584 01-24-00

201,216 01-24-00

$192,000 \quad 01-24-00$

$197,120 \quad 01-24-00$

$189,440 \quad 01-24-00$

227,840 01-31-00

$10,286 \quad 01-20-00$
$6: 16 \mathrm{pm}$

2:09 pm

$11: 18 \mathrm{pm}$

$11: 16 \mathrm{pm}$

7:43 pm

10:38 am

7:43 pm

6:04 am

3:33 pm

9:32 am

8:17 pm

12:04 am

7:26 pm

2:19 pm

2:20 pm

8:29 pm

9:06 pm

9:04 pm

2:33 pm

$10: 52 \mathrm{pm}$

1:24 pm

3:45 pm

8:20 pm

2:56 am

$1: 26 \mathrm{pm}$

3:28 am

6:01 am

9:27 pm

5:30 pm

9:23 pm

9:33 pm

7:02 pm

9:33 pm

7:07 pm

$1: 29 \mathrm{pm}$

3:09 am

3:02 am

3:06 am

2:48 am

3:09 am

8:46 pm

2:13 am 
Title: Far-Field Accumulation of Fissile Material from Waste Packages Containing Plutonium Disposition Waste Forms

Document Identifier: CAL-EDC-GS-000002 REV 00

ATTACHMENT IV, Page IV-6 of IV-6

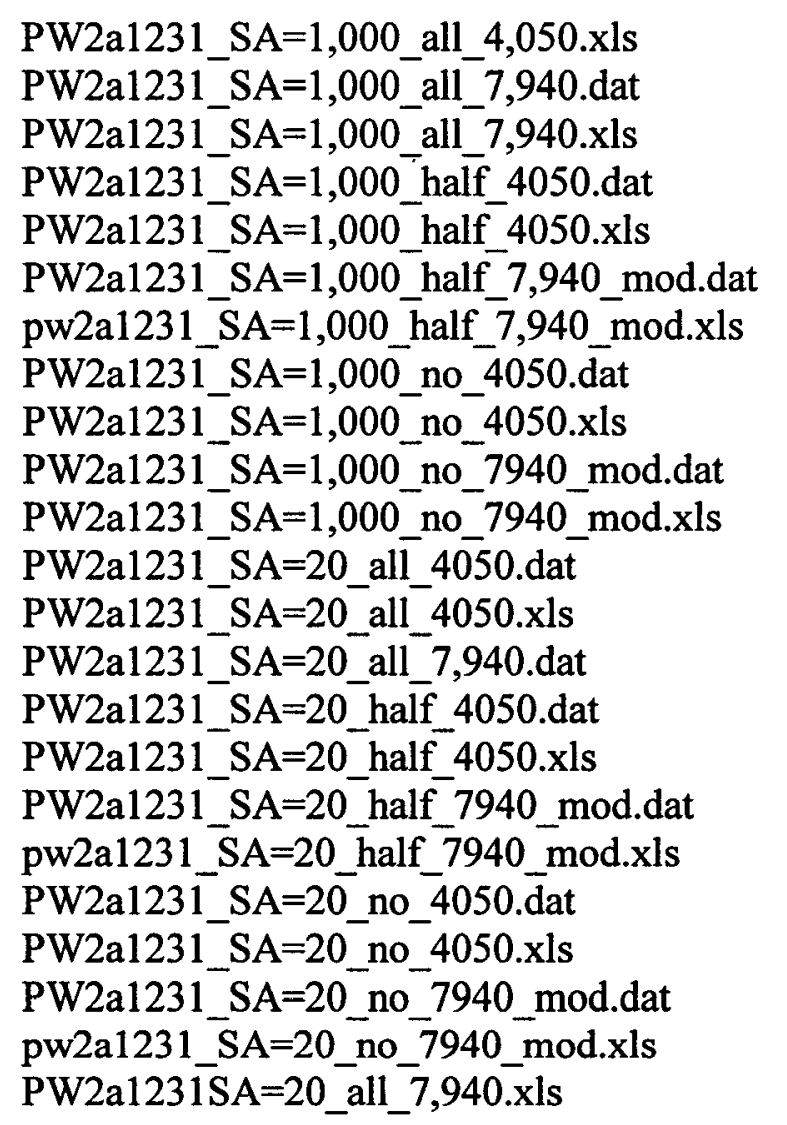

$\begin{array}{rlc}471,240 & 01-20-00 & 1: 27 \mathrm{pm} \\ 10,286 & 01-18-00 & 12: 34 \mathrm{am} \\ 471,240 & 01-19-00 & 2: 35 \mathrm{pm} \\ 10,326 & 01-20-00 & 10: 00 \mathrm{pm} \\ 474,290 & 01-24-00 & 2: 19 \mathrm{pm} \\ 10,428 & 01-19-00 & 2: 47 \mathrm{pm} \\ 474,492 & 01-20-00 & 7: 04 \mathrm{pm} \\ 10,310 & 01-20-00 & 9: 59 \mathrm{pm} \\ 474,290 & 01-24-00 & 2: 19 \mathrm{pm} \\ 10,418 & 02-01-00 & 1: 18 \mathrm{pm} \\ 474,492 & 02-02-00 & 5: 57 \mathrm{am} \\ 10,285 & 01-20-00 & 10: 01 \mathrm{pm} \\ 474,290 & 01-22-00 & 2: 17 \mathrm{pm} \\ 10,275 & 01-18-00 & 7: 23 \mathrm{pm} \\ 10,312 & 01-20-00 & 9: 59 \mathrm{pm} \\ 474,290 & 01-22-00 & 6: 03 \mathrm{am} \\ 10,428 & 01-20-00 & 10: 02 \mathrm{pm} \\ 474,492 & 01-21-00 & 11: 41 \mathrm{pm} \\ 10,297 & 01-20-00 & 10: 00 \mathrm{pm} \\ 474,290 & 01-21-00 & 5: 30 \mathrm{pm} \\ 10,416 & 01-20-00 & 10: 01 \mathrm{pm} \\ 474,492 & 01-24-00 & 9: 28 \mathrm{am} \\ 471,240 & 01-20-00 & 3: 22 \mathrm{pm}\end{array}$


Title: Far-Field Accumulation of Fissile Material from Waste Packages Containing Plutonium Disposition Waste Forms

\title{
A USER'S MANUAL FOR:
}

TRANSL

Version 1.0s

A TRANSLATION PROGRAM

FROM THE EQ3/6 TO THE PHREEQC

THERMODYNAMIC DATABASE FORMATS.

\author{
Jean-Philippe Nicot
}

Duke Engineering \& Services, Austin, TX

August 1999 
Title: Far-Field Accumulation of Fissile Material from Waste Packages Containing Plutonium Disposition Waste Forms

Document Identifier: CAL-EDC-GS-000002 REV $00 \quad$ ATTACHMENT V, Page V-2 of V-9

The program transl translates an EQ3/6 thermodynamic database in the "com" data01.f format into a PHREEQC compatible format. The translation program is only valid for "com" archetype datalf files (activity coefficients calculated with Davies or B-dot equations) and is not valid for "hmw" archetype datalf files (activity coefficients calculated with the Pitzer formulation). This manual first briefly overviews the key differences between PHREEQC and EQ3/6, then details the main aspects of the translation. Version 1.0s does not include temperature variations and produces a thermodynamic database only valid for a user-supplied constant temperature.

\section{DIFFERENCES BETWEEN THE PHREEQC AND EQ3/6 FORMATS}

Differences between the PHREEQC and EQ3/6 thermodynamic database formats are detailed below:

1- PHREEQC requires a list of all the primary master species (roughly equivalent to the strict basis species of EQ3/6) and secondary master species (roughly equivalent to the auxiliary basis species of EQ3/6) at the beginning of the input file because the order a) strict basic; b) auxiliary basic and; c) non-basic is not enforced in PHREEQC. This implies scanning for the PHREEQC secondary species in the reaction section of the aqueous field of the EQ3/6 thermodynamic database.

2- PHREEQC expresses redox reactions in terms of $\mathrm{O}_{2}(\mathrm{aq})$ (because all master species must be aqueous); $\mathrm{EQ} 3 / 6$ does it with $\mathrm{O}_{2}(\mathrm{~g})$ as an exception to the rule that all basic species are aqueous. This implies recomputing all the $\log _{-} \mathrm{k}$ constants involving $\mathrm{O}_{2}$.

3- EQ3/6 displays $\mathrm{O}_{2}$ thermodynamic data in the aqueous field. Because of point 2, PHREEQC displays these $\mathrm{O}_{2}$ data in the PHASES field.

4- PHREEQC requires aqueous species of interest to be the first species on the right-hand side of the reaction. EQ3/6 writes it on the left-hand side. This implies writing the reaction the other way around for the aqueous species and also using the negative of all $\log \mathrm{k}$ analytical coefficients as read in EQ3/6. However, species are written the same way in the PHREEQC "PHASES" field and in the EQ3/6 thermodynamic database.

5- PHREEQC requires the presence of several species of the $\mathrm{H}_{2} \mathrm{O}$ system. They must be added to the thermodynamic database if not present. The species are: $\mathrm{H}(0), \mathrm{e}-, \mathrm{O}(0)$ for the

SOLUTION_MASTER_SPECIES field and $\mathrm{H} 20, \mathrm{O} 2, \mathrm{H} 2$ and $\mathrm{OH}-$ for the SOLUTION_SPECIES field.

6- The reaction $2 \mathrm{H} 2 \mathrm{O}=\mathrm{O} 2+4 \mathrm{H}++4 \mathrm{e}$ - is hard-wired into $\mathrm{EQ} 3 / 6$ but needs to be included in the PHREEQC thermodynamic database. $\log _{-} \mathrm{k}^{\prime} \mathrm{s}$ values for this reaction are provided by the xlkeh EQ3/6 field.

7- PHREEQC does not allow descriptive information like (g) for gas or (aq) for aqueous in brackets at the end of a species. They all have to be removed. 
Title: Far-Field Accumulation of Fissile Material from Waste Packages Containing Plutonium Disposition Waste Forms

Document Identifier: CAL-EDC-GS-000002 REV 00 ATTACHMENT V, Page V-3 of V-9

\section{MAIN STEPS OF TRANSLATION}

\section{PRACTICAL ASPECTS}

The translation program requires two input files: datalf.nuc and watersys.dat. The former is obtained by running the EQPT (Ref. 46) program with the data0.* EQ6 thermodynamic database. The extrastep of going from data0 to datalf was added to allow for a perfect PHREEQC-EQ3/6 fit of the temperature-dependent variations of $\log _{-} k$ and to better constrain the B-dot parameters in the version of the translation program which includes temperature variations (Non QA). The file watersys.dat contains only one data field: the $\mathrm{O}_{2}(\mathrm{~g})$ field cut and pasted from the EQ3/6 thermodynamic database.

The executable file results from the compiling of one file written in the ANSI C language:

transl.c: main and general purpose routine.

The program generates one output file:

phreeqc.nuc: the actual thermodynamic database.

After launching the program, it will ask at what constant temperature the PHREEQC thermodynamic database has to be computed. It will then ask what activity coefficient formulation is desired (Davies or B-dot). The program will then computes log_k's and b-dot parameters strictly identical to the ones computed in EQ6.

\section{MAIN STEPS}

The program flow chart is displayed in Figures V-1 to V-3. Because the information is displayed in a different order in both thermodynamic databases, all of the EQ3/6 thermodynamic database must be read first before writing to the PHREEQC thermodynamic database. The code first reads the EQ3/6 element field. It then reads all the information provided on species including elements making up the species and the subscript for that element. This also allows the code to separate primary master species from all secondary species. A key point of PHREEQC is that all the secondary species must be written in terms of primary master species, directly or indirectly. In addition, if an element in a secondary species has a redox number different from the master primary species, a secondary master species with that redox number must be also declared. The code scans all the reactions to detect if redox is involved. If it is, the redox state associated with the element is computed and species, element and redox state are stored in a temporary array. Meanwhile, minor routines check for the correct writing of the reaction by deleting extra characters, inverting species if needed, rewriting charges, checking for misleading spelling and problematic species and recomputing the value of $\log _{-} \mathrm{k}$ to accommodate the different expression of $\mathrm{O}_{2}$ in redox reactions. B-dot parameters are then calculated for the chosen constant temperature. The species included in the alkalinity declaration and in the gram formula weight 
Waste Package Department

Calculation

Title: Far-Field Accumulation of Fissile Material from Waste Packages Containing Plutonium Disposition Waste Forms

Document Identifier: CAL-EDC-GS-000002 REV $00 \quad$ ATTACHMENT V, Page V-4 of V-9

(gfw) correspond to the common practice and can be changed either in the code itself or in the thermodynamic database phreeqc.nuc.

The code then starts writing to the phreeqc.nuc thermodynamic database. It first sorts and writes all the primary master and secondary master species. The code then writes reaction, $\log \mathrm{k}$ information, and B-dot information if applicable for aqueous species, minerals and gases. However, mineral and gas subfields must be preceded by the species name.

\section{ACTIVITY COEFFICIENTS}

Although EQ6 and PHREEQC have both the option of using either the Davies or B-dot model for the activity coefficients, there are small differences detailed below. The general expression for charged species for the Davies (Eq. V-1a) and B-dot (Eq. V-1b) models are:

$$
\log _{10} \gamma=-A z^{2}\left(\frac{\sqrt{\mu}}{1+\sqrt{\mu}}-c \mu\right)
$$

where $c=0.2$ in EQ6 and $c=0.3$ in PHREEQC

$$
\log _{10} \gamma=-\frac{A z^{2} \sqrt{\mu}}{1+B a^{o} \sqrt{\mu}}+b \mu
$$

In these equations, $\gamma$ is the activity coefficient, $\mathrm{z}$ is the species charge, $\mu$ is the ionic strength, $\mathrm{A}$ and $\mathrm{B}$ are constant at a given temperature, $\mathrm{a}^{\mathbf{0}}$ is the hardcore diameter of the species and $\mathrm{b}$ is the B-dot parameter. EQ6 provides coefficients for the analytical expressions of A, B and b as a function of temperature and a list of the hardcore diameters $\mathrm{a}^{\circ}$. PHREEQC requires the parameters $\mathrm{a}^{\circ}$ and $\mathrm{b} ; \mathrm{A}$ and $\mathrm{B}$ are computed internally. The parameter $\mathrm{a}^{0}$ is constant for a given species and not function of temperature and can be written with no change from EQ6 to PHREEQC.

Activity of neutral species in PHREEQC and EQ6 are handled differently as shown on the following table:

\begin{tabular}{|l|l|l|}
\hline & EQ6 & PHREEQC \\
\hline Charged Species & $\begin{array}{l}\text { Davies or B-dot Model } \\
\text { (Temperature varying B-dot) }\end{array}$ & $\begin{array}{l}\text { Davies or B-dot Model } \\
\text { (constant B-dot) }\end{array}$ \\
\hline $\begin{array}{l}\text { Neutral Species } \\
\text { (Not strongly polar) }\end{array}$ & $\begin{array}{l}\log _{10} \gamma=\log _{10} \gamma_{\mathrm{CO} 2} \\
\text { (Temperature varying) }\end{array}$ & $\gamma=0.1 \mu$ \\
\hline $\begin{array}{l}\text { Neutral Species } \\
\text { (Strongly polar) }\end{array}$ & $\gamma=1$ & $\gamma=0.1 \mu$ \\
\hline
\end{tabular}


Title: Far-Field Accumulation of Fissile Material from Waste Packages Containing Plutonium Disposition Waste Forms

Where $\gamma_{\mathrm{CO} 2}$ is the activity of $\mathrm{CO}_{2}$ expressed in an analytical form.

\section{OTHER COMMENTS}

This code has been tested on Unix DEC and HP workstations using standard C compilers and on Pentium PCs using the Microsoft Visual C++ compiler. 
Title: Far-Field Accumulation of Fissile Material from Waste Packages Containing Plutonium

Disposition Waste Forms

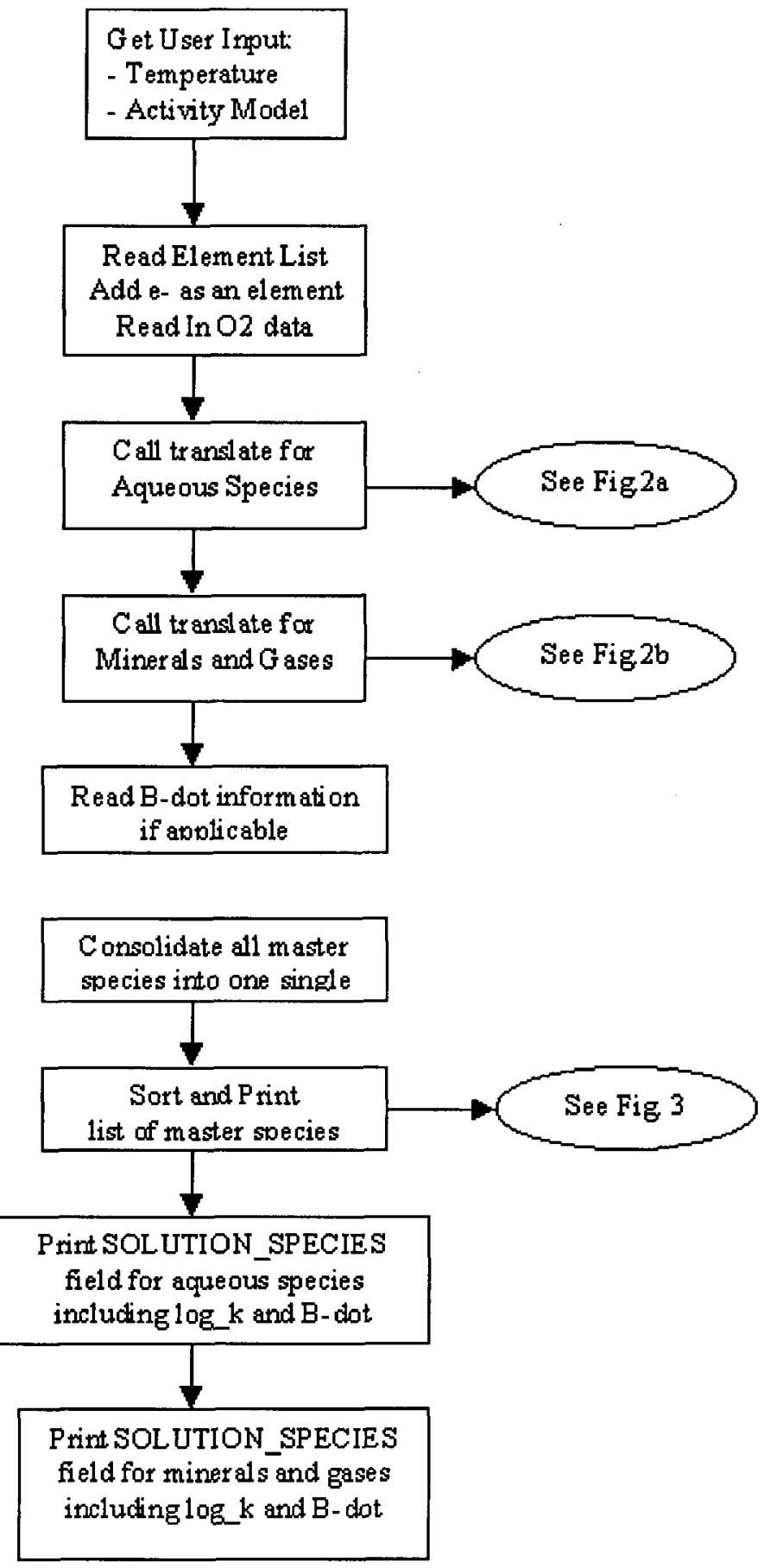

Figure V-1. "Main" Flow Chart 
Title: Far-Field Accumulation of Fissile Material from Waste Packages Containing Plutonium Disposition Waste Forms

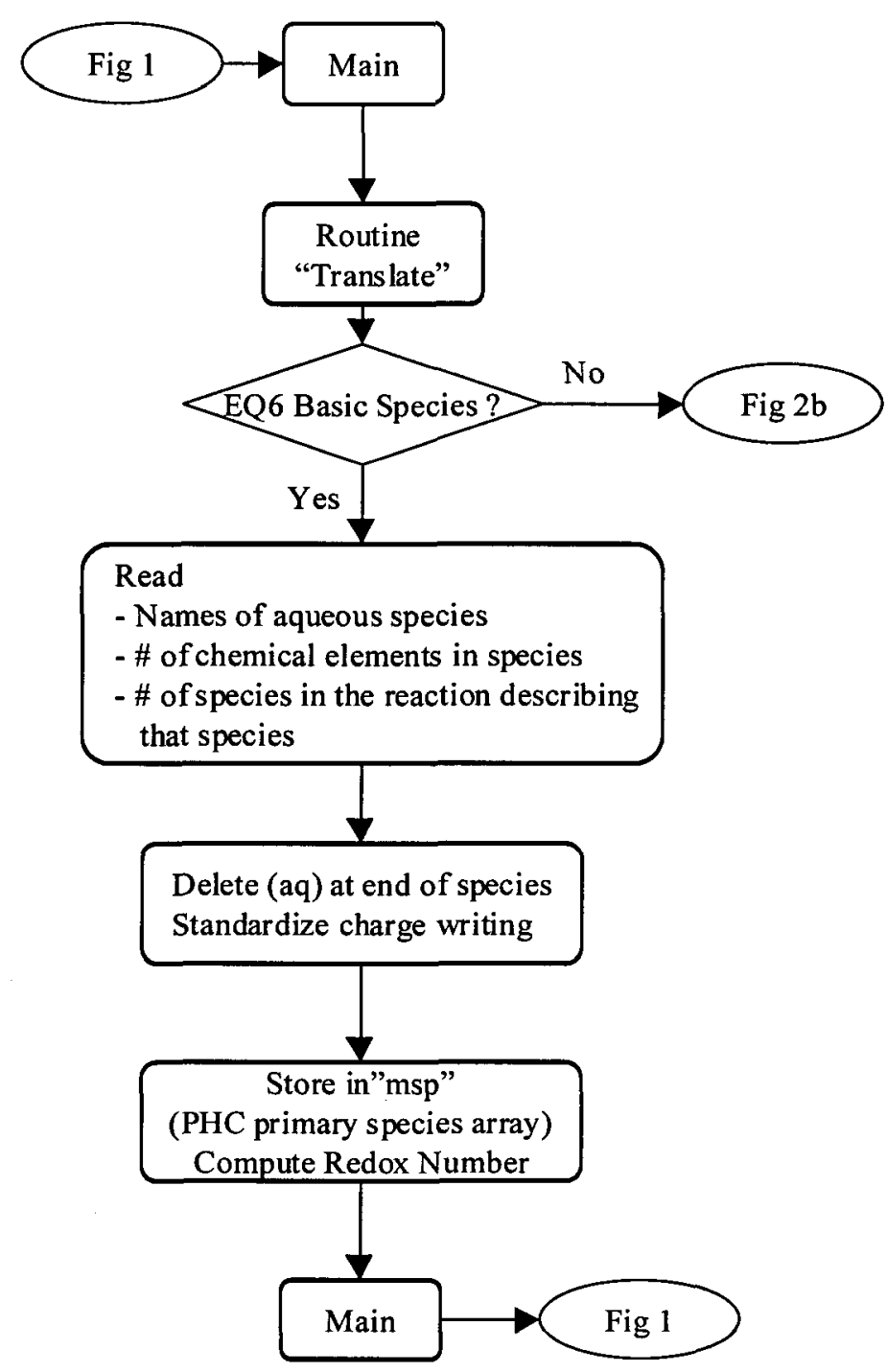

Figure V-2a: Routine "Translate" Flow Chart (first part) 
Waste Package Department

Calculation

Title: Far-Field Accumulation of Fissile Material from Waste Packages Containing Plutonium

Disposition Waste Forms

Document Identifier: CAL-EDC-GS-000002 REV 00

ATTACHMENT V, Page V-8 of V-9

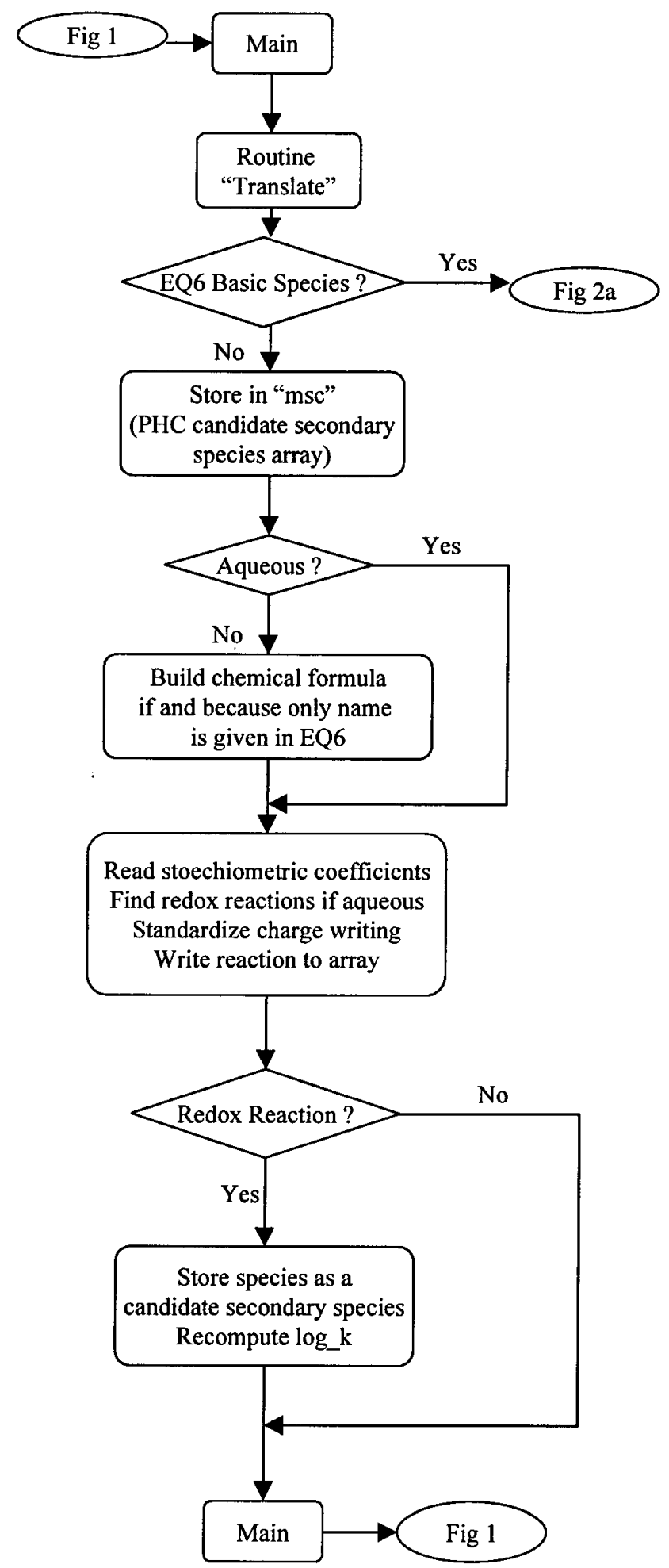

Figure V-2b. Routine "Translate" Flow Chart (second part) 
Title: Far-Field Accumulation of Fissile Material from Waste Packages Containing Plutonium Disposition Waste Forms

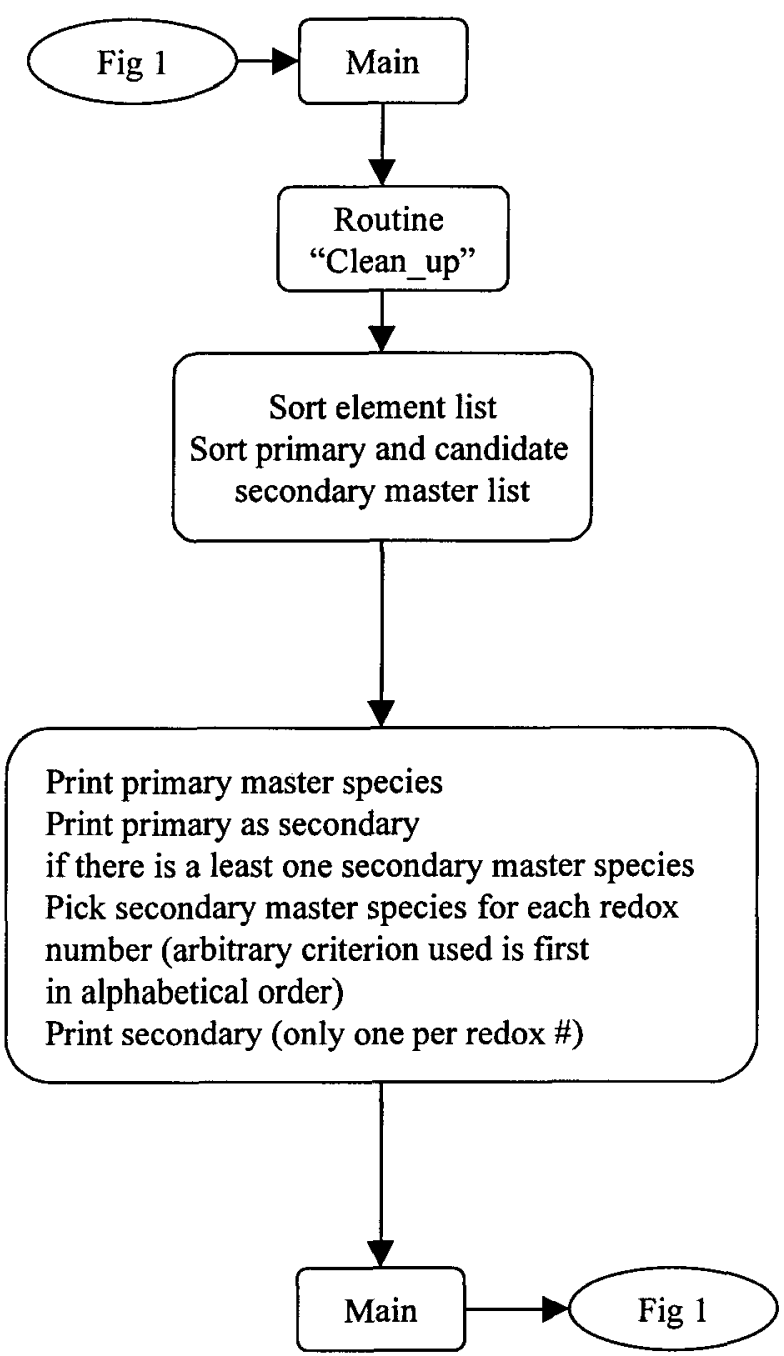

Figure V-3. Routine "clean_up" Flow Chart 


\section{ATTACHMENT VI-C LANGUAGE CODE FOR TRANSL.C}

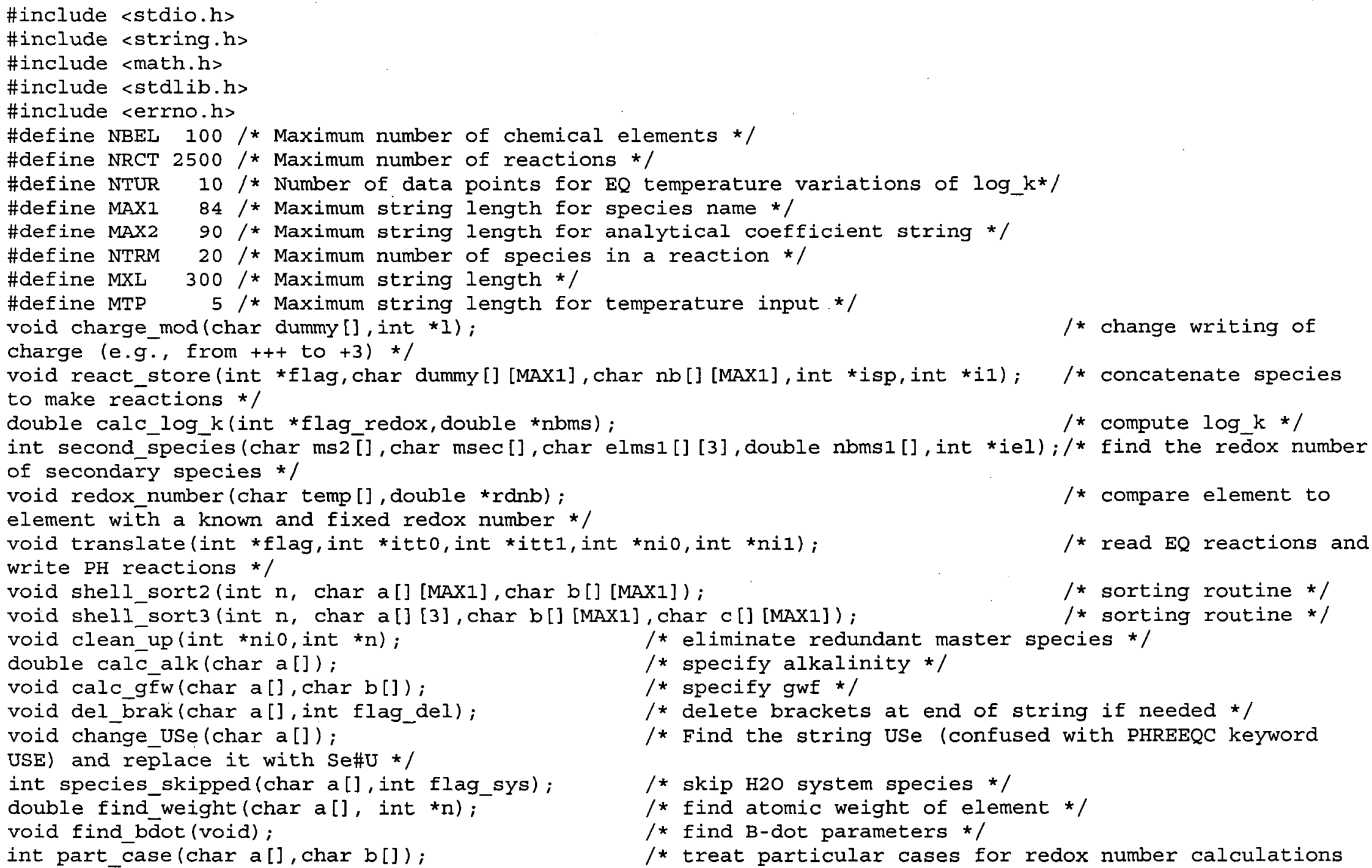


Title: Far-Field Accumulation of Fissile Material from Waste Packages Containing Plutonium Disposition Waste Forms Document Identifier: CAL-EDC-GS-000002 REV 00

ATTACHMENT VI, Page VI-2 of VI-24

int test_rmv(char a []);

\section{*/}

/* compare a species with list of species to be removed

FILE *innuc, *indat, *outp

char pfile [20];

char elm [NBEL] [3];

double elw [NBEL];

char msp [NBEL] [MAX1];

char elmsp [NBEL].[3];

char msc [NRCT] [MAX1]; ....)*/

char elmsc [NRCT] [MAX1];

$\mathrm{N}(+3), \ldots) *$.

char elmspc [NBEL] [MAX1]

species ( $\mathrm{Ca}$ becomes $\mathrm{Ca}(+2) *$ /

char nameph [NRCT] [MAX1];

char chemfph [NRCT] [MAX1];

char react [NRCT] [MXL];

char allms [NRCT+2*NBEL] [MAX1] ;

species */

char elallms [NRCT $+2 *$ NBEL] [MAX1]; /* element of primary master or candidate for secondary master species on combined list */

char msrmv [NRCT] [MAXI];

double anal_EQ [NTUR];

double anal_PH [NTUR] ;

double log_k [NRCT] ;

int flag davies;

int flag_rmv[NRCT]; data) */

int flag_sup $100=0$;

int flag_o2aq;

double tci

static int $\max 1 \max =0$; be rerun*/

static int $\max 2 \max =0$; be rerun*/

double anal_EQO2. [NTUR]; double anal_EQH2O[NTUR] double bdot_EQ[NTUR] ; double bb;

/* output file name */

$/ *$ element list $(\mathrm{H}, \mathrm{K}, \ldots) * /$

$/ *$ element atomic weight list $(1.008,39.102, \ldots) * /$

/* primary master species list $(\mathrm{Ca}+2, \mathrm{CH} 4, \ldots) * /$

/* element of the primary master species ( $\mathrm{Ca}, \mathrm{C}, \ldots$... *)

/* list of candidates for secondary master species (KNO3, NO3-,NO2-,

/* element of the candidate for secondary master species $(N(+5), N(+5)$,

/* element of primary master species written as an element of a secondary

/* name of non-aqueous phases (Calcite, $02(g), \ldots$ ) */

/* chemical formula of non-aqueous phases */

$/ *$ list of reactions $\mathrm{FeCl} 2=\mathrm{Fe}+2+2 \mathrm{Cl}-1 * /$

/* combined list of primary master and candidate for secondary master

/* list of species removed from the database */

$/ *$ coefficient for analytical expression of $\log _{k}(\mathrm{~T})$ in $\mathrm{EQ}$ */

$/$ * coefficient for analytical expression of $\log _{-} k(T)$ in PHREEQC */

$/ *$ log_k for constant temperature runs (in C) */

$1 * \operatorname{davies}(=1)$ or $\mathrm{B}-\operatorname{dot}(=0)$ formulation of activity */

$/$ * removal $(=1)$ of species if some criteria not met (acceptable thermo.

$/ *$ temperature range below $(=0)$, above $(=1)$ or including $(=2) 100 \mathrm{C}$ */

$/ *$ flag=1 if redox reaction in terms of $02(\mathrm{aq})$ rather than $\mathrm{O} 2(\mathrm{~g})$ */

$/ *$ constant temperature (C) or midrange if variable*/

/* if maxlmax>MAXI a warning message will be displayed and program should

/* if maxlmax>MAX2 a warning message will be displayed and program should

/* read in EQ coefficients for analytical expression of 02 log_k $(T)$ */

$/$ * coefficients for analytical expression of H2O log_k $(\mathrm{T})$ */

$/$ * read in $E Q$ coefficients for analytical expression of B-dot */

$/$ * b-dot parameter */ 
Waste Package Department

Title: Far-Field Accumulation of Fissile Material from Waste Packages Containing Plutonium Disposition Waste Forms Document Identifier: CAL-EDC-GS-000002 REV 00

char diamspc [NRCT+NBEL] [MAX1]; double diam [NRCT+NBEL]; double gam [NRCT+NBEL] [2]; int neleq

int naux;

int naqueous;

int nbdot;

int rmvcount $=0$,

int main()

$\{$ int $i, i i, i c, i 0, i 1,1$; int nel;

int nio

int nil

int itto,itt 1 ,

int nallms;

double $a, b$;

double nbms;

char trsh [MXL]

char dum [7];

char answer [2];

char tc_stri[MTP]

int flag_molvol;

mineral $(=1)$ or gas $(=2)$ */

innuc=fopen ("datalf nuc", "r") i indat=fopen ("watersys dat " "r")

/* USER INPUT * /

$1 *$.. Temperature inquiry */

lp_temp: printf ("Enter constant temperature in Celsius: ");

fgets (trsh, sizeof (trsh), stdin);

sscanf (trsh, "ss", tc strl) ;

tc=atof (tc_strl);

strcpy (pfīe, "phreeqc.nuc") ;

strcat (pfile," ") ,

strcat (pfile, strtok (tc str1,"."));

outp=fopen (pfile, "w") ;

if $(t c>300)$ \{printf("Temperature should be between $O C$ and $300 \mathrm{C} \backslash \mathrm{n} ")$; goto lp_temp;

if $(t c>100)$ flag sup $100=1$

printf("Constant temperature is: $\% f C \backslash n \backslash n ", t c$ );

fprintf (outp, "\# Constant temperature is: \&fC $\backslash n \# \backslash n ", t c)$; $/ *$...Activity calculation inquiry */

read in EQ hard core diameter species */

declared number of elements in $\mathrm{EQ}$ database */

a candidates for secondary species) */

* counter for removed species */

counters */

* loop counters */

variables when reading input files */

* dummy variable */

* dummy variable */

$/ *$ user answers * $/$

( temperature string */

* if $=0$ no molar volume provided $=>$ aqueous; if molar volume provided $=>$ 
Waste Package Department

Title: Far-Field Accumulation of Fissile Material from Waste Packages Containing Plutonium Disposition Waste Forms Document Identifier: CAL-EDC-GS-000002 REV 00

printf ("Please, enter the activity model you want to use $\backslash n "$ );

Ip_dav: printf ("Enter d for Davies or enter b for B-dot ")

fgets (answer, sizeof (answer), stdin);

fgets (dum, 7 , stdin);

if (strncmp (answer, "d", I) ==0 || strncmp (answer, $D ", 1)==0$ )

$\{$ flag_davies $=1$;

printf("\nActivity coefficients will be computed according to the Davies model \n\n"); fprintf (outp, "\# Davies model is used for activity $\backslash n \# \backslash n ") ;\}$

else if (strncmp (answer, "b", 1)==0 || strncmp (answer, "B", 1)==0)

\{flag_davies=0;

printf("\nActivity coefficients will be computed according to the $B-\operatorname{dot} \operatorname{model} \backslash n \backslash \mathrm{n}$ ")

fprintf (outp, "\# B-dot model is used for activity $\backslash n \# \backslash n$ ");

else \{printf ("\%) is not an appropriate answer $\backslash n$ ", answer); goto lp_dav;

/* ADD COMMENTS NEW TO THIS VERSION */

fprintf(outp,"\# This program translates an EQ3/6 database in the \".com\" data01.f format\n\ \# into a PHREEQC compatible format $\backslash n \backslash$

$\# \backslash \mathrm{n} \backslash$

\# Version $1.0 \mathrm{~s} \backslash \mathrm{n} \backslash$

\# Author : Jean-Philippe Nicot, DE\&S, (512) 425-2000\n\

\# Date: May 1999\n\

$\# \backslash \mathrm{n} \backslash$

\# This program is only valid for \".com\" archetype datalf files (activity coefficients $\backslash$ \

\# calculated with Davies or B-dot equations) and is not valid for \".hmw " archetype \n\

\# datalf files (activity coefficients calculated with Pitzer formulation). \n\

$\# \backslash \mathrm{n} \backslash$

\# Main differences between PHREEQC and EQ3/6 database format are: $\backslash n \backslash$

\# 1- PHREEQC requires a list of all the primary master species (roughly equivalent to \n\ the strict basis species of EQ3/6) and secondary master species (roughly $\mid \mathrm{n} \backslash$ equivalent to the auxiliary basis species of $E Q 3 / 6$ ) at the beginning of the $\backslash n \backslash$ input file because the order strict basic, auxiliary basic and non-basic is not $\backslash n \backslash$ enforced in PHREEQC. This implies scanning for the PHREEQC secondary species in the $\backslash n \backslash$ reactions of the aqueous field of the $E Q 3 / 6$ database. $\mid n \backslash$

In EQ3/6, the strict basic species block must start with $\mathrm{H} 20$ and finish with 02 (g), not. $\backslash \mathrm{n} \backslash$ in PHREEQC. $\backslash n \backslash$

2- PHREEQC expresses redox reactions in terms of 02 (aq) (because all master species $\backslash \mathrm{n} \backslash$ must be aqueous); $\mathrm{EQ} 3 / 6$ does it with $\mathrm{O} 2(\mathrm{~g})$ as an exception to the rule that all $\backslash \mathrm{n} \backslash$ basis species are aqueous. This implies recomputing all the $k$ constants $\backslash n \backslash$ involving 02 . This is also true for any reactions involving gaseous species. $(n ") ;$ fprinte (outp,") 
Title: Far-Field Accumulation of Fissile Material from Waste Packages Containing Plutonium Disposition Waste Forms

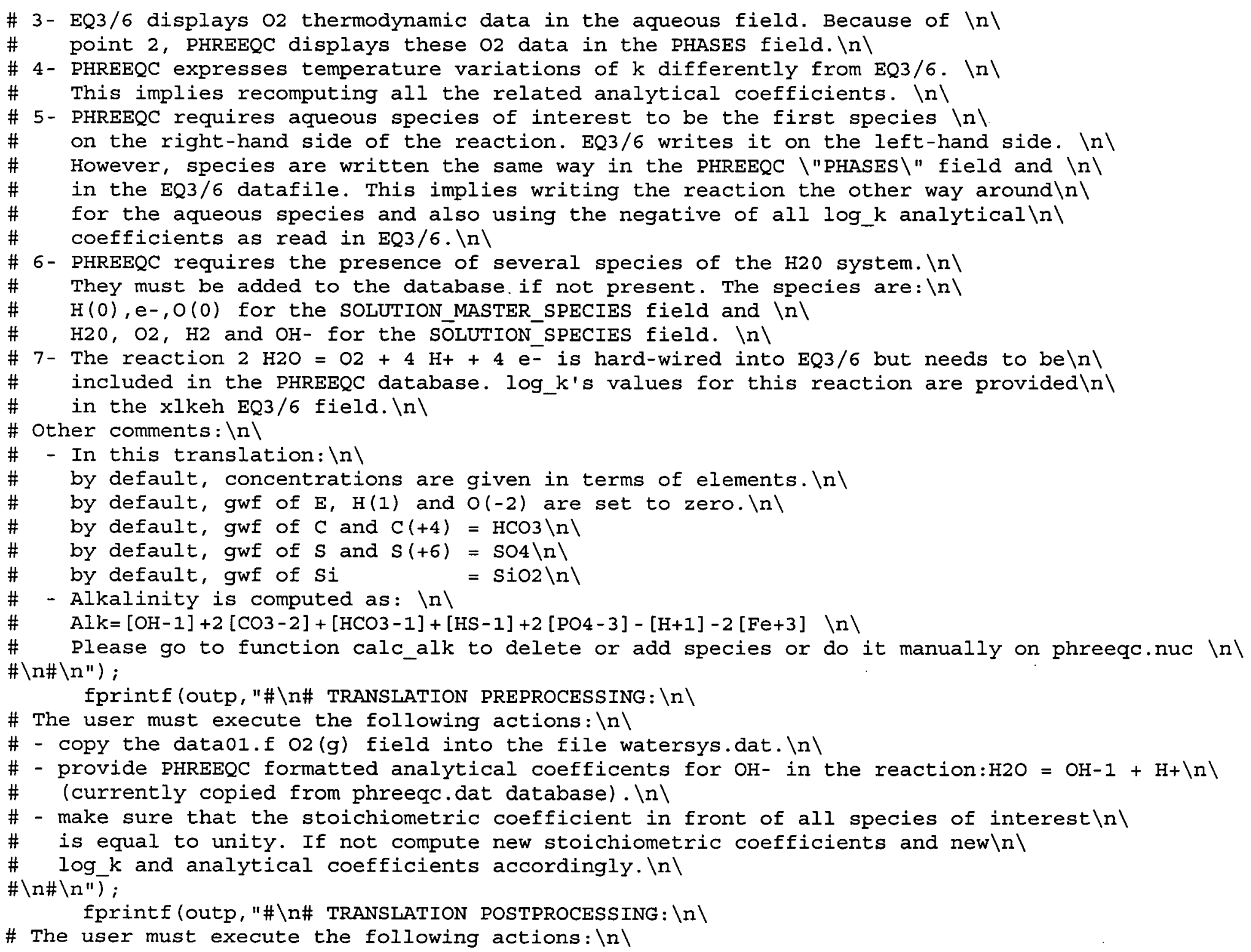


Title: Far-Field Accumulation of Fissile Material from Waste Packages Containing Plutonium Disposition Waste Forms

\# - check that the program retained the approppriate secondary master species $\backslash n \backslash$

\# in BLOCK 16 of phreeqc.out. If not, correct accordingly. \n\

$\# \backslash \mathrm{n} \# \backslash \mathrm{n} ")$;

/ * READ INITIAL INFORMATION */

fprintf (outp, "\# THE FOLLOWING TEXT IS IMPORTED FROM THE EQ DATABASE: \n\#\n");

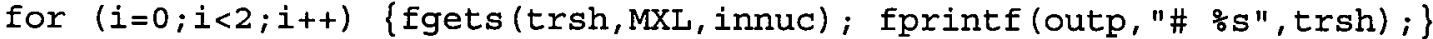

if (strncmp (trsh, "stfipc",6)!=0) \{printf("This not a \".com\" archetype file and it cannot be

translated by this code $\backslash n ") ; \operatorname{exit}(1) ;\}$

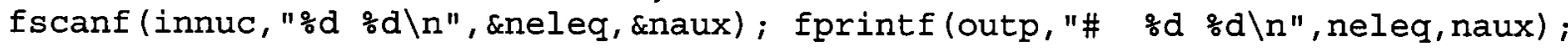

/* READ AND WRITE INTRODUCTION OF EQ DATA FILE */

while (strncmp (trsh+10,"--.-",5)!=0) \{fgets(trsh, MXL, innuc); fprintf (outp, "\# $8 s ", t r s h) ;\}$

fscanf (innuc, "s lf $\left.\frac{\circ}{8} l f \backslash n ", \& a, \& b\right)$; fprintf (outp, "\# $\left.\frac{\circ}{\circ} \% f \backslash n ", a, b\right)$;

fprintf (outp, "\#\n\# Even if the original EQ3/6 database had at least partial data for the temperature

range $\left.\% f C \quad \% f C, \backslash n^{\prime \prime}, a, b\right)$;

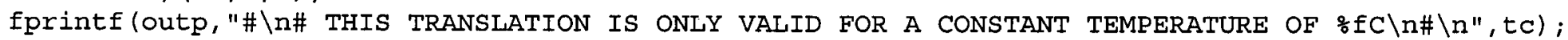

if (flag davies==1) fprintf(outp,"\# ACTIVITY COEFFICIENTS WILL BE COMPUTED ACCORDING TO THE DAVIES

MODEL $\backslash \mathrm{n} ")$;

if (flag davies==0) fprintf (outp, "\# ACTIVITY COEFFICIENTS WILL BE COMPUTED ACCORDING TO THE B-DOT

MODEL $\backslash n "$ ) ;

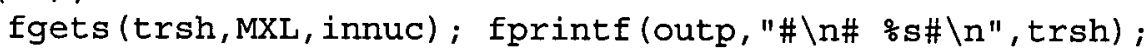

/* READ ELEMENT LIST FROM EO6 *

$i=0$;

for $(; i)$

\{fscanf (innuc, "安s", elm[i]);

if (strcmp (elm[i], "pr")==0) break; /* Element list stops at "press" */

fscanf (innuc, "\%lf $\%$ lf $\backslash n ", \& e l w[i], \& a)$;

it+;

/* ADD ELECTRON AS AN ELEMENT */

strcpy (elm [i], "E").

$e l w[i]=0.0$;

nel $=\mathbf{i}+1$

/* READ IN PARAMETER LIST */

for ( $i=0 ; i<10 ; i++)$ fgets (trsh, MXL, innuc)

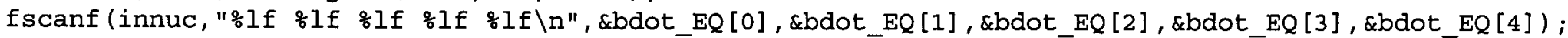

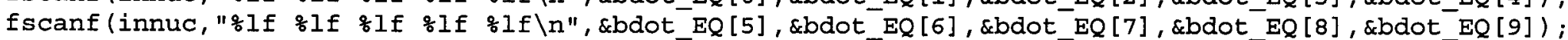
if (flag_sup $100==1)$ for $(i=0 ; i<=4 ; i++)$ bdot_EQ [i]=bdot_EQ [5+i].

for $(i=0 ; i<3 ; i++)$ fgets (trsh, MXL, innuc);

fscanf (innuc, "\%lf

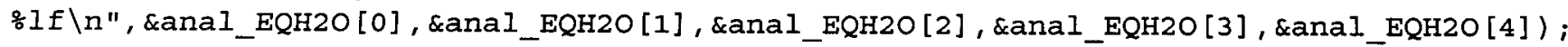


Waste Package Department

Title: Far-Field Accumulation of Fissile Material from Waste Packages Containing Plutonium Disposition Waste Forms

Document Identifier: CAL-EDC-GS-000002 REV 00

ATTACHMENT VI, Page VI-7 of VI-24

fscanf (innuc, "잉

:If \n", \&anal_EQH2O [5], \&anal_EQH2O [6] , \&anal_EQH2O [7] , \&anal_EQH2O [8] , \&anal_EQH2O [9]);

if (flag_sup $100==1)$ for $(i=0 ; i<=4 ; \overline{i++})$ anal_EQH2O[i]=anal_EQH2O[5+ $\bar{i}]$;

* READ IN O2 DATA FROM H20 SYSTEM DATA */

for $(i=0 ; i<5 ; i++)$ fgets (trsh, sizeof(trsh), indat);

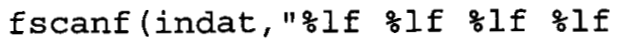

:If $\backslash \mathrm{n}$ ", \&anal_EQO2 [0], \&anal_EQO2 [1] , \&anal_EQO2 [2] , \&anal_EQO2 [3] , \&anal_EQO2 [4]);

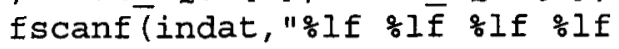

: $1 f \backslash \mathrm{n} "$, \&anal $\mathrm{EQO2}[5]$, \&anal $\mathrm{EQO2} \mathrm{[6],} \mathrm{\& anal} \mathrm{EQO2} \mathrm{[7],} \mathrm{\& anal} \mathrm{EQO2} \mathrm{[8],} \mathrm{\& anal} \mathrm{EQO2} \mathrm{[9]);}$

if ( $f$ lag_sup $100==1)$ for $(i=0 ; i<=4 ; \bar{i}++)$ anal_EQO2[i]=anal_EQO2 [ $\overline{5}+\bar{i}]$;

/* READ FIRST FIELD ("aqueous") */

fgets (trsh, MXL, innuc); printf ("\%s $\backslash \mathrm{n} "$, trsh);

flag_molvol=0;

itt $0=0$; itt $1=0$;

translate(\&flag_molvol, \&itto,\&ittl,\&nio, \&nil); /* will read all aqueous species and will extract needed info */

/* ADD e-, $\mathrm{H}+$ and $\mathrm{H} 2 \mathrm{O}$ as primary species */

$\operatorname{strcpy}(\operatorname{msp}[\mathrm{niO}], " \mathrm{H}+1 ")$;

strcpy (msp [nio+1], "e-");

strcpy (msp [niO+2], "H2O");

strcpy (elmsp [nio], "H");

strcpy (elmsp [niO+1], "E");

strcpy (elmsp [niO+2], "O");

strcpy (elmspc [nio], "H(+1)");

strcpy (elmspc [nio+1], "E(-1)");

strcpy (elmspc [nio +2$], " \mathrm{O}(-2) ")$;

ni $=$ ni $0+3$; naqueous $=$ nil-1;

/* GO TO NEXT FIELD ("Minerals") */

fgets (trsh, MXL, innuc); printf("\%s $\backslash n ", t r s h)$;

flag_molvol=1;

itt $0=$ nio ; itt $1=n i 1$;

info * 1

translate (\&flag_molvol, \&itto, \&ittl,\&nio,\&nil); /* will read all minerals and will extract needed

/* GO TO NEXT FIELD ("Gases") */

fgets (trsh, MXL, innuc); printf("ss $\backslash n ", \operatorname{trsh})$;

flag_molvol=2;

itto=nio; itt $1=$ nil

*

translate (\&flag_molvol, \&itto,\&itt1, \&nio,\&nil); /* will read all gases and will extract needed info 
Title: Far-Field Accumulation of Fissile Material from Waste Packages Containing Plutonium Disposition Waste Forms

fgets (trsh, MXL, innuc);

/* GO TO NEXT FIELD ("Solid Solutions") */

while (strncmp (trsh, "endit",5)!=0) \{fgets (trsh, MxL, innuc); if (strncmp (trsh, "endit", 5) ==0) break;

/* skip solid solutions */

/* GO TO NEXT FIELD (diameter information for B-dot equation) */

if (flag davies==0) printf ("Ion diameters $\backslash n$ ")

$\operatorname{trsh}[0]=\bar{N} U L L$;

$i=0$;

while (strncmp (trsh, "endit",5)!=0)

\{fgets (trsh, MXL, innuc);

if (strncmp (trsh, "endit", 5) ==0) break;

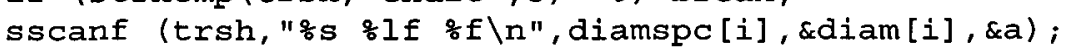

l=strlen (diamspc [i]);

charge mod(diamspc[i], \&1); /* write charge with PHC format */

del_brak (diamspc $[i], 1) ; / *$ get rid of (aq) */

$i++\bar{i}\}$

nbdot=i;

/* CONSOLIDATE ALL AQUEOUS MASTER AND SECONDARY MASTER SPECIES IN ONE SINGLE ARRAY */

$1 *$ all the info have aready been partially structured in the few calls to routine translate */

for $(i 0=0 ; i 0<n i 0 ;++i 0)$

\{strcpy (allms [io], msp [io]);

strcpy (elallms [io], elmsp [io]);

ic $=$ nio ;

for $(i 0=0 ; i 0<n i 0 ;++i 0)$

\{strcpy (allms $[i c], \operatorname{msp}[i 0])$;

strcpy (elallms [ic], elmspc [io]);

iC $++;\}$

ic $=2 \star$ nio ;

for $(i 1=0 ; i 1<$ naqueous $;++i 1)$

\{if (msc[i1] [0]!=NULL \&\& elmsc[i1] [0]!=NULL)

\{strcpy (allms [ic], msc [i1]);

strcpy (elallms [ic], elmsc[il]); ic $++;\}\}$

nallms=ic;

/* SORT, CLEAN UP AND PRINT LIST OF MASTER AND SECONDARY MASTER SPECIES */

fprintf (outp, "SOLUTION MASTER SPECIES (n\#\n") :

fprintf(outp,"\#element species alk gfw_formula element_gfw $(n \# \backslash n ")$;

$/$ *..print Alkalinity species */ 
Title: Far-Field Accumulation of Fissile Material from Waste Packages Containing Plutonium Disposition Waste Forms

$$
\left(\mathrm{n}^{\prime \prime}\right) \text {; }
$$

fprintf (outp, "Alkalinity $\mathrm{HCO}-1$

$1.0 \quad \mathrm{CaO} .5 \mathrm{HCO} 3$

81.05

shell_sort2 (nallms, elallms-1,allms-1); / " "-1" because of Numerical Recipes conventions */ clean_up (\&nio,\&nallms); /* list of master species is printed from this routine */

/* FIND B-DOT PARAMETERS */

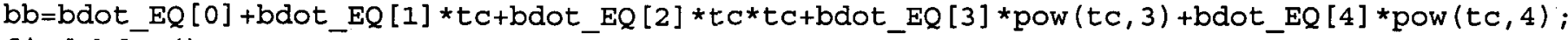
find_bdot () ;

/* PRINT LIST OF REACTIONS, LOG K AND B-DOT PARAMETERS * /

/* print SOLUTION_SPECIES field for master species */

fprintf (outp, "\nSOLUTION_SPECIES $\backslash \mathrm{n} \backslash \mathrm{n} "$ );

for $(\mathrm{iO}=0 ; \mathrm{i} 0<\mathrm{niO} ; \mathrm{iO++})$

\{fprintf (outp, "ㅇs = \%s $\backslash n ", \operatorname{msp}[i 0], \operatorname{msp}[i 0])$;

$i=$ strlen (msp [io]);

chraged species */

if ( $($ flag_davies $\left.==0) \& \&\left(\left(\operatorname{msp}[i 0][i-2]==^{\prime}+{ }^{\prime}\right)||\left(\operatorname{msp}[i 0][i-2]==^{\prime}-{ }^{\prime}\right)\right)\right) /$ * write gamma only for

$$
\begin{aligned}
& \text { \{fprintf (outp," } \quad \log _{-} \mathrm{k} \quad 0.000 \backslash \mathrm{n} " \text { ) ; }
\end{aligned}
$$

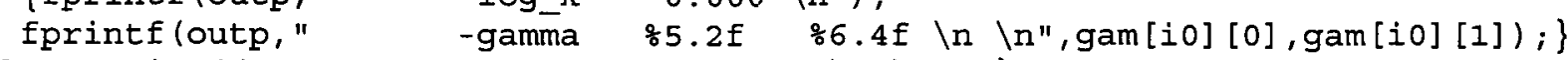$$
\text { else fprintf (outp, " } \left.\left.\quad \log _{-} \mathbf{k} 0.000 \backslash \mathrm{n} \backslash \mathrm{n} "\right) ;\right\}
$$

$/$ * print O2 DATA for SOLUTION_SPECIES */

fprintf (outp, "2 $\mathrm{H} 2 \mathrm{O}=\mathrm{O} \overline{2}+4 \mathrm{H}++4 \mathrm{e}-\backslash \mathrm{n} "$ );

for $(i=0 ; i<N T U R ; i++)$ anal_EQ $[i]=$ anal_EQH2O $[i]$;

nbms $=1.0$;

$i=1 ; / * i . e$. flag redox $=1 * /$

flag_o2aq=0;

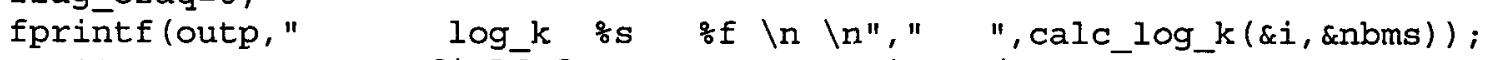

/* print SOLUTION SPECIES field for aqueous species */

for $(i 1=0 ; \bar{i} 1<=$ naqueous $; i 1++)$

\{if (flag $r m[i 1]==1$ ) continue;

if $($ strcmp (react [i1]," $02=02 ")==0$ ) continue;

fprintf (outp, "ss $\backslash n$ ", react [i1]);

fprintf (outp," $\quad$ log_k $\frac{\circ}{s}$ of $\backslash n ", "$ ", log_k[i1]);

$i=\operatorname{strlen}(\operatorname{msc}[i 1])$;

species */

if ((flag davies==0) \&\& ((msc[il] [i-2]="'+')||(msc[i1][i-2]=='-'))) /* print only if charged

\{fprintf(outp," -gamma $\% 5.2 \mathrm{f} \% 6.4 \mathrm{f} \ln \backslash \mathrm{n} ", \operatorname{gam}[i 1][0], g a m[i 1][1]) ;\}$

/* print SOLUTION_SPECIES field for mineral and gas species */

fprintf (outp, "PHASES \n $\backslash \mathrm{n} "$ );

for ( $i 1=$ naqueous $+1 ; i 1<n i 1 ; i 1++)$ 
Title: Far-Field Accumulation of Fissile Material from Waste Packages Containing Plutonium Disposition Waste Forms

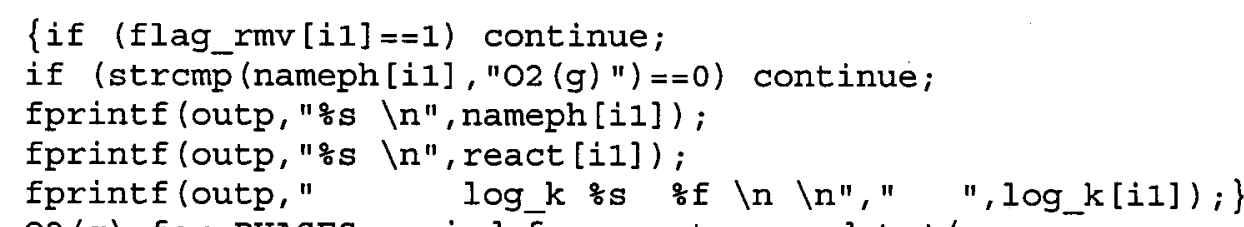

$/$ * print $02(\mathrm{~g})$ for PHASEs copied from wartersys.dat */

fprintf (outp, "O2 (g) $\backslash \mathrm{n} "$ );

fprintf (outp, " $02=02 \backslash \mathrm{n} "$ );

nbms $=0.0$;

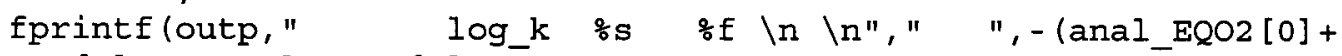

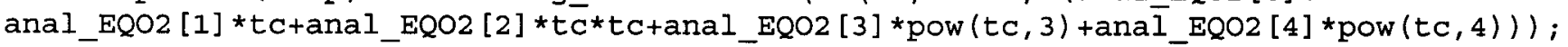

fprinte (outp, "END $\backslash \mathbf{n} "$ ) ;

return $(0) ;\} \quad /$ End of main */

/* FUNCTION: read $\mathrm{EQ}$ reactions and write $\mathrm{PH}$ reactions

* The routine checks if an element has species with different redox numbers

* In this case, it computes it and all the corresponding secondary species

* The routine computes log_k's for the constant temperature tc from the EQ6 data

* and modify it if the reaction is a redox reaction (point 2 from comments) $* /$

void translate (int *flag molvol, int *itto, int *ittl, int *nio, int *nil)

$\{$ int $i, i 0, i 1,1$;

int iel,iiel;

int isp, iisp;

int iisp_first_term;

int strcount;

double nbms

double nbms3 [NTRM] ;

reaction *1

double nbms1 [10];

char snbms [MAX1] :

char snbms 3 [NTRM] [MAX1]; reaction* /

double a,b,c;

char ms2 [MAX1];

char elmsi[10] [3].

char elms2 [MAXI];

char elms3 [NTRM] [MAX1] ;

char test_redox [3]

int flag_redox;

int flag sys:
$1 *$ counters *

$/ *$ number of elements in a species + counter */

$/ *$ number of species in a reaction + counter */

$/ * \quad !=0$ species of interest is not at the right location in reaction */

/* counter for maxlmax to check for maximum species length */

/* temporary double with subscript of an element */

/* temporary double array with stoichio. coefficient of all species in a

/* temporary double array with subscripts of all elements in a species */

/* temporary string with stoichio. coefficient of a species */

/* temporary string array with stoichio. coefficient of all species in a

/* a is molar weight, b charge and c molar volume */

/* temporary string with species name */

/* temporary string array of all elements of a species */

/* temporary string of element */

/* temporary string array of all species in a reaction */

/* temporary string for testing for redox reaction */

$/ *$ flag $=1$ if redox reaction */

/* flag=1 if species belongs toi the water system */ 
Waste Package Department

Title: Far-Field Accumulation of Fissile Material from Waste Packages Containing Plutonium Disposition Waste Forms

char temp $[\operatorname{MAX} 1]$;

char msec [MAX1];

int 1 max 1 max;

/* Transfert from function second_species */

$\mathrm{ms} 2[0]=\mathrm{NULL}$;

/* READ MASTER SPECIES AND CANDIDATE SECONDARY MASTER SPECIES LIST FROM EQ6 */

$i 0=* i t t 0 ; i 1=* i t t 1 ;$

/* read name, number of elements in species and number of species in reaction */

while (strncmp (ms2, "endit", 5)!=0)

\{ fscanf (innuc," \%s \%d \%d", ms2, \&iel, \&isp);

if (strncmp (ms2, "endit", 5)==0) break;

del_brak (ms2,1); /* delete (aq) at end of species if any *

change_use (ms2); $/$ * change order in USe if needed */

l=strlen (ms2);

charge mod(ms2,\&l); / modify charge writing */

/* READ PRIMARY MASTER SPECIES */

if (isp==0) /* no reaction written for that species * /

\{ strcpy (msp[i0], ms2); /* store species name in species list */

fscanf (innuc, "\%lf $: 1 \mathrm{f} \backslash \mathrm{n}$ ", \&a, \&b); $/ *$ skip one line */

/* read each indice of element and each element for a given species */

iiel $=0$;

flag sys=0;

while (iiel<iel)

\{fscanf (innuc, "官lf \%s", \&nbms, elms2):

del_brak (elms2,1); / delete (aq) at end of element if any */

nbms 1 [iiel] =nbms ;

strcpy (elmsl [iiel], elms2)

flag_sys $=1 ;\}$

if ((strcmp (elms2, "H")!=0) \&\& (strcmp (elms2,"O")!=0)) \{strncpy (elmsp [i0],elms2,2) ;

* handle ilel++i\}

/* handle special case for $\mathrm{H}+-\mathrm{H} 2, \mathrm{H} 2 \mathrm{O}$ and $\mathrm{O} 2$ : skip these primary master species */

if (species_skipped (ms2, flag sys) ==1) continue;

$/ *$ compute primary written as secondary */

if (second species (ms2, msec, elms1, nbms1, \&iel) ==1)

(printf ("FRACTIONAL REDOX NUMBER IN PRIMARY MASTER $\backslash n "$ );

printf("THIS SHOULD NOT BE POSSIBLE\n"); exit(1);

strcpy (elmspc [io], msec);

/* increment primary master species counter */

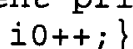

/* READ CANDIDATE SECONDARY MASTER SPECIES (INCLUDING GASES AND MINERALS) */ 
else /* isp>0: there is a reaction written for this species */

$\{$ flag_rmv $[i 1]=0 ; / *$ initialization of flag to remove species if needed */

/* store secondary species name in secondary species list * /

strcpy (nameph [i1], ms2);

strcpy (msc [i1], ms2) ;

/* skip one line, read each indice of element and each element for a given species */

iiel $=0$; isp $=0$;

if $(* f l a g$ molvol $==0) / *$ if aqueous */

\{fscanf(innuc," "sif solf $\backslash \mathrm{n} ", \& a, \& b)$;

while (iiel<iel)

\{fscanf (innuc, "\%lf $\% s "$, \&nbms, elms2);

nbms 1 [iel] =nbms ;

strcpy (elmsl[iiel], elms2)

iielt+;\}\}

else /* if mineral or gas; build chemical formula is only name is given */

\{ Escanf(innuc,"\%lf $\%$ lf $\%$ lf $\backslash \mathrm{n} ", \& a, \& b, \& c) ; / * a$ is molar weight, b charge and $c$ molar volume */

strcount $=0$

lmaxlmax $=0$; / initialization for length of species string *

while (iiel<iel)

\{fscanf (innuc, "ㅇํ의 ㅇs", sanbms, elms2);

nbms1 [iiel] =nbms ;

if (strstr(ms2, elms2) !=NULL) strcount++;/* if element in name, add 1 to strcount */

strcat (chemfph [i1], elms2); /* concat elements to make chem. form. */

lmaxlmaxt=strlen (elms2);

sprintf (temp, "\%8.5f", nbms) ;

for $(i=7 ; i>0 ; i--)$

/*because temp format has 8

characters */

if (temp[i]!='0') break; else temp [i]=NULL; $\}$

if (temp $[i]=='$ ' ')

$\{$ temp $[i]=$ NULL .

if ( (temp $[i-1]==11$ ') \&\&

(temp $\left.[i-2]<' 1 '|| \operatorname{temp}[i-2]>9^{\prime}\right)$ ) temp[i-1]=NULL; $/ *$ get rid of subscript $1 * /$

appropriate */

if (temp $[0]==1$ ') $\operatorname{strcpy}$ (temp, temp +1 )

$/ *$ get rid of initial blank if

strcat (chemfph [i1], temp);

lmaxlmax+=strlen (temp);

strcpy (elms1 [iiel], elms2)

iiel $++;\}$ 
Waste Package Department

Title: Far-Field Accumulation of Fissile Material from Waste Packages Containing Plutonium Disposition Waste Forms

if (strcount==iel) /* if all elements are in name, name is chemical formula */

\{if (iel>1) strcpy (chemfph[il],ms2); $/ *$ but only if species is not a pure element */

if ( 1 max 1 max $>\max 1 \max )$

$\{\max 1 \max =1 \max 1 \max ;$

if ( 1 maxlmax>MAX1) printf ("MAX1 must be changed to $\% d$ because of $\% s \backslash n ", 1 \max 1 \max +1, \operatorname{ms} 2) ;\}$ \}

/* read reaction coefficients and species and find redox reactions */

flag_redox $=0$;

flag_o $2 \mathrm{aq}=0$;

while (iisp<isp)

\{fscanf (innuc, "\%s $\frac{o}{8} "$ ", snbms, elms2);

and gases */

del brak (elms 2,1$) ; / *$ delete (aq) at end of species if any for both aqueous species and mineral

del brak (elms2,3); /* change $02(\mathrm{~g})$ to 02 for both aqueous species and mineral and gases */

* ...find redox reactions *

if (strlen $(e l m s 2)>1) \quad$ test_redox [0]=elms2 [0]; test_redox [1] =elms2 [1]; test_redox [2] =NULL;

else $\{$ test_redox $[0]=e l m s 2[\overline{0}] ;$ test redox $[1]=$ NULL;

if (strcmp (test_redox, "O2") ==0) flag_redox=1;

/* ...modify charge writing for reaction species */

l=strlen (elms2);

charge mod (elms2, \&I);

/* ...save all reaction species in an array */

strcpy (elms3 [iisp], elms2);

if (stramp (ms2, elms2)==0) iisp_first_term=iisp

strcpy (snbms3 [iisp], snbms);

iisp $++;\} /$ * closure of while (iisp<isp) */

/*...put formula in first element of array for reaction instead of name */

if $\left(\left(* f l a g \_m o l v o l==1\right)||\left(* f l a g \_m o l v o l==2\right)\right) / *$ if mineral or gas */

\{strncpy (temp, chemfph [iI], MAX̄i);

del brak (temp, 0); / delete everything but (aq) and $(\mathrm{g})$ */

del_brak (temp, 1); $/$ * delete $(\mathrm{aq}) * /$

del brak (temp, 2); $/$ * delete $(g) * /$

strncpy (chemfph [i1], temp, MAX1);

formula */

strcpy (elms $[0]$, chemfph $[i 1]) ;\} / *$ overwrite species in reaction if name is not a chemical

/* find oxidation number of redox reactions to obtain secondary master species */

if (flag redox $==1$ ) (if (second species (ms2, msec, elms1, nbms1, \&iel) = =0) strcpy (elmsc[i1], msec).

else elmsc[iI] [0]=-NULL; \} / * fractional redox number */

else elmsc[il] [0] =NULL;

/* warn if species of interest is not first term of reaction */ 
Title: Far-Field Accumulation of Fissile Material from Waste Packages Containing Plutonium Disposition Waste Forms

if ((iisp first term!=0) \&\& (isp>2)) printf("\%s is not first term of reaction $\backslash n "$, ms2); $/ *$ isp>2 because otherwise pick equation like $02=02 * /$

/* read coefficients for $\mathrm{EQ}$ analytic expression of $\log _{\mathrm{k}} \mathrm{k}=\mathrm{f}(\mathrm{T})$ and store removed species (=no data) in array */

for $(i=0 ; i<N T U R ;++i)$ fscanf (innuc, "\%lf", \&anal_EQ[i]);

if (flag sup $100==1)$ for $(i=0 ; i<=4 ; i++)$ anal $E Q[i]=a n a l E Q[5+i]$;

if (anal_EQ[0] $==500.00)$

$\{\mathrm{flag} \overline{\mathrm{rmv}}[\mathrm{il}]=1 ;$

or gas */

if $\left(* \bar{f} l a g \_m o l v o l==0\right) / *$ copy to removed species array if $\mathrm{ms} 2$ is an aqueous species, not mineral

$\{$ strcpy (msrmv [rmvcount], ms2);

rmvcount $=$ rmvcount $+1 ;\}$

il++;

continue;

react_store (flag_molvol,elms3,snbms3,\&isp, \&il); /* write reactions to array, invert reaction and take $-\log k$ if needed */

for $(i=0 ; i<i s p ; i++) \quad\{$ if (strcmp(elms3[i],"O2")==0) \{nbms=atof(snbms3[i]); break;\}\}/* find o2 stoichiometric coefficient to modify $\log k$ expression * /

log_k[i1]=calc_log_k (\&flag_redox, \&nbms); /* compute log_k and analytical coefficients if applicable (correction for $0 \overline{2}(\mathrm{aq})-02(\mathrm{~g})$ inside routines) */

$i 1++;\} / *$ increment candidate secondary master species counter */

*niO=i0; $\left.{ }^{n} \mathrm{nil}=i 1 ;\right\} / *$ save number of primary master species and number of reactions *//* closure of while (strncmp (ms2...**/ return;

/* FUNCTION: find the redox number of secondary species */

int second species (char ms2 [], char msec [], char elms1 [] [3], double nbmsl[], int *iel)

\{char temp [3], str [MAX1];

int iiel, count, length;

double rdinb, redox [MAX1];

int nmber, iiel_unkn, rdnbint;

double nmberl; $/ *$ nmber is set equal to nmberl, if not we have fractional redox number $=>$ skip that species $\star /$

/* ms2[MAX1] : IN species from which one element has a redox number to be computed

* msec [MAX1] : OUT element with redox number in brackets

* elms1[][3]: IN list of elements contained in the species

* nbms1[] : IN list of subscript for element in species

* *iel : IN number of element in species */

/* if ms2 is a single element and is listed in function "redox_number" */

if $(* i e l==1)$ 
Waste Package Department

Title: Far-Field Accumulation of Fissile Material from Waste Packages Containing Plutonium Disposition Waste Forms Document Identifier: CAL-EDC-GS-000002 REV 00

\{strncpy (temp, elms1 [0],2);

redox_number (temp, \&rdnb);

if $(r \bar{d} n b !=99)$

\{strncpy (msec, elms1 [0], 2);

if (rdnb>0) strcat (msec," (+");

else strcat (msec," (");

rdnbint $=r d n b$;

sprintf (str, "\%d", rdnbint);

strcat (msec, str);

strcat (msec, ") ");

if (strncmp (ms2,"O2",2)==0) strcpy (msec, "O (0)");

if (strncmp (ms2, "H2", 2)==0) strcpy (msec, "H (0)");

return $(0) ;\}\}$

/* general case */

count $=0$;

for (iiel=0;iiel<*iel;iiel ++ )

\{strncpy (temp, elms1 [iiel],2);

temp [2] =NULL;

redox_number (temp, \&rdnb);

if $(r \bar{d} n b==99$.$) count ++$;

redox $[$ iiel] $=r d n b ;\}$

/* Exit or compute charge of species */

if (count!=1) \{msec [0]=NULL; part_case (ms2, msec);

else

\{length=strlen (ms2);

if (ms2 [length-2] ==43) nmberl=atof (\&ms2 [length-1]);

if (ms2 [length-2] ==45) nmber1=-atof (\&ms2 [length-1]);

if ( (ms2 [length-2] !=45) \&\& (ms2 [length-2]!=43)) nmber1=0.;

/* compute unknown redox number */

for (iiel=0;iiel<*iel;iiel++) \{if (redox[iiel]!=99.) nmberl=nmber1-nbmsl[iiel]*redox[iiel]; else

iiel_unkn=iiel;

nmberl=nmber1/nbms1 [iiel_unkn];

/ * check for fractional redox number */

nmber $=$ nmber 1 ;

/ * conclusion for export */

strncpy (msec, elmsl [iiel_unkn], 2) ;

msec [2] =NULL ;

if (nmber>0) strcat (msec, " (+");

else strcat (msec," (") ; 


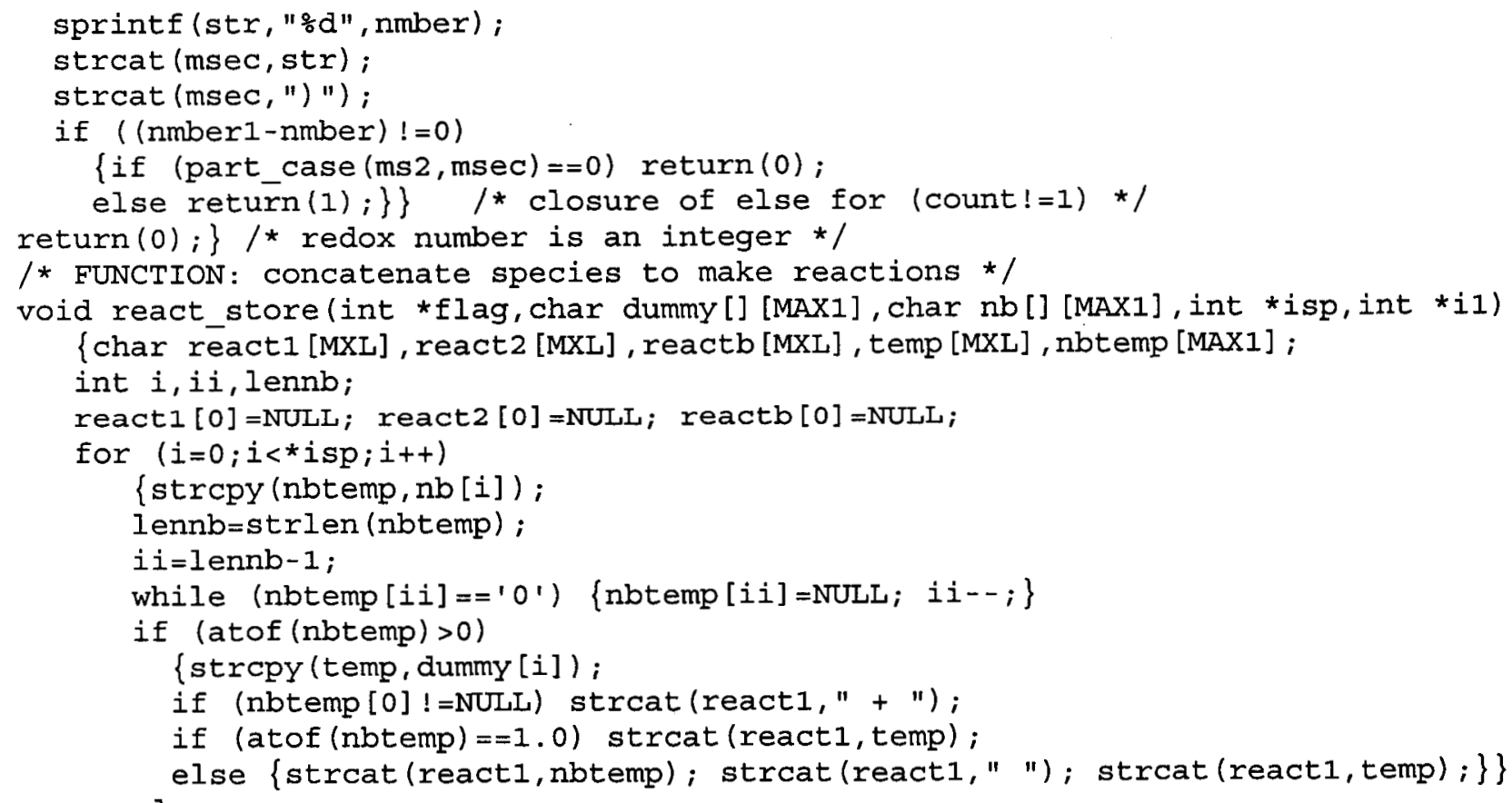


Waste Package Department

Title: Far-Field Accumulation of Fissile Material from Waste Packages Containing Plutonium Disposition Waste Forms Document Identifier: CAL-EDC-GS-000002 REV 00

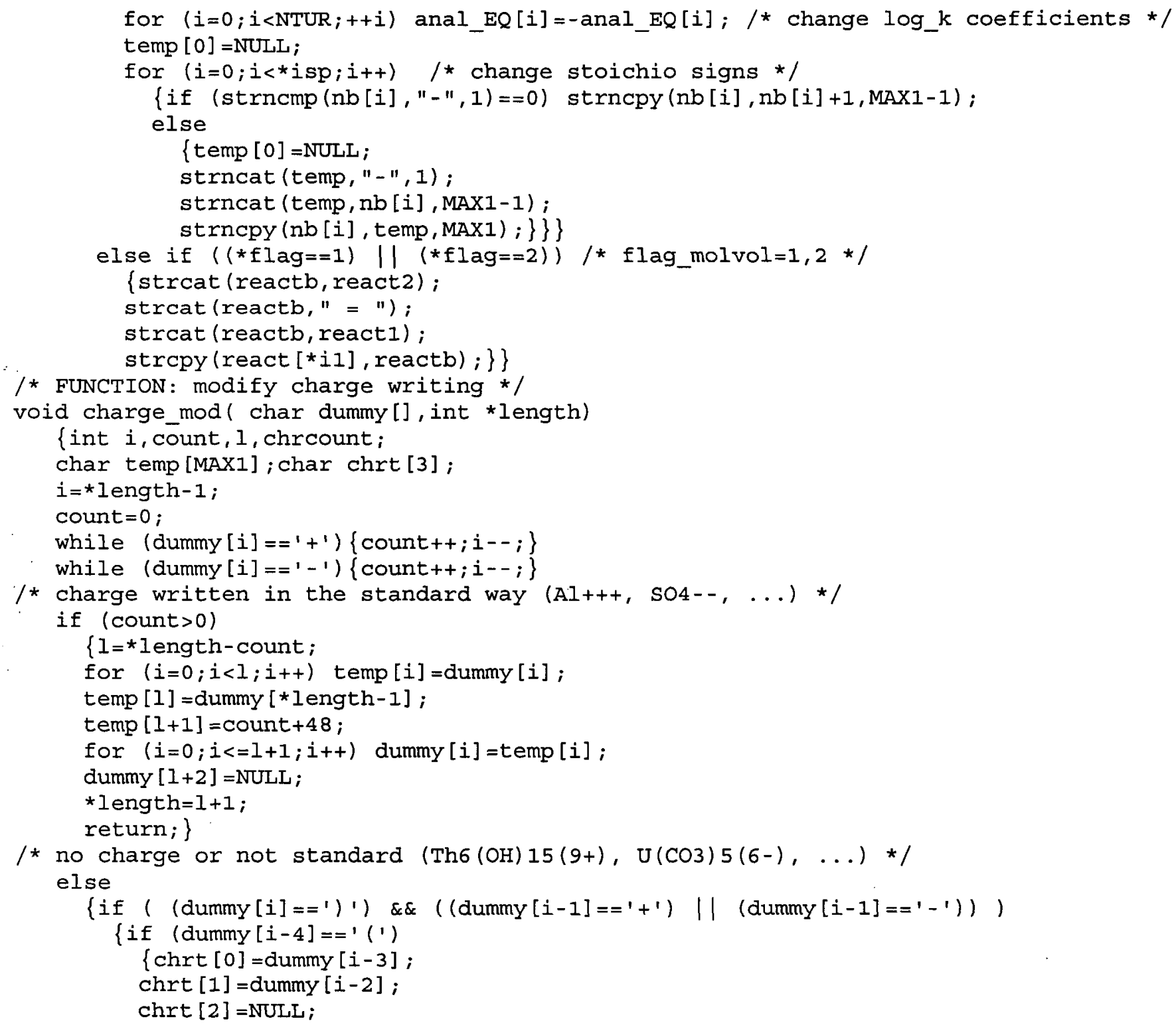


chrcount $=2$;

else if (dummy $[i-3]==1(1)$

$\{$ chrt $[0]=$ dummy $[i-2]$;

chrt [1] =NULL;

chrt [2] =NULL

chrcount $=1 ;$;

strncpy (temp, dummy, i-2-chrcount) ;

temp $[i-2-\operatorname{chrcount}]=\mathrm{NULL}$;

strncat (temp, dummy+i-1,1);

strcat (temp, chrt);

strcpy (dummy, temp);

return; \} \}

/* FUNCTION: compute $\log \mathrm{k}$ * /

double calc_log_k (int *flag_redox, double *nbms)

\{ double logk, logko2;

logk=anal $E Q[0]+a n a l ~ E Q[1] * t c+a n a l ~ E Q[2] * t c * t c+a n a l E Q[3] * p o w(t c, 3)+a n a l \quad E Q[4] * p o w(t c, 4)$;

if $\left(\left(* f l a \bar{g} \_r e d o x==0\right) T \mid\left(\left(* f l a g \_r e d o x==1\right) \& \&\left(f l a g \_o 2 a q==1\right)\right)\right)$ return $(\operatorname{logk})$;

else if $((\star f l a g$ redox $==1) \& \&(f \bar{l}$ ag $o 2 a q==0))$

$\{$ logkO2=anal_EQO2[0]+anal_EQO2[1]*tc+anal_EQO2 [2]*tc*tc+anal_EQO2 [3]*pow (tc, 3)+anal_EQO2 [4]*pow (tc, 4);

logk=logk $-\star n \bar{b} m s * \operatorname{logkO} 2$;

return (logk);

else \{printf("ERROR IN FUNCTION calc_log_k\n"); exit(1);\}\}

/* FUNCTION: compare element to element with a known and fixed redox number $* /$

void redox number (char temp [], double *rdnb)

\{int $\mathrm{flag}=\overline{0}$;

if (strcmp (temp, "O") $==0) \quad\{\star r d n b=-2 ;$ flag $=1 ;\}$

if (strcmp (temp, "H") ==0) $\quad$ *ranb $=+1 ;$ flag $=1 ;\}$

if (strcmp (temp, "F") $==0) \quad\{* r d n b=-1 ; f l a g=1 ;\}$

if $(\mathrm{flag}==0) \quad * \mathrm{rdnb}=99 ;\}$

/* FUNCTION: sort master species element list $a$ and companion array $b * /$

void shell sort2 (int $n$, char a [] [MAX1], char b [] [MAX1])

\{int $i, j, i \bar{n} c$, istr;

char va $[\mathrm{MAX} 1], \mathrm{vb}[\mathrm{MAX} 1], \mathrm{w}[\mathrm{MAX} 1]$

for (istr $=0$; istr $<\operatorname{MAX} 1 ;$ ist $r++$ )

$\{\mathrm{inc}=1$;

do $\{$ inc $+=3$; inct+; $\}$ while (inc $<=n)$;

do $\{$ inc $/=3$;

for $(i=i n c+1 ; i<=n ; i++)$

$\{$ strcpy $(v a, a[i])$; 


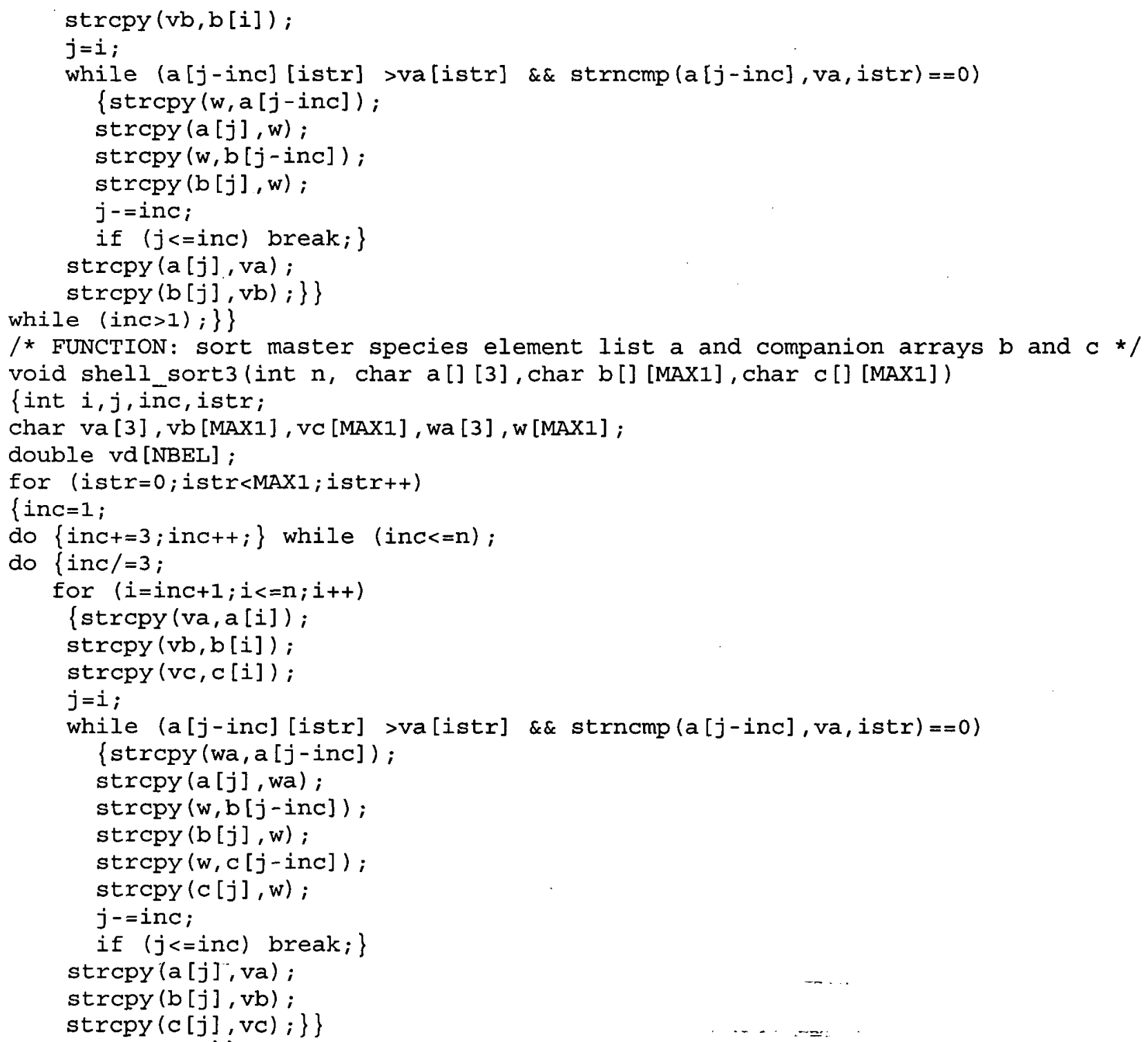


/* FUNCTION: eliminate redundant master species and print list of master species*/ void clean_up (int *nio, int *n)

${ }^{*}$ if there is a secondary master species, the primary master species must also be declared as a secondary master species

* and added to the list of master species */

\{int icount, $i$;int iel=1;int io,ic;int mscount [NBEL]; char temp [3];

/* Sort element list (master species were already sorted in sort2) */

shell sort3 (*nio, elmsp-1, msp-1, elmspc-1);

/* count number of master species for each element */

$i=0$;

for $(i 0=0 ; i 0<* n i 0 ; i 0++)$

mscount $[i 0]=0$;

for (ic=i;ic<* $n ; i c++)$

\{strncpy (temp, elallms[ic],2); /* copy at most 2 characters to compare with element 1 ist */

temp [2] =NULL;

if $($ strncmp $($ temp $+1, "(", 1)==0)$ temp $[1]=$ NULL;

if $($ strncmp (temp, elmsp $[i 0], 2)==0)$ mscount $[i 0]++; / *$ compare with element */

else $\{i=i c ;$ break; $\}\}\}$

/* print only selected species */

$i=0$;

$i$ count $=0$

for $(i 0=0 ; i 0<*$ nio;i0++)

\{if (mscount $[i 0]==2$ ) /* primary master species has no secondary master species */

\{if (test_rmv $(\operatorname{msp}[i 0])==1) / *$ print if not a removed species */

\{calc_gēw (elmsp [io], temp);

fprintf (outp, "\%-10s \%-25s $\frac{3}{6}$.1f $\frac{\mathrm{s}}{\%}-10 \mathrm{~s}$

$\div 10.4 f \backslash n ", \operatorname{elmsp}[i 0], \operatorname{msp}[i 0], \operatorname{calc}$ _alk(msp [i0]), temp, find_weight $(\operatorname{elmsp}[i 0], n i 0)) ;\}$ $i=i+2$;

icount $=i \operatorname{count}+2 ;\}$

if (mscount $[i 0]>2) / *$ primary master species has at least one secondary master species, the primary

must also be printed as a secondary */

\{if (test_rmv $(\operatorname{msp}[i 0])==1) / *$ print if not a removed species */.

\{calc_gfw (elmsp [io], temp);

fprinteloutp, "\%-10s \%-25s $\% 3.1 \mathrm{f} \quad \%-10 \mathrm{~s}$

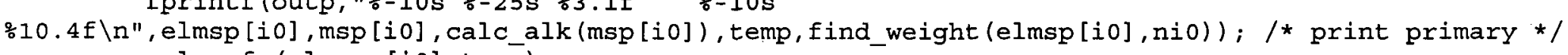
calc_gfw(elmspc[io], temp);

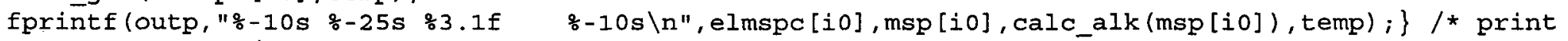

primary as a secondary */

$i=i+2$; 


\section{icount $=i$ count +2 ;}

for (ic=i-1;ic<i+mscount $[i 0]-2 ; i c++)$

\{if (strcmp(elmspc[io], elallms[ic])!=0) /* skip primary written as secondary */

\{if (strcmp (elallms [ic-1], elallms [ic]) !=0)

if (test $\mathrm{rmv}(\mathrm{allms}[i c])==1$ ) $/ *$ print if not a removed species */

\{calc_g $\bar{f} w(e l a l l m s[i c], t e m p) ;$

fprintf (outp, "\%-10s $\%-25 s \% 3.1 f$

\% -

10s $\backslash \mathrm{n}$ ", elallms[ic], allms [ic], calc_alk(allms[ic]), temp); $\}$ / print true secondary */

icount $=i$ count $+1 ;\}$

else icount=icount $+1 ;\}\}$

$i=i c ;\}\}\}$

/* FUNCTION: specify alkalinity (as it is phreeqc.dat) */

double calc_alk (char a[])

\{double alk; $a l k=0.0$;

if (strncmp $(a, " H+1 ", 3)==0$ ) alk $=-1$.;

if (strncmp $(a, " \mathrm{Fe}+3 ", 4)==0$ ) alk $k=-2$.;

if (strncmp $(a, " \mathrm{CO}-2 ", 5)==0$ ) alk $=2$.

if (strncmp $(a, " \mathrm{HCO}-1 ", 6)==0$ ) alk $k=1$.

if (strncmp $(a, " H S-1 ", 4)==0$ ) alk=1.;

if (strncmp $(a, " P O 4-3 ", 5)==0$ ) alk $=2$.;

return $(a \perp k) ;\}$

* FUNCTION: specify gram formula weight (as it is phreeqc.dat) */

void calc gfw (char a[], char b[])

\{char temp [MAX1];

* Deal with special cases */

if $(\operatorname{strcmp}(a, " E ")==0)$

if $(\operatorname{strcmp}(a, " H(+1) ")==0)$

if $(\operatorname{strcmp}(a, " O(-2) ")==0)$

if (strcmp $(a, " S i ")==0)$

if (strcmp $(a, " S ")==0$ )

if $(\operatorname{strcmp}(a, " S(+6) ")==0)$

if $(\operatorname{strcmp}(a, " C ")==0)$

$\{$ strcpy $(b, " 0.0 ")$; return; $/ *$ electron */

\{strcpy $(b, " 0.0 ") ;$ return; $\quad / * \ldots$ H $(1) \star /$

$\{$ strcpy $(\mathrm{b}, " 0.0 ") ;$ return; $\} / \ldots \ldots(-2) * /$

$\{$ strcpy $(\mathrm{b}, " \mathrm{SiO} 2$ "); return; $\} / * \ldots \mathrm{si} * /$

\{strcpy $(b, "$ SO $4 ") ;$ return; $/ * \ldots s * /$

if $(\operatorname{strcmp}(\mathrm{a}, " \mathrm{C}(+4) ")==0) \quad\{\operatorname{strcpy}(\mathrm{b}, " \mathrm{HCO} 3 ") ; \operatorname{return} ;\} / \ldots \mathrm{C}(+4) * /$

* Regular cases: gfw formula is element */

strcpy (temp, a)

strcpy (b, strtok (temp, "("));

* FUNCTION: delete brackets at end of string if needed */

void del brak (char a[], int flag del)

\{int $i, \bar{t} \overline{t h}=s$ trlen $(a)-1, f l a g=0$; 
Title: Far-Field Accumulation of Fissile Material from Waste Packages Containing Plutonium Disposition Waste Forms

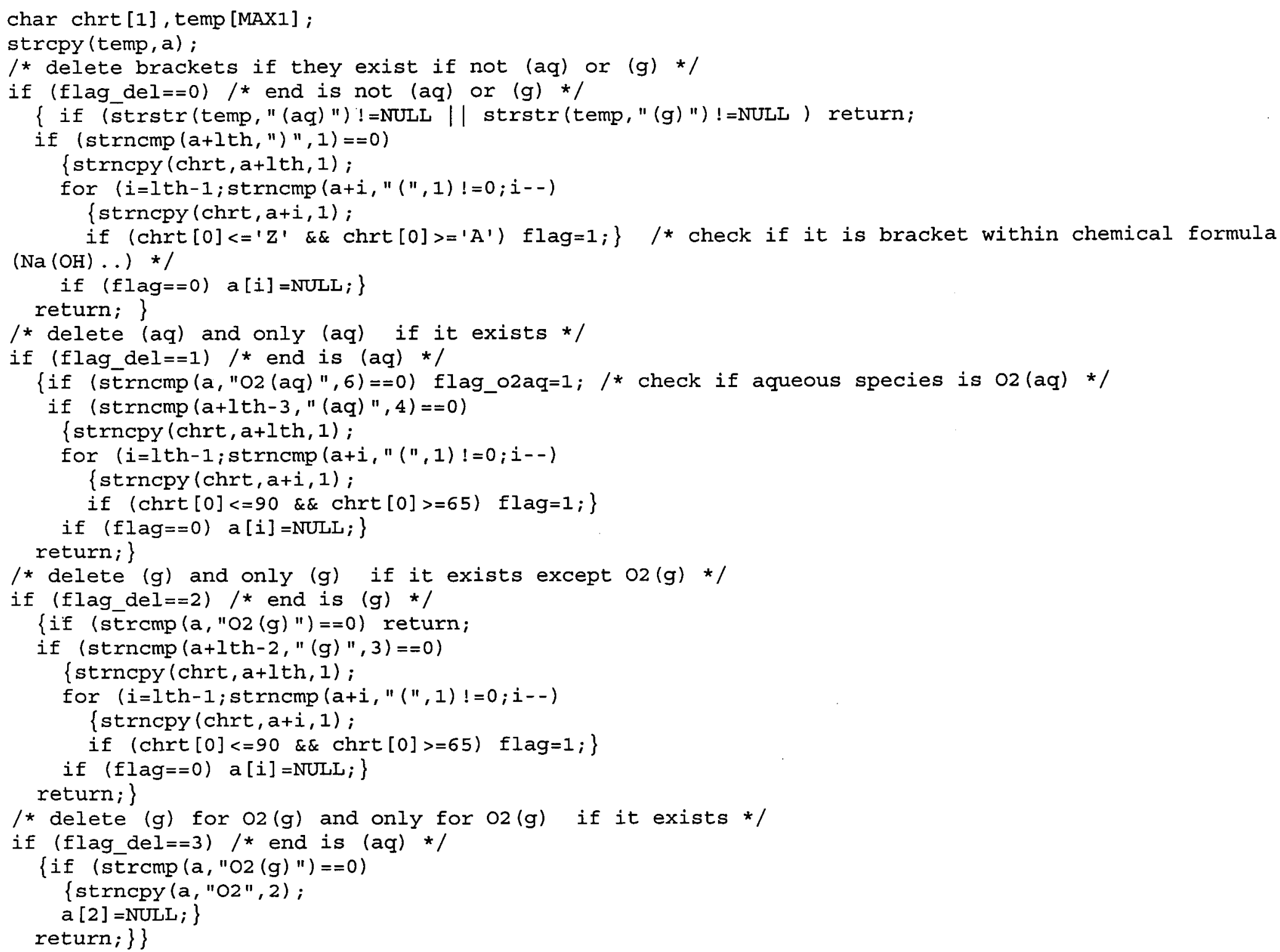


Waste Package Department

Title: Far-Field Accumulation of Fissile Material from Waste Packages Containing Plutonium Disposition Waste Forms

/* FUNCTION: Find the string USe (confused with PHREEQC keyword USE) and replace it with Se\#U */

void change_use (char a [])

\{char temp [MAX1]; int i;

strcpy (temp,a)

for $(i=0 ; a+1 !=$ NULL $; i++)$

\{if (strncmp $(a+i$, USe", 3) $==0)$ /* Is the string USe present? *

\{if $\left(a[i+3]>{ }^{\prime}{ }^{\prime} \& \& a[i+3]<=g^{\prime}\right) / *$ if of the form USe\#, change to Se\#U*/

$\{$ strncpy (temp+i, "Se", 2);

strncpy (temp $+i+2, a+i+3,1)$;

strncpy (temp $+i+3, " U ", 1) ;\}$

break ;

$\operatorname{strcpy}(a$, temp) ; $\}$

/* FUNCTION: skip H2O system species */

int species_skipped(char a[], int flag_sys)

\{int flag sk̄ipped;

flag_skipped=0;

if $(\bar{s} \operatorname{trncmp}(a, " H+", 2)==0|| \operatorname{strncmp}(a, " O 2 ", 2)==0|| \operatorname{strcmp}(a, " H 2 O ")==0|| \operatorname{strcmp}(a, " H 2 ")==0)$

flag skipped=1;

else

if (flag sys $==0$ )

/...catch other $\mathrm{HxOx}$ species if $\mathrm{H} 2 \mathrm{O}$ system is not set with $\mathrm{H}+, \mathrm{O} 2$ and $\mathrm{H} 2 \mathrm{O}$ */

\{fprintf (stderr, "H2O system not set right $\backslash \mathrm{n} "$ );

fprintf (outp, "H2O system not set right $\backslash \mathrm{n} ") ;\}\}$

return (flag_skipped) ;

/* FUNCTION: find atomic weight of element *

double find weight (char a [], int *n)

\{int $i$; for $\left(i=0 ; i<{ }^{-} n ; i++\right)$ if (strcmp(elm[i],a) $\left.=00\right)$ return(elw $\left.\left.[i]\right) ;\right\}$

* FUNCTION: find B-dot parameters */

void find bdot (void)

lint $i I, i \bar{i}$

for $(i 1=0 ; i 1<=$ naqueous; $i 1++)$

ffor $(i=0 ; i<$ nbdot $; i++)$ \{if (stramp (msc[il], diamspc[i])==0) \{gam[il] [0]=diam[i];break;\}\}/*... hard core diameter */

gam [i1] [1] =bb;\}) /*...b-dot parameter (constant for all ions at a given temperature */

/* FUNCTION: treat particular cases for redox number calculations */

int part case (char $a[]$, char $b[]$ )

\{if $(\operatorname{strñ} c m p(a, " B r 3-", 4)==0)\{\operatorname{strcpy}(b, " B r(-1) ") ; \operatorname{return}(0) ;\}$

if (strncmp $(a, " C N-", 3)==0) \quad\{\operatorname{strcpy}(b, " N(-5) ")$; return $(0)$; 
Waste Package Department

Title: Far-Field Accumulation of Fissile Material from Waste Packages Containing Plutonium Disposition Waste Forms

Document Identifier: CAL-EDC-GS-000002 REV 00

ATTACHMENT VI, Page VI-24 of VI-24

if $(\operatorname{strncmp}(a, " I 3-", 3)==0) \quad\{\operatorname{strcpy}(b, " I(-1) ") ; \operatorname{return}(0) ;\}$

if $(\operatorname{strncmp}(a, " N 3-", 3)==0) \quad\{\operatorname{strcpy}(b, " N(-1) ") ; \operatorname{return}(0) ;\}\}$

/* FUNCTION: compare a species with list of species to be removed */

int test rmv(char a [])

\{int $i$;

for $(i=0 ; i<\operatorname{rmvcount} ; i++)\{$ if $(\operatorname{strcmp}(a, \operatorname{msrmv}[i])==0)$ return $(0) ;\}$

return $(1) ;\}$ 
Title: Far-Field Accumulation of Fissile Material from Waste Packages Containing Plutonium Disposition Waste Forms

Document Identifier: CAL-EDC-GS-000002 REV 00

ATTACHMENT VII, Page VII-1 of VII-3

\section{ATTACHMENT VII}

\section{Software Routines}

Among all the files cited in Attachment IV, only those files in the main directory, listed below, perform tasks other than plotting or being direct input or output files to PHREEQC runs.

\begin{tabular}{|l|l|}
\hline \multicolumn{1}{|c|}{ File Name } & \multicolumn{1}{|c|}{ Comments } \\
\hline dispersion_linesource.xls & $\begin{array}{l}\text { Simple implementation of Equation 2.6a. The spreadsheet has been } \\
\text { verified by visual inspection and by its reasonable results. }\end{array}$ \\
\hline dispersion_pointsource.xls & $\begin{array}{l}\text { Simple implementation of Equation 2.6b. The spreadsheet has been } \\
\text { verified by visual inspection and by its reasonable results. }\end{array}$ \\
\hline dispersion_pointsource_plot.xls & Plot of outputs from the file dispersion_pointsource.xls \\
\hline expo-VG.xls & $\begin{array}{l}\text { Implementation of Equations 2.2 and 2.17. The spreadsheet computes the } \\
\alpha \text { coefficient of Equation } 2.2 \text { given the } \alpha_{\mathrm{G}} \text { of Equation 2.17 using the } \\
\text { goalseek function. The spreadsheet has been verified by visual inspection } \\
\text { (the curves resulting from both equations coincide). }\end{array}$ \\
\hline PuAccProfile_pe0a1231.xls & $\begin{array}{l}\text { Summary of results from the different runs (source term pe0a1231). The } \\
\text { spreadsheet performs simple operations and plots the results. }\end{array}$ \\
\hline PuAccProfile_pw2a1231.xls & $\begin{array}{l}\text { Summary of results from the different runs (source term pw2a1231). The } \\
\text { spreadsheet performs simple operations and plots the results. }\end{array}$ \\
\hline sat_calc.xls & $\begin{array}{l}\text { Implementation of Equations 2.11 to 2.19. The spreadsheet computes a } \\
\text { water saturation given a flow rate and rock properties. The spreadsheet } \\
\text { uses the goalseek_saturation macro described below. }\end{array}$ \\
\hline Tuff_composition.xls & $\begin{array}{l}\text { Determination of the mineral fraction of the tuff given the normative } \\
\text { composition of the tuff. }\end{array}$ \\
\hline
\end{tabular}

\section{Description of the Excel Macro goalseek_saturation}

The macro goalseek_saturation V.1.0 automatically applies the EXCEL built-in function goalseek to a group of cell. The macro does nothing more and has been verified by hand calculation (reapplying manually the built-in goalseek function on any cell gives the same result)

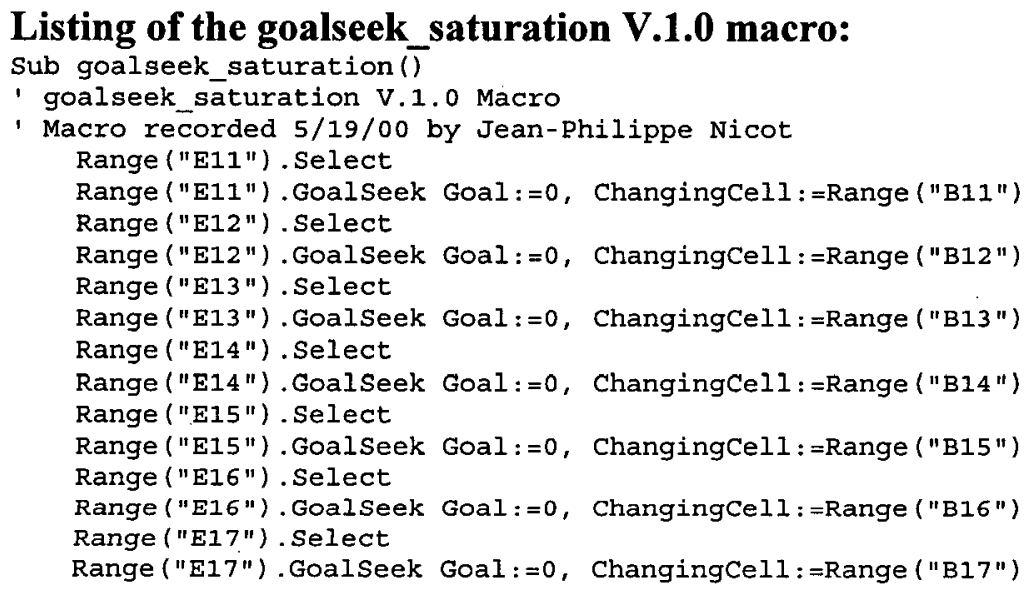


Title: Far-Field Accumulation of Fissile Material from Waste Packages Containing Plutonium

Disposition Waste Forms

Document Identifier: CAL-EDC-GS-000002 REV 00

ATTACHMENT VII, Page VII-2 of VII-3

Range ("E18") . Select

Range ("E18") . Goalseek Goal:=0, ChangingCell :=Range ("B18")

Range ("E19") . Select

Range ("E19") .Goalseek Goal:=0, ChangingCell:=Range ("B19")

Range ("E20") . Select

Range ("E20") . Goalseek Goal:=0, ChangingCell:=Range ("B20")

Range ("E21") . Select

Range ("E21") .Goal Seek Goal:=0, ChangingCell:=Range ("B21")

Range ("E22") . Select

Range ("E22") .Goalseek Goal:=0, ChangingCe11:=Range("B22")

Range ("E23") . Select

Range ("E23") .Goalseek Goal:=0, ChangingCell :=Range ("B23")

Range ("E24") . Select

Range ("E24") . Goalseek Goal:=0, ChangingCell:=Range ("B24")

Range ("E25") . Select

Range ("E25") . Goalseek Goal:=0, ChangingCe11:=Range ("B25")

Range ("E26") . Select

Range ("E26") . Goalseek Goal:=0, ChangingCell:=Range ("B26")

Range ("E28") . Select

Range ("E28") . Goalseek Goal:=0, ChangingCell :=Range ("B28")

Range ("E29") . Select

Range ("E29") . Goalseek Goal:=0, ChangingCell:=Range ("B29")

Range ("E30"). Select

Range ("E30"). Goalseek Goal: =0, ChangingCell:=Range ("B30")

Range ("E31"). Select

Range ("E31") . Goalseek Goal:=0, ChangingCell:=Range ("B31")

Range ("E32") . Select

Range ("E32") . Goalseek Goal:=0, ChangingCell :=Range ("B32")

Range ("E33") . Select

Range ("E33") . Goalseek Goal: =0, Changingcell: =Range ("B33")

Range ("E34"). Select

Range ("E34") . Goalseek Goal:=0, ChangingCell: =Range ("B34")

Range ("E35"). Select

Range ("E35"). GoalSeek Goal:=0, ChangingCell :=Range ("B35")

Range ("E36"). Select

Range ("E36") . GoalSeek Goal:=0, ChangingCell:=Range ("B36")

Range ("E37") . Select

Range ("E37") . Goalseek Goal:=0, ChangingCell:=Range ("B37")

Range ("E38") . Select

Range ("E38") . Goalseek Goal:=0, ChangingCell:=Range ("B38")

Range ("E39"). Select

Range ("E39") . Goalseek Goal:=0, ChangingCell:=Range ("B39")

Range ("E40"). Select

Range ("E40") . Goalseek Goal:=0, ChangingCell:=Range ("B40")

Range ("E41") . Select

Range ("E41") . Goalseek Goal:=0, ChangingCell:=Range ("B41")

Range ("E42") . Select

Range ("E42") .Goalseek Goal:=0, ChangingCell :=Range ("B42")

Range ("E43") . Select

Range ("E43") .Goalseek Goal:=0, ChangingCell:=Range("B43")

Range ("E45") . Select

Range ("E45") .GoalSeek Goal:=0, ChangingCell:=Range ("B45")

Range ("E46") . Select

Range ("E46") .Goalseek Goal:=0, ChangingCell:=Range ("B46")

Range ("E47") . Select

Range ("E47") .Goalseek Goal:=0, ChangingCell :=Range ("B47")

Range ("E48"). Select

Range ("E48") . Goalseek Goal:=0, ChangingCell:=Range ("B48")

Range ("E49"). Select

Range ("E49") . Goalseek Goal:=0, ChangingCell :=Range ("B49")

Range ("E50"). Select

Range ("E50") . Goalseek Goal:=0, ChangingCell :=Range ("B50")

Range ("E51"). Select

Range ("E51") .Goalseek Goal:=0, ChangingCell:=Range ("B51")

Range ("E52") . Select

Range("E52") . Goalseek Goal:=0, ChangingCell :=Range ("B52")

Range ("E53"). Select 
Waste Package Department

Title: Far-Field Accumulation of Fissile Material from Waste Packages Containing Plutonium Disposition Waste Forms

Document Identifier: CAL-EDC-GS-000002 REV 00

ATTACHMENT VII, Page VII-3 of VII-3

Range("E53") . Goalseek Goal:=0, ChangingCell:=Range("B53")

Range ("E54"). Select

Range("E54") . Goalseek Goal:=0, ChangingCell:=Range ("B54")

Range ("E55"). Select

Range ("E55"). Goalseek Goal: =0, ChangingCell:=Range ("B55")

Range ("E56"). Select

Range ("E56").Goalseek Goal:=0, ChangingCell: =Range ("B56")

Range ("E57") . Select

Range ("E57") . Goalseek Goal:=0, ChangingCell:=Range ("B57")

Range ("E58"). Select

Range ("E58") . Goalseek Goal:=0, ChangingCell:=Range ("B58")

Range ("E59"). Select

Range ("E59") .Goalseek Goal:=0, ChangingCell:=Range ("B59")

Range ("E60") . Select

Range ("E60") . Goalseek Goal:=0, ChangingCell:=Range ("B60")

End Sub 